\title{
GRADIENT STRATEGIES \\ Reconciling the Public and Private Realms in Suburbia
}

Alan Stringer

A thesis submitted to Victoria University of Wellington in partial

fulfillment of the requirements for the degree of:

Master of Architecture (Professional)

completed at the

Faculty of Architecture and Design

of

Victoria University of Wellington 



\section{Abstract}

Last century saw significant changes in the way we occupy land for living. Technological advances in individual and mass transportation has both extended city peripheries and effectively claimed the suburban public realm for the automobile. Analysis of historical residential development models reveals that our traditional neighbourhood characteristics and qualities have deteriorated as a direct result of this shift. The urban expansion and resultant neglected street environments are two imperatives for change which lead to the core focus of this research; the reconciliation of the public and private realms within suburbia. A holistic approach to design recognises the benefits of considering community and individual needs simultaneously. This is reflected in the design of a residential

subdivision seeking alternative street patterns and use hierarchies, both aimed at stimulating the public realm. Under this premise a robust place-based perception of 'community' is important to the idealised functional operation of the public suburban street requiring an effort from the entirely private domain of the suburban house. A graduated transition from public to private is the means used to mediate the pre-existing tension. Through the acquisition of a series of strategies a gradient between public and private is achieved to successfully facilitate and manage the connection to the street from within the house. Thus, the urban responsibility of housing is realised and addressed allowing the private house dweller to participate in the activation of the suburban street. 


\section{Contents}

\section{Acknowledgements}

\section{Chapter One: Introduction}

1.1. Rationale

1.2. Key Word Definitions

1.3. Academic Context

1.4. Chapter Outline

\section{Chapter Two: Background}

2.1. Introduction

2.2. Sustainable Growth Patterns for New Zealand Suburbs

2.3. The Value of Community in Contemporary Suburbs

2.4. Place-making in Suburbia

2.5. Managing the Public-Private Gradient

\section{Chapter Three: Historical Analysis}

3.1. Introduction

3.2. Discovering the Public-Private Gradient in Wellington Suburbs

3.3. Key Observations

3.4. Conclusion

\section{Chapter Four: Precedent Studies}

4.1. Introduction

4.2. Urban Precedent Studies

4.3. ArchitecturalPrecedentStudies

4.4. Conclusion 


\section{Chapter Five: Pre-Design}

5.1. Introduction

5.2. Design Brief

5.3. Site Selection and Analysis

5.4. Modification of the Master-plan

5.5. Design Strategies

5.6. Conclusion

\section{Chapter Six: Design Case Study}

6.1. Introduction

6.2. Site Selection

6.3. Design Brief and Programme

6.4. Conceptual Design and Formal Development

6.5. Design CaseStudy Outcomes

6.6. Establishing andManaging a Public-Private Gradient

6.7. Design in Review

\section{Chapter Seven: Conclusion}

7.1. Introduction

7.2. Significant Research Outcomes

7.3. Shortcomings, Limitations and Opportunities for Further Research

7.4. Final Comments

\section{Bibliography}

\section{List of Figures}

\section{Appendix}




\section{Acknowledgements}

First and foremost I would like to take this opportunity to thank Chris McDonald for your assistance over the course of the last fifteen months. This would not look anything like a thesis without your tireless supervision.

Thanks also to my family, particularly my parents Daphne and Stephen Stringer for your unconditional support and to Uncle Richard for the financial assistance.

To my friends and colleagues, the humour, camaraderie and advice has been greatly appreciated, thank you so much and all the very best for your various and colourful futures.

Finally, a big thank you to Belinda McAdams for standing by me so valiantly throughout this process. 


\section{Chapter One: Introduction}

1.1. Rationale

1.2. Key Word Definitions

1.3. Academic Context

1.4. Chapter Outline 


\subsection{Rationale}

Technological advances in mass transportation during the Industrial Revolution granted easy access to land previously considered to be too far from city centres to be useful for housing urban populations. This increased access to space allowed people to live at the urban periphery, distanced from the degraded and polluted urban environment that the unprecedented inner-city factories produced. Additionally, global travel provided an economically viable opportunity for others to move away from what had essentially become a slum and factory work lifestyle and start afresh. Plans for New Zealand's first urban centres responded to this poor lifestyle by accommodating initial population growth with planned subdivisions. The automobile proved to be highly influential on further settlement patterns in the post-war period as governmental investment in private transportation infrastructure ensured that owning and using a car was cheap and efficient in comparison to the aging rail network. Increased transport possibilities combined with significant changes to mortgage policies ensured that the suburban lifestyle became highly sought after and easy to attain. People have since been able to live increasingly further from urban centres while maintaining employment links there. The continuation of sprawling suburbia since the post-war period is evidenced in New Zealand's main centers which, with projected population growths and increased demand for housing, is not sustainable. New settlement development patterns are required.

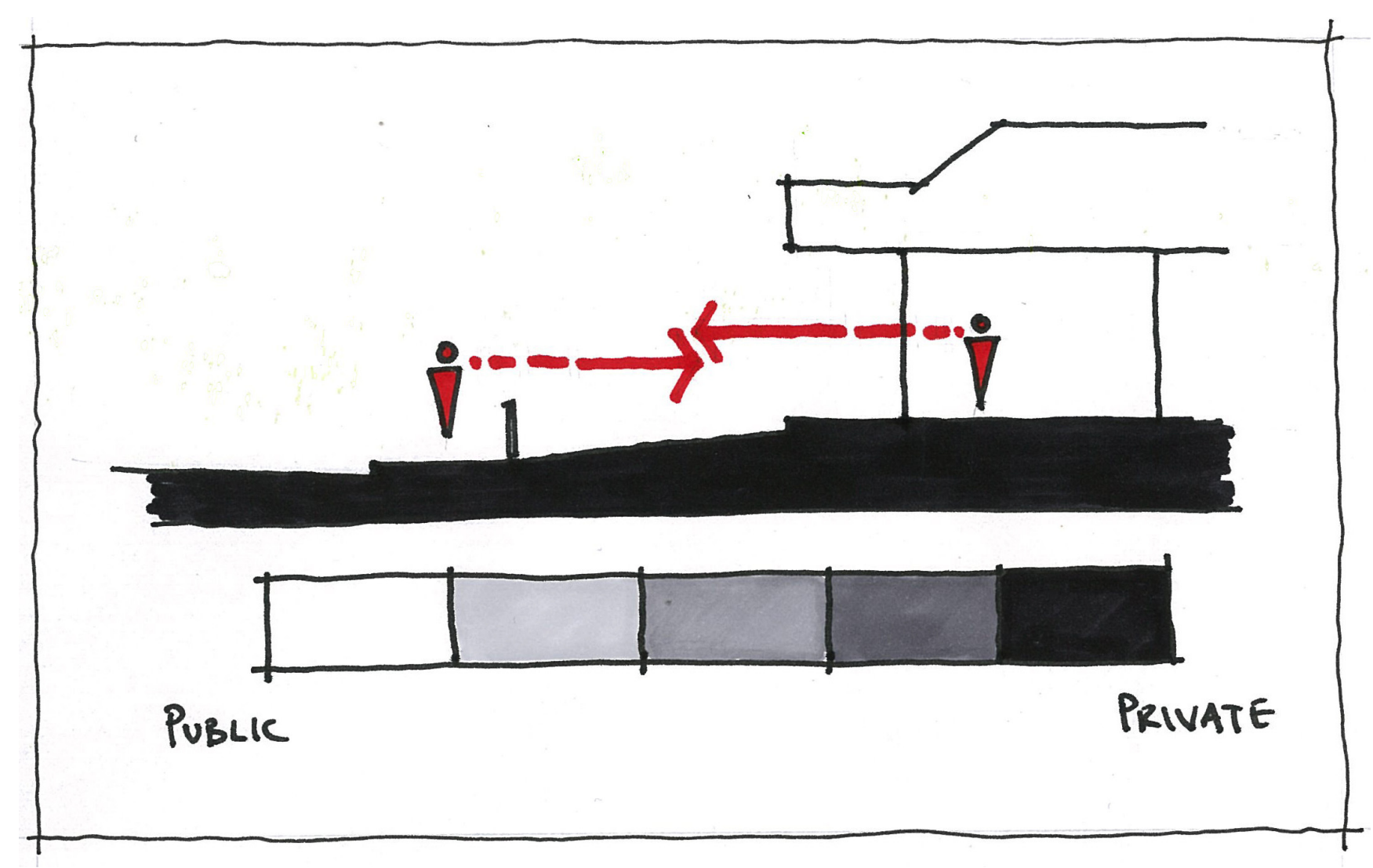

Critique of the current American predicament and development model has been very well documented. As suburban development has moved towards satisfying the needs of car users, the public realm of suburbia has suffered. The classic neighbourhood model that provided a clean, vibrant living environment which was once the aspiration of many is apparently no longer attainable. The suburban residential settlement pattern has evolved over time through planning policy, landscape misuse, and architectural standardisation. The treatment of the interface between the private, domestic interior and the civic realm of the street has suffered considerably as a direct result. The urban grain, street environments, and rich characters of original settlements are key aspects which are scarcely recognisable in the contemporary development model.

This thesis responds to this contemporary suburban situation and poses the question: How can the suburban house enable a public-private gradient to successfully mediate the interface between the street and the domestic interior?

The solution to this question is developed through a design case study examining the potential for reconciliation between the public and public realms in suburbia. This thesis proposes an alternative suburban residential development pattern by demonstrating a series of design decisions and strategies informed through current and historic research

Fig. 1.1. The public-private gradient. A diagram demonstrating the area of interest: the transition from the public environment of the street to the private domestic interior. 


\subsection{Key Word Definitions}

Suburban House: this refers to a contained private domestic environment which is controlled by a single household at the periphery of an urban centre.

Public: for the purposes of this research 'Public' refers to the realm or established territory outside the boundaries of privately owned, tenanted or occupied land. This includes State and Council property, Civic buildings, shared spactes such as parks, roads and sidewalks, and any space that does not have specific access limitations.

Private: this refers to the domestic realm or established domestic territory which is owned, tenanted or occupied and by an individual or by a single household. The occupant of this arena assumes authority and control over access to activities and within the legal boundaries.

Public-Private Gradient: this refers to the nature of a mediated relationship between public and private which is hypothesised to be successful. It includes the zone spanning from the street through to the domestic interior of the home and is modified by the installation of thresholds defined by architecture, landscape elements and planning decisions.

Mediate: this refers to the reconciliation of the public and private realms of suburbia which is achieved through the application of specific design strategies. The strategies facilitate the establishment of thresholds to create a gradient from public to private.

Thresholds: thresholds are the primary components defining the grades of change or transition in the gradient between the public and private realms.

\subsection{Academic Context}

This research is situated within a wider scholarly discussion and critique of sustainable suburban development. Early authors writing about the effect of the Industrial Revolution on urban centres, institutionalised in part by suburban expansion and the perceived negative global and local effects it has, have been particularly condemning. Greenfield residential development has commonly been seen to be inevitable; however, alternative development models and experiments under the labels of New Urbanism or Smart Growth have been explored with varying levels of success. Debate and critique of these alternative ideas is abundant as they have found grounding and significance in the literature surrounding suburbia. However, scholarly architectural analysis and critique of the successful elements of pre-existing suburban vernacular beyond a surface or documentation understanding is lacking. It is in this area that this design research contributes. There is sufficient academic material discussing the negotiation between public and private but not necessarily with specific reference to suburban residential architecture. By examining housing precedents it is possible to identify design strategies, in the form of architectural devices and components, which successfully mediate the interface between the public and private realms.

This research is set within the wider Wellington region; therefore, local and regional policy, planning and prescriptive texts will be inherently relevant. 


\subsection{Chapter Outline}

Having established a premise for research, the thesis will progress accordingly;

Chapter Two: this chapter contains a comprehensive review of the literature surrounding suburbanisation, New Zealand's residential development context, and the public private gradient. Two progressive imperatives for change in the way residential suburban developments are designed are explored and provide a framework for a literature review leading ultimately to the focus of the research.

Chapter Three: five Wellington suburbs which are representative of chronological housing or residential development trends are examined. Of particular importance are changes in attitudes and strategies concerning how the public private gradient is managed. Suburbs with consistent terrain are chosen to eliminate variables and ensure that a consistent comparison is achievable.

Chapter Four: a series of urban, and architectural precedent studies are investigated in this chapter. The urban precedents demonstrate alternative suburban development models. Analysis of these models culminates in a series of urban design decisions producing a suitable suburban development model to serve as a design vehicle. Architectural precedent studies reveal design strategies, elements, components and devices that successfully establish and modify a public private gradient in a suburban residential street.

Chapter Five: this chapter addresses the initial imperatives for change in the way residential suburban developments are designed. The purpose of this segment is to set up a suitable context in which the core issue of the public-private interface can be tested. The design strategies uncovered in the prior analyses are introduced and specified in the second part of the chapter.

Chapter Six: presents the results of the previous three chapters as they come together in an iterative, holistic design case study of a site that is consistent with the suburb choices of Chapter Three. A design project including conceptual and detailed architectural design is followed by critique and evaluation of the design outcomes products and processes.

Chapter Seven: this chapter reviews the design research by highlighting the key conclusions from each chapter, discussing the design case study, and identifying weaknesses and further opportunities and areas for investigation. 


\section{Chapter Two: Background}

2.1. Introduction

2.2. Sustainable Growth Patterns for New Zealand Suburbs

2.3. Placemaking and the Value of 'Community' in

Contemporary Suburbs

2.4. Managing the Public-Private Gradient

2.5. Conclusion 


\subsection{Introduction}

The focus of this research is the interface between the public and private suburban realms. The following chapter examines the literary context for the establishment and management of a graduated transition between public private. The structure of this chapter follows two imperatives for change in the way residential suburban developments are designed:

- Projected population growth ensuring that land consumption propagated by the spread of suburbia is not sustainable;

- And, suburbia produces poor suburban places which affects the perception of 'community' in suburban neighbourhoods.

These two imperatives are discussed with the intention of setting a clear foundation for the third design imperative, and the core subject and scope of this research:

- The public-private interface between the domestic dweller and the street user within suburbia is poorly handled.

\subsection{Sustainable Growth Patterns for New Zealand Suburbs}

Suburban Trends in New Zealand

New Zealand's suburban residential development trends have largely followed well documented American patterns. The intention of this section is to briefly highlight the evolution of suburban residential development ideas and demonstrate the effect the car has on New Zealand's suburban neighbourhoods.

Fundamental suburban values stem from initial attempts during the Industrial Revolution to make the city more accommodating of the city dweller's needs. This accommodation was achieved by removing home environments from the decaying, polluted and overpopulated urban centres during the nineteenth century. Urban centres with offices, stores and entertainment attracted people in the Victorian era, “... bu a suburban trend in the mid 1920s became a suburban tide in the 1950s. By 1970 more Americans lived in suburbs than in either central cities or rural areas. By 2000, more Americans lived in suburbs than in central cities and rural areas combined" (Hayden 10). Kenneth T. Jackson predicted in 1985 that because of rising energy and land costs, people would be driven back to the urban centres. However, evidence suggests that the opposite has occurred; the American population has settled at the urban periphery at an alarming rate.

Similar trends have materialised in New Zealand. Prosperity in the post-war era led to a dramatic rise in car ownership and use; consequently requiring the construction of arterial road networks to carry them (Department of Internal Affairs 1). Traffic and congestion problems soon followed providing city dwellers with further reason to move from urban centres and establish decentralised 'suburban centres'. Suburban development is now completed further from urban centres requiring more time spent commuting to and from employment for residents. A decentralised urban environment is a symptom of these lowdensity suburban residential areas (Chamberlain 14). Wellington demonstrates these characteristics. While Wellington's urban centre is a robust and coherent city form, increased suburban development has displaced domestic activity. Continued population growth and pressure on the existing housing stock has seen suburban development spread right up the Kapiti Coast, some distance from the city centre. Of all the 'Territorial Authorities' in the greater Wellington region, Kapiti Coast has the highest population growth rate. Between 1996 and 2006 the population of Kapiti Coast increased by 19.7\%, the highest growth rate in the region. The second highest rate, achieved in Wellington City, was 13.8\% (Transit NZ 43). 


\section{The Need for Sustainable Development Pattern}

In contrary to the evidence suggesting otherwise, New Zealand has a rural image. This rural-ism is bound up in the ideology of our national identity. However, according to the Department of Internal Affairs New Zealand is an urbanised nation. $72 \%$ of the population currently dwells in any of the 16 recognised urban centres (1).

Wellington City Council expects the regional population to increase by approximately 33,000 in the 25 years from 2001 to 2026, and eventually 56,000 by 2051 (2). The City Council has estimated that in that span of time around 30,000 new dwellings are required to house the growing population (9).

On top of the increasing population, the demand for housing in New Zealand is complicated by a decreasing average household size. The City Council suggests that while 30,000 new households will be formed, the average size of those households is projected to settle at 1.8 people per dwelling compared with 2.7 people per household in 2001 (Wellington City Council 23). This decrease is influenced primarily by the increase in number of single-person and childless-couple households, coupled with the decline of the traditional 'nuclear family' household (Stiles 12). The key conclusion drawn from this data is that the population is increasing in a manner that produces more household units per capita than ever before. The pressure on housing stock and the rise in urban land values over time gives rise to the subdivision of available land, typically land at the peripheries of urban centres. This pressure is currently characterised by large houses on relatively small lots resembling the sprawling 'cookie cutter' American suburban model (Department of Internal Affairs 1). The continuing consumption of land is the initial imperative for change in the methods we use to create suburban residential developments.

\section{The Need for Improved Public Suburban Realms}

Along with the greater distances to be travelled comes the customary solution of providing infrastructure for increased use of private transport. Because this investment facilitates faster and more convenient travel, the cost of commuting is reduced. This reduction allows residents to enjoy cheap housing in the suburbs while paying minimal commuting-cost penalties. As a result, suburban locations are increasingly attractive as commuting costs fall, which only spurs further suburbanization (Brueckner 162). However, according to Joshua Arbury the most important effect of the automobile on urban development patterns is the total spatial disconnection between the home and the workplace (Arbury 22). City functions were being separated through exclusive zoning patterns and regulations, enabling people to escape the pollution and 'bustle' associated with business or industrial precincts (Arbury 19-20). This attractive separation is enabled by the extensive use of the car, firstly, by isolating the dweller's home environment from any unattractive characteristics and secondly, by maintaining an affordable and increasingly efficient commutable link to the workplace. By advocating private car use, authorities propagate a mono-functional suburban realm which is governed by the residents' use of cars. Jane Jacobs recognises, however, that the car in itself is not the problem; it merely amplifies issues stemming from city planning decisions. Because the needs of cars are easily understood and catered for than those of a city, more professionals have been led to believe that the success of urban design is brought about by solving traffic problems (Jacobs 7).
The core issue of this design imperative is that the fundamental need to accommodate large numbers of cars in suburban development leads to the creation of poor public realms, particularly for pedestrians. Brueckner suggests that open space provides an easy escape from the frenetic urban scene and a chance to enjoy the outdoors. Such open-space benefits are not taken into account when land is converted to suburban use (Brueckner, p.164). The predominance of the car in suburbia ensures that there is a friction between pedestrians and car users. The possibility of accidents on suburban streets ensures that design measures are now taken to avoid any such confrontation between pedestrians and car drivers. The contemporary street is therefore reduced to a bleak, inhospitable and hazardous environment for the pedestrian that has no other official function except to act as a conduit for cars (Kunstler 49-50). 


\subsection{Place-making and the Value of 'Community' in Contemporary Suburbs}

An improved interaction between the public and private realms significantly affects the potential to build a stronger sense of community in contemporary suburban environments. The key conclusion arriving from relevant literature is that 'community' is not successfully catered for in contemporary suburbia. This conclusion prompts the requirement to reveal how place based community is achieved and how this both affects, and is affected by, a successful public-private interface. A sense of community is a different consideration than that of 'actual' community because it has more to do with people's perception of the environment they live in. The intention of this section is not to examine community, as that falls outside the research scope, but rather to establish the value of a 'place-based' perception of community for suburban neighbourhoods. This establishment sets the context for an investigation of a graduated transition from public to private.

\section{Deterioration of the Perception of Community in Suburbs}

According to Peter Chamberlain the social dimensions of suburban development have been lost and people's sense of community has deteriorated as a result. He suggests that there has been a significant weakening of relations within suburban groups (Chamberlain 14). These relations are dictated by connections and common ground established through interaction among people and people groups. The critical social transaction aids the establishment and reinforces a set of common values, norms, meanings, history and identity which are the fundamental 'building blocks' to a positive perception or sense of community (Chamberlain 14).

The assertion that 'community' has become public property is pertinent in this context. The titles 'community' and 'neighbourhood' have become a commodity which are fundamentally synonymous with advertising vocabulary for residential developments (Chamberlain 15) (Brown and Burns). 'Community' is merely a noun describing a 'cluster of houses with people inside,' there is no community in any true sense of the word (Brown and Burns). A conclusion drawn from these arguments is that the suburban paradigm is one where the house is seen as a container that isolates the domestic household from the public.

Inhabitants are permitted to engage and consume the world from the comfortable confines of their privacy.

A widely held conjecture is that suburbs were instigated to establish pleasant living conditions for city dwellers. Arbury's inference that most people seek to own and inhabit homes on their own lots suggests that the suburban ideal still does fulfil that promise. Within suburbia there will always be the lure of a large house on a large lot, with good car access to facilities which are all distinctly attractive at an individual level (Arbury 17). Often these things are seen as status symbols and signs of success.

The previous contention, though, is tempered by the notion that individualism and privatism propagated by mass private property ownership degrades the significance of the public realm. The literature suggests that the public realm in suburbia is a territory with no inhabitant. Public space in suburban developments has become anonymous. Private domains have absorbed the former functions of the public realm to become increasingly autonomous as the common ground for 'community' is eliminated (Calthorpe and Van der Ryn xiii). A suggested consequence of this trend is that the suburb dweller is able to disregard any pre-existing responsibility to the public realm (Kunstler 26-27). When the suburban fabric advocates wholly private space, then the public environment becomes car dependant and entirely vacant of people, preserving the privacy of the suburbanite. This wholesale privacy eliminates people's 'personal sovereignty,' or their ability to manage themselves in their own environment and their connection to civic, commercial and social amenity (Brown and Burns). In other words, an extensively privatised street environment reduces the residents' connection to amenities, activities and other people which are crucial in developing one's ability to understand and interpret situations and implement solutions to problems in everyday life. The interface between public and private is quite clearly implicated in these notions as an edge condition with obvious protective and isolating qualities.

Place-making: The 'Creation' of Place

To understand how the characteristics of place and the process of place-making affect the perception of community, it is crucial to first briefly highlight the key principles and origins of the notion. Christian Norberg-Schulz writes about the genius loci, or the spirit of place, which is established through designing from a start-point of understanding basic relationships between man and the environment. This gives rise to the idea of 'dwelling.' In its simplest terms, 'dwelling,' is defined by a significant or meaningful experience of an environment (Norberg-Schulz 5). The construction of this significance or meaning is a psychological process evolving from one's individual personal experiences. "Perceptions of a place are made up of layers of understanding - the settlement in the landscape, its overall structure, the district, the street, the building. They arise from understanding the physical and human geography" (Davies-Yeang 22).

This is most easily recognised when people can orientate and identify themselves in a particular environment. Typically, this happens in the home, explaining the synonymous connection between 'dwelling' and 'house.' Because one's home is the environment in which one is most comfortable, and the environment which means the most, home is the embodiment of what it means to be able to 'dwell.' The purpose of architecture in this context is to contain an inhabitant's emotional investment in a site, in order for it to become a 'preferred space,' a place that retains value and meaning (Norberg-Schulz 16). Along similar lines, Yi-Fu Tuan suggests that a 'place' is centre of value where fundamental human needs are satisfied (Tuan 4). This conclusion advocates that purpose of architecture transcends mere functionalism; architecture provides more than just a shelter.

\section{Place-making to Improve the Perception of Community}

Having established an understanding of 'place-making,' it is important to now develop the significance of 'place' in relation to the design intention of improving the perception of community in suburbs. The notable conclusion extracted from the literature is that fostering the creation of a 'sense of place' within the suburban public realm is critical to increasing the value of the suburban street. The scope of design in this research is in facilitating a successful interaction between public and private to enhance the perception of community, rather than in the establishment of community itself. Therefore, the subsequent shift to 
an understanding of place-making to inform the perception of community enables a transition to more physical and tangible characteristics addressed in the field of architecture and urban design.

The Ministry for the Environment's definition of the 'public realm' of cities indicates the inclusion of all parts of the physical environment that the public can experience, or have access to (Ministry for the Environment 48). This includes the physical environment of the suburban street, and also the facades of private buildings or dwellings which frame public spaces.

While his general argument is that our need for a 'sense of place' is too idealised and that contemporary human needs are better satisfied in different contexts, David Kolb acknowledges that the ideal street is place where social norms set out possibilities for action and activity across a spatial landscape or territory (Kolb 31). In other words, the street environment embodies and facilitates a set of principles which articulate and inform acceptable inhabitancy. This suggests that the public realm provides an inclusive setting for cultural, social and recreational interaction, while facilitating movement from one place to another (Ministry for the Environment 49).

Because of the following suggestions, an improved suburban street condition offers a distinctive and legible environment. Kevin Lynch suggests that the positive characteristics of this are: increased comfor and security; a heightened depth and intensity of human experience, which leads to development of a framework for communication and organisation; and ultimately, emotional satisfaction (Lynch 5).

Lynch writes about enhancing the 'legibility' and 'imageability' of physical environments to improve their visual quality. He suggests that a generalised image is held by an observer which is used to interpret surroundings and guide subsequent action. The image is produced by the immediate sensation of the environment, intertwined with memory and past experience (Lynch 4). A key conclusion he arrives at is that:

We are continuously engaged in the attempt to organise our surroundings, to structure and identify them Various environments are more or less amenable to such treatment. When reshaping cities it should be possible to give them a form which facilitates these organising efforts rather than frustrates them (90).

His writing highlights a concerted effort to improve the quality of city environments to the point that they inherently maintain a "... high probability of evoking a strong environmental image in any observer" (9). The perception of the environment is a critical aspect of orientation and satisfaction within the physical environments.

In a similar fashion, Calthorpe and Van der Ryn advocate for the importance of high quality public spaces, the provision for fundamental human needs and the subsequent improvement of the perception of community. The focus on increasing the value of the common spaces is intended to the create a bette pedestrian experience with increased socialisation and participation within the street (129). Two specific considerations contributing to this objective is the reduction of private open space in residential areas, and the protection of the private realm. They suggest that reducing the amount of private open space available to residents can be offset by increasing the value and accessibility of communal open space (126). However, this statement is moderated by the observation that the critical sense of community fails to develop when people's fundamental requirement of privacy is not protected (125). Both of these factors affect Lynch's 'legibility' of the suburban realm and strengthen the physical elements that form the 'environmental image' of the suburban street. According to the Ministry for the Environment, 'micro-scale' urban design factors also affect the success and quality of the public realm. These factors are attributed to the architecture of the surrounding buildings, highlighting specifically: building orientation, street connectivity and design, and building design (United States Environmental Protection Agency qtd. in Ministry for the Environment 51). It is also noted that the surrounding buildings can negatively affect the public realm. Dull building facades and inactive building edges combine to reduce the visual quality of the environment and decrease the legibility of the street. (Bentley qtd. in Ministry for the Environment 51).

According to Llewwlyn Davis-Yeang, one of the most important tenets of good urbanism is for buildings to give positive definition to the shape and function of outdoor space, and for this outdoor space to be designed to encourage a range of activities to take place (86). Understanding the street-to-house relationship in this manner underpins the significance of 'place' for this research. In the way that the home offers significance and meaning to the individual, the purposes of an improved street environment transcends absolute functionalism; the street condition evokes a place-based perception community, offering distinctly more than just a conduit for cars. 


\subsection{Managing a Public-Private Gradient}

Up to this point, the conclusions of this chapter have demonstrated the governance of the car and its effect on the public realm in suburbs creating a tension with pedestrians, and the degraded sense of community because of the poor suburban public realms. The switch to remedying these issues has uncovered that notions of 'place-making' and 'legibility' produce an improved perception of community because of the high quality public realm environments. These points effectively set the scene for an architectural response to mediate the interface between public and private.

Davis-Yeang advocates an 'urban architecture,' or a design in which buildings and open spaces are considered as a totality. It is suggested in this context that the success of a building is determined by its ability to make a positive contribution to the public realm; its ability to face and animate the street. It is this interaction between buildings and the public domain that determines the relationship between inside and outside, built and open, individual and community, and most importantly, between public and private (89)

\section{The Public-Private Interface: Boundaries and Thresholds}

In dealing with the creation of high quality suburban places or public realms the problematic conventional edge condition between public and private is challenged. Public and private realms are fundamental to all urban space and are inextricably linked. The relationship between the two realms, the separations and connections, comprises the central focus of this research.

Perceptually and practically the worlds of inside and outside, and correlatively private and public, are mutually exclusive. Richard Lo suggests that both realms are entirely dependent on each other for their character and identity; to cut either one out completely is to deny the existence of part of our environment and abolish the fundamental act of architecture. Architecture attempts to manipulate and mediate this relationship, most obviously through the use of doors and windows (Lo 12).

The fundamental act of architecture is to define one space from another (Brookes 4). This assertion comes from Robert Venturi's suggestion that because the inside is different from the outside, the wall - the point of change - becomes an architectural event. Architecture occurs at the meeting of these interior and exterior forces (86). In other words, the point of separation between inside and outside is an act of spatial definition attributing significantly different characteristics to either side. Because one cannot occupy both of the contrasting situations at the same time, even though they border directly on each other, a boundary condition is established; a threshold through which one must pass in order to occupy either space (Arnheim 2).

In her thesis, Paula Jean Krugmeier suggests that the facades of buildings are principally boundaries which define open space, and as such, can be interpreted as containing surfaces. The facades, therefore, serve as the primary interface between the public and private realms (16). This claim reflects Venturi's thinking on the fundamental act of architecture, separating and creating opposing situations. Similarly, making frontages 'active' adds interest, life and vitality to the public realm (Davies-Yeang 89).

The boundary or the edge condition, including the implementation of thresholds, is crucial in defining the relationship between public and private. An 'interface zone' is defined in Krugmeier's research, by the relationship between: the function of the interface, the territories between which it functions, and the physical elements and spaces which perform the function (Krugmeier 18). In other words, the 'interface zone' is defined by what it achieves, where it is positioned and how it actually functions. To articulate this point, the transition from public to private is broken down into a series of physical elements including walls, fences, screens, plants, and windows. The spaces defined and constructed between these elements constitute an important part of the interface including the likes of yards, set-backs, lobbies, corridors and entrance alcoves. The elements and spaces subsequently combine with the primary facade to create a series of ways in which the interface is regulated (Krugmeier 20). The significance of this zone as a mediating component of the interface between public and private is again a by-product of Venturi's fundamental act of architecture.

The facades, physical elements and spaces combine to define the interface that the domestic interior maintains with the public realm. From a holistic standpoint the characteristics of the resultant interface greatly affect the realisation of place-making and the establishment of community in suburbia.

\section{The Implementation of a Gradient to mediate from Public to Private}

The focus of this research centres on the final imperative for change, creating an improved public-private interface. The assertion that our wellbeing needs to be based less on commodities, that is private and individualistic, and more on community is pertinent in the discussion of the role of the house in the interface between public and private (Calthorpe and Van der Ryn xvi-xvii). This endorses a responsibility on behalf of the suburb dweller, for the action, behaviour and emergence of the public realm. The proposa of a graduated, negotiated relationship is best applied in this situation, directly opposing the current trend of creating a hard, impenetrable edge between public and private.

Davis-Yeang advoctes an 'urban architecture,' where buildings and open spaces are considered as a totality. It is suggested that the success of a building is determined by its ability to make a positive contribution to the public realm. It is this interaction between buildings and the public domain that determines the relationship, most importantly, between public and private (89).

Aldo van Eyck suggests that architecture should be conceived of as a configuration of intermediary places which are clearly defined. The implication is not continual transition, conversely, it suggests a break away from the notion of a spatial continuum or the removal of articulation between spaces. His assertion is that the transition between realms must be expressed clearly by means of defined 'in-between places.' (Aldo van Eyck qtd. in Venturi 81). This principle subsequently induces 'simultaneous awareness' of spatial characteristics on either side. In this sense, an in-between space provides common ground where conflicting polarities can be reconciled (Aldo van Eyck qtd. in Venturi 82). The implementation of a gradient with this understanding ensures a negotiation and a mutual two-way awareness between the household to the public environment. 
A graduated transition between public and private designates private use zones, public use zones and intermediary zones which facilitate a successfully mediated interaction between public and private. According to Kerstin Thompson, the gradient then becomes a tool for regulating performance and managing the moments between mutually exclusive opposites. This maintains balance while negotiating the potential for social connection and the desire for privacy (Thompson 66). In other words, the increased spatial transition generated by a gradient between public and private ensures that the interface is successfully regulated and that opposing spatial objectives are balanced and mutually beneficial.

\subsection{Conclusion}

The aim for the subsequent design research is a greatly enriched and urbanised suburban public domain. This is addressed through a holistic design of a residential subdivision which addresses the design imperatives highlighted in this chapter. The projected increase in suburban development provokes the need for sustainable growth patterns, while the current street conditions stimulate the need to address 'placemaking' in the public realm of suburbia. The establishment of a successful gradient between the public and private realms within suburbia is the primary methodology employed to help transform the suburban street into a suburban place and consequently, improve the perception of community. The articulation of visual and spatial relationships in the form of 'in-between spaces' connect the resident and the pedestrian, demonstrating the 'event' of the gradient between public and private. This notion is the basis of an

improved perception of community in the suburban setting. 


\section{Chapter Three: Historical Analysis}

3.1. Introduction

3.2. Discovering the Public-Private Gradient in Wellington Suburbs

3.3. Key Observations

3.4. Conclusion 


\subsection{Introduction}

This research centres on a graduated transition between suburban house inhabitants and street users. The purpose of this chapter is to develop an understanding of the public private interface in suburban streets as it is demonstrated in Wellington's existing housing stock. The hypothesis for this particular study is that the early residential and suburban development models employed in New Zealand demonstrate means to successfully establish and mediate a public private gradient. However, over time the building forms have come to emphasise rather than mediate the tension between the public and private realms. Recent lowdensity suburban development models commemorate the segregation of public and private. To qualify this proposition five key periods in New Zealand's suburban development history, and five corresponding Wellington suburbs are identified. These suburbs are the focus of a comprehensive analysis which reveals how the public private gradient has previously been established and managed, and how this has changed over time.

\subsection{The Public Private Gradient in Wellington Suburbs}

Identifying key Suburban Development Trends

Documenting five key suburban development periods in a consistent analytical manner provides the data to compare and form conclusions about the evolution of trends affecting the interface between the public and private realms. This comparison further develops the understanding of suburban residential development in New Zealand while revealing historical traits which are useful in the subsequent design investigation.

Research undertaken by Beacon Pathways Ltd looks at New Zealand's housing stock, categorising the house types according to their era based on a workshop completed in 2007. Their 2008 report provides basic descriptions of systems and characteristics that can then categorically represent the majority of New Zealand's housing (Ryan et al 3). Five periods chosen for this study are:

- Late $19^{\text {th }}$ Century, Victorian

- 1915 - 1930’s Californian Bungalow

- Post-war State Housing

- 1970's and 1980's Housing Boom

- Recent Development

These five categories correspond to changes in design thought at the urban scale as well as the architectural scale. Other categories, and sub categories, were excluded from this study because their distinctiveness was primarily governed by aesthetics and style which did not necessarily affect the notion of the public private gradient.
The study is confined to local Wellington examples for ease of access for initial site research. Suburbs are selected because the housing stock and street patterns in each of them match the residential development models as discussed below. In addition, suburbs on flat or near flat terrain are chosen to eliminate as many variables as possible; especially as a change in elevation is in itself a means to mediate the public private gradient. The subject suburbs are:

- Newtown: Late $19^{\text {th }}$ Century, Victorian

- Miramar: 1915 - 1930’s Californian Bungalow

- Naenae: Post-war State Housing

- Totara Park: 1970's and 1980's Housing Boom

- Otaihanga: Recent Development

Methodology for Analysis

The set of conventional hand drawings for each suburb study include:

- Figure ground

- Street and Block pattern

- Chosen Street Plan

- Chosen Street Section

- Typical House Plan

- Front elevation

- House Section

- House Isometric

These drawing conventions reveal the extent of urban design, and architectural design intentions typical of each era. Each suburb study is accompanied by a hybrid explorative drawing in isometric format which is unique to the research and represents the key architectural features that create and modify the publicprivate gradient. This 'Gradient Diagram' is developed specifically for this research highlighting key components and contributing factors towards the public-private gradient. 


\subsection{Key Observations}

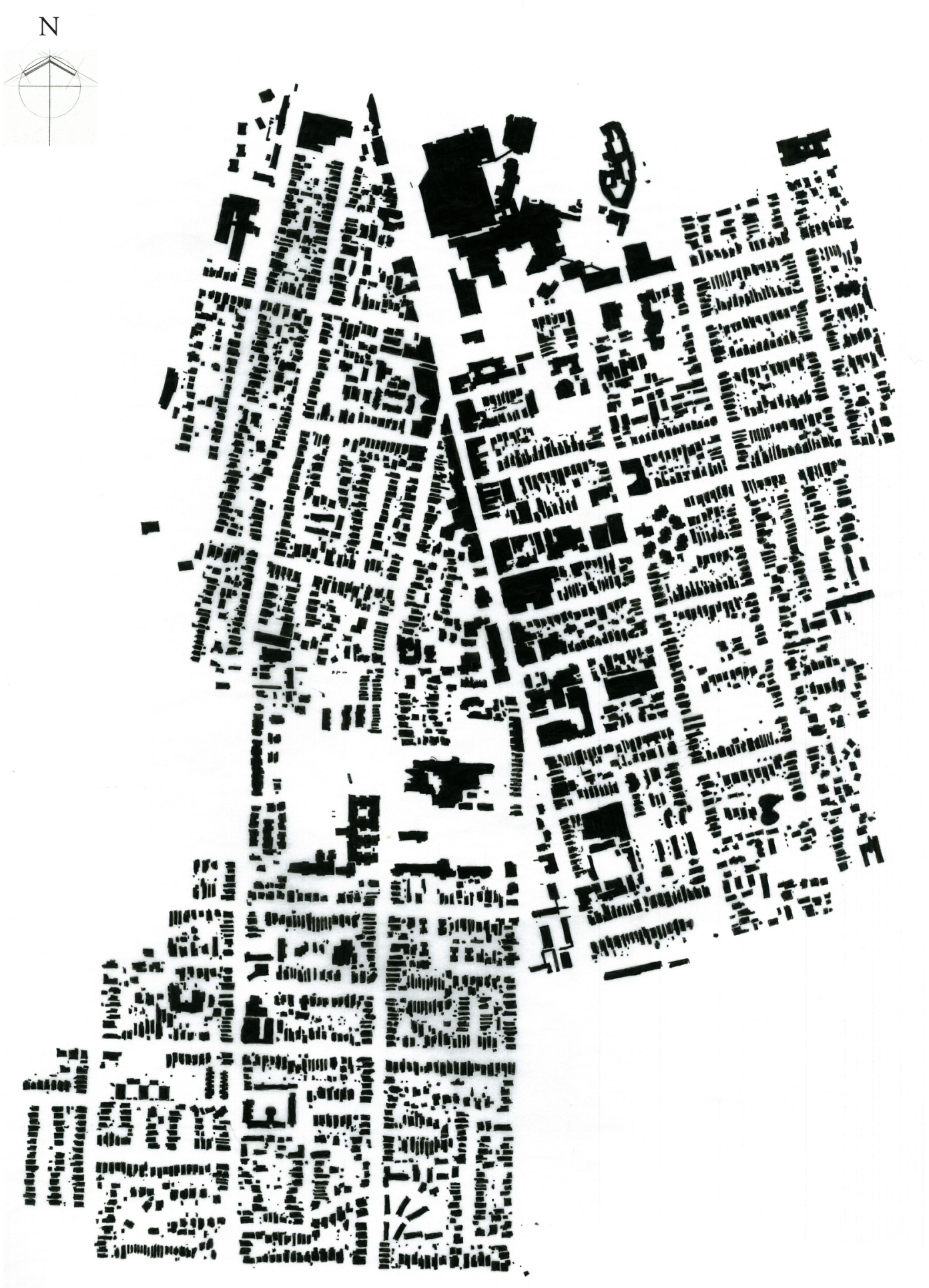

\subsubsection{Newtown: $19^{\text {th }}$ Century}

Pre-planned suburbs were part of original city plans. While largely ignoring topography, gridded suburbs used visual barriers to separate public and private spaces, reinforcing individual property rights (Schrader 8). The villa was the first mass housing style in New Zealand and generally corresponds with the late $19^{\text {th }}$ and early $20^{\text {th }}$ centuries. The first villas were plain in form and finishes and they became more ornate and complex during the 1890s culminating in the bay villa (Ryan et al 14). The intensive decoration of the street facing facade makes this era unique, demonstrating a positive and flamboyant attitude towards the public realm while the basic architectural features of the Gable, Bay and the Veranda provided a modular system for the elaboration of standardised interior volumes. 


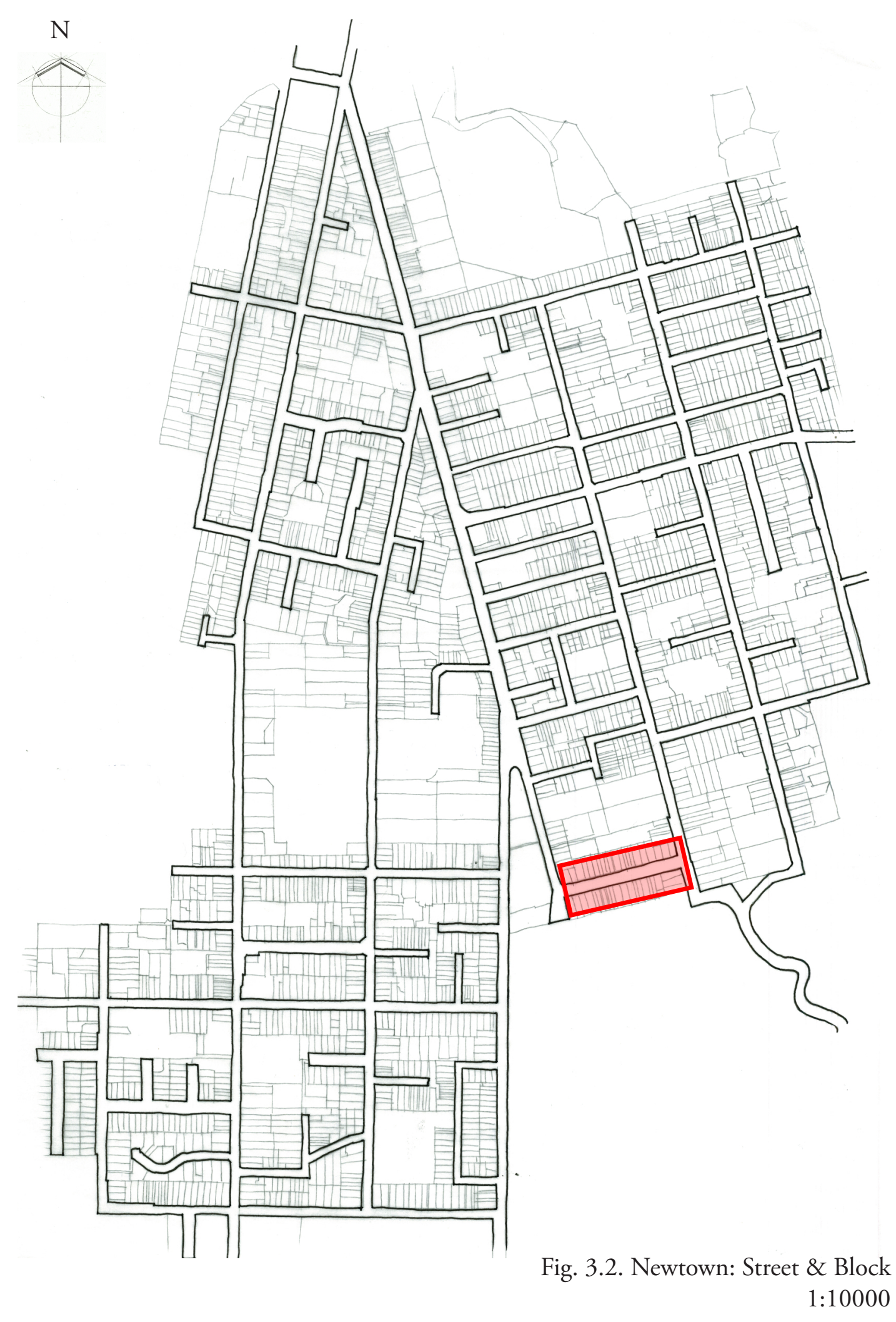

\section{biind Intid

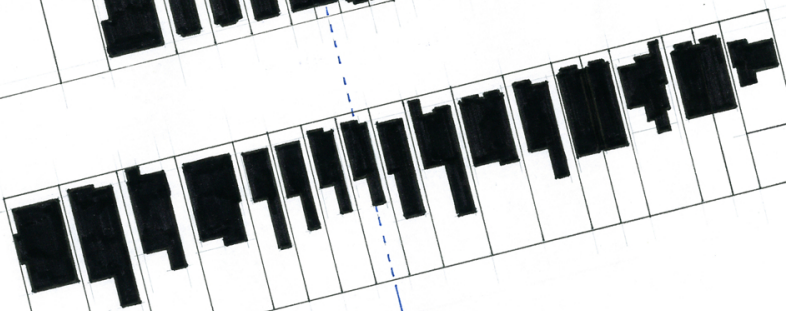

Fig. 3.3. Newtown: Roy Street Plan $1: 2000$

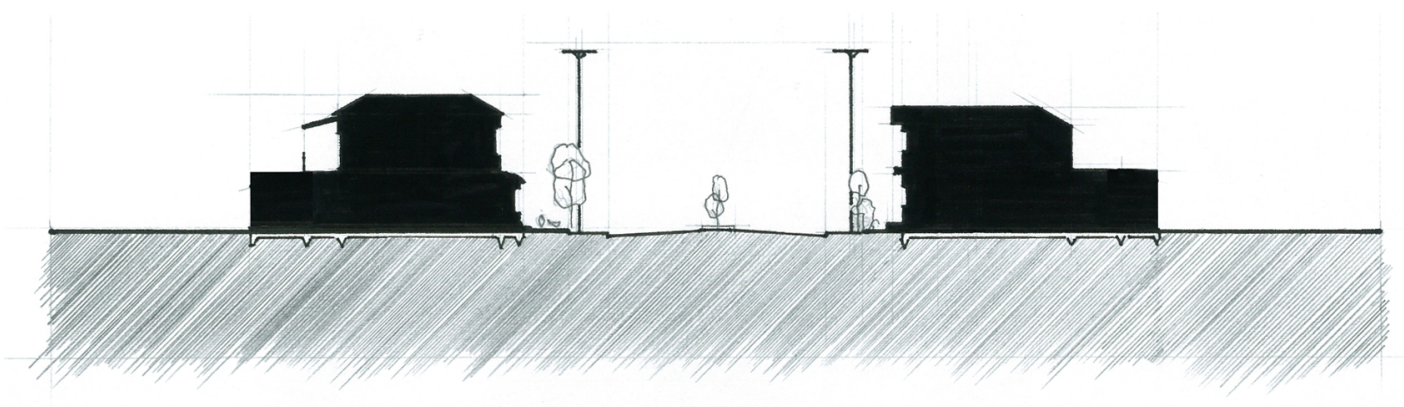

Fig. 3.4. Newtown: Roy Street Section 
The house plans of a villa in Roy street indicate what was essentially a standardised predesigned formula for house building (Vernez-Moudon 51). The drawings show that the formal and social areas (parlour or living room and master bedroom) of the household are oriented towards the street. The rooms of the house are distributed along a central corridor becoming progressively private the further into the house one moves. This is typically demonstrated by an archway and narrowing of the corridor at the threshold to more private zones. The private and service functions of the household (kitchen, dining room, bedrooms, bathroom, scullery, and wash-house) are positioned at the back of the house with access to the back yard. The primary entrance is closely associated with the parlour or living room, but not directly. Having passed through the veranda beforehand, the front door leads to the central corridor of the house. Because the veranda serves as another visual barrier it successfully establishes a key threshold directly between the public realm of the street and front yard, and the front door. The veranda also offers an inhabitable area that is distinctly domestic while retaining the transitory qualities necessary for the activity of entering the premises. Finally, the projection of the bay window from the most social room of the house facilitates an engagement between the public and private realms.

\section{Veranda}

2 Parlour

3 Master Bedroom

4 Dining Room

5 Hall

6 Bedroom

7 Kitchen

8 Bathroom

9 Toilet

10 Scullery

11 Laundry 
The street facade of the villa shows the careful ornamentation of the key architectural elements: the veranda, the bay window and the gable. The detailing of these core components places emphasis on the vertical proportions of the building. Timber construction methods permitted the ornamentation of the design modules as seen in the detailing of the gable end and veranda post brackets, the turned wooden finials and drops, the timber quoin mimicry and the variety of timber impressions of Victorian plaster casts and mouldings. The face presented to the public realm was to be as imposing and impressive to a visitor as possible, so the decoration effort seldom extended down the sides and rear of the house (Toomath 128).

The villa's longitudinal section of the house articulates the depth of the facade and the distance taken to negotiate between the immediate public environment of the street and associated front yard through to the private but social area of the domestic interior. The bay window and veranda establish that depth and maintain a soft and somewhat ambiguous threshold. The aggressive detailing described above imposes an impressive character to the bay and the veranda and this character successfully moderates the otherwise soft interface between public and private. The section drawing also demonstrates the common foundation type for the villa; piles. The piles detach the floor plane from the ground plane requiring steps up to the floors of the veranda and the house interior. The steps are significant for the organisation of the public-to-private hierarchy, and subsequently the public-private gradient. The thresholds establish a hierarchy of space, denoting a sequential change from more public to more private.

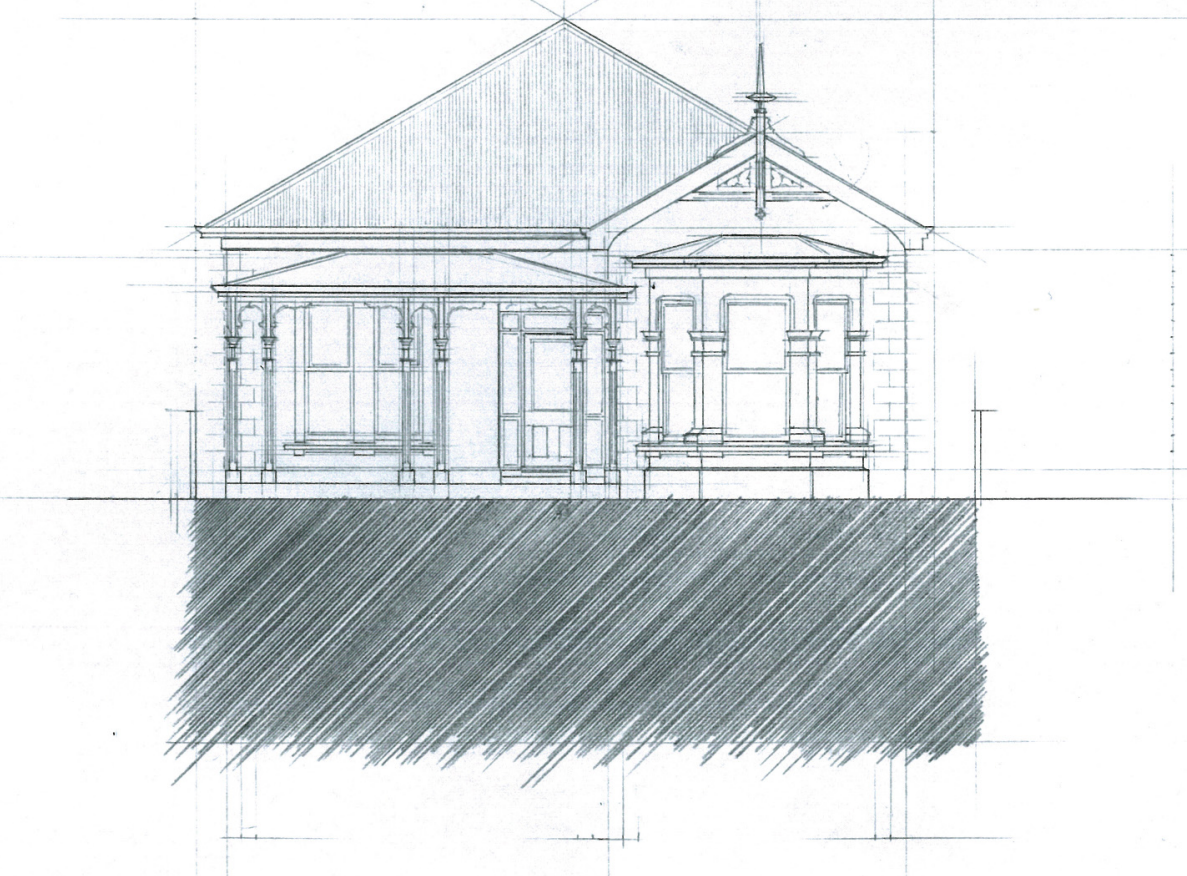

Fig. 3.6. Bay Villa Street Elevation

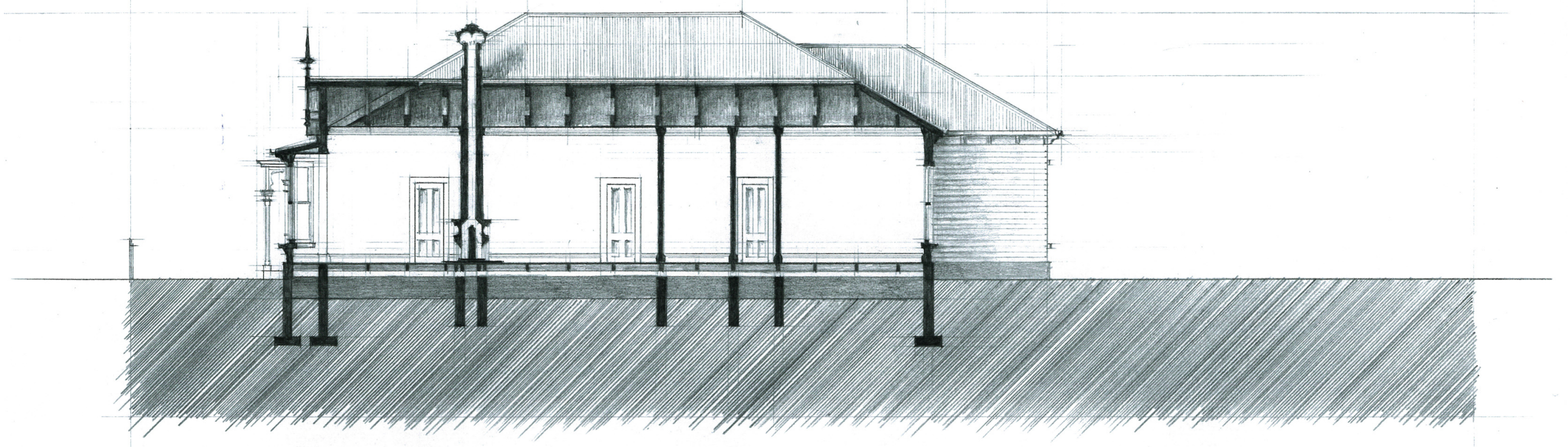

Fig. 3.7. Bay Villa Section 


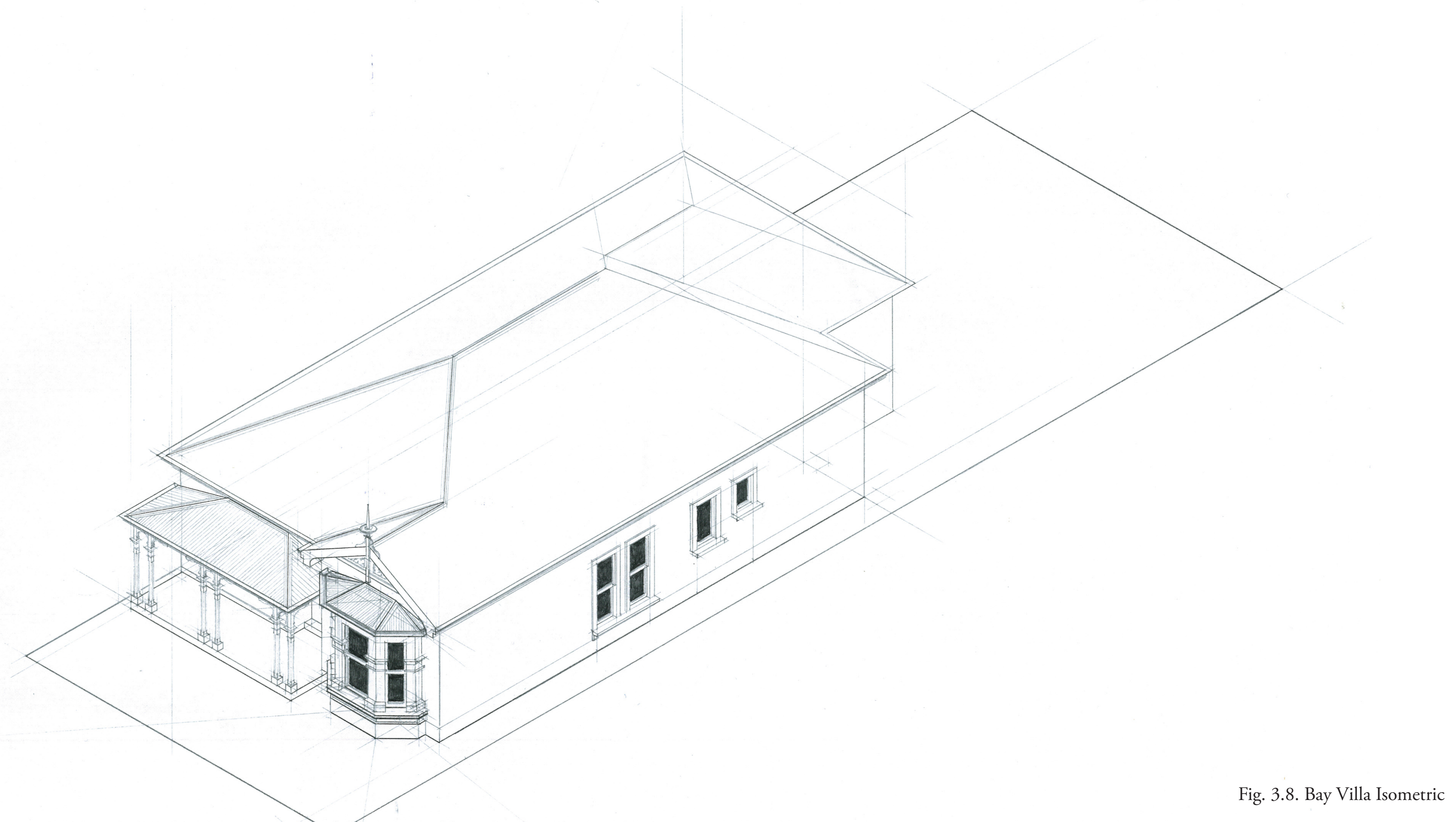




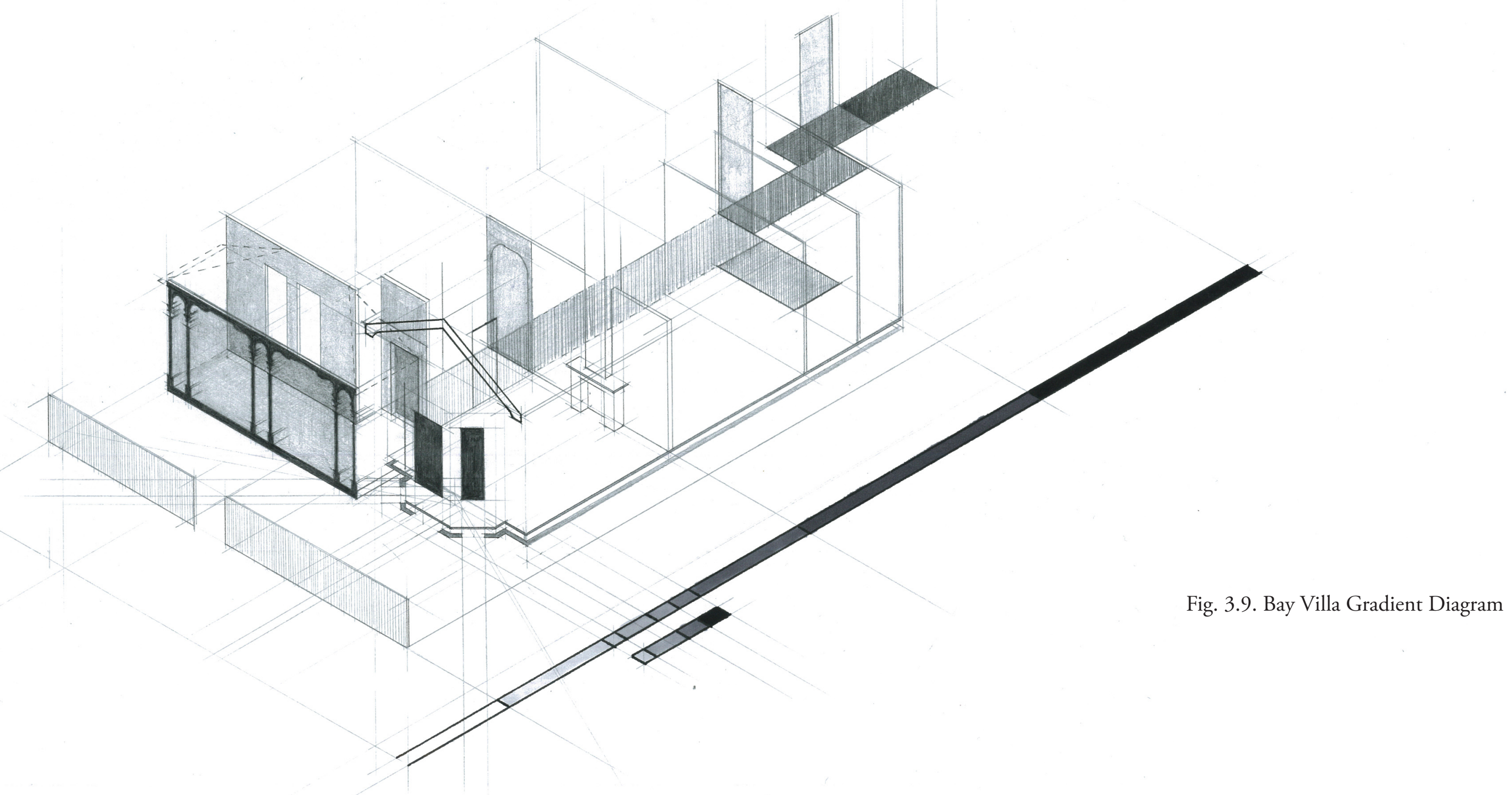




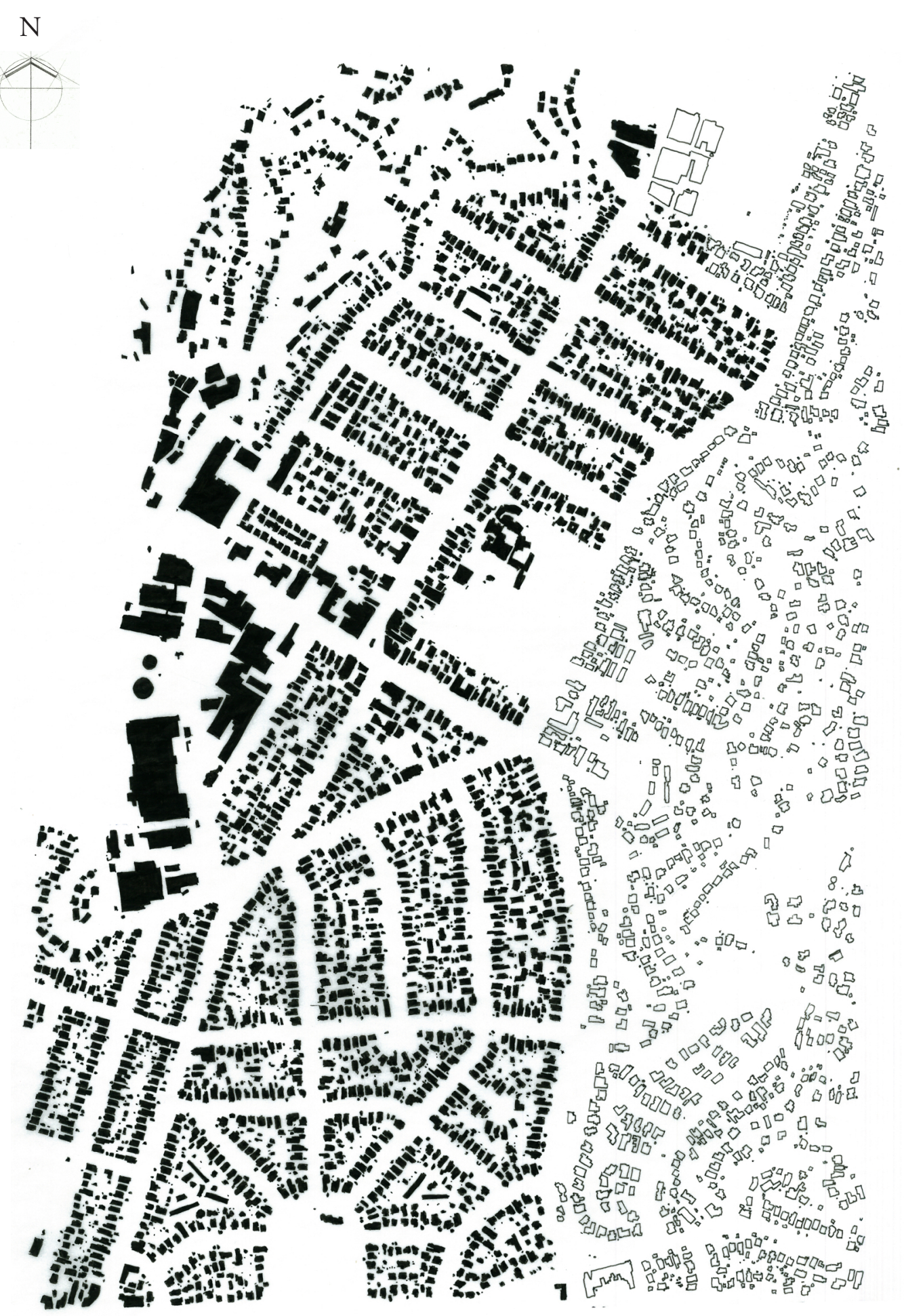

Fig. 3.10. Miramar: Figure/Ground 1:10000

\subsubsection{Miramar: Bungalow}

The Bungalow was a less ornate house than the older villas (Ryan et al 18). The transition to bungalows paralleling a shift away from the gridiron street pattern. Examples the bungalow model are synonymous with early 'Garden Suburb' ideals. Picturesque traditions began to influence town planning and resulted in more complex, but still quite formal geometric layouts. This change in layout methodology accommodated rather than ignored the topography (Schrader 8).

The bungalow style became the predominant housing type of the 1920s and 1930s when the State Advances Act of 1922 offered workers up to a 95\% loan to build their house. The bungalow required less timber than the villa and was therefore cheaper and quicker to build. Its simpler form and easy-to-follow 'pattern-book' plans also meant that nearly anybody could construct it themselves. This made it an ideal speculator's house during the economic upturn of the 1920s (Schrader 45). Following the First World War bungalow suburbs grew at the margins of the villa suburbs, or in areas with difficult topography which had been ignored by the developers of the villa suburbs.

Observations about street, block and figure/ground configurations are attached in Appendix 1. 


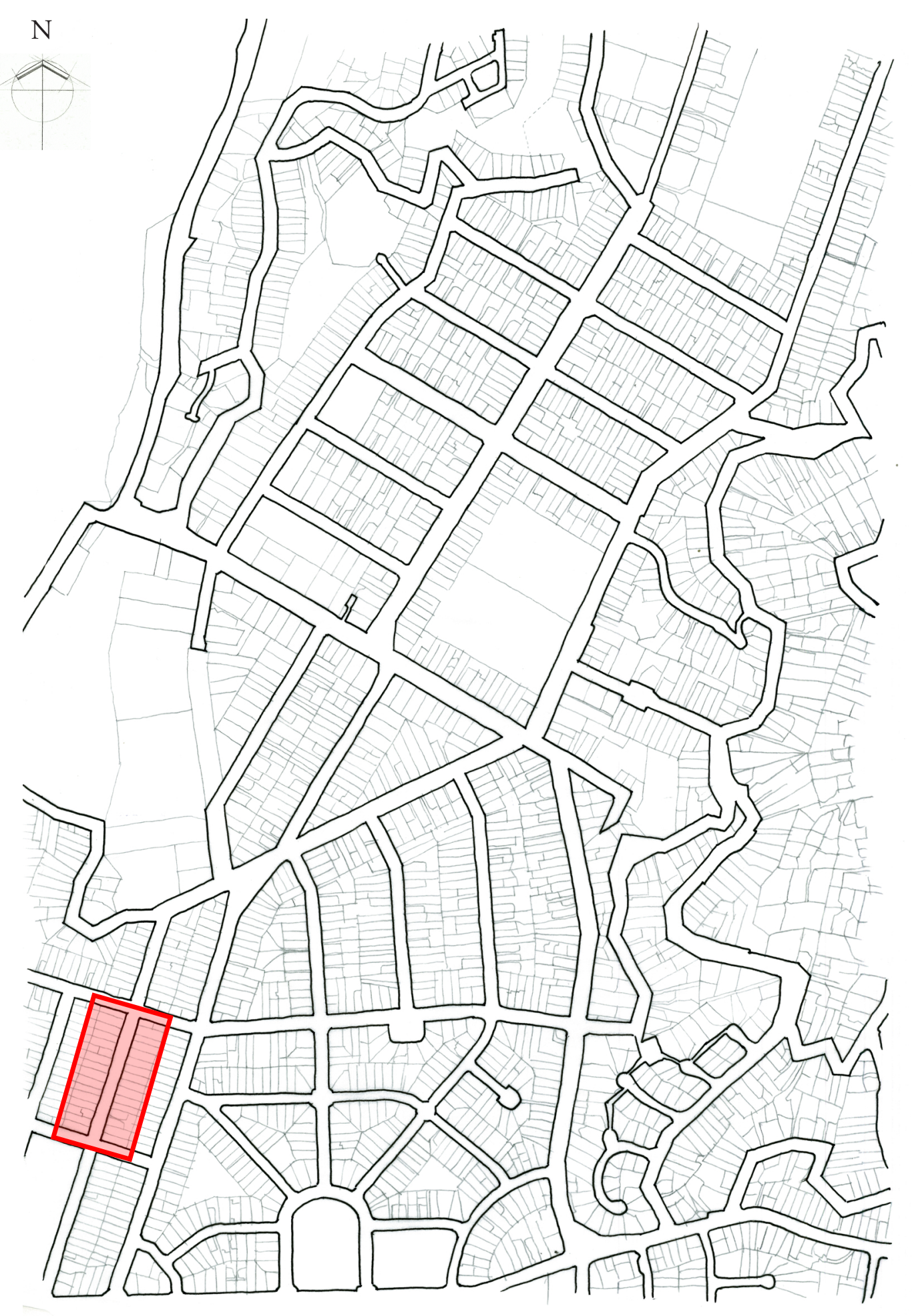

Fig. 3.11. Miramar: Street \& Block 1:10000

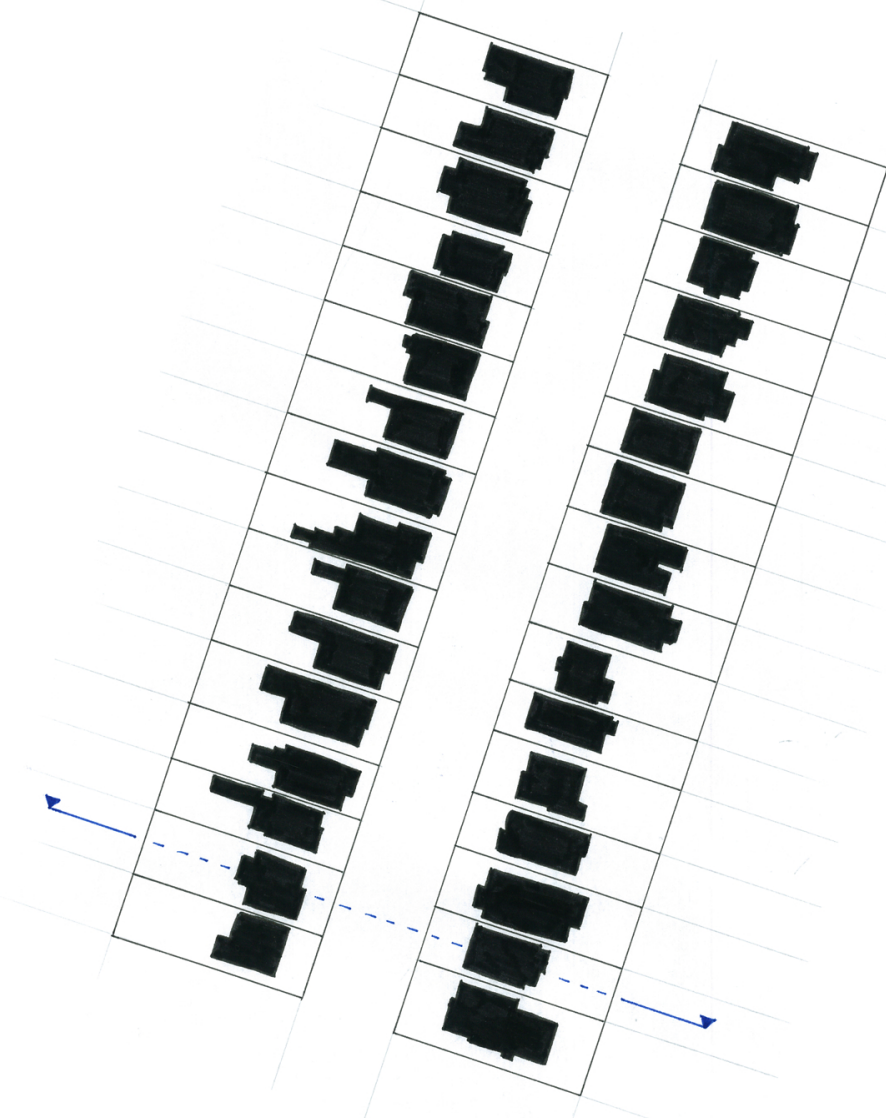

Fig. 3.12. Miramar: Kauri Street Plan 1:2000

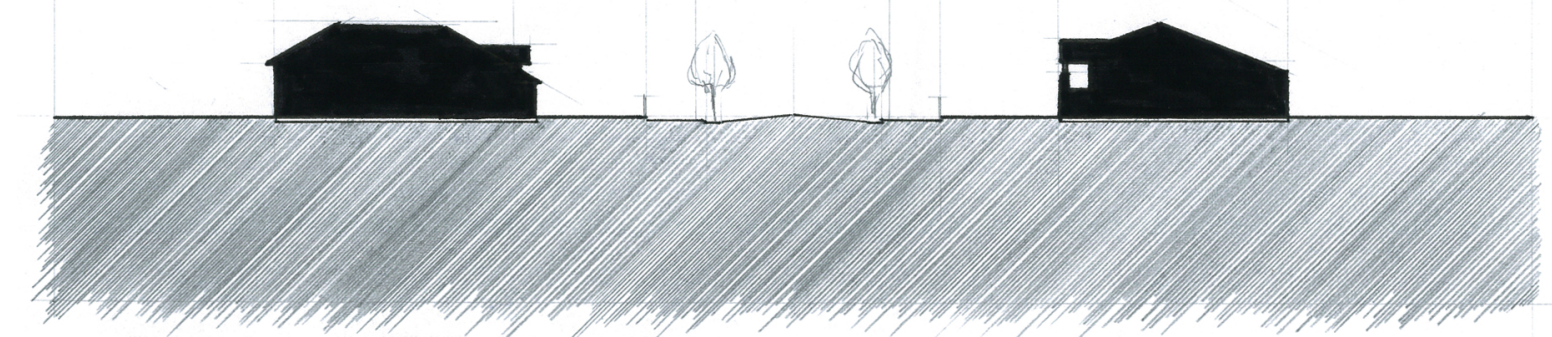

Fig. 3.13. Miramar: Kauri Street Section 
The house plan of a typical Californian bungalow in Kauri street demonstrate a shift in spatial organisation from that of the bay villa, and a reaction to Victorian formality. Bungalows were more commonly entered from the side and this necessitated a more generous side yard. The central hallway, rather than the ceremonious thoroughfare of the villa, became the hub of the house from which other spaces radiate. The living room was still often oriented towards the street, but not out of necessity. The bungalow's informality meant the primary living space could be oriented for maximum solar gain if desired. Officially the primary entrance opened directly into the living room but the adaption of the bungalow to suit New Zealand conditions meant that the primary entrance opened into a central circulation hub. From the living room the 'bow window' projects towards the street. The bow window is a more subtle projection than the Victorian bay and its effect is further reduced by the increased distance between the house and the street. A privately accessed loggia or porch typically joins the bow window on the main frontage, thereby counteracting the projection with a withdrawal back into the house. The loggia is accessed from either a master bedroom or the living room, becoming an 'open-air room' facilitating the all important romantic connection to the landscape.
1 Entry Hallway

2 Living Room

3 Master Bedroom

4 Outdoor Terrace/Loggia

5 Bedroom

6 Bsthroom

7 Dining Room

8 Kitchen

9 Toilet 
The street facade of the bungalow possesses a lower and broader proportion in comparison to the villa The accentuated horizontality accounts for the modest and subdued style while the lack of ornamentation gives it a "natural and unaffected character" (Arden and Bowman 22). Overlapping low pitched gables are decorated with shingles rather than elaborate fretwork. Overhanging eaves were common for this house style which, along with the bow window, established a framework of design modules that combined to create an elegant yet informal house. The bow window evolved from the English domestic tradition arraying a series of splayed and faceted casement windows with dormer/eye-lid windows above. The casements were more effective at keeping weather out while open than the sash or double-hung windows which were standardised in the Victorian villas. The loggia, the equivalent of the Victorian veranda, was often finished with heavy earthy materials and large veranda posts. The cave-like appearance is enhanced by the shallow arched facia board, further establishing a sense of privacy for the 'outdoor' room.

The bungalow's longitudinal section demonstrates a less forceful and direct public-private gradient than that found in the villa. The bow window and the loggia facilitate the extent of the engagement with the public realm. While the bow window is more subtle and gentle in its projection and interaction with the public realm, the loggia uses its heavy base to make a statement of private inhabitation. Because the domestic interior is distanced from the street edge by a deeper front yard, the interface between public and private is concentrated at the building frontage. On the other hand, the deep front yard and associated garden play a larger role in the mediation between street and domesticity. The outdoor connection provided by the loggia maintains a link between the house and the street but to a much lesser degree than the Victorian veranda. Like the villa, the foundations are also piles which lift the floor plane off the ground. However, without an obvious front-door or visible access point, the change in height reinforces the edge condition at the building frontage rather than a successful gradient between public and private.

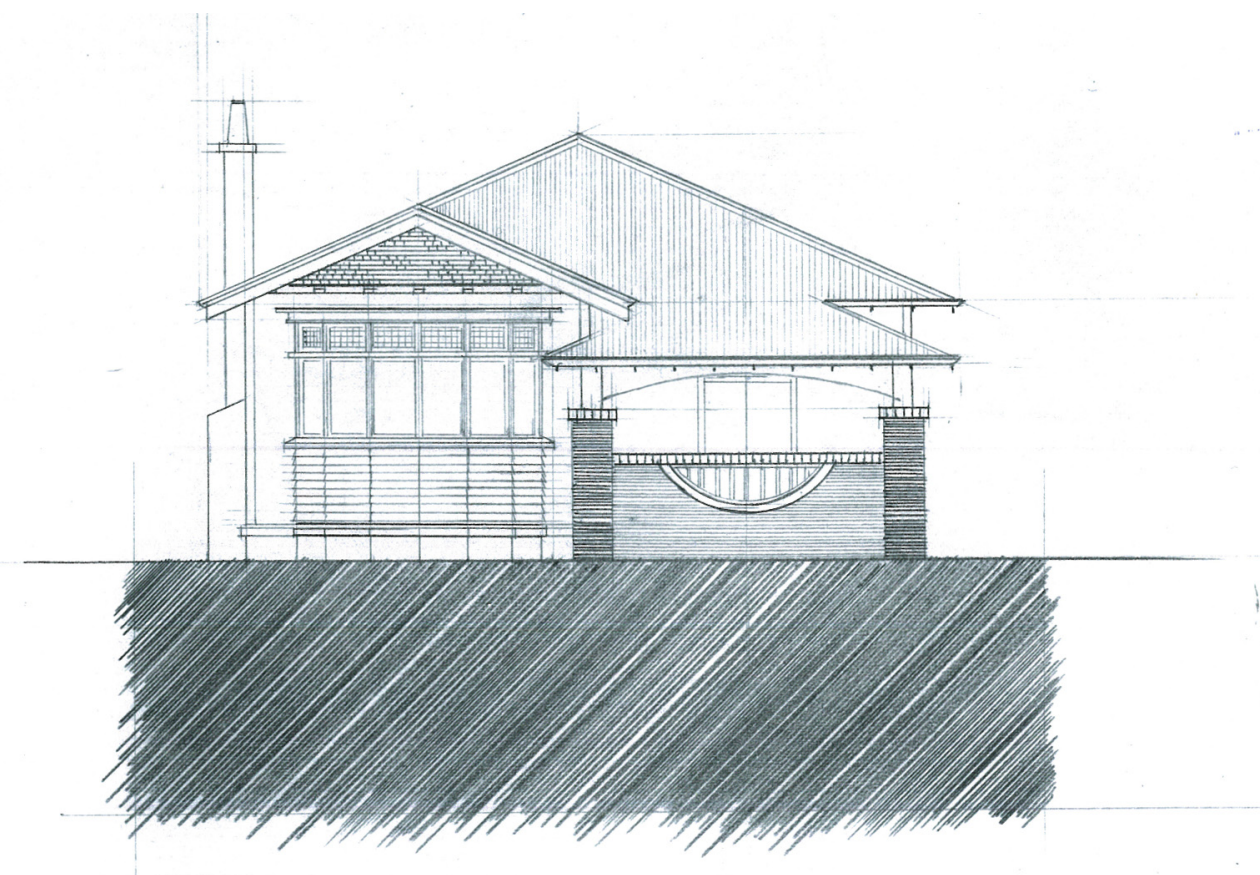

Fig. 3.15. Bungalow Street Elevation

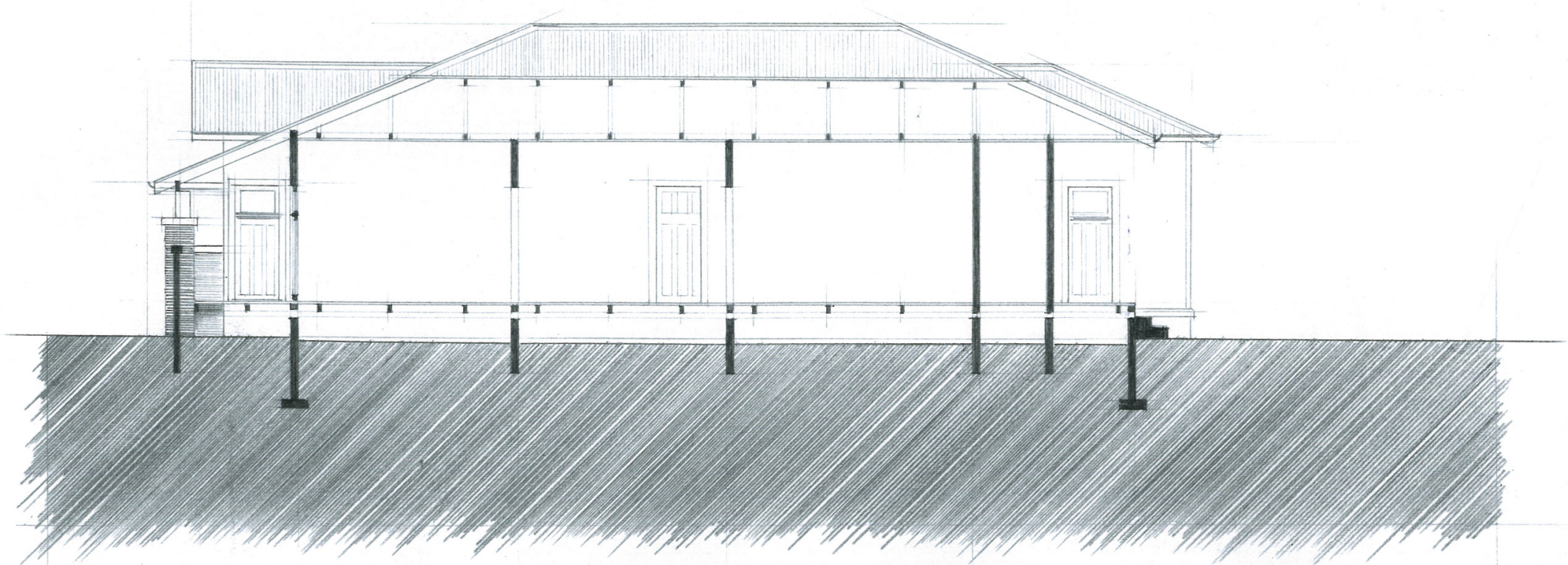

Fig. 3.16. Bungalow Section 


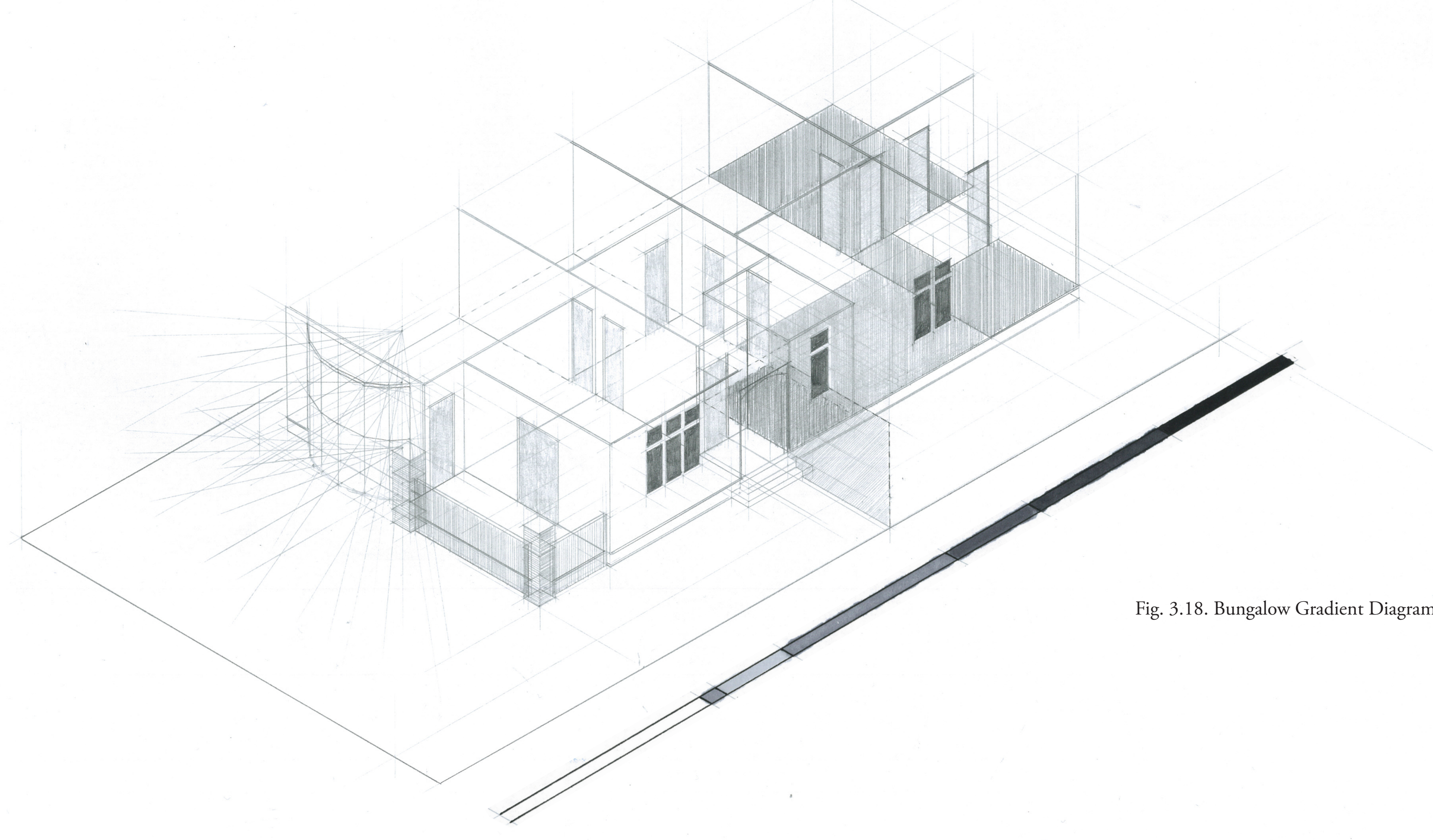




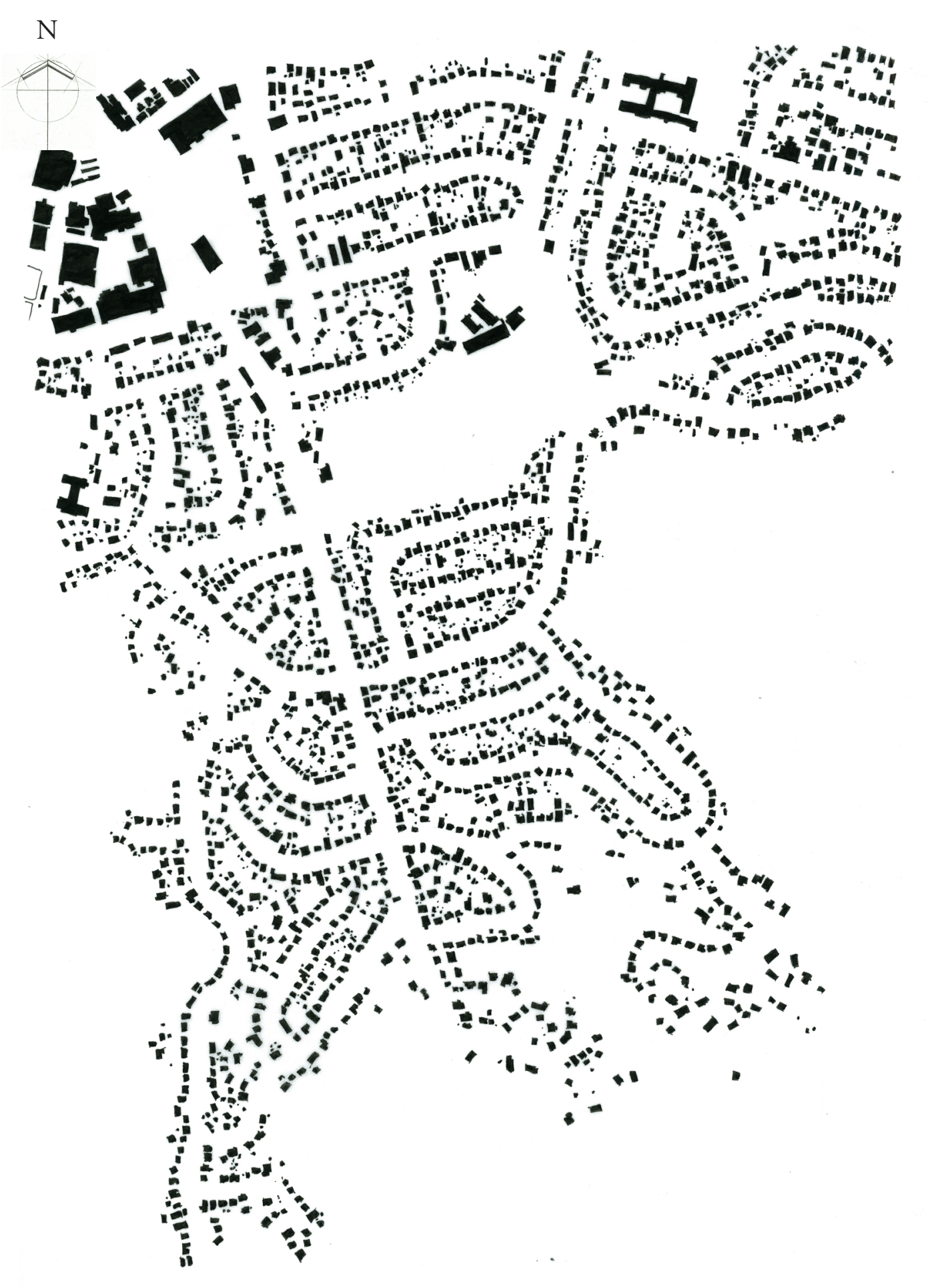

Fig. 3.19. Naenae: Figure/Ground 1:10000

\subsubsection{Naenae: State House}

Grid suburbs were popular among land speculators because of their low development costs at the time, but advocates of Romantic suburbs viewed them as 'slums in the making' and a poor model for future urban growth (Schrader 8). The principles Garden City movement, a product of the romantic tradition, largely informed the state housing programme. In combination with Modernist ideas, especially a dissociation

between the street and the home, the Post-War state housing became associated with curvilinear streets and non-uniform allotments.

The typical New Zealand state house is small and has a simple square plan. Many state houses are oriented to the north with living spaces designed and located to capture the sun as opposed to the earlier housing which usually faced the street. The most commonly known state house was developed in the 1930s by the first Labour government. State houses were built throughout New Zealand, generally in groups. Whole suburbs of state houses were developed with a variety of housing types used inpost-war development: free standing houses, semi-detached houses, row houses and apartments (Ryan et al 26). The materials used in the construction of state houses were of a very high standard as these houses were expected to have a long life. The state house was so successful that it was almost immediately emulated by private housing developers, and the form of the state house became the model for standard housing in New Zealand until the 1960s (Ryan et al 27). 


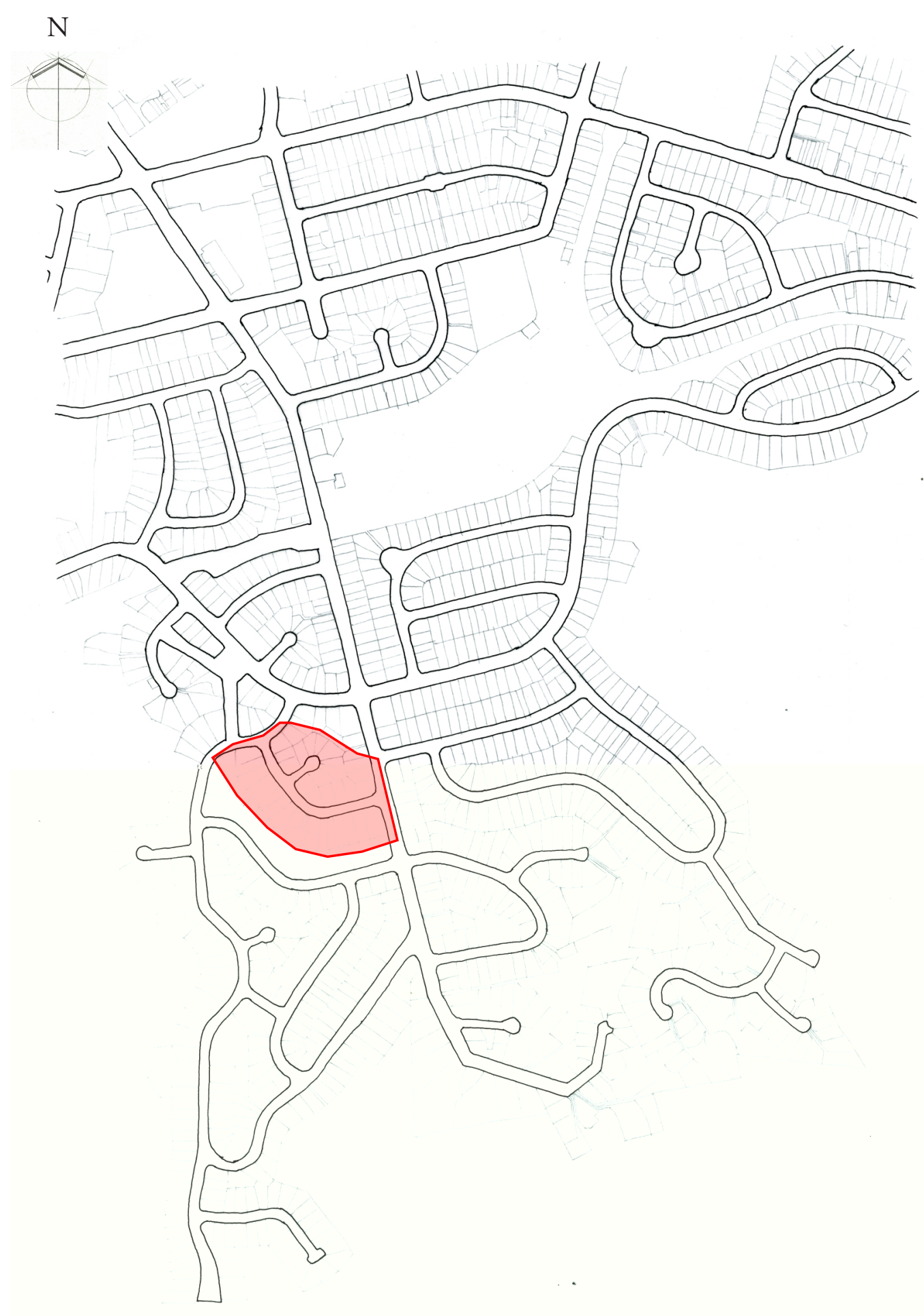

Fig. 3.20. Naenae: Street \& Block 1:10000

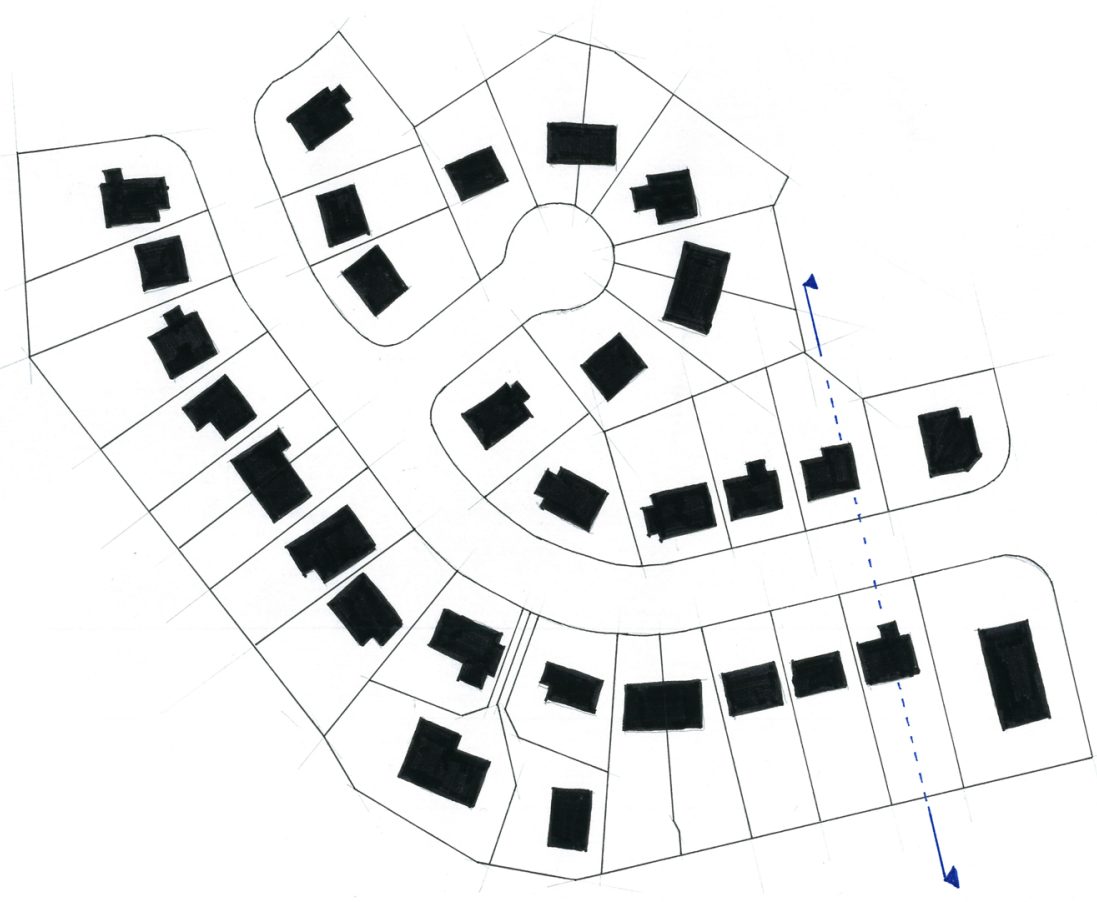

Fig. 3.21. Naenae: Feist Street Plan 1:2000

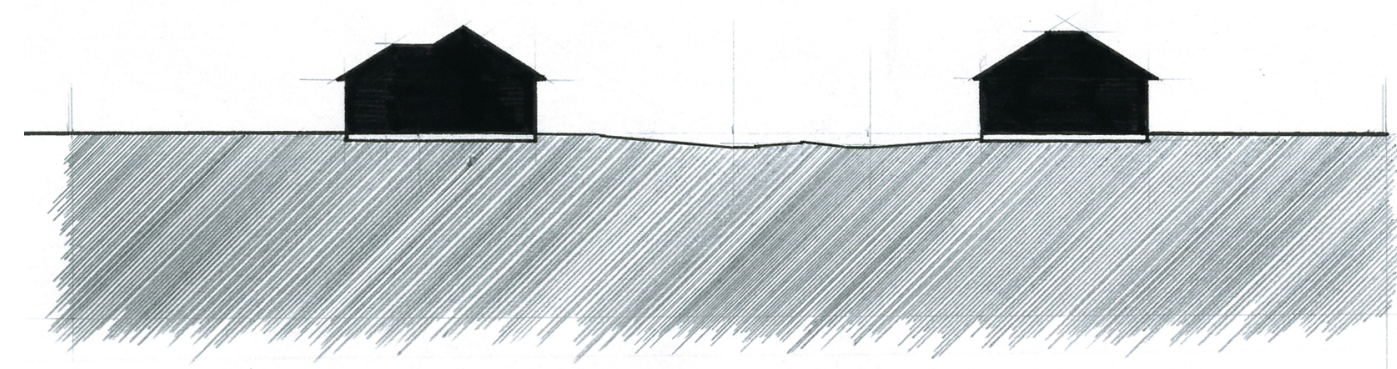

Fig. 3.22. Naenae: Feist Street Section 


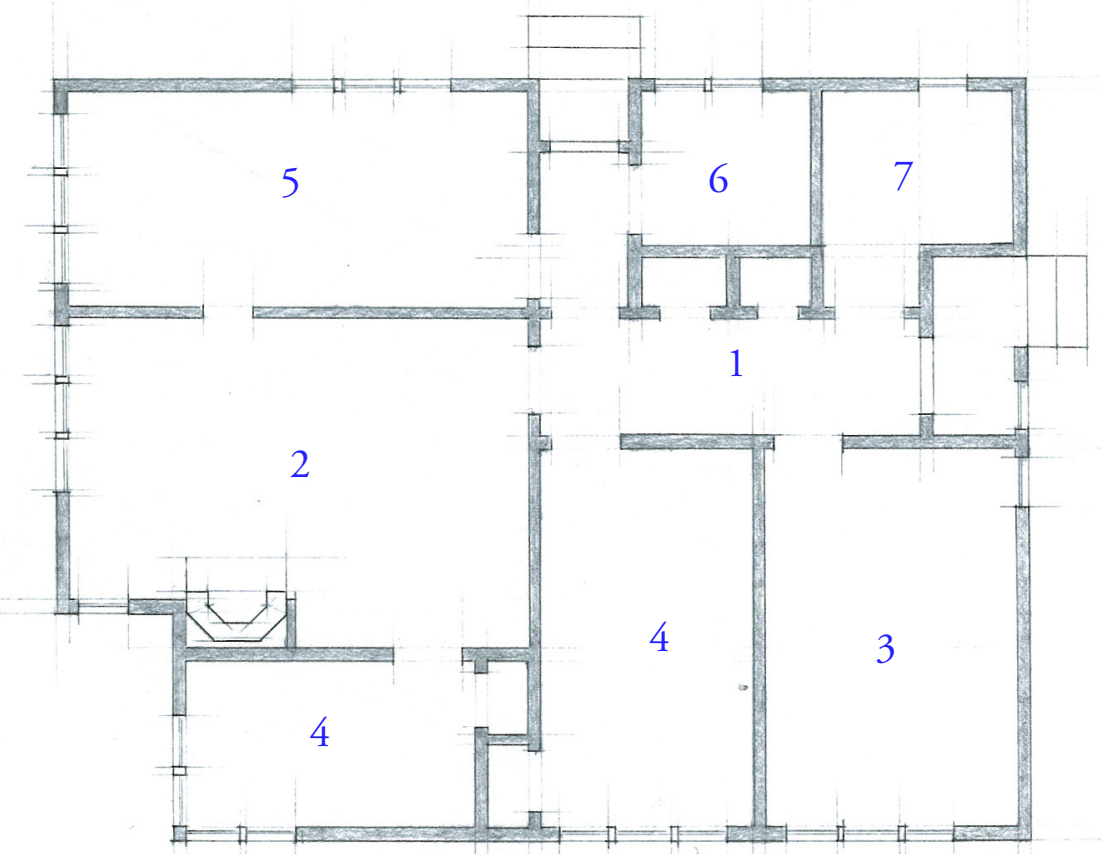

The typical state house plan is divided into two spatial areas: public and private. The public zone included the living room, kitchen and dining alcove. This area is relatively open and well connected in terms of its own functions. The private area, on the other hand, contains bedrooms, the bathroom and laundry and is compartmentalised to accommodate these functions. A hall separates but connects the two distinct areas in a utilitarian fashion acting as a buffer or a mediator to the outside. The largest room in all plans was the living room, oriented towards the north to catch the afternoon sun. The essential purpose of the living room was relaxation and it formed "the centre of family social life." (Schrader 67).

1 Entry Hallway

2 Living Room

3 Master Bedroom

4 Bedroom

5 Kitchen

6 Laundry

7 Bathroom 
The street elevation portrays what the house was meant to represent: an Arts and Crafts, or cottage, style which apparently advocated stability and domesticity which the Governmen ascertained fulfilled the population's pursuit of privatised family life. There is little about this elevation to suggest that the designers were considering the relationship of the domestic interior to the suburban street. Window and door joinery are standardised components which are employed primarily for solar gain. Local materials were used as much as possible which resulted in small panes of glass effectively limiting the size and dimensions of the windows.

The sectional drawing of the State house again suggests that there was little or no consideration of the relationship between the public and private realms. The floor plane is once again elevated above the ground plane limiting the potential of a direct physical connection between inside and outside and, subsequently, public and private.

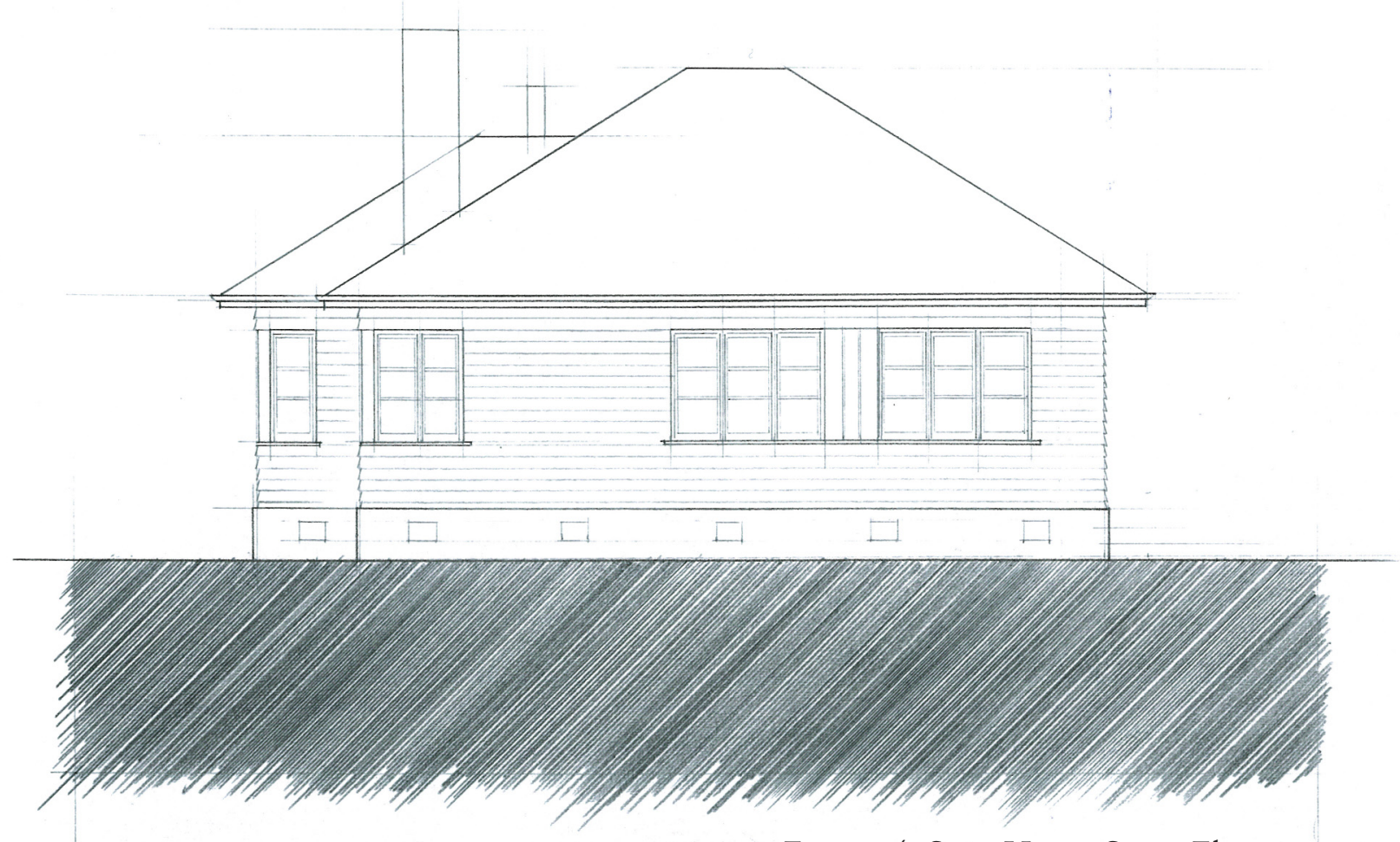

Fig. 3.24. State House Street Elevation

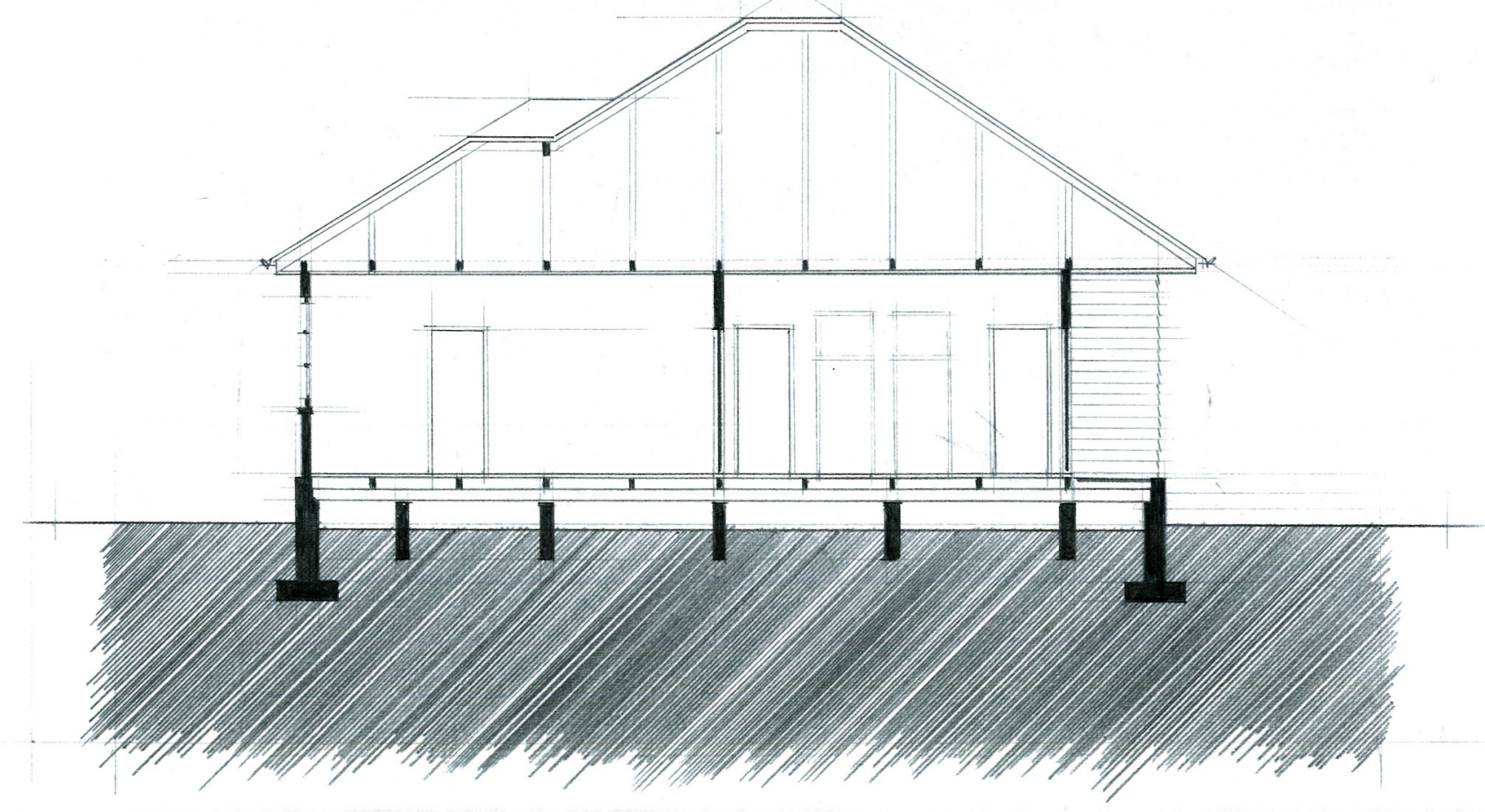

Fig. 3.25. State House Section 


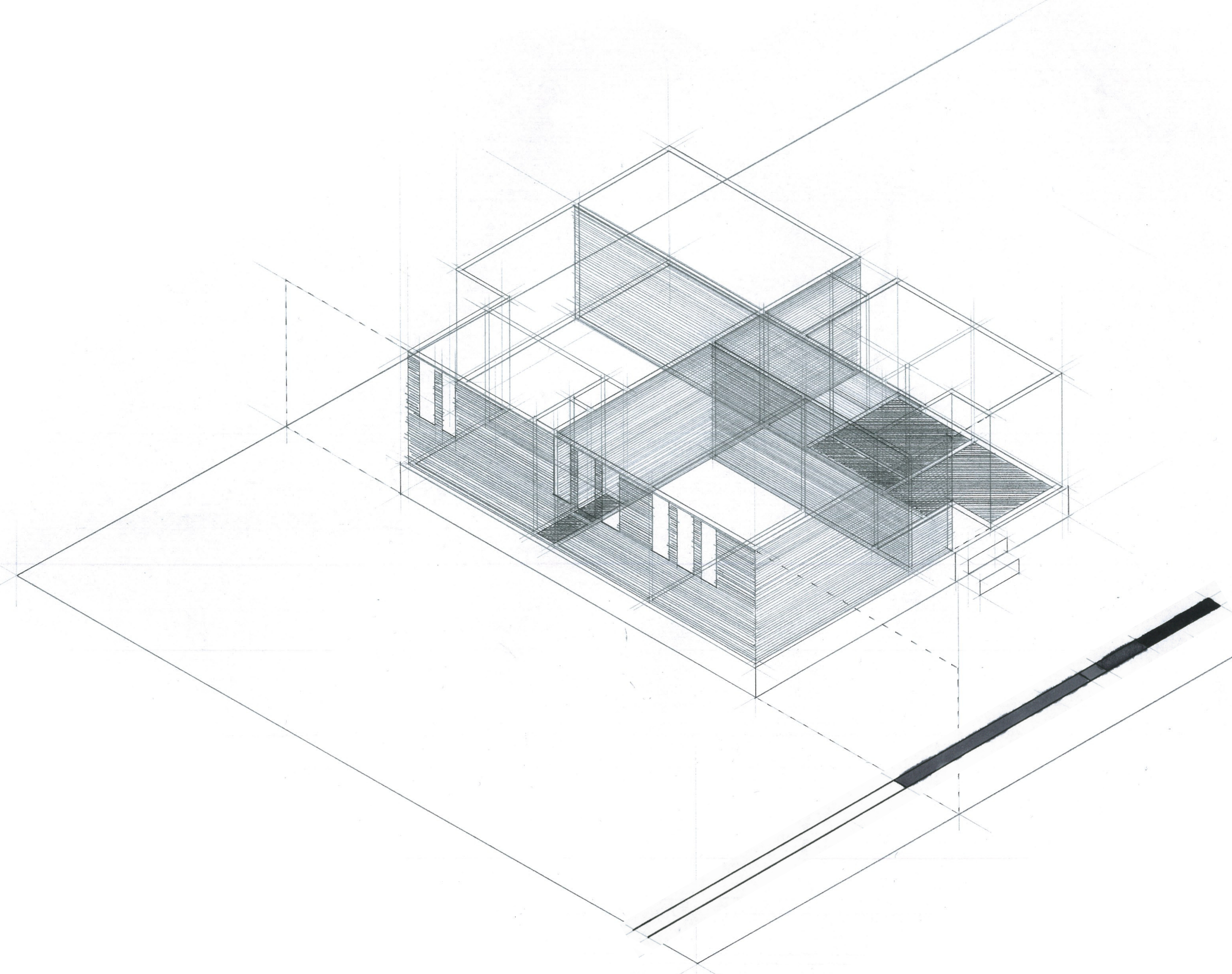

Fig. 3.27. State House Gradient Diagram 


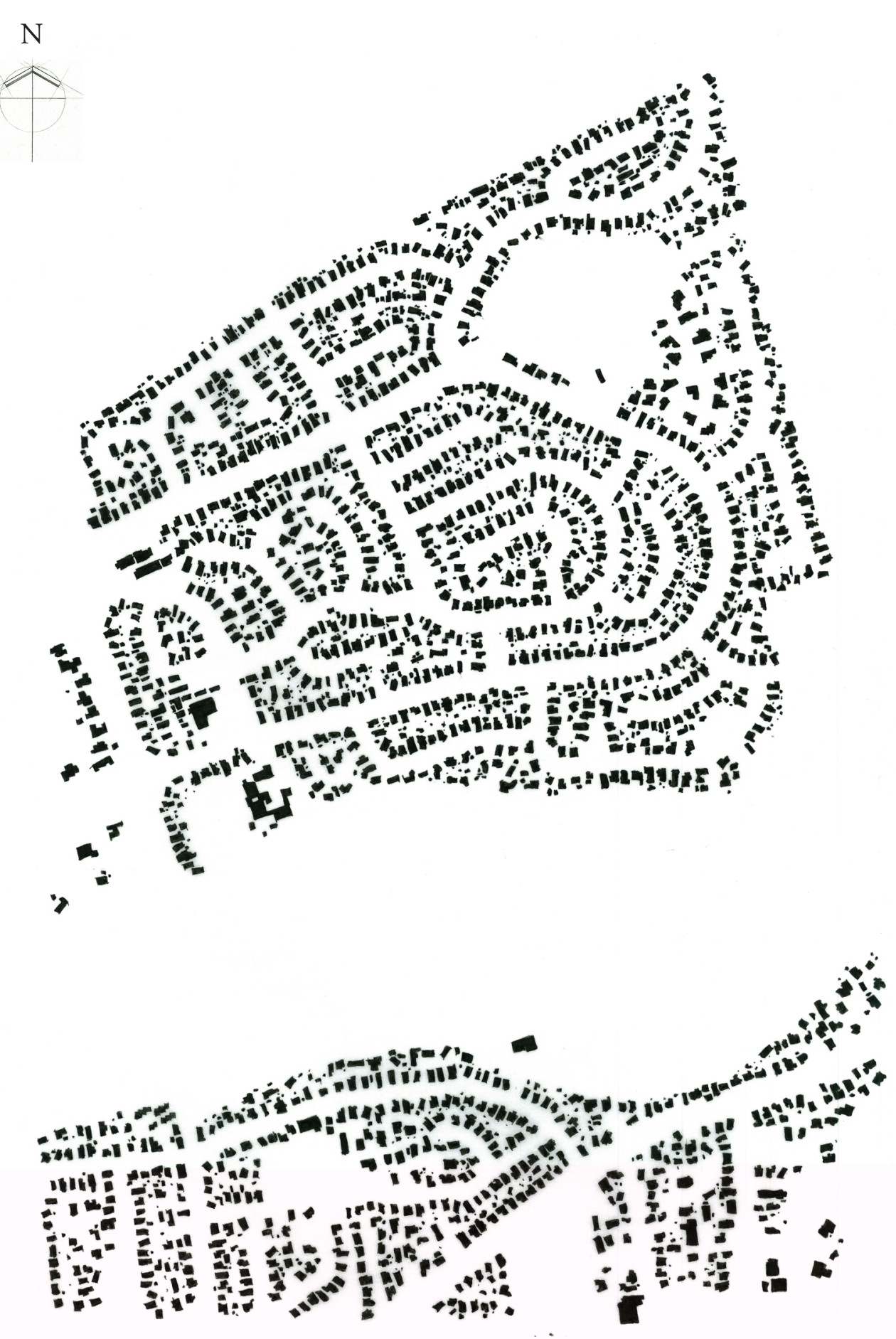

\subsubsection{Totara Park: 1970's \& 1980's}

From the 1970s onwards significant variation in both the design and materials used across the housing stock starts to appear. The stand alone low income developer housing of the late 1960s through to the 1980's is very plain. The houses of this era were constructed as part of the expanding suburban development of that period. The houses are generally simple rectangular boxes with low pitched gabled roofs. These houses utilised the cheapest available products of that time and were built to a limited range of designs all with living rooms at one end and bedrooms at the other. During this era the land at the edge of cities was inexpensive and hence the properties are more generous in size. These houses were often built by large property development companies and were built from standard plans (Ryan et al 34).

Observations about street, block and figure/ground configurations are attached in Appendix 1. 


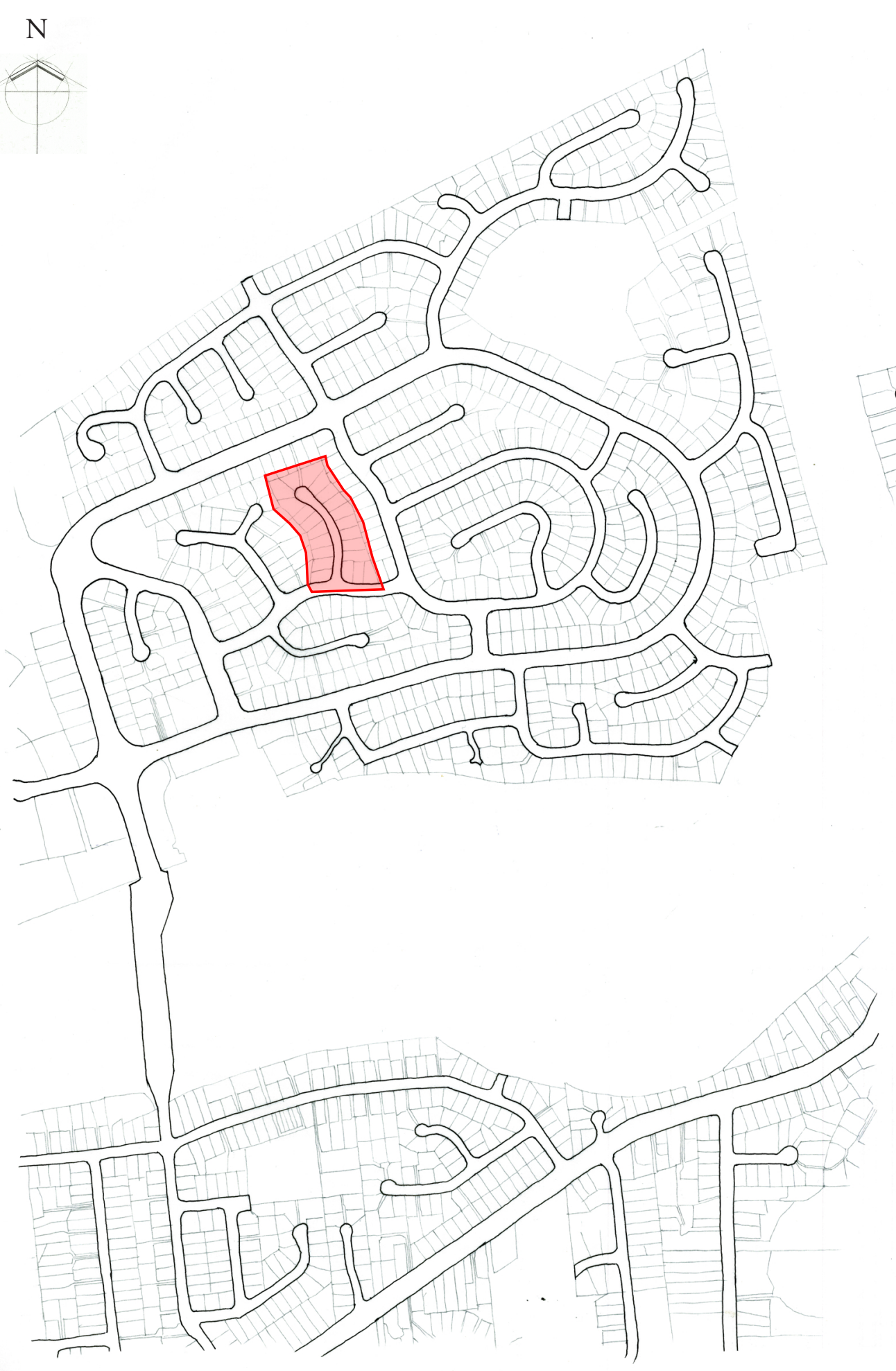

Fig. 3.29. Totara Park: Street \& Block 1:10000

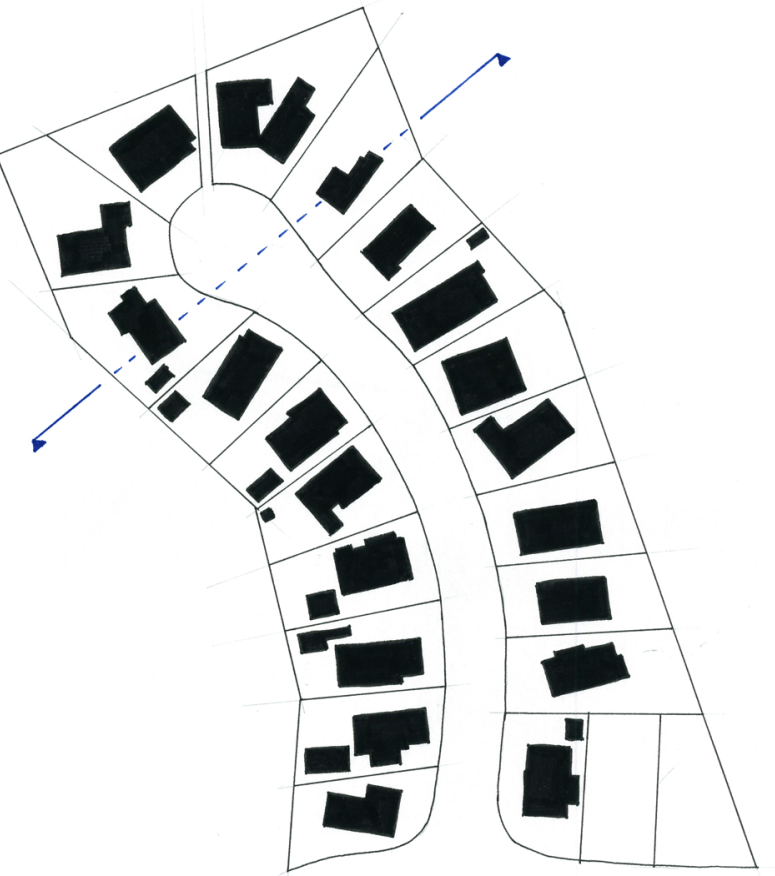

Fig. 3.30. Totara Park:Dakota Grove Plan 1:2000

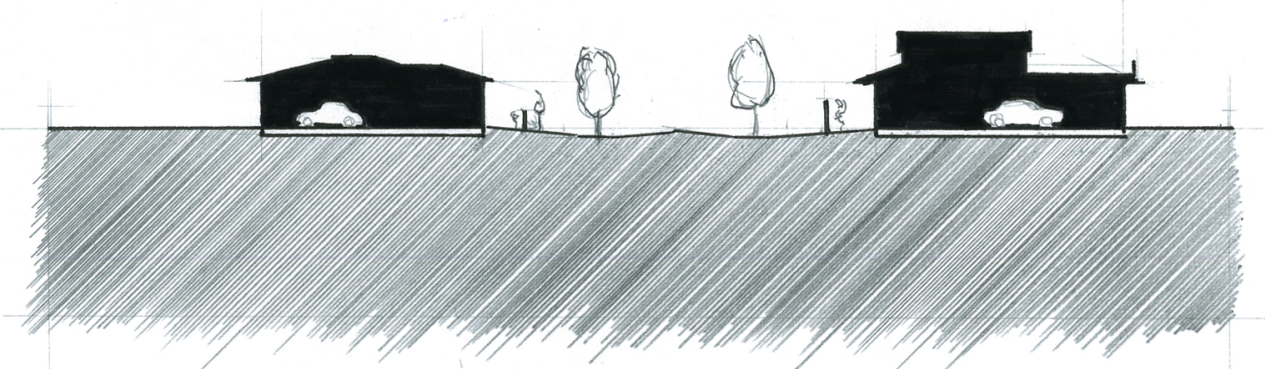

Fig. 3.31. Totara Park: Dakota Grove Section 


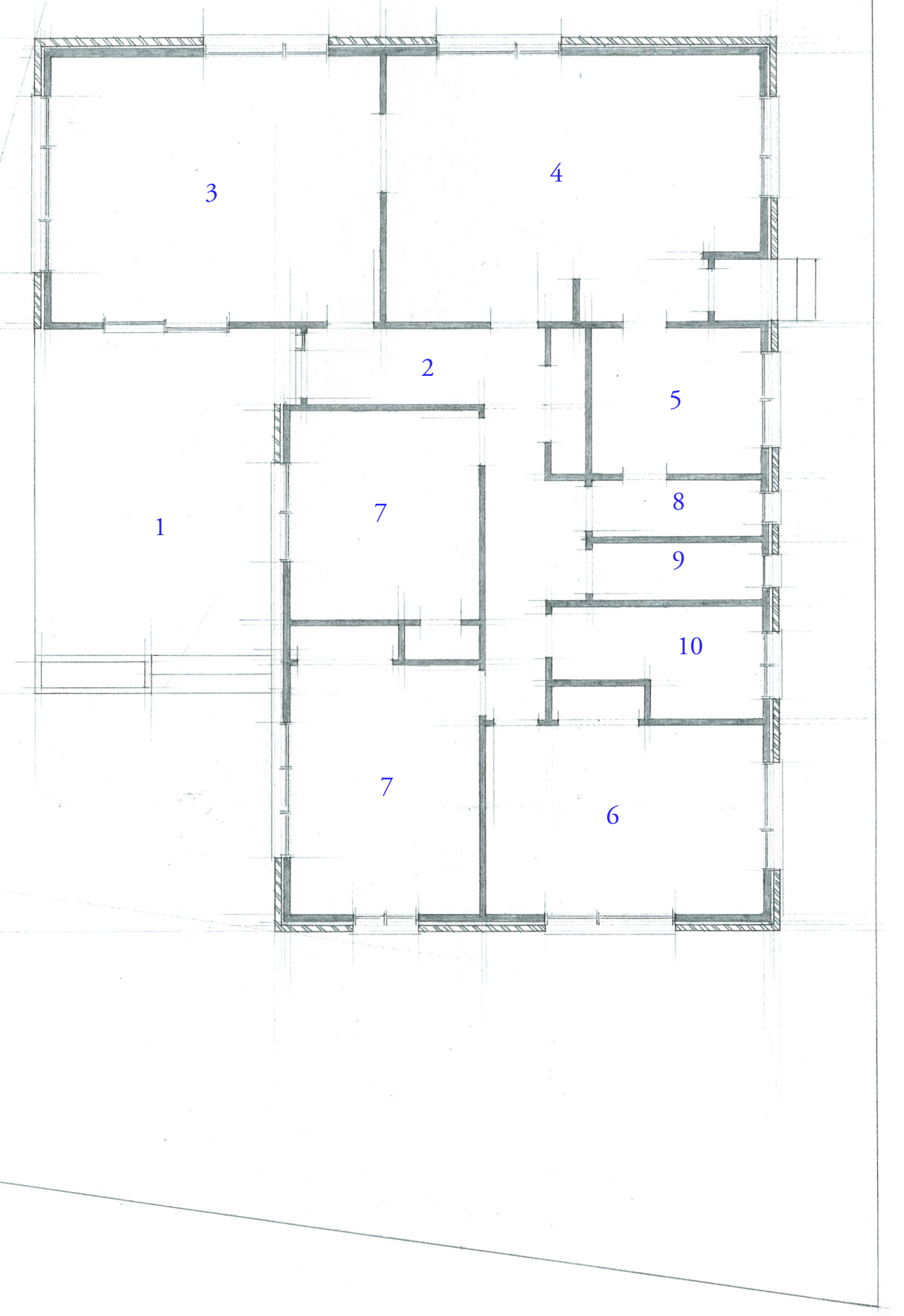

The plan of a typical Totara park house does not exhibit any particular affiliation with the street environment. The rooms closest to the street are bedrooms, while the social spaces of the house are oriented to the back yard. No direct indoor-outdoor connection is made at the back of the house, however, which is an anomaly often remedied through new openings and the addition of a back yard facing. The living room instead opens up onto an uncovered terrace adjacent to the front entrance which presumably establishes a hierarchical connection between the household, its car and the driveway. The circulation core of the house provides a buffer between the social areas of the house and the bedrooms, as in the previous Naenae example.

1 Outdoor Terrace

2 Hall

3 Living Room

4 Kitchen/Dining Room

5 Laundry

6 Master Bedroom

7 Bedroom

8 Toilet

9 Shower

10 Bathroom

Fig. 3.32. Typical House Plan 
In a similar approach to the state house, the street facing facade contributes little to the relationship

between the street and the domestic interior. Window and door joinery are again standardised components

which are employed primarily for solar gain. Their high position on the street facing wall suggests a desire

to restrict views into the interior of the adjoining rooms from the street.

While pile foundations weremost common, slab-on-grade foundations began to appear. The piles of this house elevate the floor plane up from the ground. The external terrace provides an interim space between

the ground and finished floor levels which is useful in mediating between the more public areas of the

driveway and the front-yard, and the more public areas indoors.

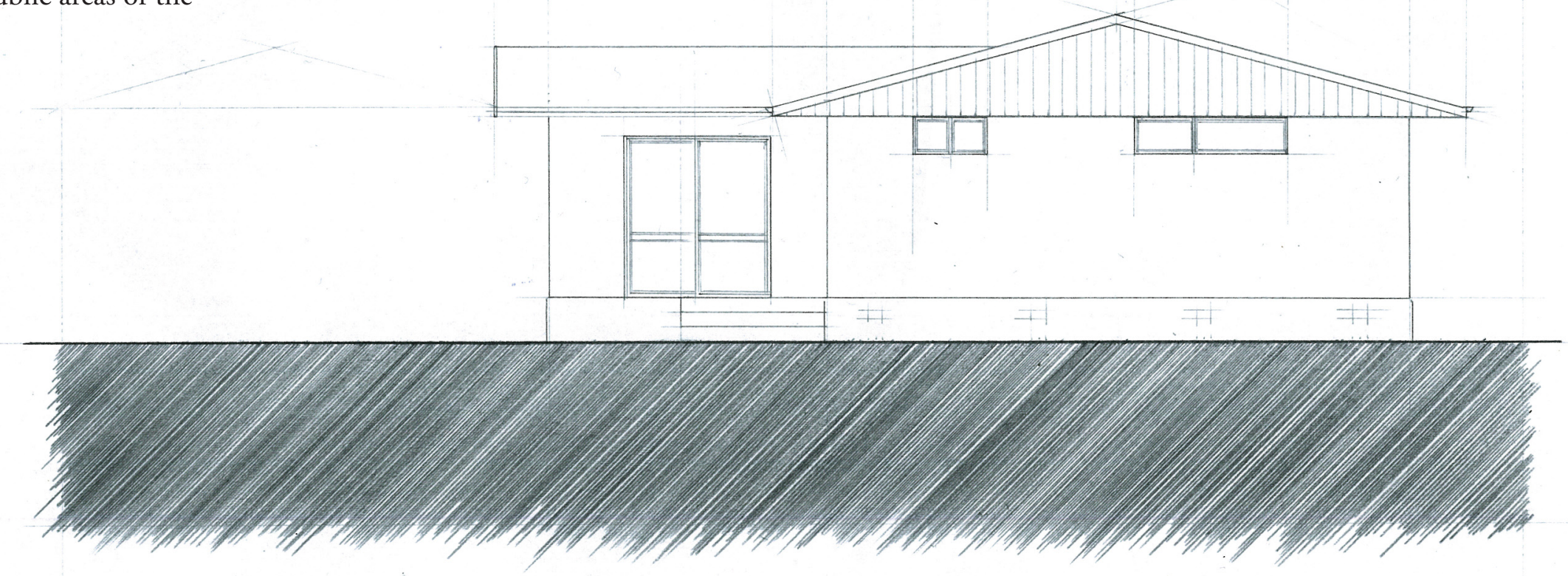

Fig. 3.33. Typical House Street Elevation

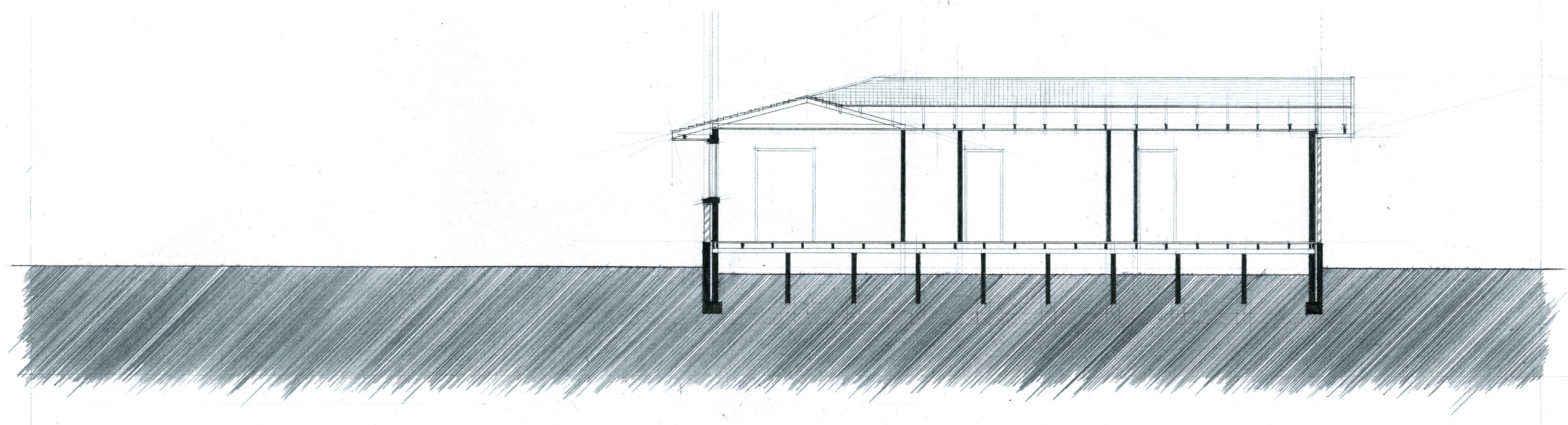

Fig. 3.34. Typical House Section 


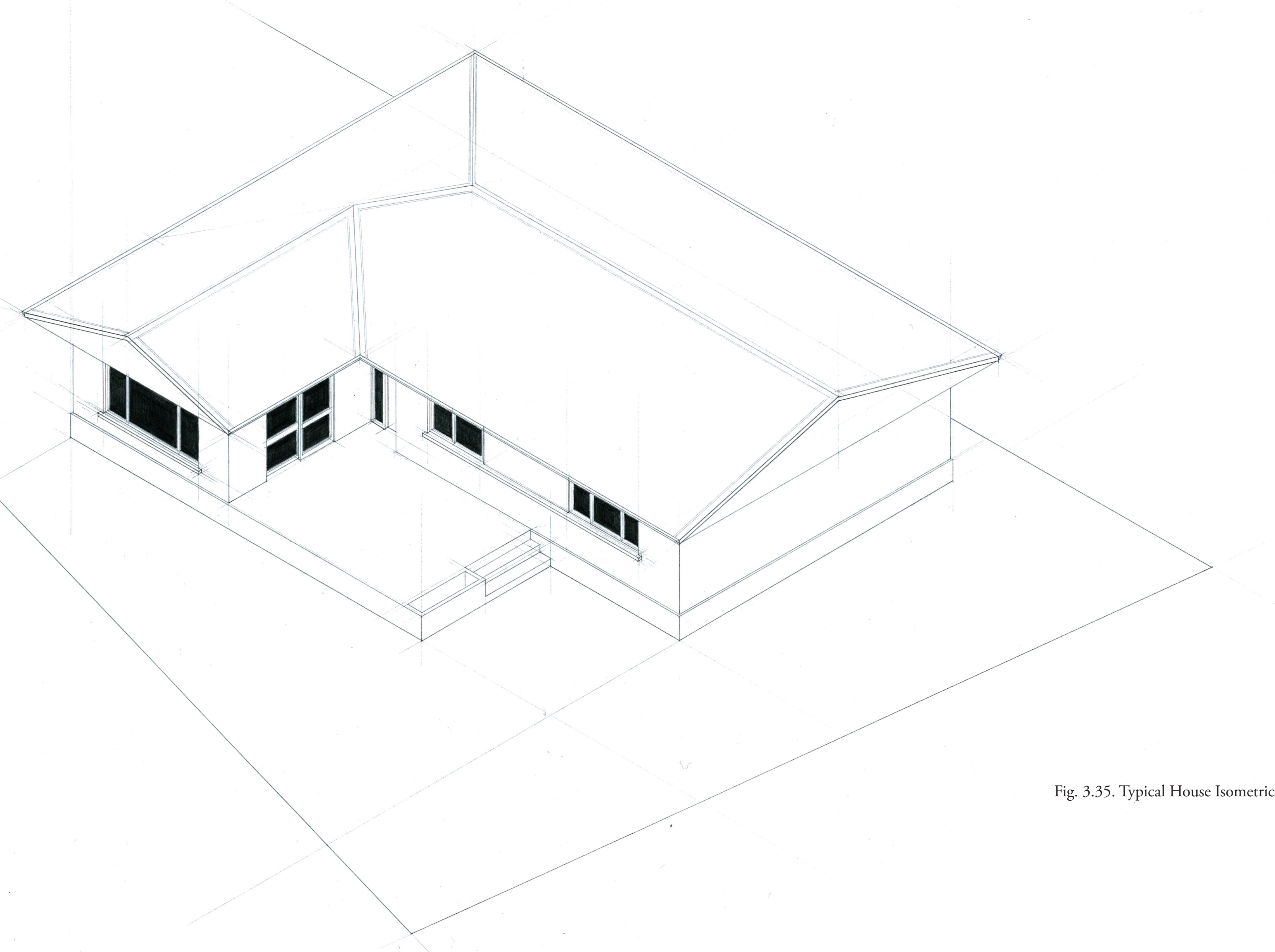




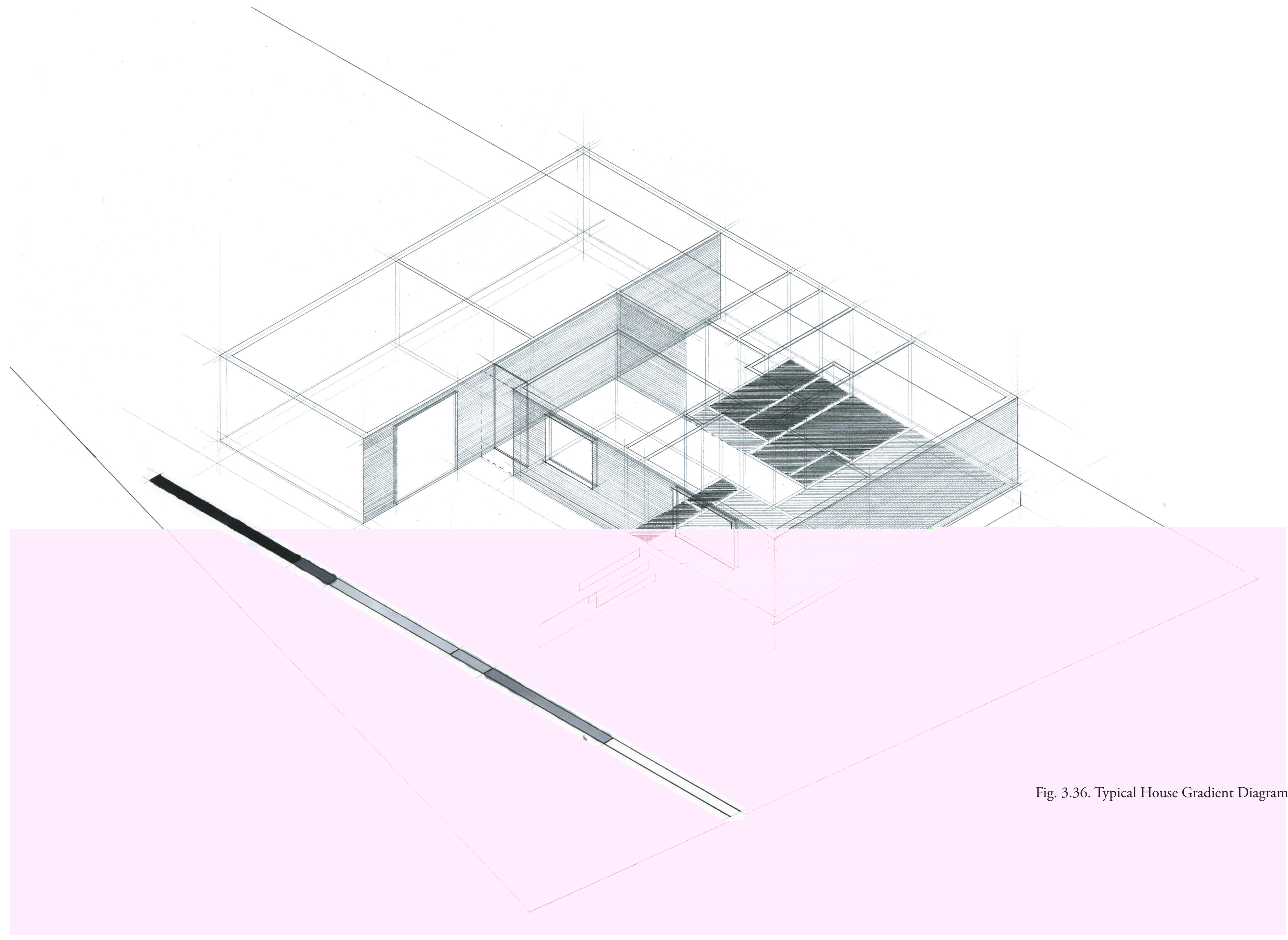




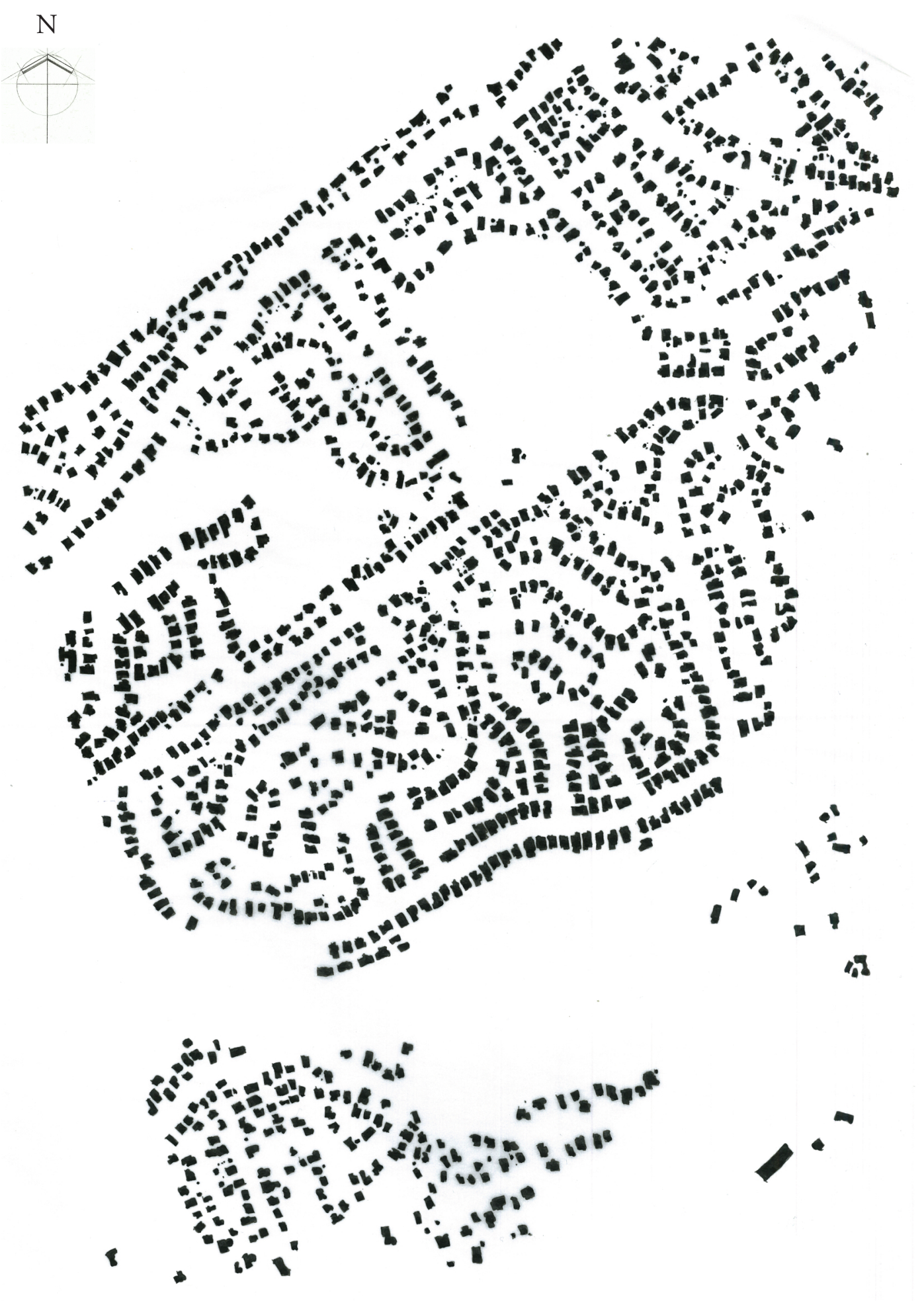

Fig. 3.37. Otaihanga: Figure/Ground 1:10000

\subsubsection{Otaihanga: Recent Development}

Houses built in the last decade were, in the majority of cases, built as part of large subdivisions and developments. Orientation of these houses is typically toward the street - in most cases, to provide vehicle access to large garages that are common throughout (Ryan et al 43). Great variation in appearance exists due to the large range of building products available and architectural styles used (Ryan et al 40).

Observations about street, block and figure/ground configurations are attached in Appendix 1. 

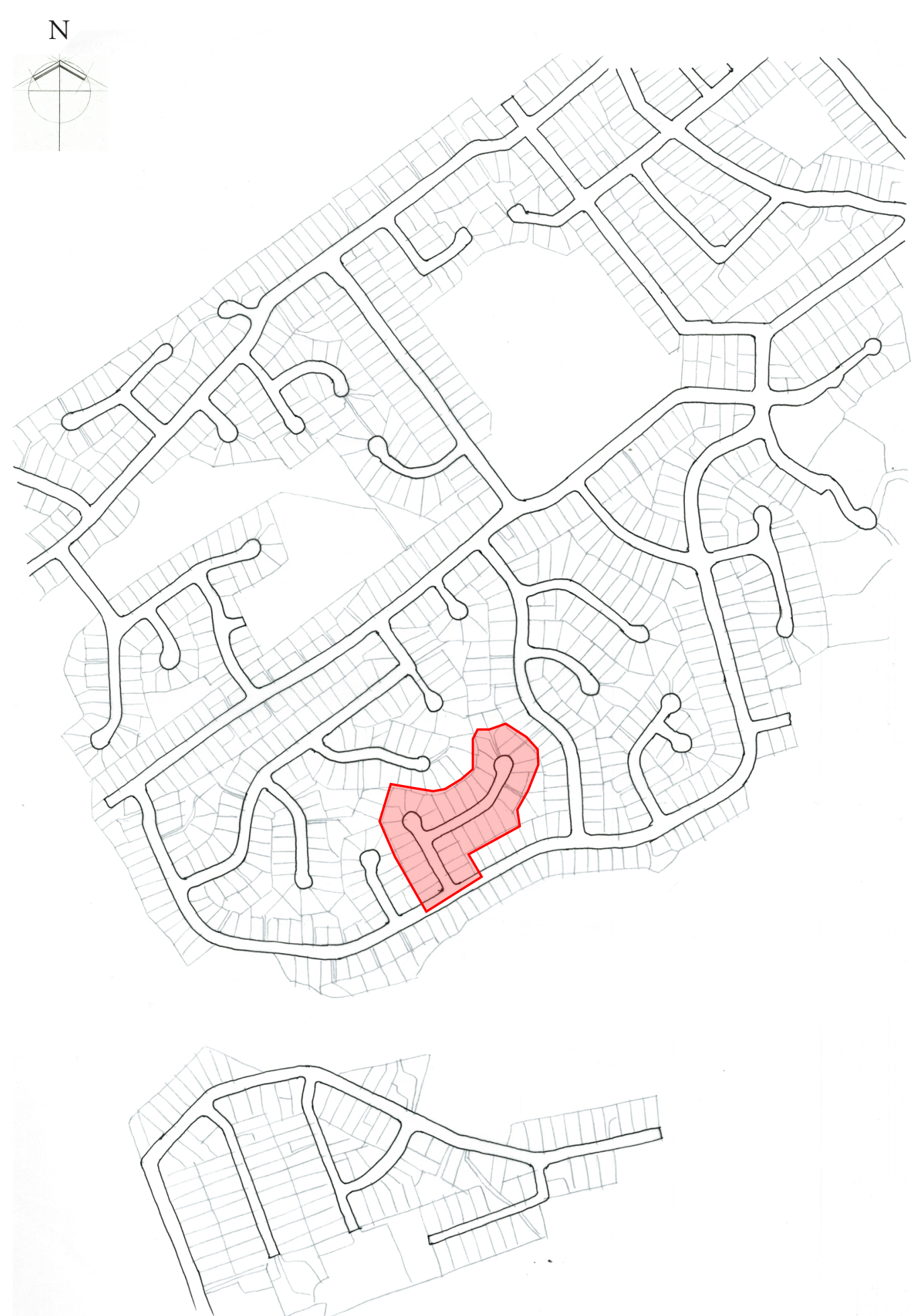

Fig. 3.38. Otaihanga: Street \& Block 1:10000
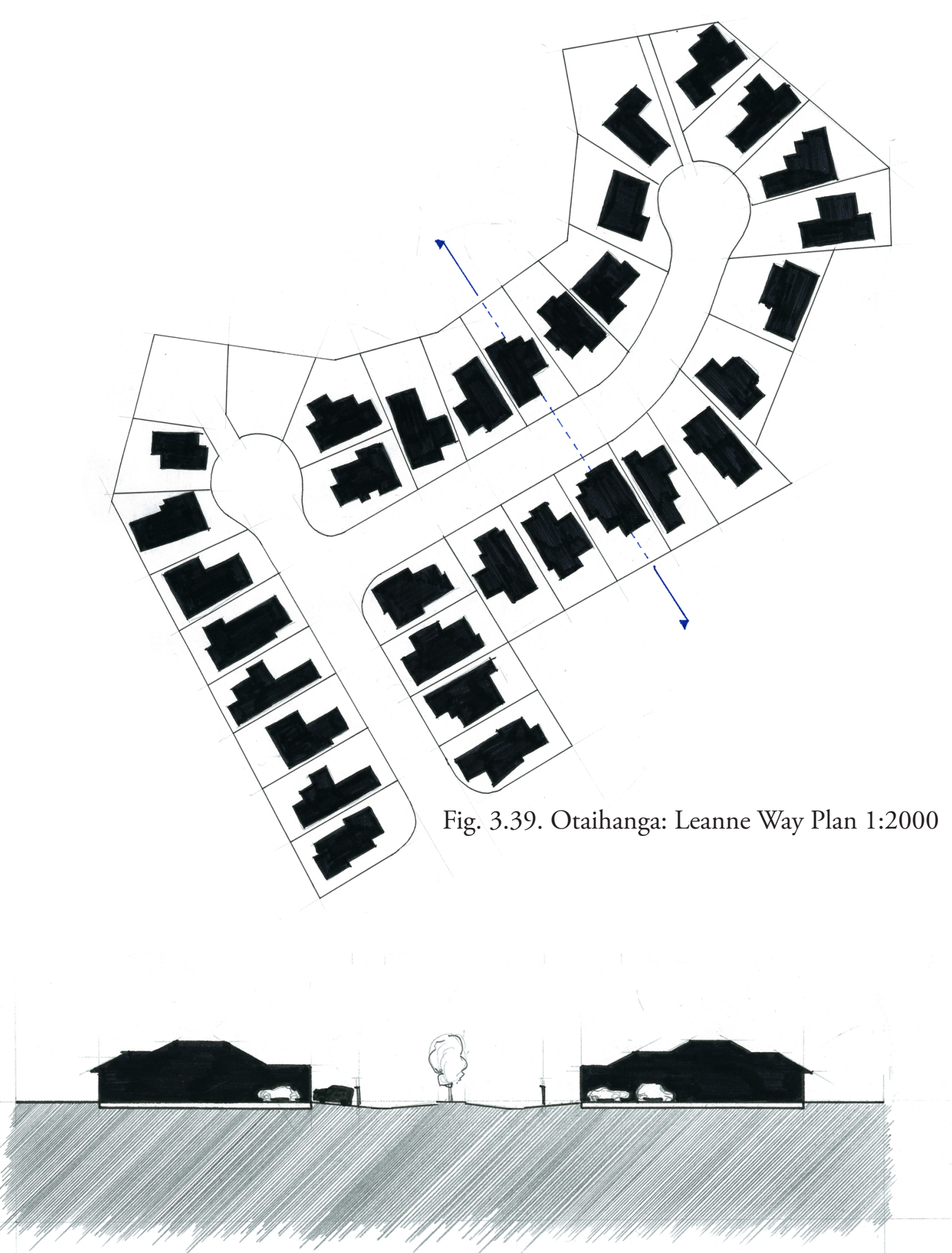

Fig. 3.40. Otaihanga: Leanne Way Section 


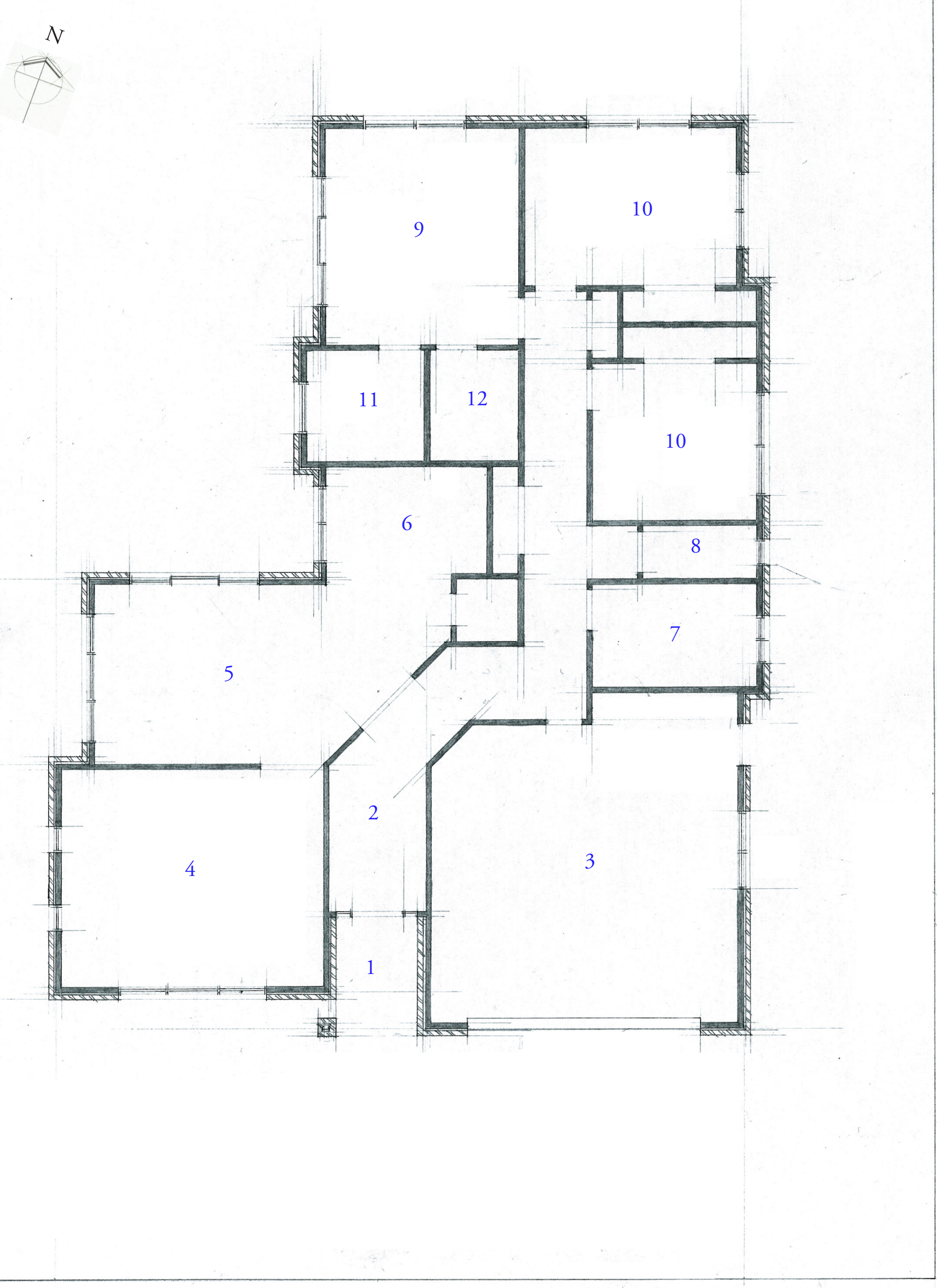

The plan of the selected house is an example of a speculatively built developer-driven property. An attached double garage which opens toward the street is the largest space within the house. The garage sits adjacent the front entrance and the hallway which separates the service functions of the house from social hub. The kitchen is contiguous with the dining area which connects directly to the living room. This area occupies its own wing on the opposite side of the house to the garage. The social wing' offers a simple and sheltered connection to a deck which extends along the side of the private end of the house towards the back yard. All of the bedrooms are pushed toward the back of the house beyond the service areas but because of the deck, this arrangement does not disrupt the valuable connection between the social areas of the house and the private open space.

\author{
1 Sheltered Entrance \\ 2 Hall \\ 3 Garage \\ 4 Living Room \\ 5 Dining Room \\ 6 Kitchen \\ 7 Bathroom \\ 8 Toilet \\ 9 Master Bedroom \\ 10 Bedroom \\ 11 Master En-suite \\ 12 Wardrobe
}


The street elevation shows that the garage door is the primary organisational device. The hipped roof extends over the garage door, thus emphasising the garage as part of the house. The roof also covers the front entrance to form a small 'veranda' space. A standard window establishes a positive connection between the adjoining living room and the space outside. However, the opening remains a static feature that does little to facilitate interaction or transition between the public exterior and the private interior.

The section drawing demonstrates that beyond the recessed primary entrance, the architecture of this house does little to contribute to the establishment of a public-private gradient.

The significant change in this model of development is the common use of concrete slab

foundations. The concrete slab allows the floor to extend beyond the interior and have a close connection with the ground plane. This development could eliminate at least part of the hierarchical change between the interior of the house and the outside and could be, in some cases be conducive to the establishment of a positive gradient between public and private.

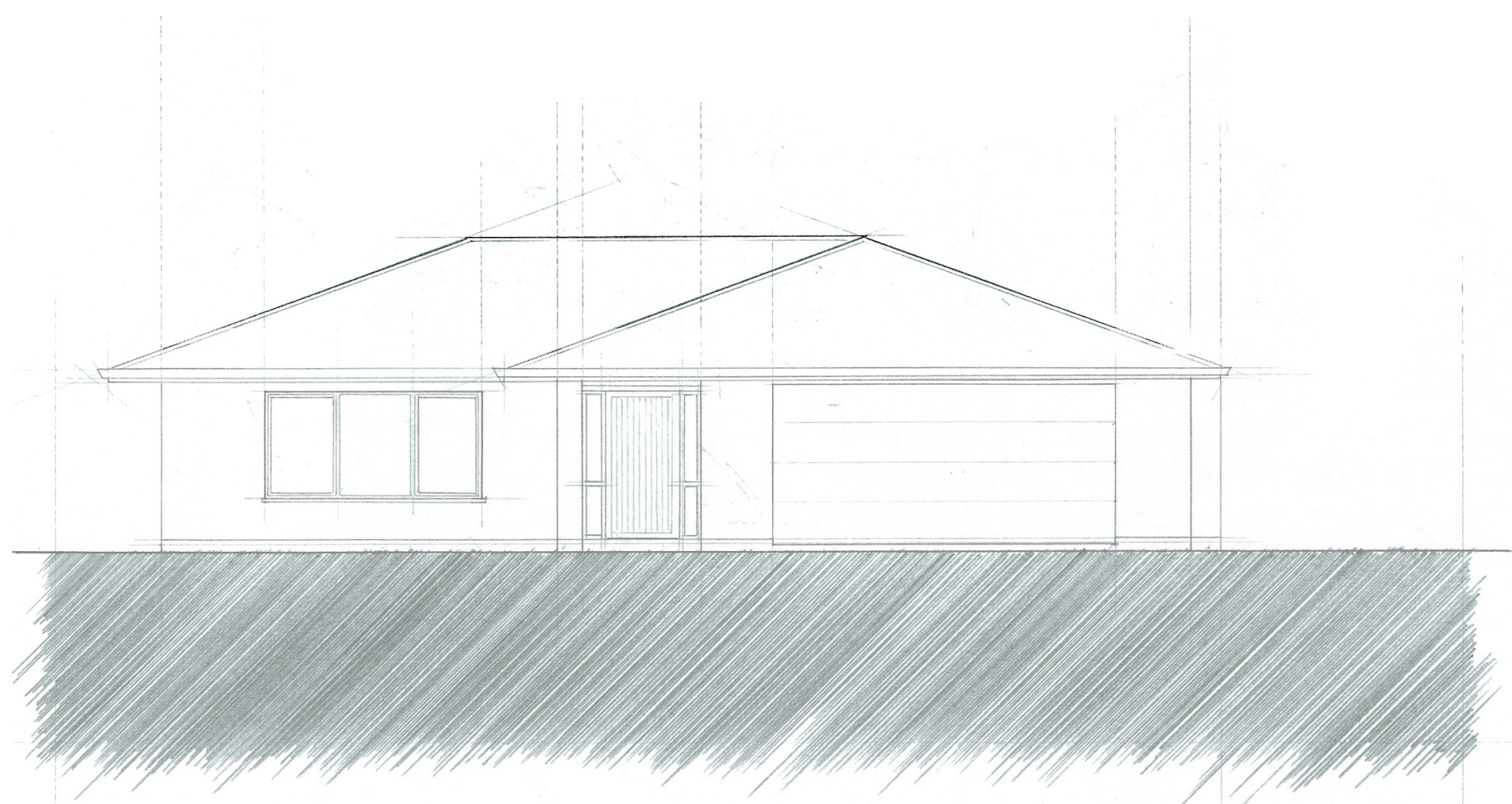

Fig. 3.42. Typical House Street Elevation

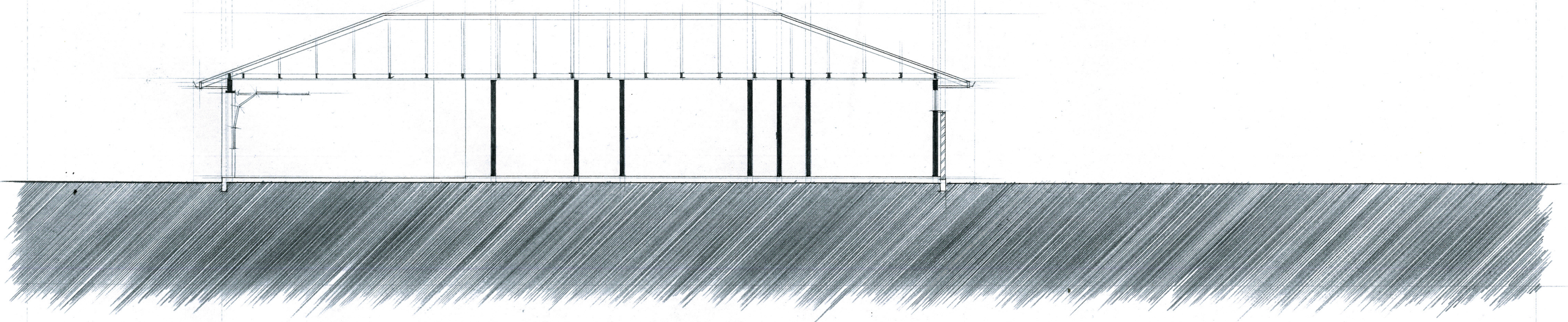

Fig. 3.43. Typical House Section 


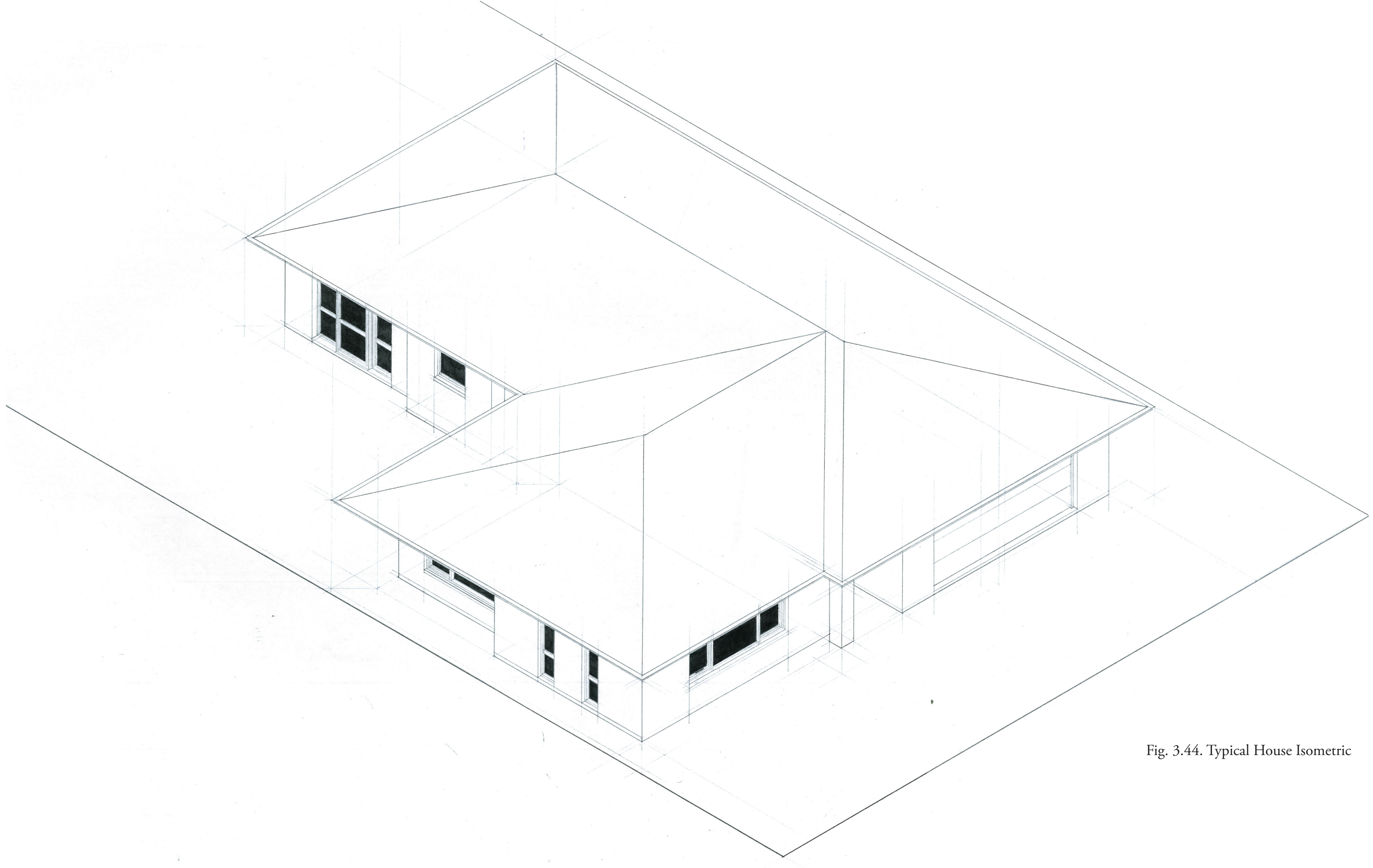




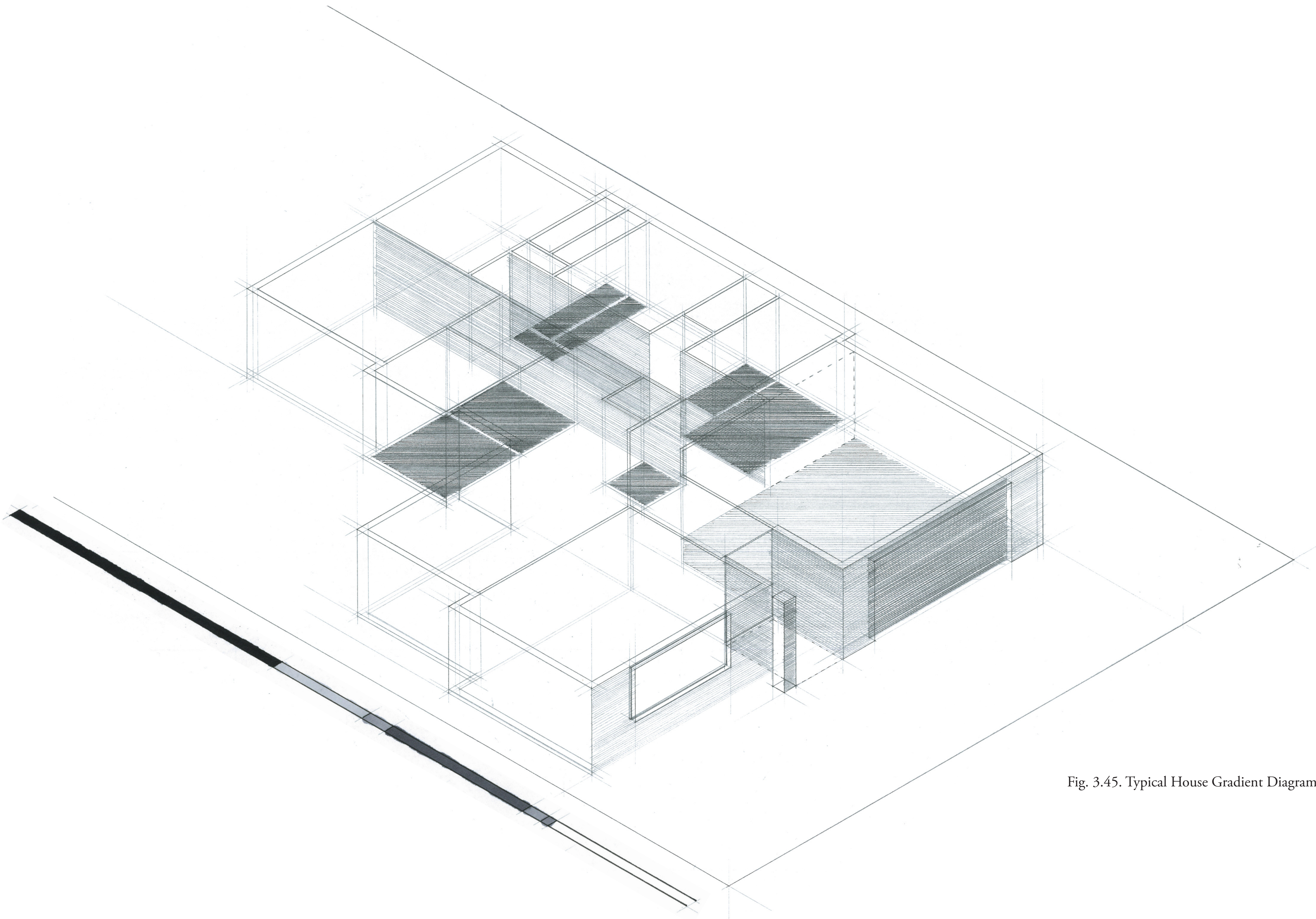




\subsection{Conclusion}

The purpose of this chapter was to document a chronological series of Wellington suburbs to determine how suburban development manages the public-private gradient between the street and the domestic interior. The graphic analysis presented in this chapter shows that the early models for residential development successfully established and managed this relationship. These early models were successful because the urban structure and the architecture it contained were in harmonious dialogue. In other words, the factors that defined the popular house forms of the time and also the street layouts were interconnected. The key conclusions drawn from this series of studies are:

- The increasing detachment of the design of the house from the planning of streets and lots led to a diminished relationship between public and private,

- The increasing separation of the 'Social' and 'Private' areas within the house,

- Social areas of the house are increasingly oriented and associated with the private rear yard,

- The advent and eventual dominance of the garage as the primary spatial element at the front of the house,

- Increasing site coverage due to larger houses occupying smaller lots which reduces the degree of graduation between the public and private realms,

- And, the simplification of standard architectural components over time which led to the production of stagnant relationships between public and private. 


\section{Chapter Four: Precedent Studies}

4.1. Introduction

4.2. Urban Precedent Studies

4.3. Architectural Precedent Studies

4.4. Conclusion 


\subsection{Introduction}

To address the central idea of this research it is critical to establish a range of design strategies that successfully mediate the interface between public and private. Therefore, the purpose of this chapter is to analyse existing architectural and urban examples to uncover a comprehensive range of design strategies that establish thresholds. To complete this chapter a consistent documentation process for each study enables the acquisition of a practical and relevant understanding of the functions, characteristics and architectural components of a suburban house.

The first set of examples, the 'Urban Precedents,' provides data pertaining to the level of design required to set up an appropriate context in which the following design strategies can be tested. They deal with the larger scale of streets, blocks and neighbourhoods, and place-making in the public realm. The second set of precedents are the 'Architectural Precedents' which provide the design strategies that combine to form a successful public-private gradient. Text, analytical drawings and diagrams are used to describe, evaluate and summarise the important aspects of the subjects.

\subsection{Urban Precedent Studies}

The following precedents demonstrate alternative suburban development models to what is currently preferred. Innovation which addresses the public realm and the urban structure is the objective for these studies. The suburban models explored in this section will demonstrate unconventional approaches to:

- Suburban street, block and allotment layout;

- house type and orientation on allotments;

- and street use hierarchies.

Text is the primary mode of investigation in this section. Accompanying images are intended to provide a general overview for each development. 


\subsubsection{Nar Ouse Regeneration Area(NORA), South Lynn, England}

NORA is endorsed by English Government as an exemplar of sustainable development. The first phase of the project, completed in 2007 has provided 109 new dwellings while the entire development is expected to reap 600-700 dwellings across 48.5 hectares (Institute of Highway Engineers 1). This first phase is the subject for this analysis.

The internal streets in the NORA development are 'Homezones' which are designed to reorganize the usage hierarchy prioritising pedestrians and residents over the car. The intention of this scheme was to have residents adopt the streets as an inhabitable public domain.

The homezone surfaces appear to be relatively ambiguous and potentially confusing for motorists and pedestrians alike. More physical landscape features would help increase the legibility of the homezone street environment and reinforce its usage hierarchy intentions, although the ambiguity is useful as a device for ensuring that motorists drive more carefully.

Three sided perimeter blocks with communal internal block gardens are formed by attached terraced housing with few narrow access points distributed around the block. Each residential unit includes a portion of the interior court for a private garden which in turn backs onto the communal garden. The communal garden incorporates parking for residents while providing an informal and semi-private setting for play and recreation activities.

The key lessons from this precedent are:

- The use of homezones or shared streets to create a more dynamic public realm;

- A three sided variation of a Perimeter Block terraced house arrangements clearly articulating the transition from public to private;

- And, off-street car parking and additional communal gardens at the interior of the blocks to successfully remove the garage from the street facades of the houses.

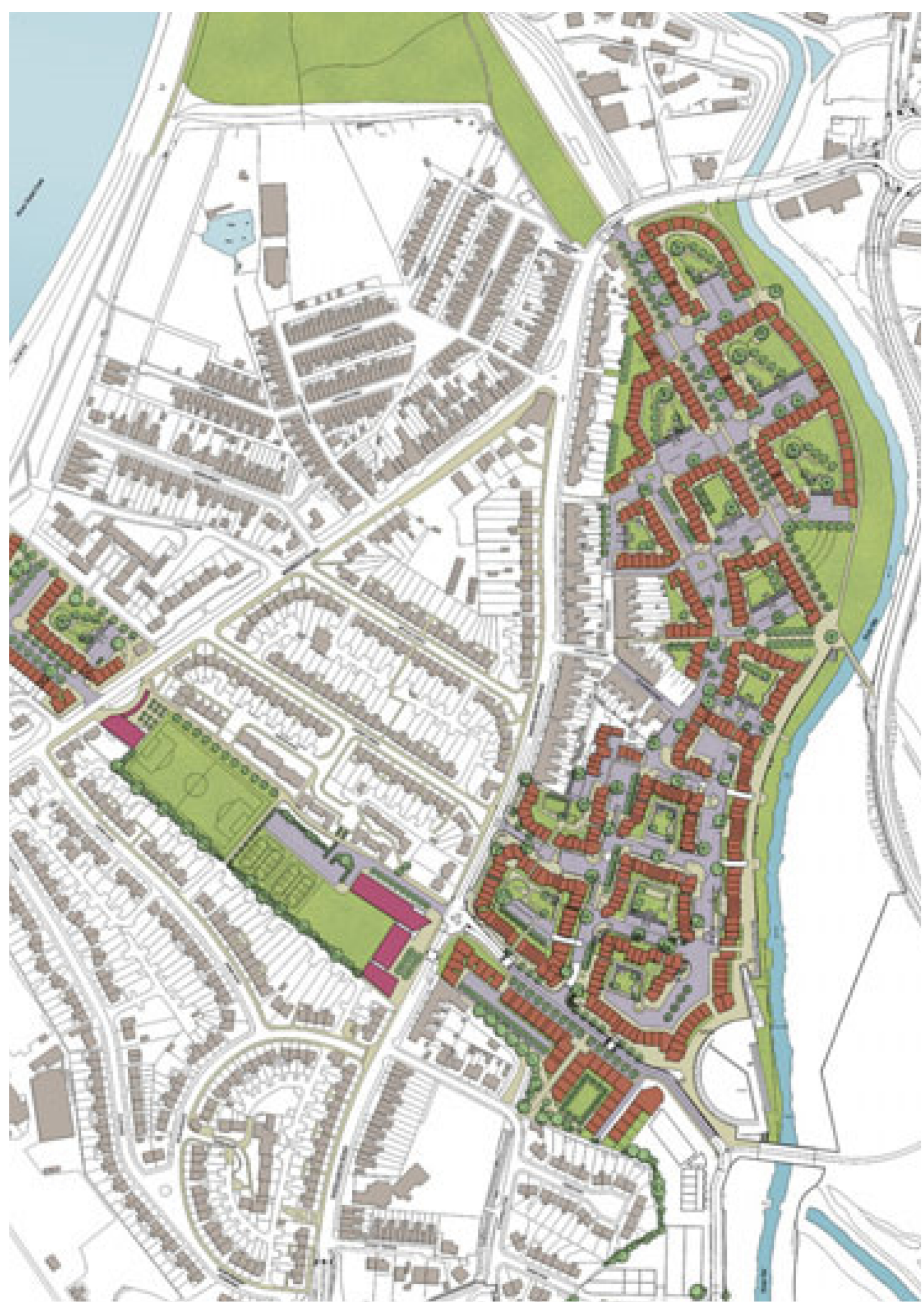

Fig. 4.1. Master-plan image of the Nar Ouse Regeneration Area
produced by LSI Architects (p.10) 
4.2. Tullimbar, New South Wales, Australia

The Tullimbar development proposal is designed as an alternative to the conventional low density sprawl. The goal for Tullimbar was to create a dense, compact, walkable community that will help residents reduce their vehicle use and increase social interaction.

The master-plan of Tullimbar reflects traditional town planning ideas including a 'Main Street' precinct. The master-plan implements a grid pattern to create a legible street layout with direct walking routes. The street layout features more fluent aspects though, which have modified the grid to suit the natural features of the site. This allows the primary streets to turn providing shorter vistas increasing the opportunities for landmark characteristics to be installed at the points of termination. This can increase the legibility of the plan and enhance way-finding. A clear street hierarchy is achieved through street planting strategies and changes in widths.

The street-use hierarchy appears to be conventional. Priority is designated to the car and the carriage way over the pedestrian. Street planting, used to slow and calm down traffic to mitigate the standard hierarchy, and broad footpaths help provide quality environments for pedestrians.

The master-plan provides a number of public open spaces to encourage people to use the centre for both formal and informal gatherings. The open spaces are well connected to form a legible network of open space. This strategy explains why the streets target transit rather than occupation for lengths of time.

Tullimbar includes a diverse mix of housing types ranging from apartments in town centre, to detached houses at the periphery. Design codes for the housing ensures that they implement wide usable front verandas and active frontages which ideally provide opportunities for of social engagement between pedestrians and residents

The key lessons from this precedent are:

- Main street planning axis which acts as a mixed-use precinct facilitating a range of housing density concentrations across the development;

- Elegant amalgamation of a gridded master-plan and natural features to encourage more legibility characteristics;

- And, building design codes which encourage the use of architectural elements to create dynamic relationships between the houses and the streets.

Fig. 4.2. Master-plan image of the Tullimbar development project (Tullimbar Village Centre Building Design Guidelines 10)

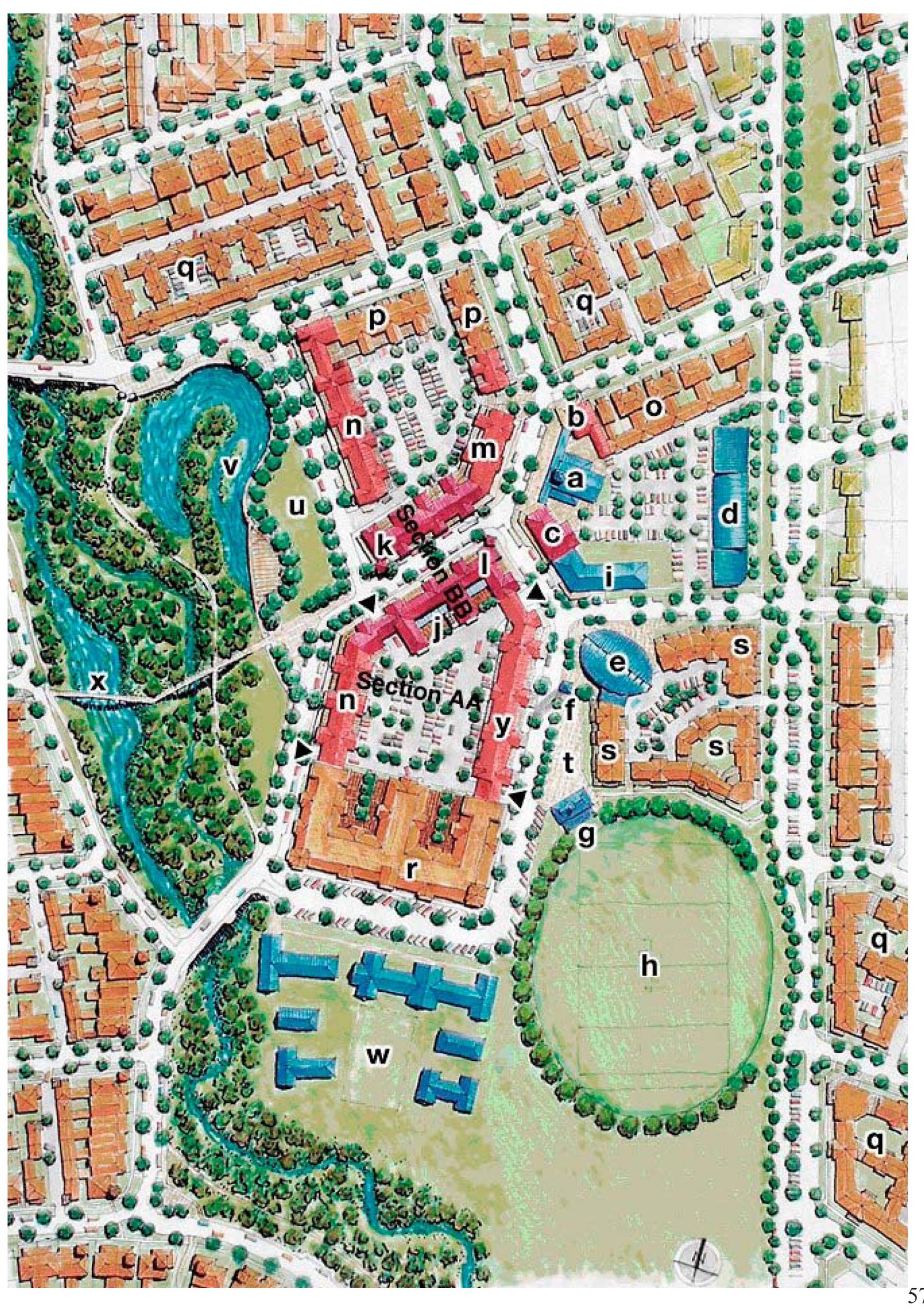




\subsubsection{Addison Housing Project, Takanini, Auckland}

The Addison Housing Project has been chosen by Ministry for Environment as a case study demonstrating best practice urban design principles with a wide range of house types, all aimed at creating an increased sense of place and community (Ministry for the Environment 2). To achieve this, a target was set to achieve an average density of 20 households per hectare over the entire site, in comparison to 10-12 households per hectare of the surrounding development.

The master-plan for the Addison Housing Project indicates a connected network of local streets and larger distributor roads. These streets are arrayed in a grid form. A central, north-south street is the primary organisational device. Three local roads at the top, middle and bottom of the plan connect perpendicular to this spine to create four distinct neighbourhood precincts.

The blocks are small ensuring that the houses appear gathered together rather than lined up along a length of street. There are a variety of block types, but most include a rear lane for car access removing the garage door from the street, allowing the allotments to become narrower. Consequently, the roads around the outside of the blocks maintain a pedestrian and community focus rather than vehicle passage.

All of the dwellings in this development are projected to be two-storeys high and set on the compact sites indicated in the master-plan. The range of housing types include:

- terraces that front onto pocket parks, with access lanes at the rear;

- large terraced homes that front onto the street;

- large detached family homes, with double garages and gardens;

- and detached compact dwellings on small sections (Ministry for the Environment 8).

In all instances, the compact terrace dwellings front onto open space to create amenity within this higher density environment. This strategy requires the homes in question to have vehicle access through rear lanes. The key lessons from this precedent are:

- Street network dividing the plan into distinctive neighbourhood precincts;

- Small block sizes

- Range of house types encouraging a diverse distribution of density concentrations;

- And, internal block 'Rear Lanes' as an alternative for dealing with cars, freeing up the street to give precedence to the pedestrian.

Fig. 4.3. Master-plan image of the Addison Housing Project produced by Harrison Grierson Consultants.

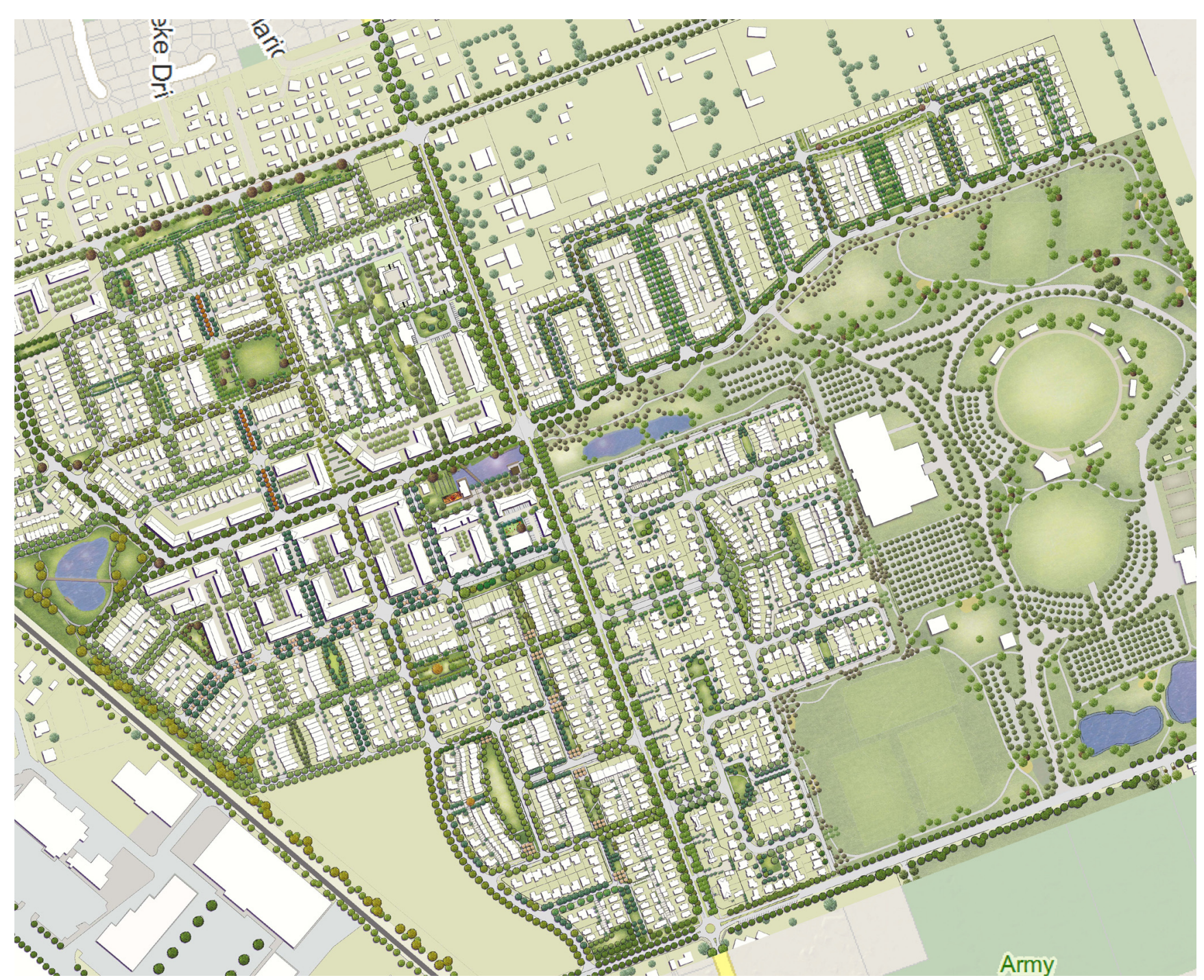




\subsection{Architectural Precedent Studies}

The following architectural precedents uncover the design strategies which will eventually be employed to mediate the tension between the public and private suburban realms.

Method: To produce alternative suburban design methods a consistent set of investigative drawings will form the basis of a graphical analysis for each precedent. These drawings will permit the extraction of

innovative ideas. The translation of specific architectural elements and relationships in the precedents into diagrams of more generic strategies or principles is a further step in the methodology for finding the design strategies.

The drawing analysis consists of:

- Floor Plans at 1:200

- Gradient Diagram in Isometric format 
This house occupies a corner site within a Victorian era suburb. The ground level accommodates the formal, more public areas, while the upstairs contains the more private bedrooms and work areas. The open-space occupies almost half of the allotment along the northern edge interacting with the facade of the building establishing a courtyard connected to the social areas within the house.

The primary entrance steps up from ground plane isolated from the small front yard by a front fence. The front door leads to a double height formal lounge which is strongly connected to the open space to the north. The configuration of this space directs movement towards the circulation spine. The functions of the spaces become progressively private as they are situated deeper into the site. A kitchen is followed by an informal sitting room which opens to the courtyard. A laundry is followed by the garage on the southern boundary, while the master bedroom and en-suite enclose the courtyard. On the first floor a study looks out over the formal lounge. The study hangs over a portion of the courtyard providing shelter. Two

bedrooms look out over the open space to the north followed by a family living room which opens to a

balcony directly above the master bedroom.

The geometry of the enclosed volumes play a significant role in establishing a hierarchy of thresholds

between public and private. The twisting form of the roof scales down the entry and then transitions into

the higher second floor. A variety of glazing strategies, including translucent glazing, screened windows and

curtain walls, enhance the sculptural and formal intentions of the building

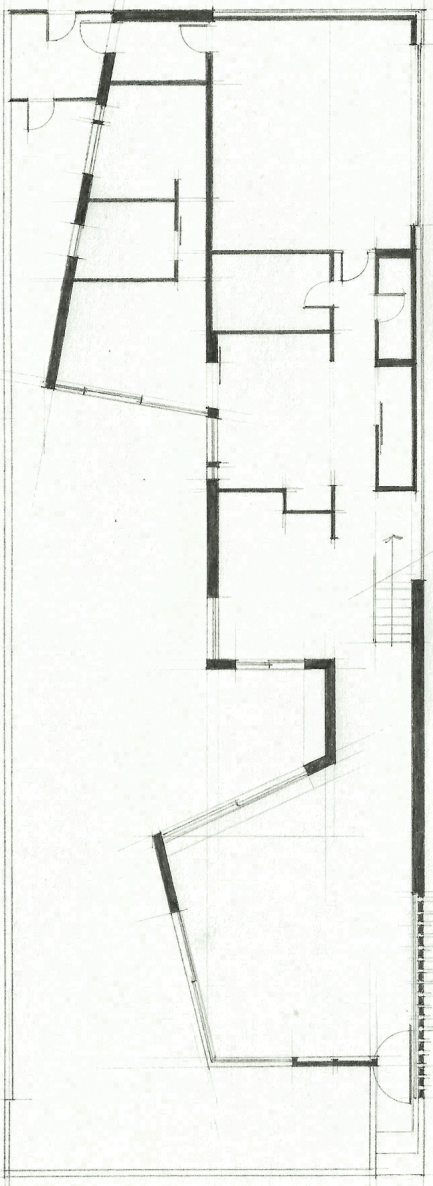

Fig. 4.4. Ground Floor

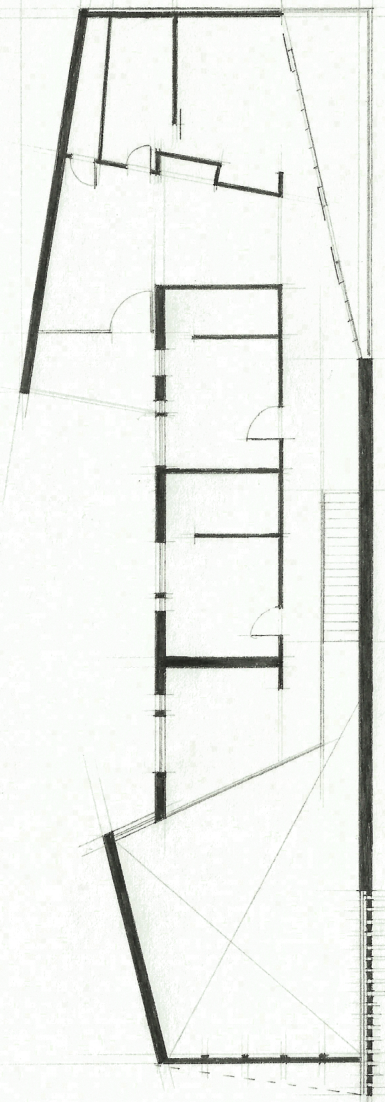

$\mathrm{N}$
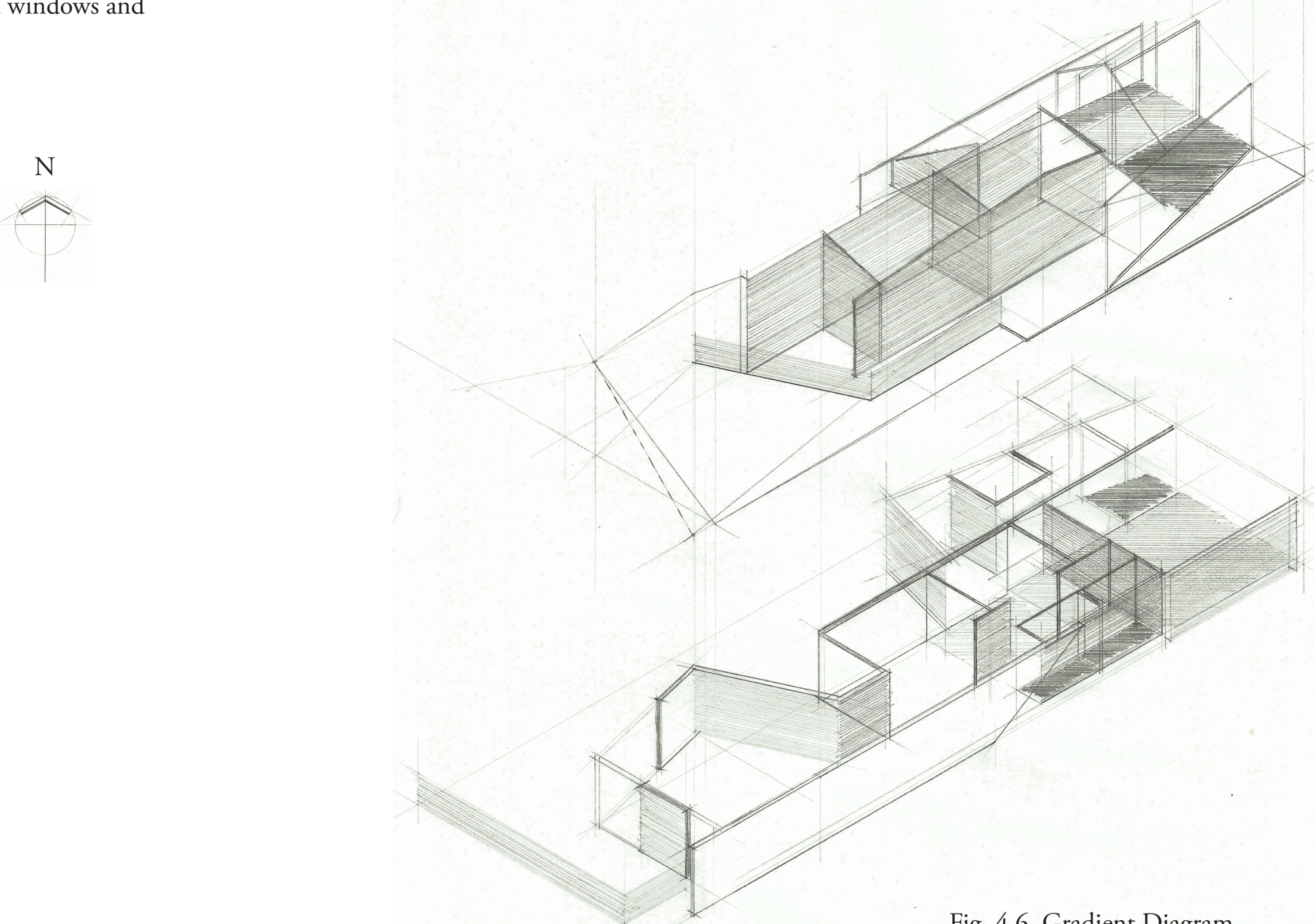

Fig. 4.6. Gradient Diagram 
This house occupies a narrow allotment on a waterfront site. Public access at the northern end leads past a front lawn terrace which is raised off the ground plane. This feature establishes an immediate hierarchy of public to private without relying on complete segregation. An angled entry wall channels movement towards the front door while creating a front wing or bay to the house.

On the ground floor the front door opens directly to the generous living space and the adjacent

vertical circulation. The stair angles away from the front door opposing the angle of the entry wall and appropriately isolates the bathroom and mechanical services. The kitchen and dining area occupy the front wing of the house, connected to the front lawn terrace by a gridded curtain wall. The angle of the entry wall orientates to engage pedestrians as they approach the entrance. The first floor contains a master bedroom, facing the waterfront, and a spare room in the front wing, both with adjoining closets and ensuites. The laundry is located off the angled circulation spine and, along with various storage units, fills up redundant space created by the angles.

The spare room features a 'bay window' which continues the wall planes before squaring off, consistent with the front wing of the house. Retractable louvers begin from the floor level but stop short of the ceiling providing clerestory windows. The glazed bay eliminates the presence of the front two corners and, to an extent, erodes the sense of enclosure. The adjustable louvers mediate this effect, retaining the integrity of the private bedroom.
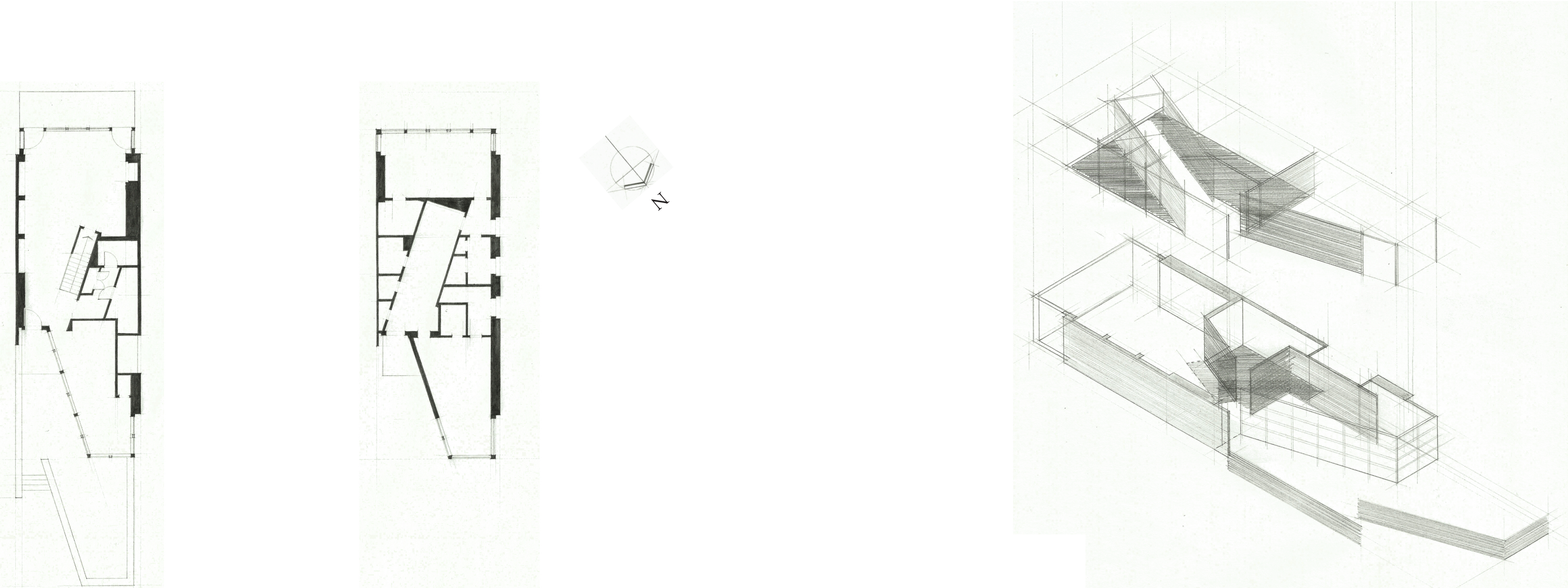

Fig. 4.9. Gradient Diagram 


\subsubsection{Bernal Heights Residence, San Francisco: SB Architects}

The general layout of this house is defined by a central stair core at the southern edge of the building The core is surrounded by service areas on the ground floor, private rooms and functions on the first floor which is the entry floor, and social spaces on the top floor. The garage dominates the ground floor which isolates the living and social spaces from the street. The importance of this precedent is in the way connections back to the public realm are made.

The treatment of the facade contributes significantly. A geometric interplay of positive and negative projections create depth and visual movement across the facade, focusing attention at specific areas, usually an opening, prompting an interaction with the private realm. An interpretation of a bay window projects out over the top of the semi-submerged garage entrance to juxtapose the recess, and focus visual direction towards the interior. A balcony follows the contours of the bay inhabiting the edge of the volume directly above while also withdrawing to connect social functions of the house with the outside environment.

A number of window strategies are implemented to compliment the dynamic facade scheme. Basic cut-out windows, edge and corner windows, curtain walls, articulated frame windows and deep reveal windows are used in this home. They erode the sense of enclosure by creating soft thresholds and removing spatial elements, like walls and corners.
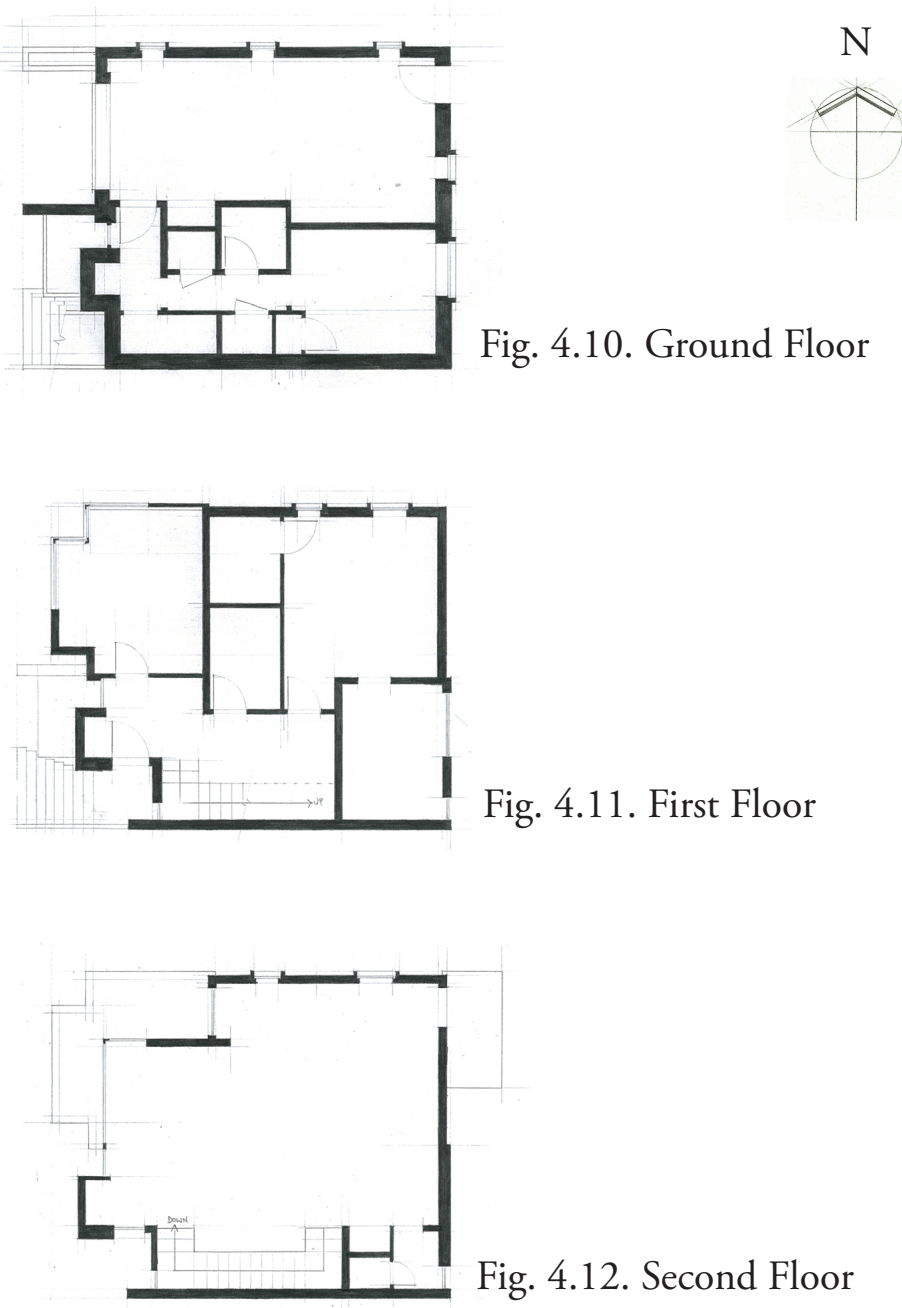
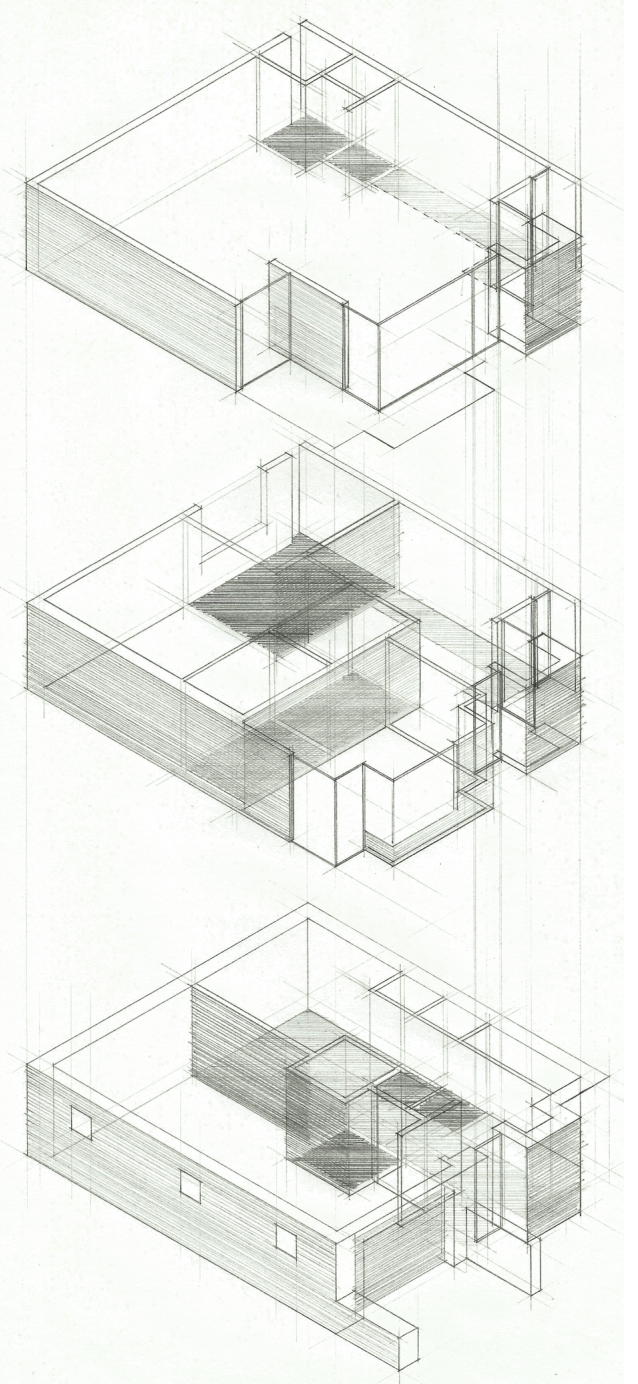

Fig. 4.13. Gradient Diagram 
Slot House is an addition which positions an open planned vertical loft over the top of a small existing residence. The house is located on a narrow Victorian era suburban lot with traditional houses close to the street on either side. A pre-existing maple tree remains in the front yard and has placed significant

limitations around the way the second residence was to be added to the site. A large front yard is the result of this consideration, secured from the public realm by a front fence.

In plan, the ground floor provides a relatively small flexible social space which also serves as a spare sleeping area. The upper floor includes an informal sitting area at the front of the building, with small bathroom and kitchen facilities adequately separated towards the back. A grill slides over the window at the back of the kitchen area providing security and ladder access to a sleeping loft.

The important feature of this dwelling is the full height edge window slot cut into the street facing facade providing consistent views of the large maple tree from the interior. When the house is so small, eroding the sense of enclosure attained within the space greatly impacts comfort levels and perceived security. The tree itself then becomes an important mediating factor. The tree screens views back into the house from the street while providing a strong focal point for street users. This effect allows the house inhabitants to benefit fully from the light and ventilation qualities achieved by the large window.

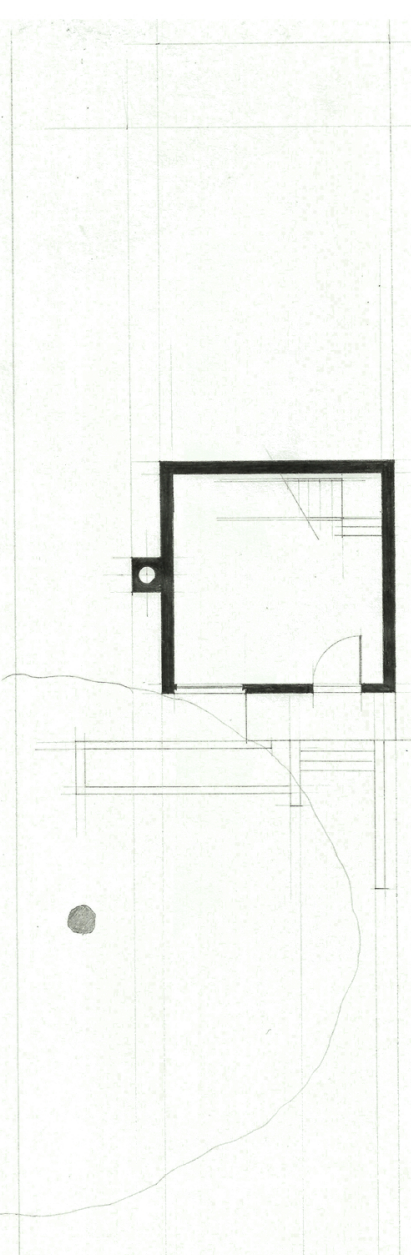

Fig. 4.14. Ground Floor

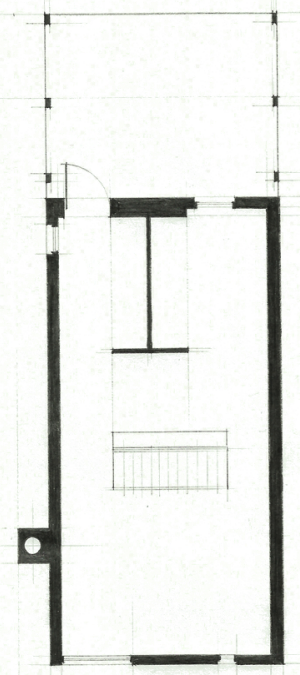

Fig. 4.15. First Floor

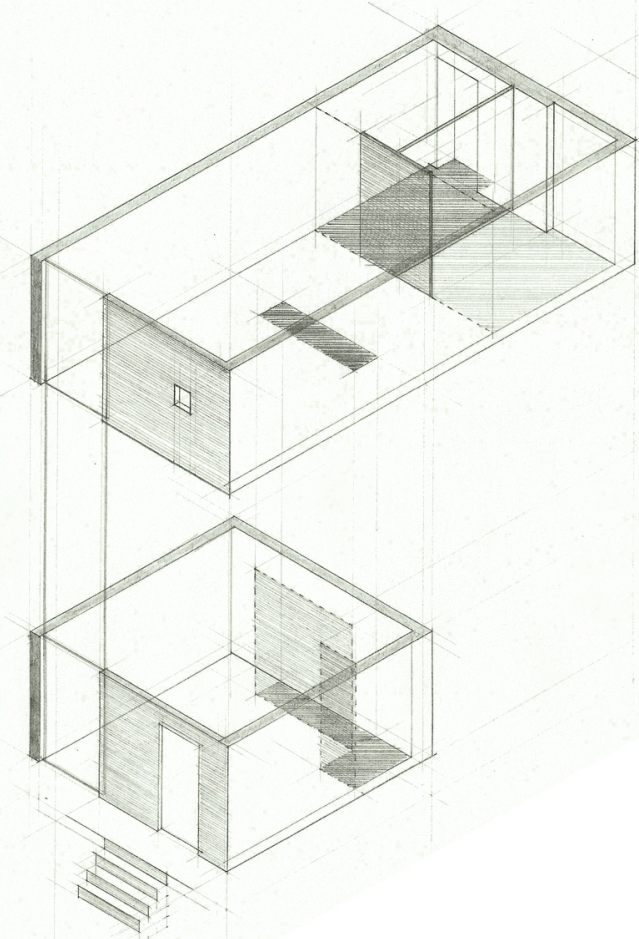


The Madrona residence occupies a long, narrow lot. The house is pushed forward on the site, stopping to leave a landscaped three metre setback from the footpath. The building hugs the northern boundary of the ite allowing the volume to open up to the remaining space to the south.

In plan, the functions are situated around a stair and service core. On the ground floor, the entry and formal lounge room are west of the core, and the living and dining functions to the east. The kitchen is located in the secondary volume south of the core. On the second floor, the stair opens up to the office.

The house is comprises three main formal components: an extruded volume containing most of the

program, a smaller secondary volume to the south, and the cantilevered timber screen. The first volume measures 5 by 18 metres leaving two terraced yards on opposite sides of the secondary volume. The front terrace is raised approximately a metre above the ground level, responding to the street. conversely, the rear terrace is at ground level freely connecting with the social areas, but protected by the smaller secondary volume. Full height glazing opens the southern facade and portions of both the east and west facades to these terraces and the environments beyond, with the wrapping timber screen mediating the intensive relationship on the first and second floors.
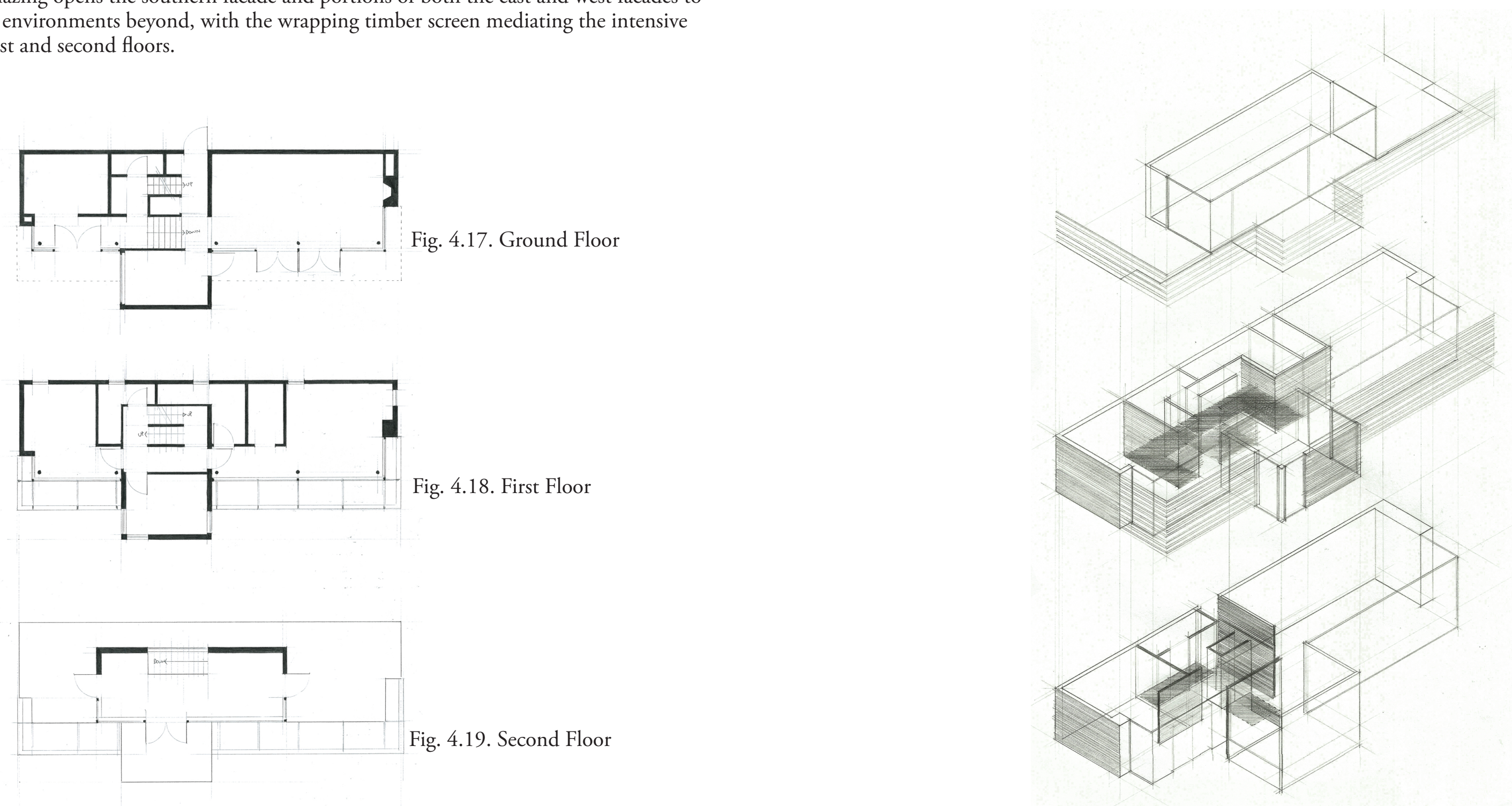

Fig. 4.20. Gradient Diagram 
4.3.6. Chen House, Taiwan: Casagrande Laboratory

Chen House is located in a remote clearing on an old cherry farm. The house is oriented on the north south axis, with an open platform at the northern end and access to a roof deck at the southern end. The east and west facades of the house include selective penetrations which are generally tall and linear. The house is built on heavy concrete blocks so that the floor level is raised substantially above the ground plane.

The main volume, containing living and sleeping quarters, is a narrow single storey wedge which sits on the platform. A smaller secondary volume contains the bathroom, a sauna and the kitchen area. The overall arrangement distinguishes formal and informal spaces within the main volume eliminating the need for interior partitioning. The roof and walls of the main volume extend at the wider northern end to fo a sheltered ' $y$ ard' directly adjacent to the open platform. This space suits informal outdoor dining and reclining.

Lifting the house volume up onto a clearly defined platform establishes an immediate threshold designating a hierarchy of private and public use spaces: the raised platform indicates where private occupation begins and ends. The direction of approach is uncertain, but orientation and access to the platform is located at the southern end suggesting that the primary approach is from the south. The roof and walls form a 'hood' that the entrance to the main volume of the house recedes beneath. This achieves a veranda effect elongating the threshold connecting the initial access platform and the domestic interior. The subtle

wedge shape of the main volume, which widens along the angled eastern wall towards the northern end, is another feature that differentiates the northern end of the platform from the south, protecting its privacy as a pseudo-backyard.
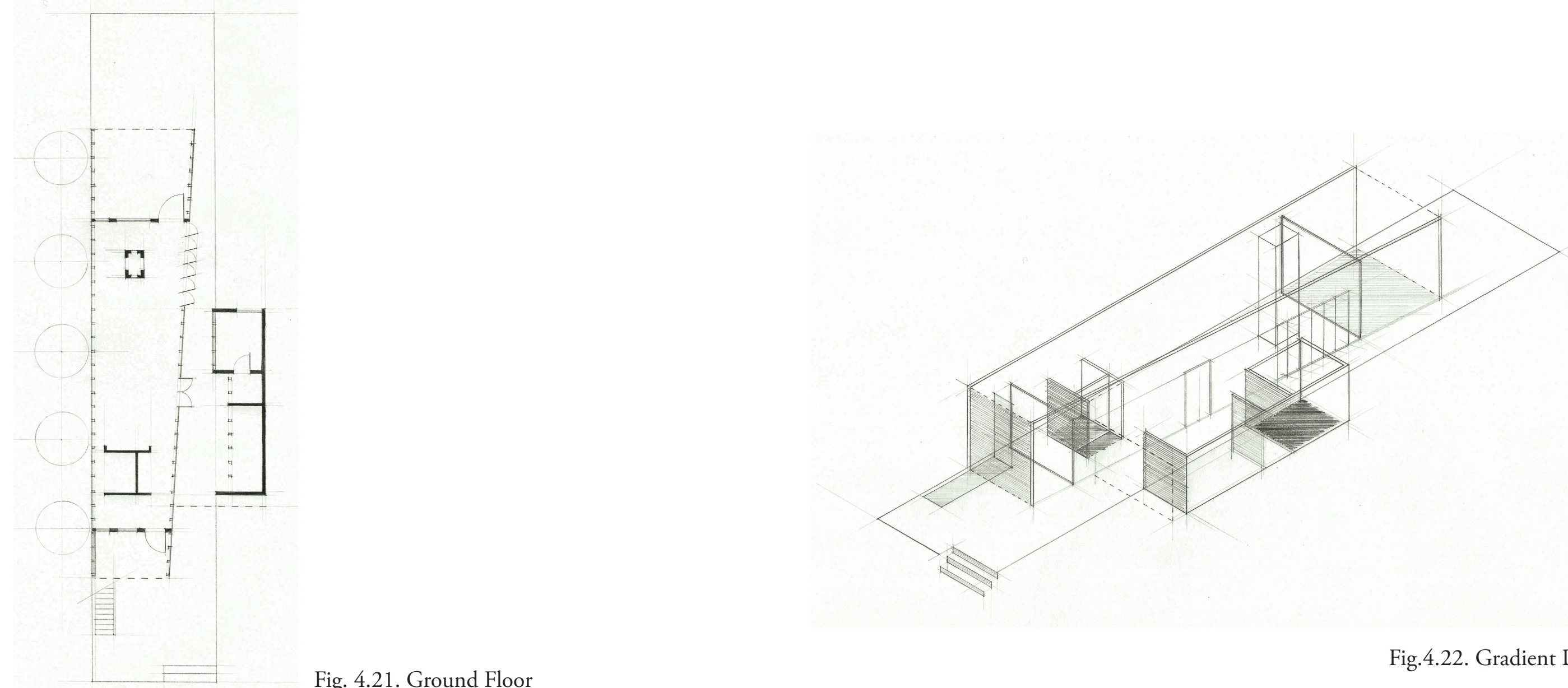

Fig.4.22. Gradient Diagram 
The PC-1 Residence occupies a long, narrow site oriented towards the east. The site falls away to the west facilitating a ramped car access at the rear to a semi-submerged basement level. The building is pulled back fom the street edge leaving the front of the site as the primary open space.

The building comprises three floors with a main residence and a semi-submerged private 'Accessory

Dwelling Unit' including its own kitchen, laundry, bathroom and lounge, on the lower floor. Separate access to this unit is accommodated at the rear of the building as the site slopes away.

The main residence begins at the ground floor which is lifted off the ground plane to accommodate the basement. Access to the main residence is provided on the southern facade, but the main gesture is a wide series of steps leading to a front deck. The adjacent formal living area opens fully to the deck. Functional flexibility is achieved by a 4.5 metre tall timber slatted steel framed screen which pivots open. The front deck transforms from an enclosed, private outdoor area to an extroverted deck fully open to the front yard beneath a slatted canopy. This space successfully contributes as an intermediary 'courtyard' zone allowing the inhabitants to control the degree of interaction the house maintains with the public realm beyond the front yard.

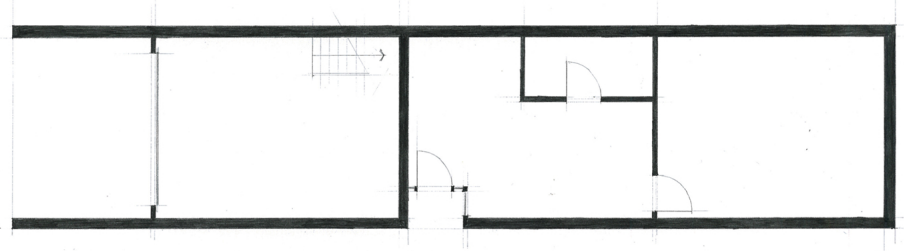

Fig. 4.23. Ground Floor

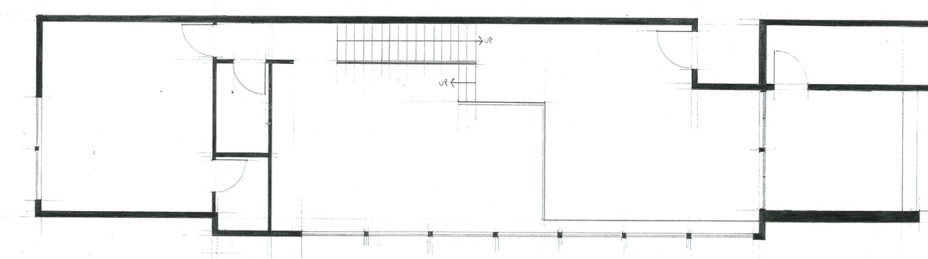

Fig. 4.24. First Floor

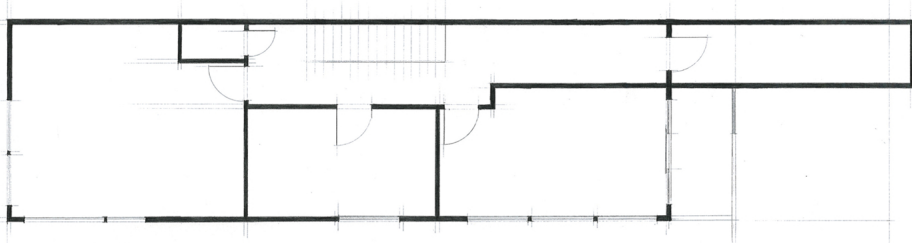

Fig, 4.25. Second Floor

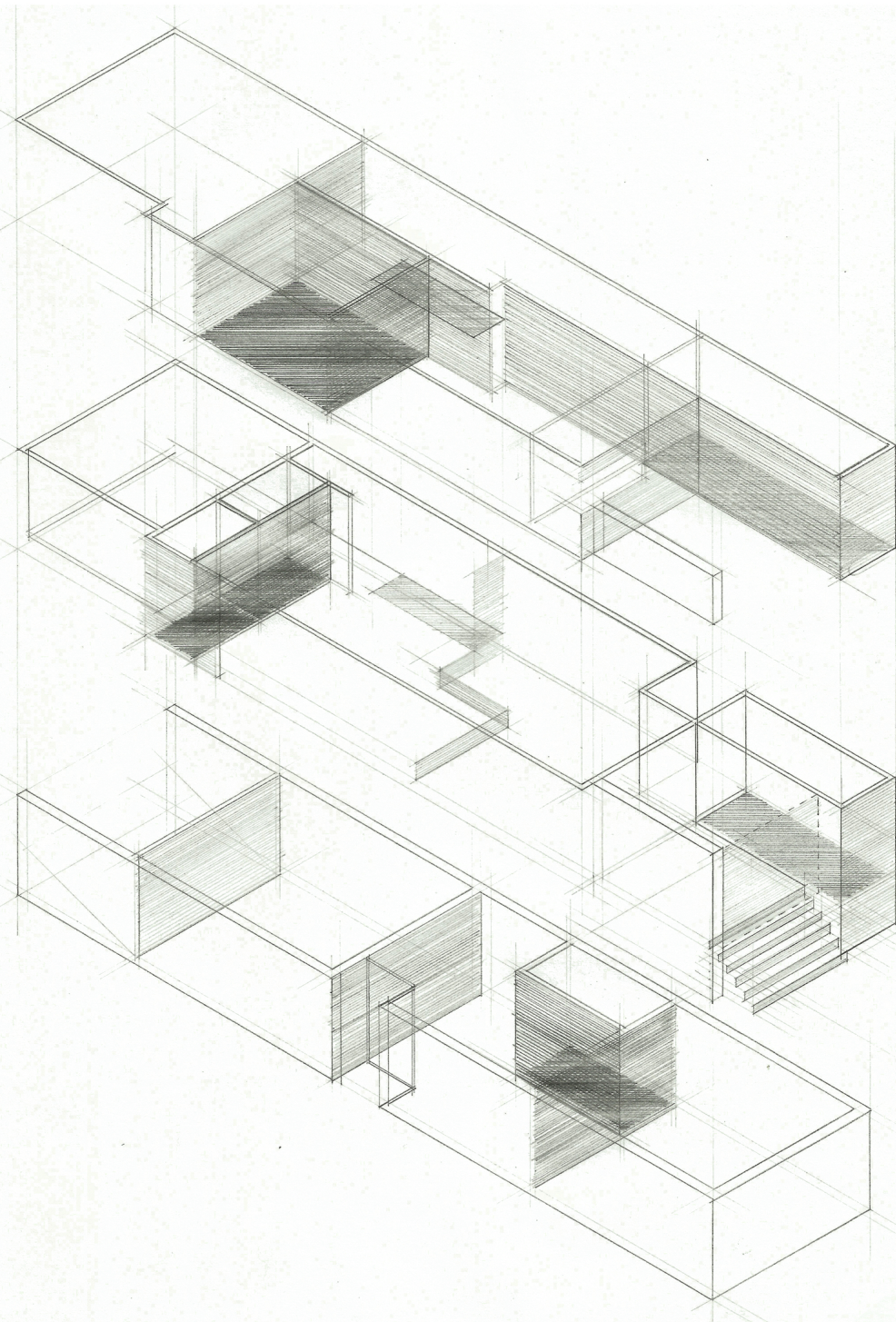

Fig. 2.26. Gradient Diagram 
Slip house consists of three orthogonal box forms which are progressively 'slipped.' This creates a strong form that both physically protects the minimal front yard while establishing a cantilevered gesture to the street over top of the front wall.

The ground floor contains a studio work place for the residing architect which provides a typically

commercial public interface. A simple kitchen services the private part of the house as well as the public but because of the business aspect of the ground floor, the social role for the inhabitants shifts away from the kitchen. Two bedrooms are located on the first floor with a shared bathroom, while the living room, and the social hub of the building, resides on the second floor with access to a roof terrace. Translucent glass 'planks' surround the living floor permitting the emission of light which enhances the formal

contribution of the house to the street. The translucency also transmits light into the interior without

compromising the privacy of the home.
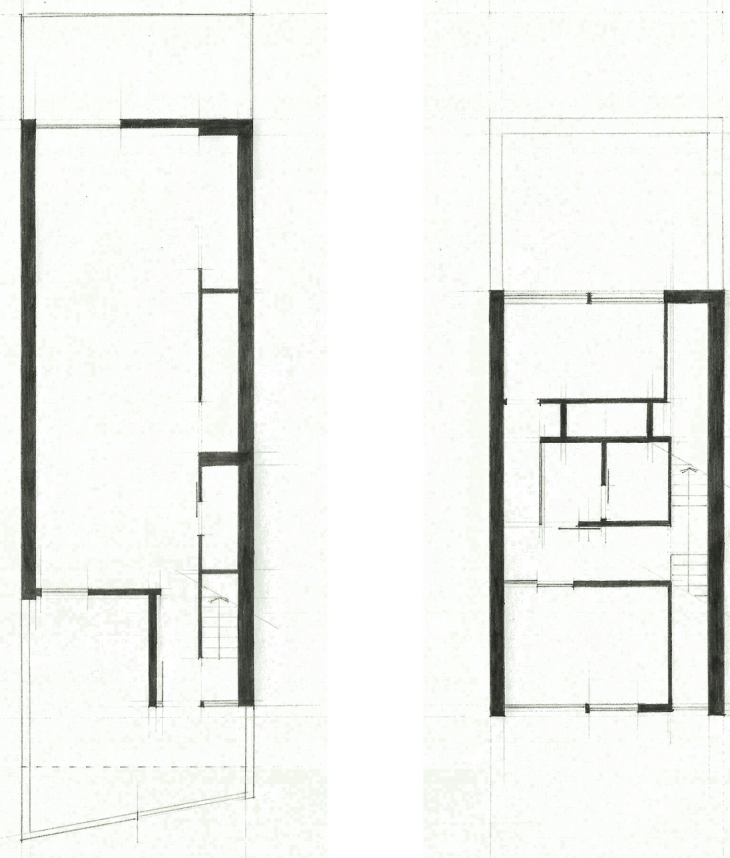

Fig. 4.27.Ground Floor

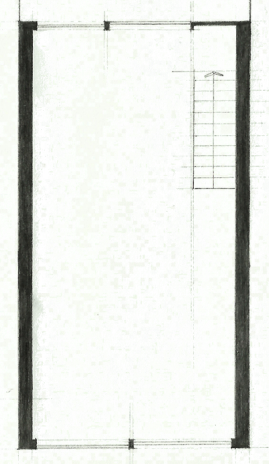

Fig. 4.28. First Floor

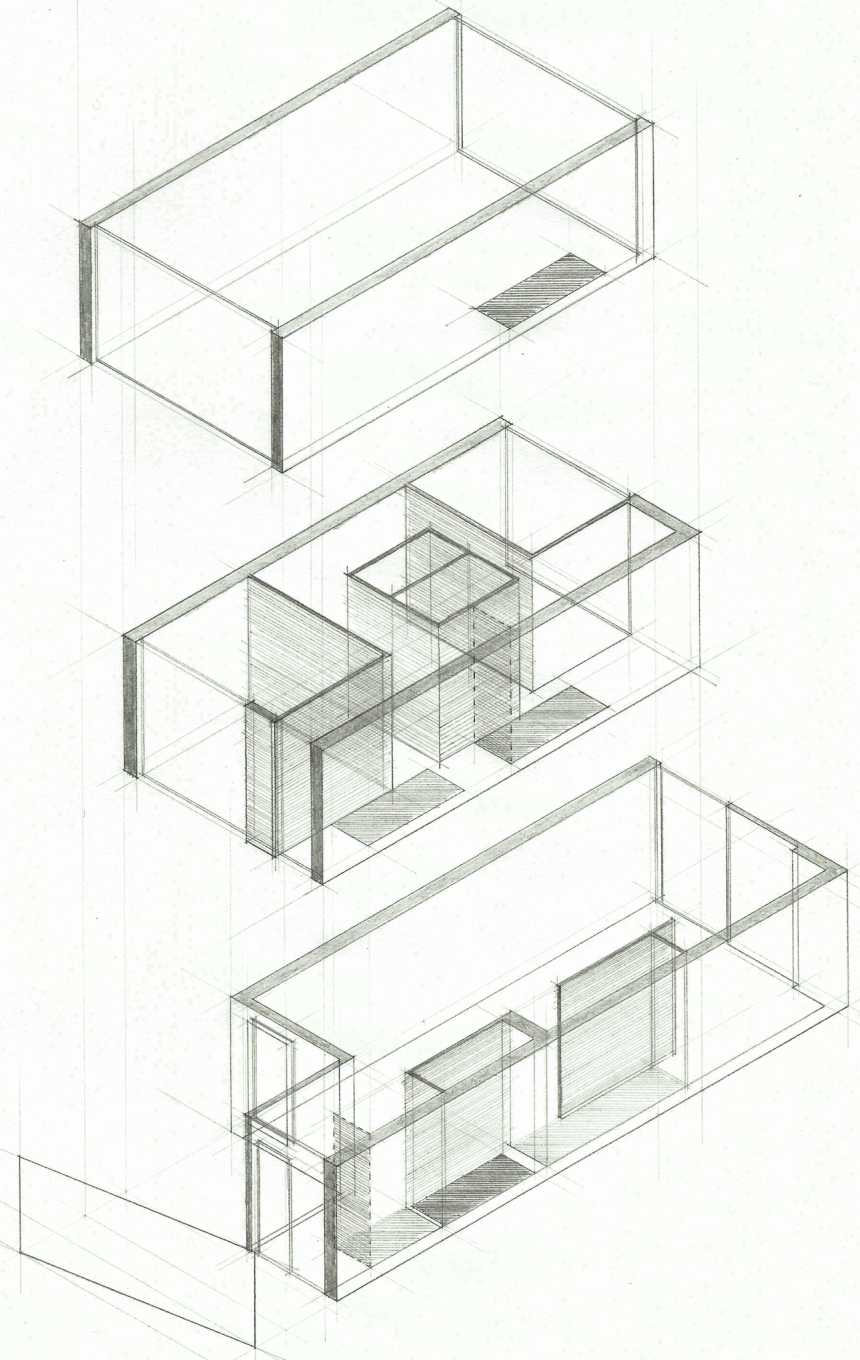

Fig. 4.30. Gradient Diagram 
4.3.9. Hanging Home, Naxxar, Malta: Chris Briffa Architects

Hanging home is a semi-detached dwelling, which frees up the ground plane for a proportionately large garden, pool, and open space area.

When viewed from the street, a staircase bridges over an underlying front garden and passes beneath the sheltering white mass to the front door. This movement is augmented by a large shear wall which acts as a spine throughout the whole building. A ramp on the other side of the wall leads to the basement which includes the garage. Penetrations in the shear wall permit access from the garage to a service passage and to the private office. The office shares a wall with the swimming pool and is situated beneath the front lawn. The front door on the ground floor leads to a hallway which facilitates circulation within the home directly adjacent to the shear wall. Penetrations in the wall provide access to the long double height living area and the kitchen. The dining room is located on the other side of the circulation spine, cantilevered over the swimming pool. The first floor consists of two bedroom units on either side of the shear wall. The units are formed by a bedroom, separate en-suites, wardrobe storage, south facing balconies, and the master unit includes a lounge suite. The two units, while they open up towards the south, are enclosed within the white mass which projects out over the front lawn towards the street.
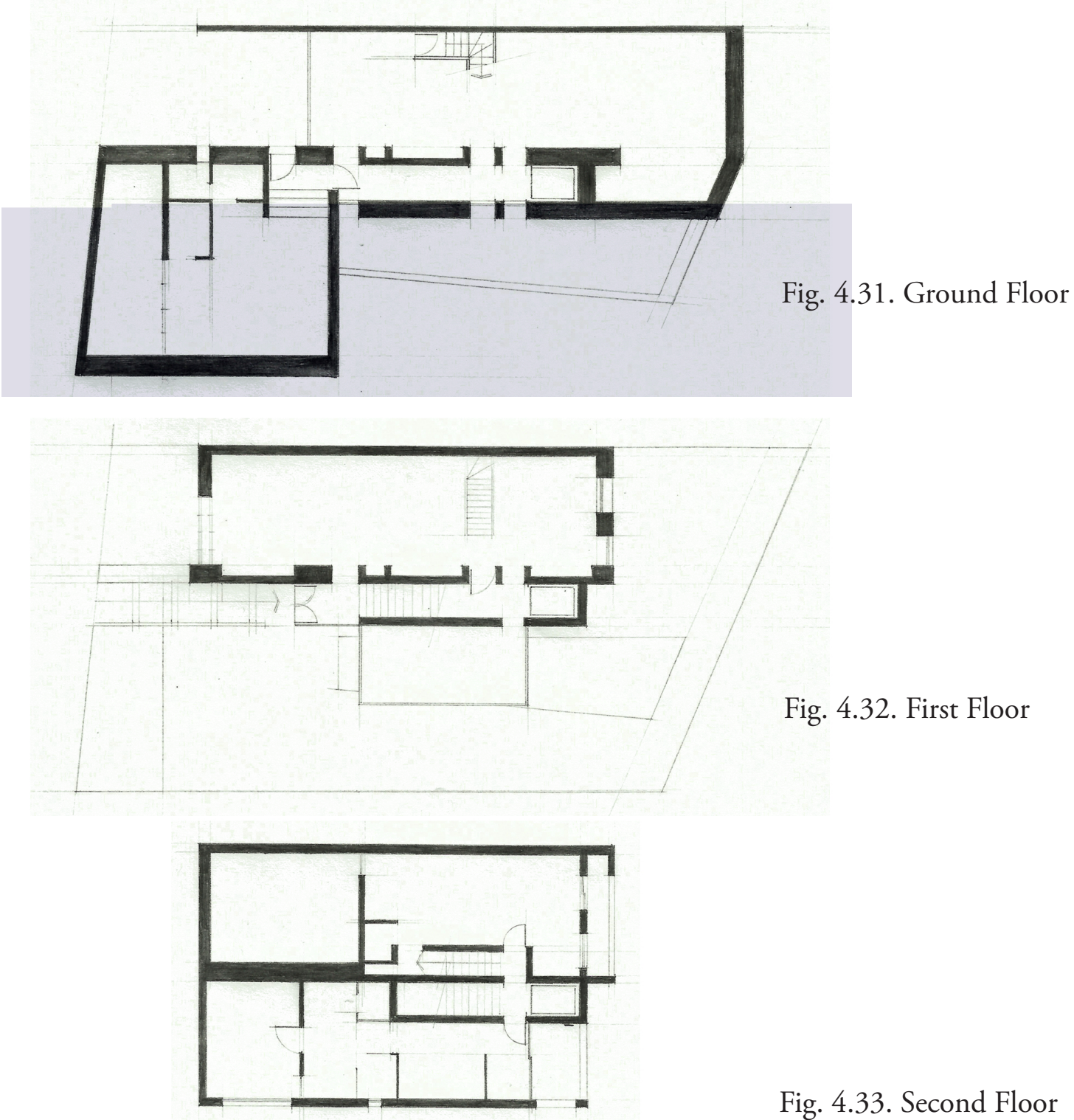

Fig. 4.32. First Floor

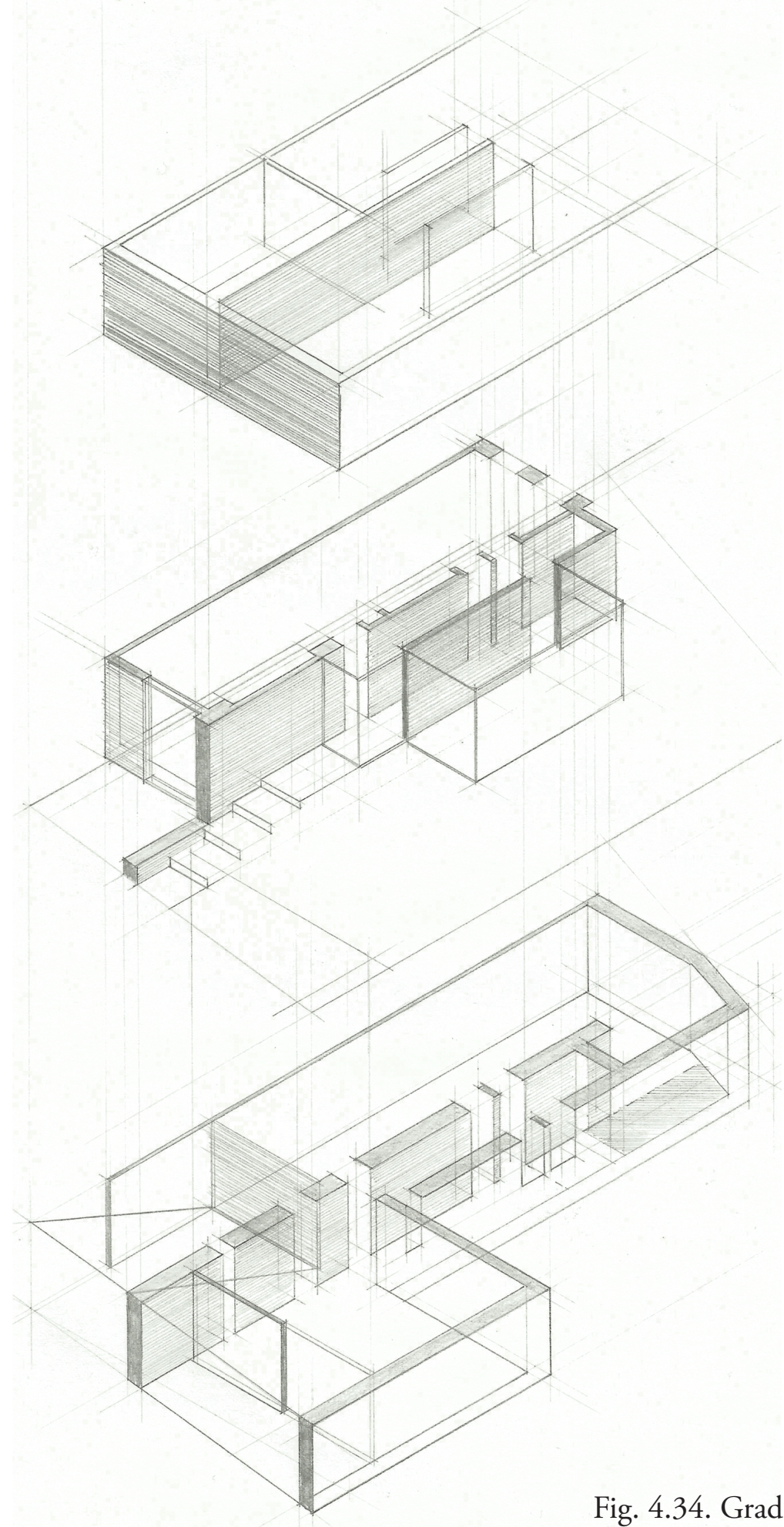

Fig. 4.34. Gradient Diagram 
This house occupies a proportionately long site oriented on an east-west axis. A narrow stretch of open space connects the front (west) and back (east) ends along the southern edge of the site. A semi-public courtyard penetrates the building mass to create two volumes. In doing this, a porch or outdoor lounge environment is created establishing a visual node on the stretch of open space. The courtyard services the public access to the rear volume which contains the most public spaces of the home.

The ground floor of the building is lifted off the ground plane allowing the private functions of an office, the laundry and a family sitting room to be submerged into the basement. The basement maintains views to the outside with clerestory windows. On the ground floor a formal reclining area occupies the front volume which is connected to the front garden and beyond, to the street, with an edge window. A full height glazed wall wraps the courtyard connecting the informal living, dining and kitchen areas with the semi-public zone outside. The first floor incorporates the master bedroom and en-suite in the front volume, and two further bedrooms and a bathroom in the rear volume.

The circulation within the house is contained along the northern edge of the site connecting the two volumes. Within the building there is minimal partitioning, particularly on the ground floor, to separate functions. The formal properties of the building establish the necessary thresholds to achieve the

appropriate separation; solid walls defining the southern edges of the two volumes both restrict and then permit, at specific moments, visual access to the adjacent volumes.

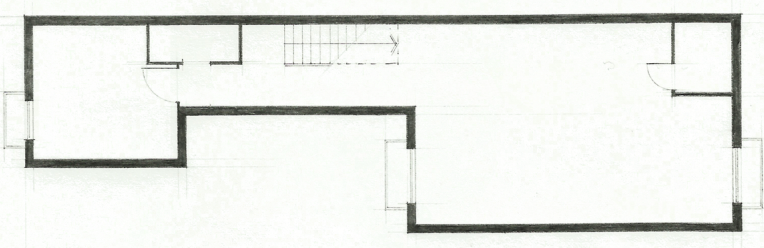

Fig. 4.35. Ground Floor

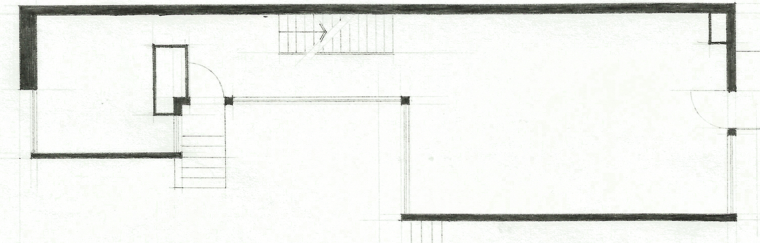

Fig. 4.36. First Floor

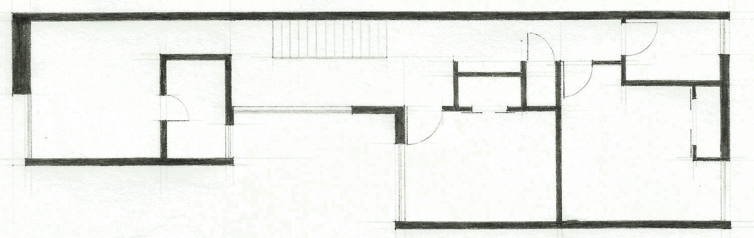

Fig. 4.37. Second Floor

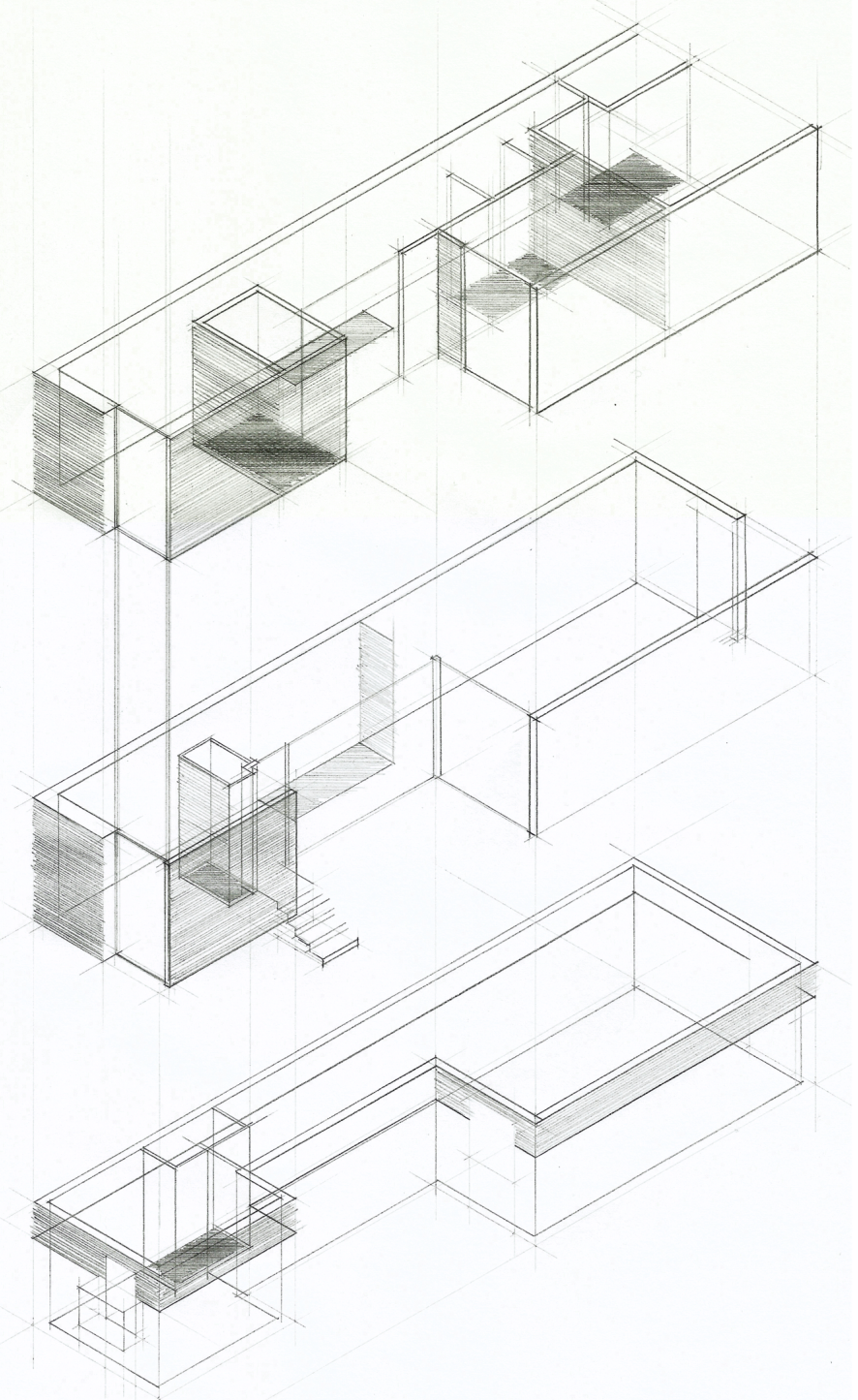

Fig. 4.38. Gradient Diagram 


\subsection{Conclusion}

This chapter has further developed a practical framework for addressing the mediation of the interface between public and private.

The important lessons coming from the urban precedents are:

- It is important to facilitate innovative approaches to street design in order to create more dynamic public street environments;

- The introduction of alternative 'off-street' car storage strategies to remove the garage door from the street facades of the houses encourages a greater degree of interaction between the public and private realms;

- Implementation of specific master-planning strategies enables the successful establishment of legible and distinctive precincts within residential developments which crucially enhances the perception of robust 'place-based' community in suburban development;

- The development of building design codes which encourage the use of architectural elements is important in the process of creating dynamic relationships between the houses and the streets.

- And, the employment of a range of house types and planning mechanisms to encourage a diverse distribution of density concentrations accross suburban residential development.

These lessons subsequently inform the holistic design of a residential subdivision, addressing the main ideas of 'place-making' and a sense of community within the public realm and the streets.

The key lessons coming from the architectural precedents are:

- The wider site or allotment planning considerations including;

- Building mass is pushed to the forward edge of the allotment bordering the street to support a stronger connection between the street and the domestic interior,

- Alternatively, pulling the building mass back from the street edge creates an intermediary zone of transition between the street and the domestic interior,

- Two alternatives for car access, rear lane access or public street access with the flexible space, remove the threat of the single use private area at the front of the house which traditionally isolates the domestic environment from the street.

- The subsequent internal spatial planning objectives such as the logical hierarchy of more public and more private areas of the household achieved by the following;

- The ideal functional layout of spaces within the house is brought about by the strategic connection and separation of the various functions to support the graduated transition from public to private,
Configuration and orientation of circulation routes and patterns within the building can be implemented as a tool to achieve separation between functional spaces while retaining visual and physical connections

- The mass, formal and geometric design of the house which primarily affects the street facing facade as a significant interface between public and private;

- The definition of the relationship of building mass to the ground plane establishes an important differentiation between habitable zones and reinforces the gradient,

- Treatment of the street facing facade in terms of positive and negative displacement of sections of the plane stimulates visual movement across the facade while articulating key thresholds,

- Similarly, the horizontal translation between floor levels aids the articulation of key thresholds while creating visual interest in the street facing facade.

- The implementation of thresholds to create permeability within the building volume is crucial for retaining visual connections and awareness of adjacent activity spaces. This is achieved through;

- The strategic use of internal partitions, generally either parallel to the street or perpendicular to the street, set up specific situations which have a significant influence on the permeability of the house,

- Similarly, the treatment of the partitions including perforations or reducing the wall to a series of screening elements changes the way their effect on the separation between spaces,

- Glazing strategies affecting the conditions of spatial enclosure and stimulating visual movement a vital method of connection between the public and private domains.

The design strategies stemming from these key conclusions enable the establishment of a public-private gradient. They are tested and developed through the process of design as demonstrated in the following two chapters.

The main reservation about this phase of the research is that no contemporary New Zealand architectura precedents are explored. This is alleviated somewhat by the previous examination of historical suburban models but specific consideration of the public-private interface in the New Zealand context would certainly have been valuable to this research. However, the diagramming process is also intended to remove contextual and cultural bias, ensuring that the resultant design strategies are universally applicable and valuable to this research. 


\section{Chapter Five: Pre-Design}

5.1. Introduction

5.2. Design Brief

5.3. Site Selection and Analysis

5.4. Critique of the Landlink Master-plan

5.5. Modification of the Master-plan

5.6. Design Strategies

5.7. Conclusion 


\subsection{Introduction}

The research enquiry of how the suburban house enables a gradient to mediate the public-private interface in suburbia is tested through design in Chapter 6. This is achieved in the design of three case study dwellings that implement a selection of specific design strategies which combine to produce a graduated transition, or gradient, between the public and private realms. However, before this can be completed it is important to first establish the context of a larger 'best practice' design for a residential development. As discussed in Chapter 2, it is the design of buildings and open spaces which are considered as a totality which allows the success of a building to be determined by its ability to make a positive contribution to the public realm (Davis-Yeang 89).

Design at an urban scale adopting the strategies from the urban precedents will establish residential development patterns which would counter the negative trends impacting the perception of community and also stimulate successful suburban places. This chapter firstly indicates a design brief for the suburban residential development, presents and analyses an existing suburban residential proposal and subsequently modifies this proposal using lessons learned from the case studies. Lastly, the full range of architectural

design strategies are demonstrated immediately prior to the design case study.

\subsection{Design Brief}

A suburb designed to include and address the following strategies will introduce a suitable context and agent for investigation for the focus of this research:

- An enriched and urbanised, high quality public realm;

- Shared street situations and rear lanes for private vehicles which challenge street use priorities;

- A legible street network and hierarchy which utilises short, narrow blocks;

- An approximate overall density of close to 20 dwellings per hectare (dph);

- Proportionately long, narrow allotments of land accommodating predominantly narrow house types

- Diverse range of household types including, detached, semi-detached and terraced houses, apartments, and studio living arrangements.

These design strategies used to amend the following subdivision proposal are not explicitly relevant to the outcomes of this research but come from the urban precedent studies completed in Chapter 4.

\subsection{Site Selection and Analysis}

This section summarizes the selection process and subsequent analysis of the site. The site selection was restricted to the Wellington region, consistent with the historical analyses of Chapter 3. The Kapiti Coast has been identified as an area of significant growth. The trend is expected to continue with the population of Kapiti Coast over next twenty years expected to grow by more than 30\% (Opus International

Consultants 43). To accommodate the anticipated influx of people, an area to the north of Waikanae has been designated as a development extension defining a new urban edge. Proposals for land subdivision and habitation have been submitted to the Kapiti Coast District Council to accommodate the predicted influxof residents. The site used in an accepted proposal by Landlink Ltd for a medium-density residential subdivision within the extension has been chosen for this design-led research. 


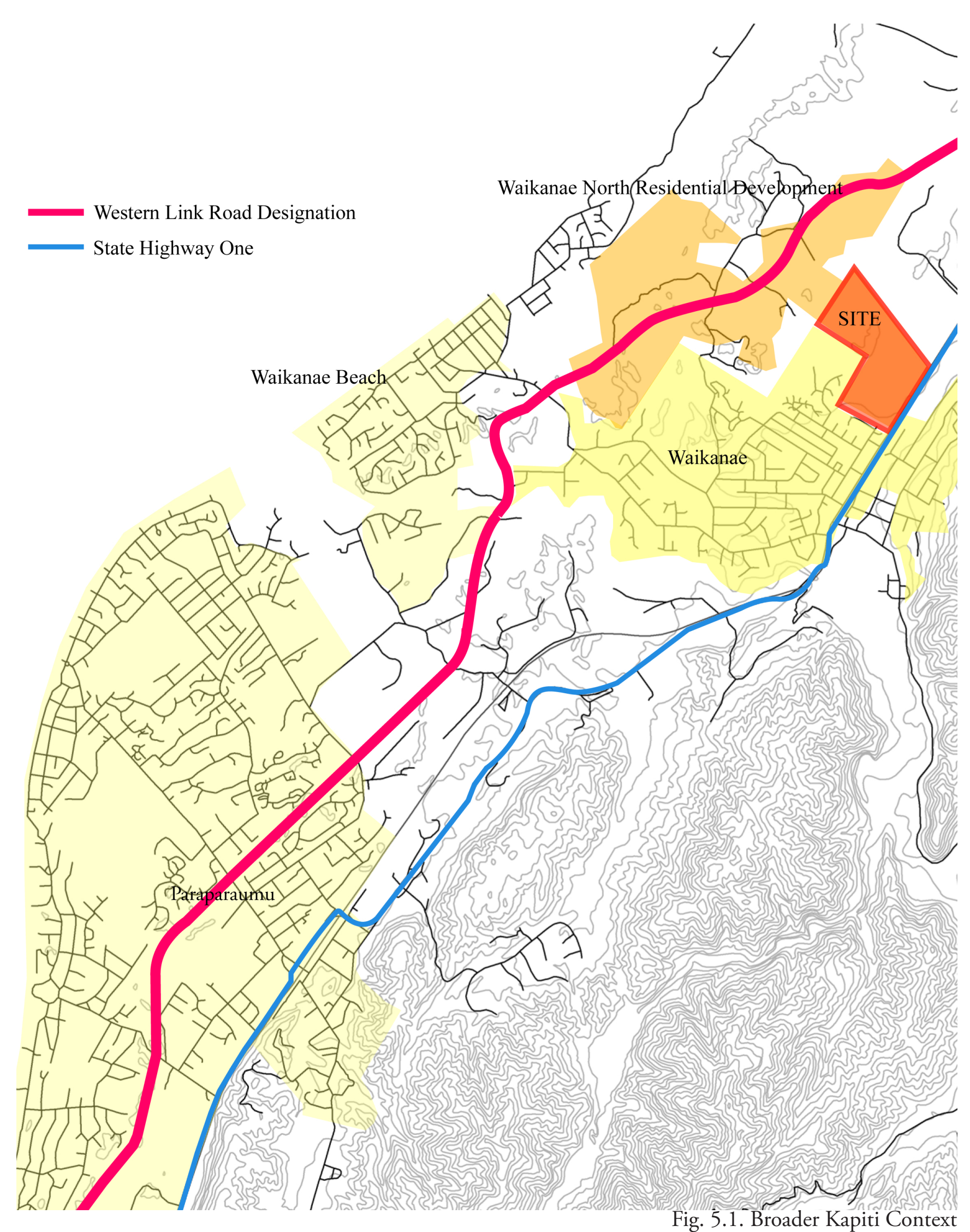

The selected development site can be split into two sections: the flat presenting ideal development conditions, and the dunes which introduce ecological issues and topographical variations. As a result area in the Landlink proposal is divided to represent these sections. The proposal illustrates two different approaches to suburban design address the different situations: the village and the reserve.

- The village is a higher density area of approximately 47 hectares consisting of primarily residential buildings occupying the flat land. The overall density of thevillage area is approximately $17.5 \mathrm{dph}$. It contains a central core to the north-east with mixed use components, pedestrian streets, squares and public green domain.

- The reserve, on the other hand, is a lower density development on the dunes consisting solely of residential units. The reserve approach allows the development to fulfil prescribed ecological and environmental intentions, while adding marketable value to the project. Because the ecological an environmentally sustainable principles fall outside the scope of this research, the reserve area will remain untouched in the modified master-plan design.

The Landlink master-plan features a buffer zone separating the development from the current State Highway One. The buffer-zone comprises lower density detached houses on land parcels comparable with the surrounding suburban development. This buffer-zone wraps around the southern and western edges as well effectively isolating the development from the surrounding suburban fabric.

Lanldink's reasonably relaxed grid structure allows for sweeping curved streets to connect to straight boulevard type streets with little difficulty. As a result the blocks vary in size and shape. The allotments of land, however, are predominantly long, narrow and considerably smaller than the surrounding suburbs.

A perimeter road sweeps along the southern and western sides. This road collects resident from the David Street entrance and distributes them to either the Parata street axis or the Principal Link road winding along the end. Within this framework a network of Home-zones or shared streets construct the irregular block forms. Inner block vehicular lanes provide shared private access to garages situated at the rear of the allotments, eliminated from the public street.

The Landlink master-plan includes a higher density core at the north-east corner, detached from the existing suburbs. This core incorporates mixed-use components presumably to exclusively serve the residents of this development. A mixture of terraced housing, semi-detached and detached housing radiates away from the core, progressively decreasing in density.

Overall, it is a compact and effective suburban form which already demonstrates some of the 'best practice' and the preferred or targeted urban design strategies:

- Shared street situations which challenge street use priorities;

- Short blocks;

- Long, narrow allotments of land accommodating predominantly narrow house types;

- And, Rear lanes for private vehicular access. 

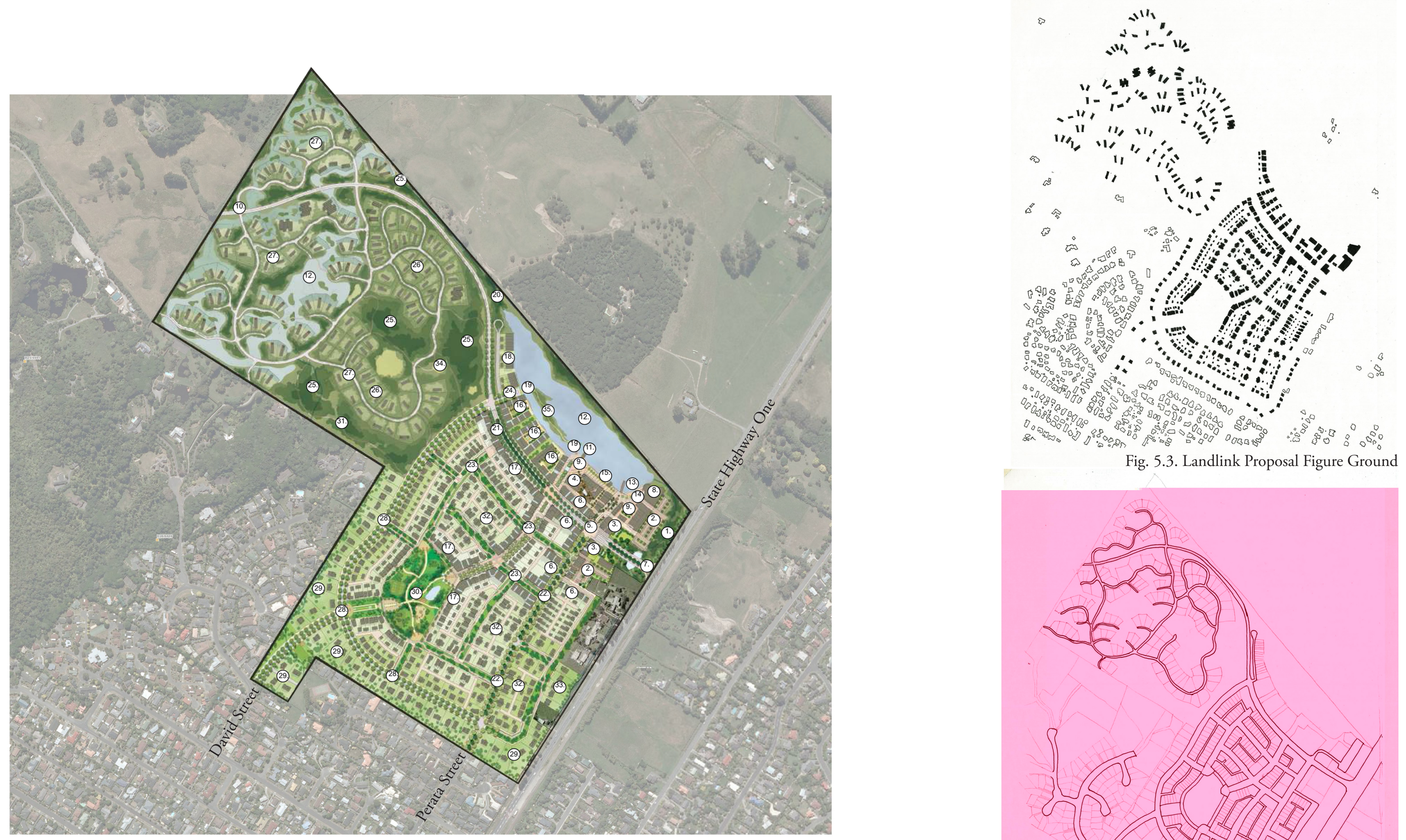

Fig. 5.2. Landlink Proposal for a section of the Waikanae North Residential Area

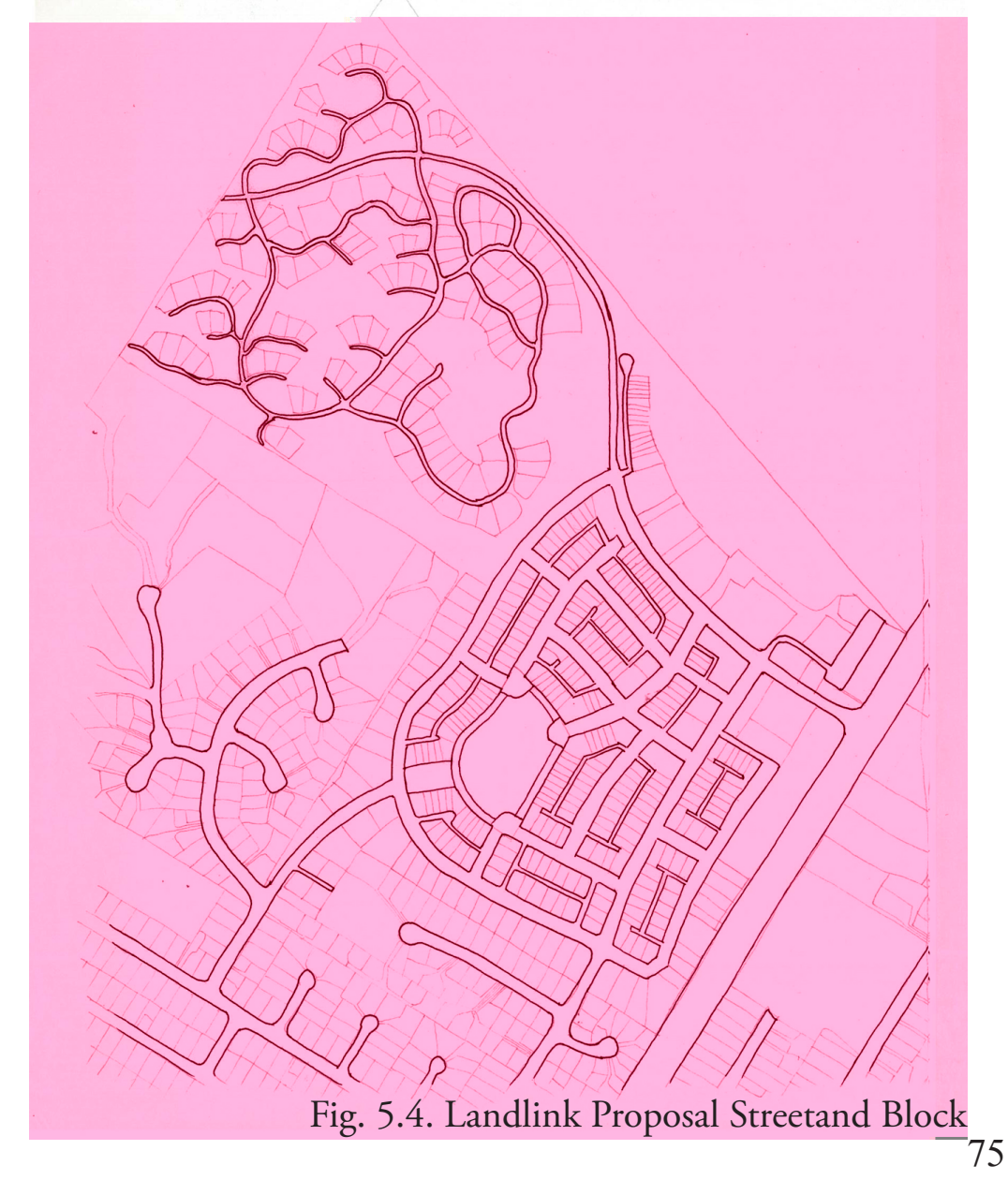



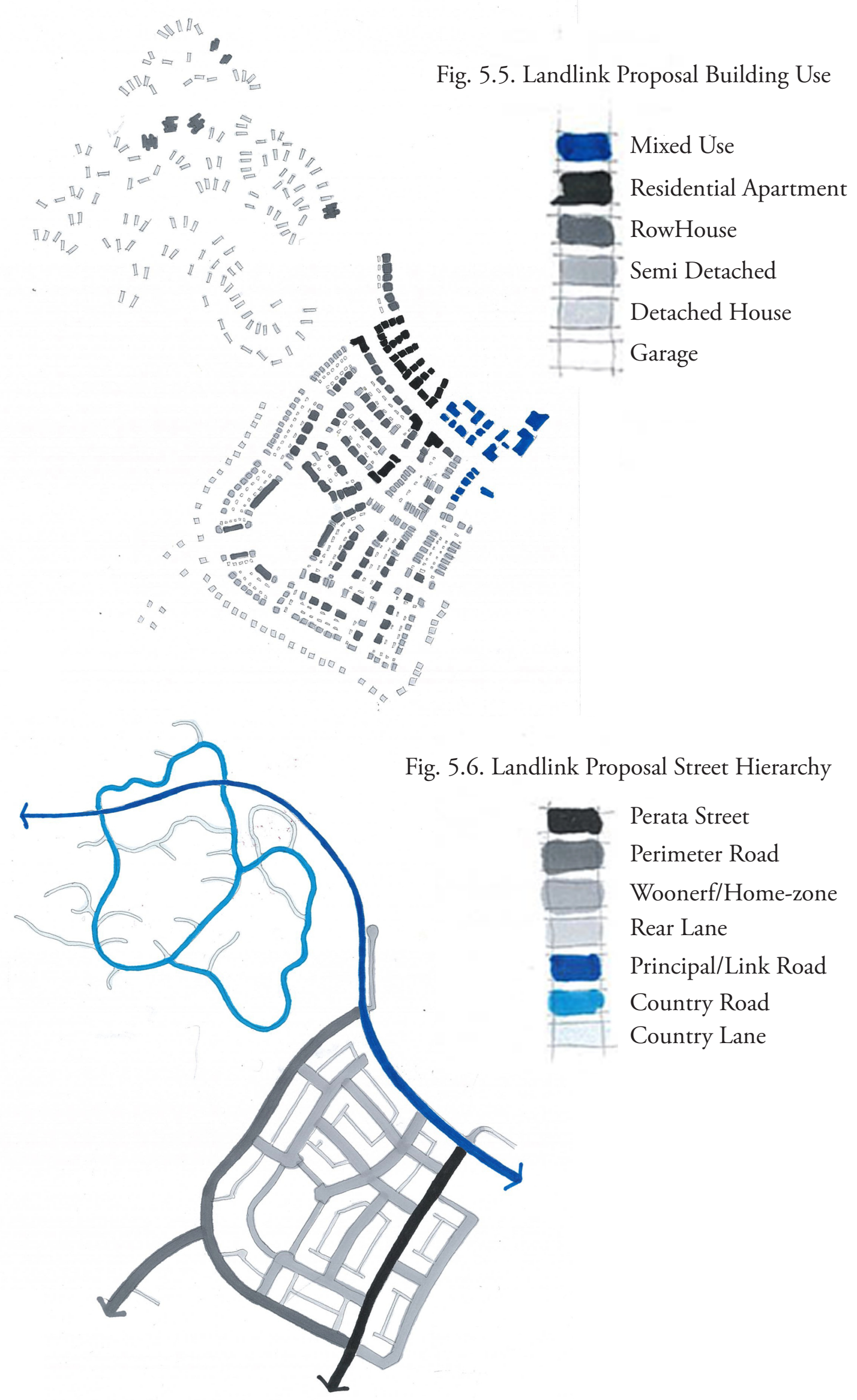

\subsection{Critique of the Landlink Master-plan}

Whilst the Landlink master-plan for the vacant Waikanae North residential zone is an elegant and relatively robust proposition, a number of deficiancies are identified and addressed prior to the architectural design inquiry. Again, the deficiancy identification is limited to the 'village' development zone of the Landlink proposal in order to preserve the ecological underpinnings of the 'reserve.' The main concerns about the Landlink master-plan are:

- The mixed-use centre is located inconveniently for the integration of the surrounding suburban fabric. Its current location in the north-east corner of the plan means that the full benefits of including a mixed-use centre in the first place are not fully realised. It is not easily accessed from the surrounding residential development, and

- A lower density residential buffer zone at the perimeter also reduces connectivity to the existing suburban fabric from within the master-plan. While a buffer zone which mitigates the harsh effects provided by State Highway One to the east is a successful and effective strategy, extending the zone around the southern and western edges only serves to isolate the development and propagate exclusivity. This is seen as detrimental to the fundamental notions of community within suburban development.

- The curvilinear perimeter road disrupts the connectivity of the plan. The lack of nodal points and destinations on this road indicate an anticipated higher volume of traffic which ensures that the residential middle of the plan isolated and relatively ambiguous.

- What would appear to be a significant connective route through the middle of the plan is instead disrupted by an oddly positioned park which reduces the route's effectiveness as a thoroughfare.

- In general, the curved streets reduce the important way-finding and legibility characteristics of axial vistas and view shafts.

- A lack of definition between various precincts in the master-plan affects the perception of 'place.' The definition of specific neighbourhood zones or territories marked by a set of individual characteristics promote inclusiveness and community within the development. 


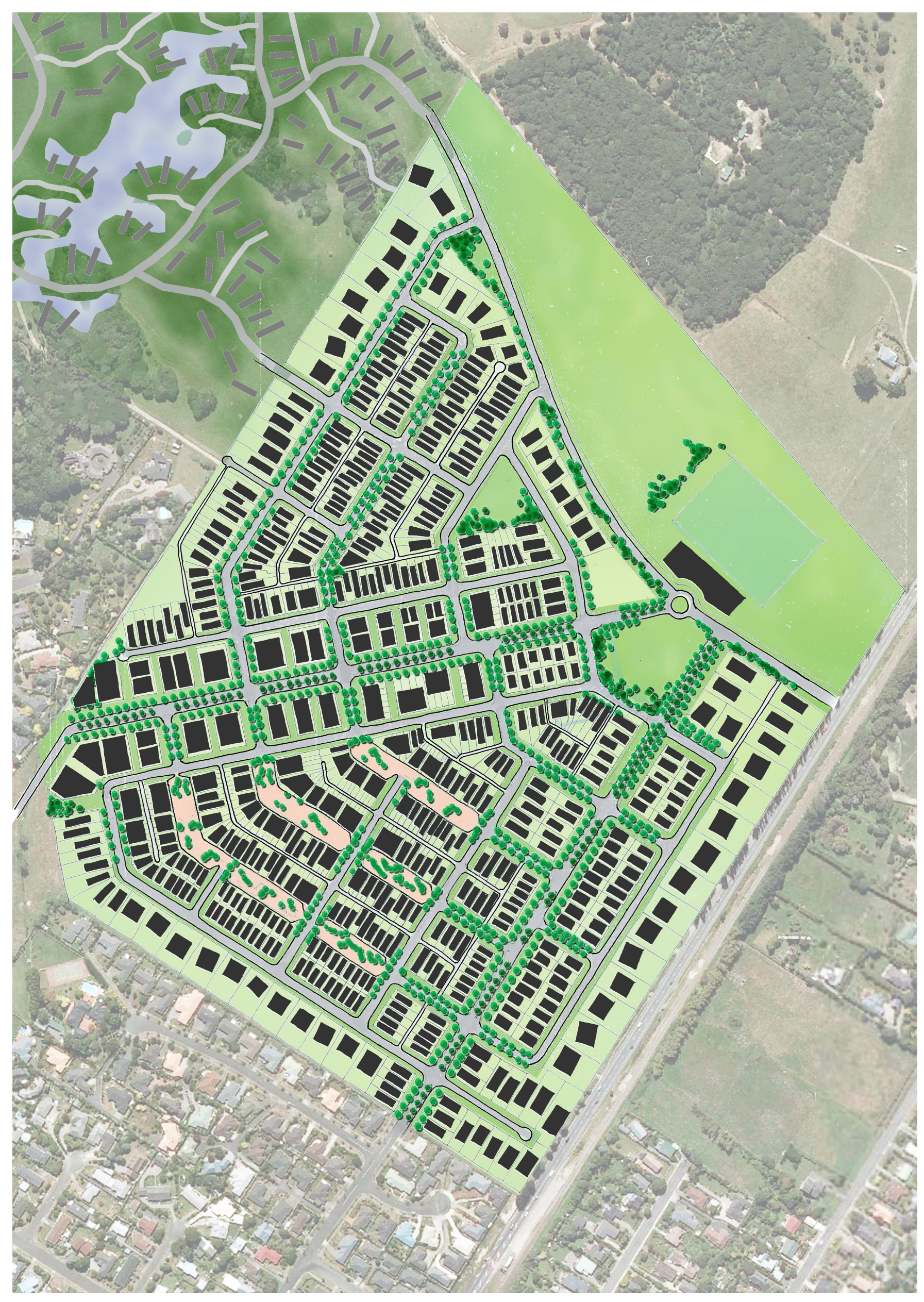

\subsection{Modification of the Master-plan}

This section features the design amendments to the Waikanae North residential development proposal. The proposal is developed to ensure it achieves the following objectives established in Chapters Three and Four:

- Employ stronger grid formations which are subsequently connected by a relocated central spine acting as the main circulation avenue increasing legibility and clarity within the master-plan;

- Produce shorter blocks to increase the levels of visual and physical permeability, augmenting the connectivity of the master-plan;

- Relocate the mixed-use core to the south-western perimeter of the site to facilitate increased integration with surrounding suburbs;

- Form a recreation precinct along the northern edge recognising the 'Urban Edge' and the agricultural land beyond;

- Emphasise home-zone design principles by designating a specific residential precinct within the master-plan. This precinct features shared public streets to alleviate the predominance of the car in the public realm and also rear lanes for private car access to the allotments;

- Further utilize narrow house forms and land parcels to increase the overall dwelling density of the masterplan to approxiately $21.5 \mathrm{dph}$ rather than $17.5 \mathrm{dph}$

- Increase the building variety to include mixed-use retail lower level/residential upper levels, walkup apartment complexes, terraced houses, semi-detached houses and detached houses.

- Introduce rear lanes to facilitate private car access for the residents while reducing the significant influence of the car on the character of the street environment as a public domain. 


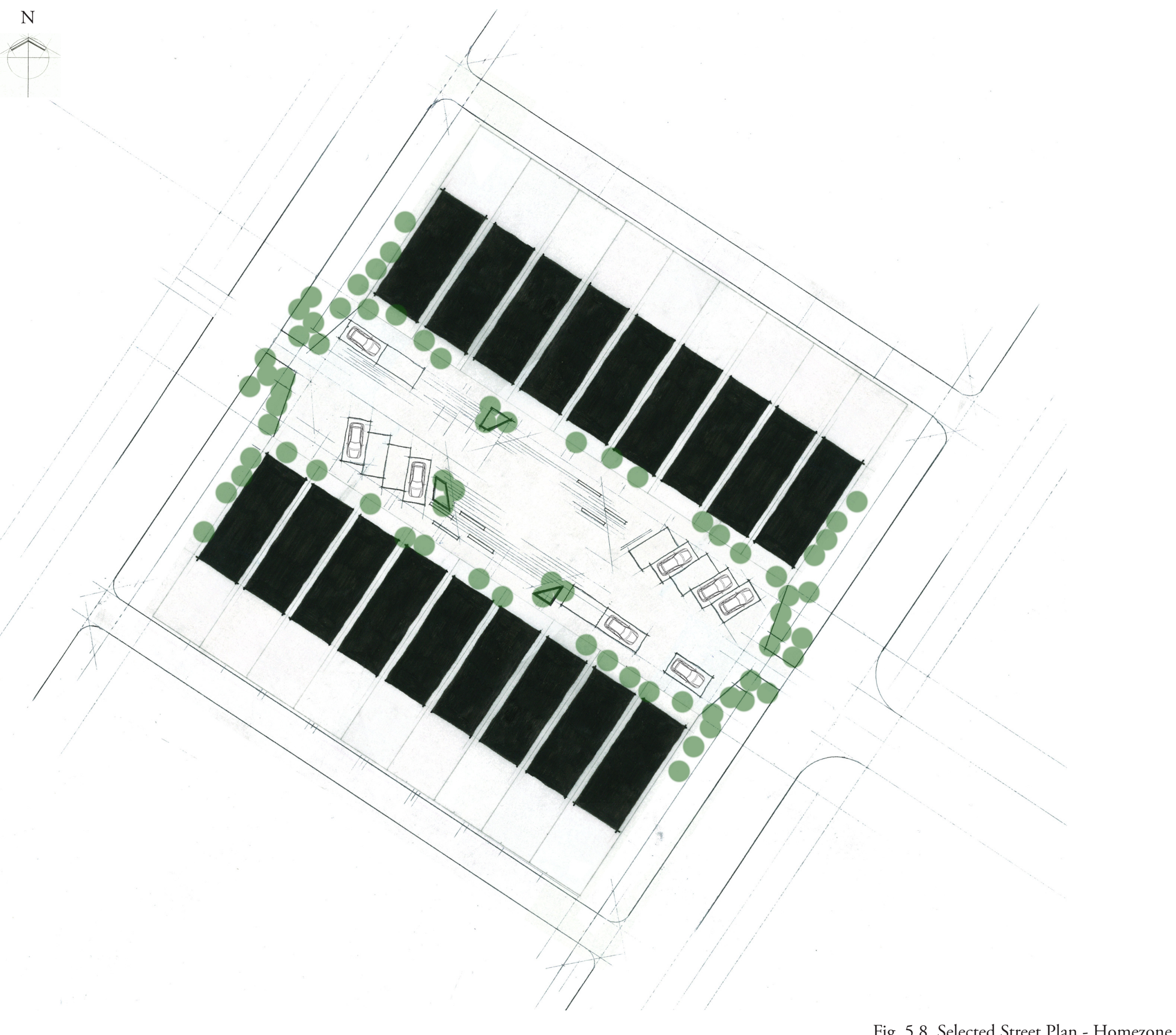




\subsection{Design Strategies}

The following tables introduce the complete series of design strategies gathered from all of the preceeding chapters. The strategies are organised according to how they affect or perform the interface between the public and private realms; they are either Planning strategies, Building Mass and Form strategies, or Threshold and Permeability strategies. In the following tables each strategy is designated a number, identified in a title, presented in a diagram, described briefly, and lastly, located in the prior research. 


\begin{tabular}{|c|c|c|c|c|}
\hline 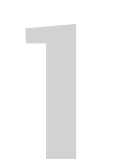 & Forward Street Edge: & & $\begin{array}{l}\text { This strategy ensures that there is a definitive relationship between the dwelling and } \\
\text { the street. The building mass is pushed right to the edge of the allotment, bordering } \\
\text { the public street. }\end{array}$ & 3.3.1: Newtown: 19th Century \\
\hline & Detached Street Edge & & $\begin{array}{l}\text { This strategy pulls the building back from the public street edge to create space for a } \\
\text { landscaped buffer zone softening the edge between the street and the house volume }\end{array}$ & 4.3.3: Bernal Heights Residence \\
\hline & Rear Lane-Car Access & & $\begin{array}{l}\text { A private vehicle storage unit is accessed from the rear lane removing the problematic } \\
\text { garage door from the street facade of the building mass. The unit can be either } \\
\text { detached or included within the house volume. }\end{array}$ & 4.2.3: Addison Housing Project \\
\hline & $\begin{array}{l}\text { Flexible Car Space } \\
\text { - Street Access: }\end{array}$ & & $\begin{array}{l}\text { Vehicular storage is accessed from the public street and must be incorporated in the } \\
\text { main dwelling volume. In this situation the car storage area is to be activated by } \\
\text { utilising it as a semi-private flexible-use area. }\end{array}$ & 3.3.5: Otaihanga: Recent Development \\
\hline$\infty$ & Functional Layout & & $\begin{array}{l}\text { This strategy facilitates the application of an ideal configuration of function spaces } \\
\text { elaborated in Chapter Four. The social and formal areas within the dwelling are } \\
\text { recognised as the most public functions of the household and are oriented towards the } \\
\text { street. The increasingly private functions are located deeper into the dwelling volume, } \\
\text { away from the street. This poses a dilemma when 'social' spaces become increasingly } \\
\text { informal and private. The value of these spaces need to be carefully considered in the } \\
\text { layout and orientation of functions in association to outdoor space }\end{array}$ & 3.3.1: Newtown: 19th Century \\
\hline
\end{tabular}




\begin{tabular}{|c|c|c|c|c|}
\hline 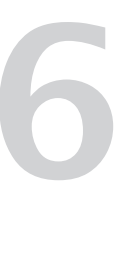 & Circulation Core: & tis & $\begin{array}{l}\text { A circulation core distributes horizontally to surrounding functions radiating away } \\
\text { from itself. In doing this, a core establishes an inhabitable intermediary transition } \\
\text { zone The transient occupation of circulation spaces ensures that a core is a suitable } \\
\text { buffer between different zones that may need to be mutually accessible such as an } \\
\text { office or work space and a bedroom or bathroom. }\end{array}$ & 4.3.5: Madrona Residence \\
\hline & Circulation Axis: & $2 e^{2}$ & $\begin{array}{l}\text { By establishing a circulation corridor, the various functions of a house can be } \\
\text { organised and distributed in a linear fashion within a dwelling volume. This suggests } \\
\text { that the function spaces of the house can become progressively more private and } \\
\text { isolated the deeper into the site they are situated but remain fundamentally connected } \\
\text { along a common access route. }\end{array}$ & 3.3.1: Newtown: 19th Century \\
\hline & $\begin{array}{l}\text { Vertical Circulation } \\
\text { Perpendicular to the } \\
\text { Street: }\end{array}$ & 2 & $\begin{array}{l}\text { The stair acts as a visual filter in this strategy. The stair can effectively terminate or } \\
\text { screen vistas following the perpendicular circulation axis from the street helping } \\
\text { to create a visual threshold transitioning from a public or social area to a more } \\
\text { private space beyond. The transient occupation of the stairs emphasises the vertical } \\
\text { circulation as an object drawing attention to itself rather than beyond. }\end{array}$ & 4.3.8: Slip House \\
\hline
\end{tabular}




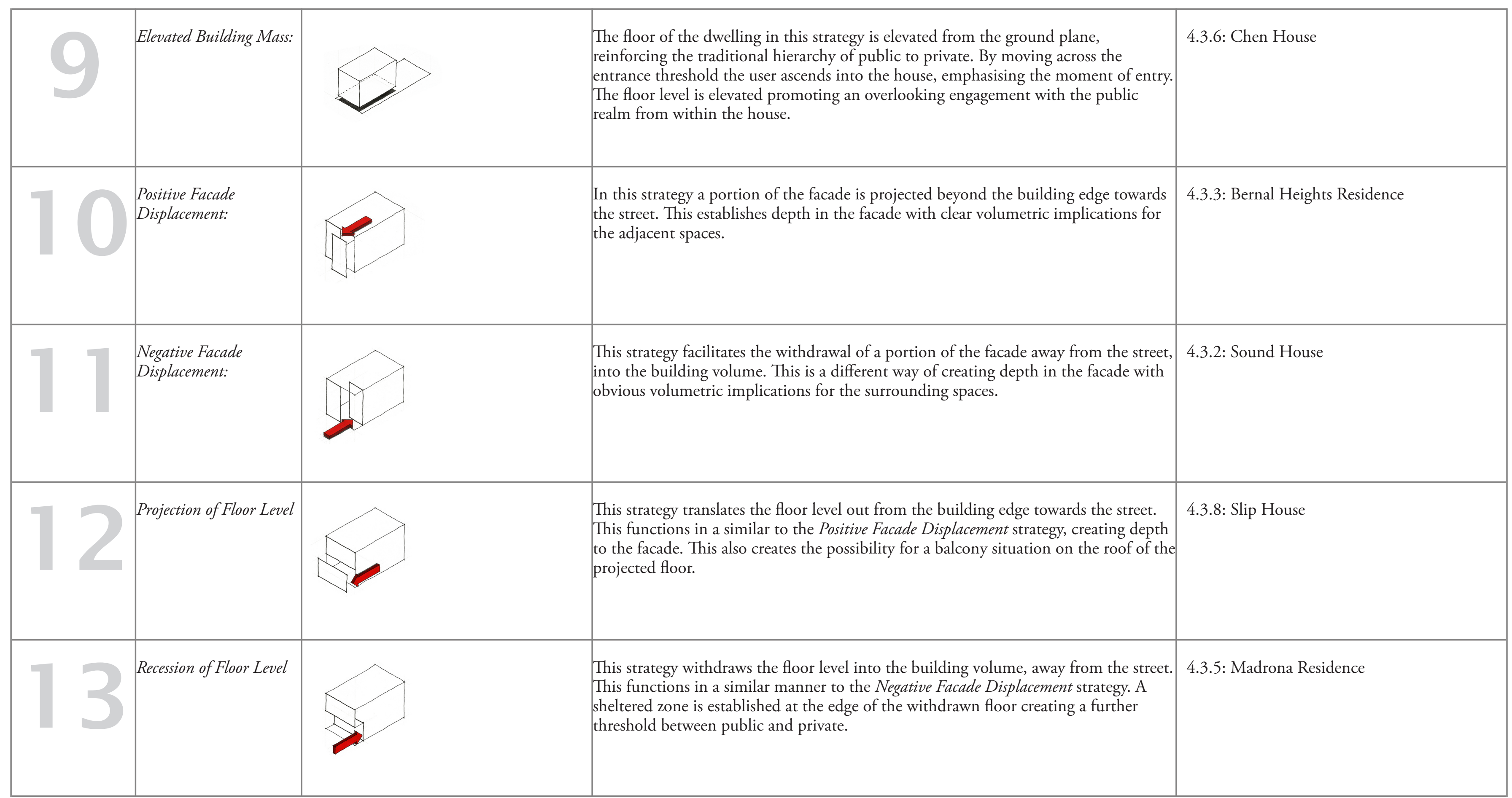




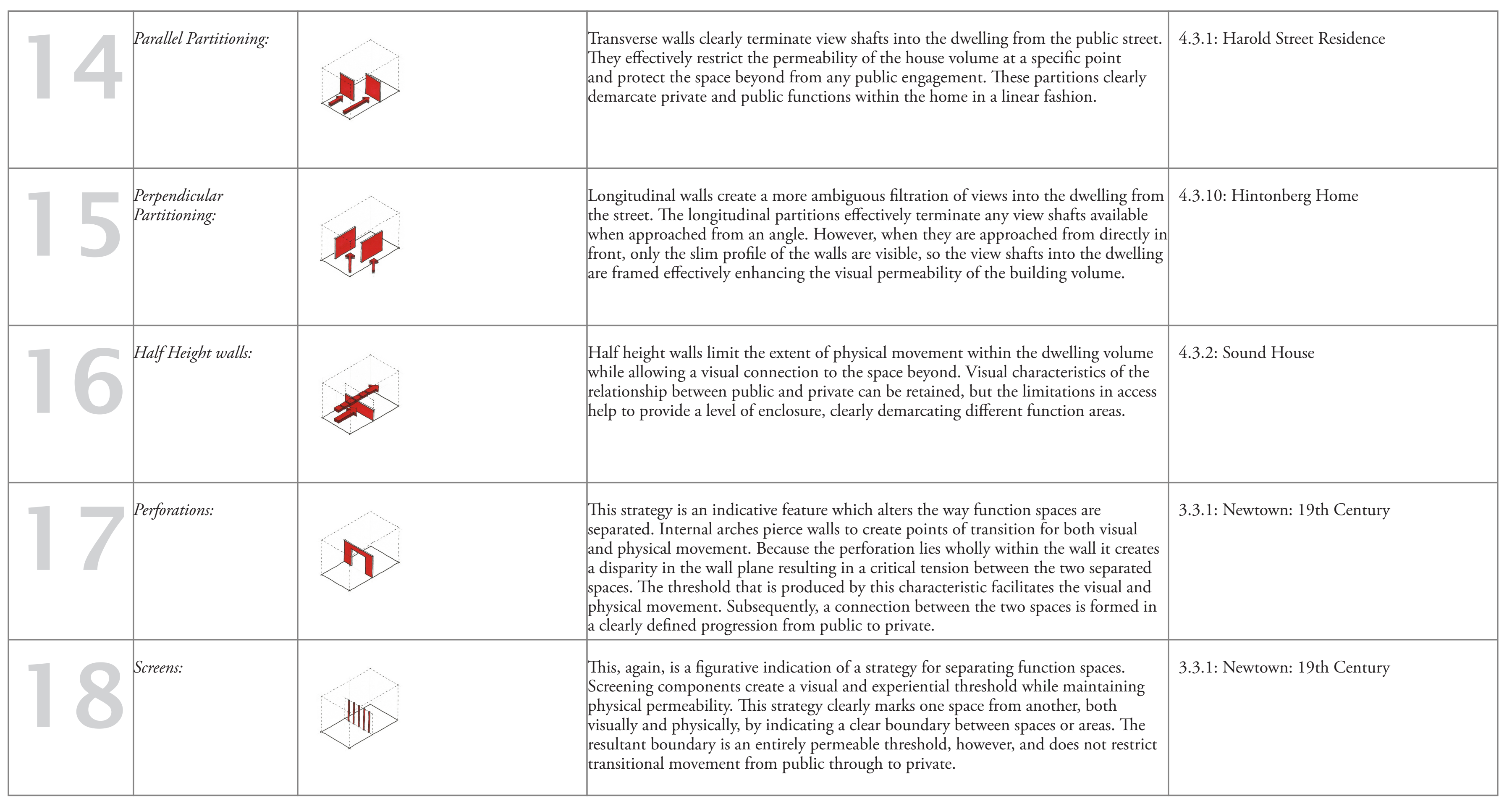




\begin{tabular}{|c|c|c|c|}
\hline & Edge Window: & $\begin{array}{l}\text { When an opening is introduced to a space, the form of the space begins to be } \\
\text { eroded as it loses its definition. This strategy features an opening that occupies the } \\
\text { vertical edge of the facade. The surrounding enclosing elements are now separated } \\
\text { into different and opposing wall planes and are seen less as enclosing elements. This } \\
\text { characteristic introduces a limited sense of exposure from within the dwelling volume } \\
\text { which is useful in facilitating an engagement between public and private realms. }\end{array}$ & 4.3.1: Harold Street Residence \\
\hline & Glazed Wall: & $\begin{array}{l}\text { The opening in this situation is extended to occupy an entire wall of the enclosure. } \\
\text { As a result, an entire architectural component which helps generate a sense of private } \\
\text { enclosure is replaced. This serves to heighten the alternative sense of exposure, } \\
\text { introducing a greater visual interaction with the public realm. }\end{array}$ & 4.3.5: Madrona Residence \\
\hline - & Cut-out Window: & $\begin{array}{l}\text { The opening in this strategy lies within the wall plane. As a result, the integrity of } \\
\text { the edges and corners are retained. While the effect of eroding the sense of enclosure } \\
\text { is minimal, the opening serves to orientate the space and generate a sense of visual } \\
\text { movement connecting the enclosed space with the public street environment beyond. } \\
\text { An access channel pierces the boundary component providing a visual threshold } \\
\text { which introduces a dynamic gesture towards the street. }\end{array}$ & 4.3.4: Slot House \\
\hline & Screened Window: & $\begin{array}{l}\text { In this strategy the effect of the opening is subsequently mitigated by a mesh or } \\
\text { screening device. By screening the opening any visual movement from the street } \\
\text { through the established threshold to the private interior is restricted. }\end{array}$ & 4.3.5: Madrona Residence \\
\hline$=$ & $\begin{array}{l}\text { Visual Movement } \\
\text { - Framed Opening: }\end{array}$ & $\begin{array}{l}\text { The edges of this access channel in the partition are thickened to emphasise its } \\
\text { positive role as an opening. By strengthening and articulating an opening's presence } \\
\text { in the street facing facade, attention will be drawn to the role it plays in creating a } \\
\text { threshold that facilitates visual movement into the interior of the dwelling. }\end{array}$ & 3.3.1: \\
\hline
\end{tabular}




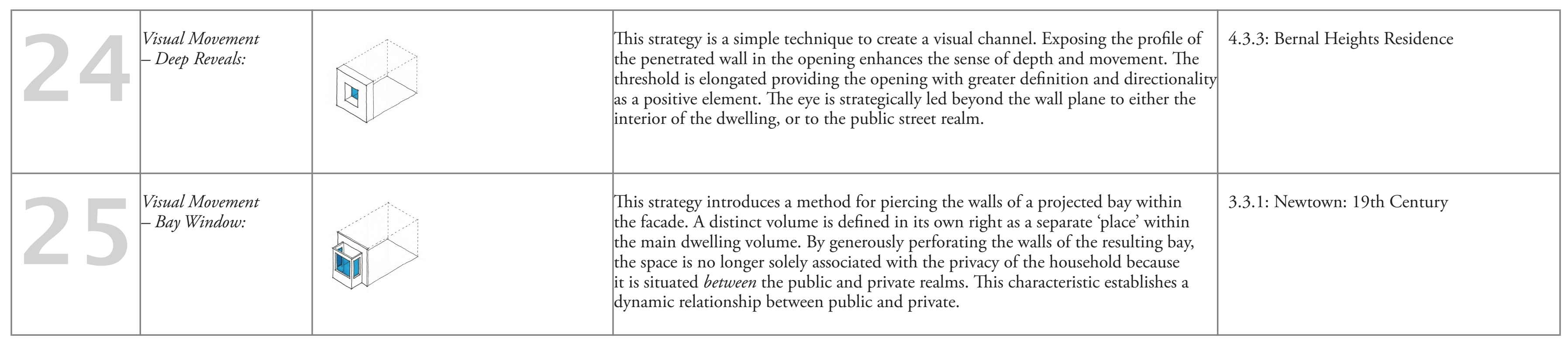




\subsection{Conclusion}

The intention of this stage of the design was to investigate and ammend a contemporary suburban development. This process was undertaken in order to produce a suitable design vehicle for investigating the establishment and management of a public-private gradient.

To achieve this, an existing medium-density development proposal for a vacant greenfield area to the north of Waikanae on the Kapiti coast was selected as the site. This particular proposal offered study conditions which were consistent with the historical analyses completed in Chapter Three making it an ideal setting for further development. Subsequent analysis of the proposal highlighted the following key areas for improvement:

- The master-plan's mixed-use centre was poorly located to assist any form ofintegration with the surrounding suburban development reducing the plan's effectiveness and efficiency,

- A low density buffer zone at the perimeter of the site also impacts the potential connection to the existing suburban fabric from within the master-plan,

- Specific streets and the characteristics of those streets disrupt the cohesion of the master-plan. The large middle residential portion of the plan is effectively isolated by the perimeter road while a significant thoroughfare opportunity is compromised. curvilinear perimeter road disrupts the connectivity of the plan,

- The curved street pattern reduces the number of axial vistas and view shafts which are helpful wayfinding devices, way-finding and legibility characteristics of axial vistas and view shafts.

- There is a lack of definition between precincts in the master-plan eliminating the benefits of the perception of 'place.'

The key policies for the improvement of the Landlink master-plan were:

- Employ stronger grid formations which are connected by a reformed central activity spine,

- Produce shorter blocks to increase visual and physical permeability,

- $\quad$ Relocate the mixed-use core to the south-western perimeter of the site to facilitate increased integration with surrounding suburbs,

- Form a recreation precinct along the northern edge recognizing and instituting the council prescribed 'Urban Edge,'

- $\quad$ Emphasise home-zone design principles to challenge preexisting street usage priorities and reclaim the street as 'public realm,'

- Further utilize narrow house forms and land parcels to increase the overall dwelling density of the
- Increase the building variety to include mixed-use retail lower level/residential upper levels, walkup apartment complexes, terraced houses, semi-detached houses and detached houses,

- Introduce rear lanes to facilitate private car access for the residents and reducing the impact of the car on the street,

The amendments to the master-plan was then incorporate and emphasise these strategies and, subsequently, generate the design vehicle required for the design case study in Chapter Six.

The final section of this chapter introduced the range of strategies available from the prior research for implementation and testing in the design case study. The strategies are differentiated by the way they affect the transition between public and private at an architectural scale; they are organised into three categories: planning strategies, form and mass strategies, and finally, threshold and permeability strategies. Many of the strategies are interdependant, these relationships are explored in the design case study phase of this research. 


\section{Chapter Six: Design Case Study}

6.1. Introduction

6.2. Site Selection

6.3. Design Brief and Programme

6.4. Conceptual Design

6.5. Description of Design

6.6. Critical Reflection on Research Outcomes 


\subsection{Introduction}

The core subject of investigation in this thesis is the establishment of a public-private gradient in suburban residential development. This chapter presents a design case study featuring three dwellings on identical allotments. These houses demonstrate three different approaches, all of which aim to establish successfully mediated public-private gradients. By implementing the design strategies from the earlier chapters in the case study dwellings, they are be tested and developed. The purpose of this design case study, therefore, is to produce a series design strategies that facilitate the establishment and mediation of a successful publicprivate gradient.

Sections 6.2 and 6.3 introduce the sites and site configurations for the dwellings, the subsequent design brief and the required programme. Section 6.4 develops an overarching design concept which generates the formal properties for the three case study dwellings. Section 6.5 portrays the outcomes of the design case studies, demonstrating the application of a selection of design strategies to the three dwellings. Floor plans, isometric gradient images, sections and perspective drawings graphically show the how the strategies are applied. Finally, section 6.6 reflects on the design case study, evaluating each strategy, any connections or implied combinations between the strategies and the effect of the overarching design concept on the application of the strategies.

\subsection{Site Selection}

This part of Chapter Six prescribes the chosen site within the suburban development proposal to facilitate the application of the design strategies to domestic house forms. A mid-block allotment is the chosen site for the subsequent design investigation. Three designs for the same site are differentiated in terms of their site configuration. The location and orientation of the private open space in relation to the street occurs in one of three ways: as a 'Back-yard', as a 'Court-yard' or as a 'Front-yard.' These configurations are employed primarily as design variants intended to test the design strategies in a wider range of situations. However, while the strategies are sufficiently numerous and robust to produce a gradient in the three situations, the three site options each present entirely different street interface conditions. Because of this factor, some site configurations are more conducive to the application of the design strategies than others. The different street interface conditions offered by the site options are discussed alongside the application of the design strategies later in this chapter.

The chosen allotments are identical in size and proportion; measuring 25 metres by 7 metres, presenting their narrow frontages to a home-zone street environment. The connection to the home-zone ensures the provision of a high quality suburban public realm to each household. The rear-lane provides a vehicular access option to each of the sites.

\subsection{Design Brief and Programme}

The three case study dwellings each require the following functions:

- Kitchen with an adjoined pantry: $9 \mathrm{~m}^{2}$ (all areas are approximate values)

- Formal dining area: $8 \mathrm{~m}^{2}$

- Formal social living space: $14 \mathrm{~m}^{2}$

- Informal family living space: $12 \mathrm{~m}^{2}$

- Connection with Private open space

- Three private bedrooms including a master bedroom with an en-suite: $12 \mathrm{~m}^{2}$ minimum

- A private, shared bathroom and toilet for household use only: $6 \mathrm{~m}^{2}$ minimum

- Sufficient storage in bedrooms and circulation spaces

- Secure vehicle storage for one vehicle: $15 \mathrm{~m}^{2}$

- A shared toilet and basin: minimum area possible

- And, laundry facilities minimum area possible

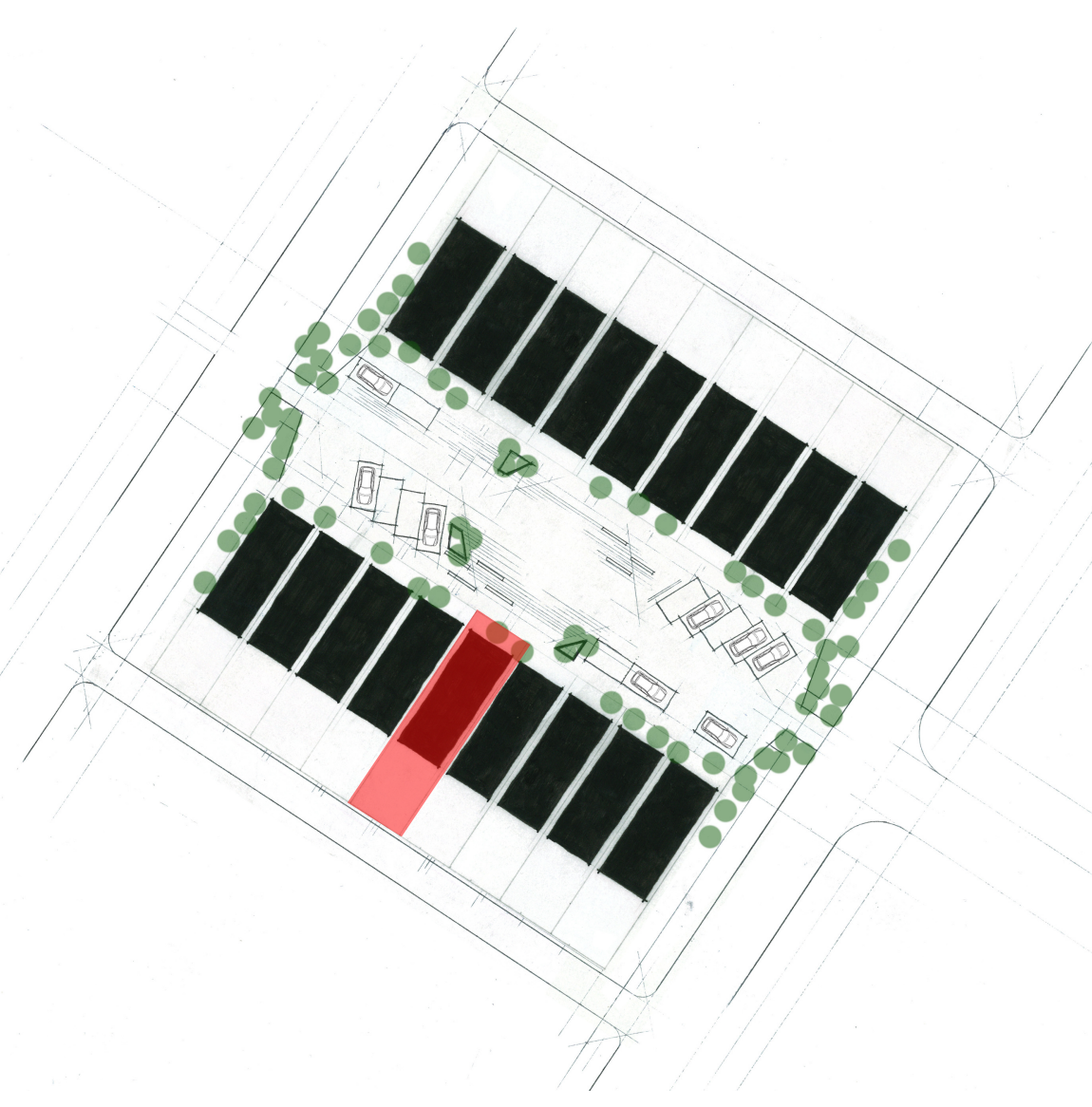




\subsection{Conceptual Design}

This section describes the conceptual formal design and development for the three dwellings. The intention is firstly to develop a concept for the architectural form, and secondly, to translate the concept into a building volume. The same formal concept for each of the three separate dwellings is adopted. Having the same concept will allow the application of the design strategies to the different houses to remain the focus of the investigation.

\section{The Design Concept}

The intention of this section is to produce a formal concept which is suitably flexible and neutral enough that it does not affect the application and testing of the design strategies.
Conceptual sketch.
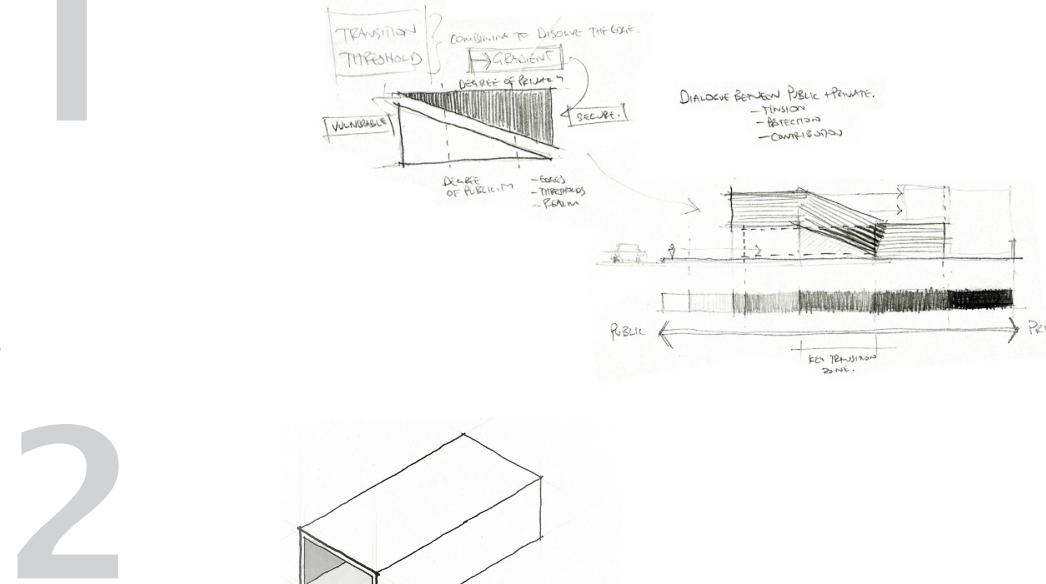

Open-ended rectangular tube. Folded or cranked tube.

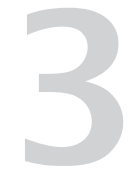

Redundant surfaces cut away.<smiles>CC12CC3C4CC5C1C4C35C2</smiles>
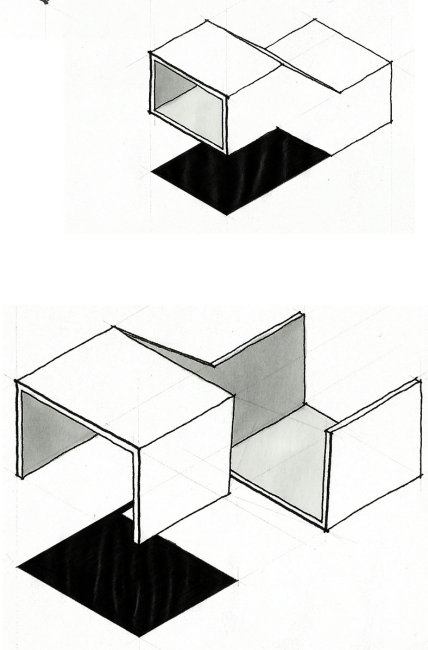

Rectangular prism insert.

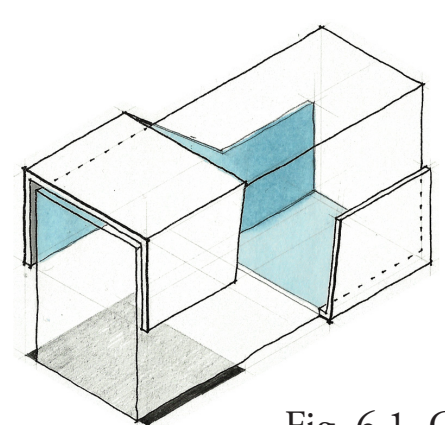

Fig. 6.1. Conceptual Formal Development process 
The result of this progression is an architectural form to which can accommodate multiple design strategies in a variety combinations and sequences to create successful public-private gradients between the street and the domestic interior. The following part of the chapter demonstrates the testing and application of the architectural form to the three different case study dwellings.

\subsection{Description of Design}

Three versions of the design are developed in greater detail as different case study dwellings. The design strategies are be explored categorically as the case studies unfold. Each case study proceeds as follows:

- A general description of the functional layout and spatial organisation accompanies each floor plan to demonstrate the application of planning and organisational design strategies.

- Isometric gradient images demonstrate the application of building mass and formal strategies, and also threshold and permeability strategies on each floor.

- Section, elevation and isometric images then summarise the implemented design strategies as they appear in a cohesive dwelling unit.

- Perspective images will finally exhibit the successful establishment of the public-private gradient as it is experienced through each dwelling. 


\subsubsection{Case Study One: Back-Yard House}

1 Entrance Alcove

2 Formal Sitting Room

3 Dining Area

4 Kitchen and Pantry

5 Informal Family Room

6 Toilet

7 Laundry

8 Car Port

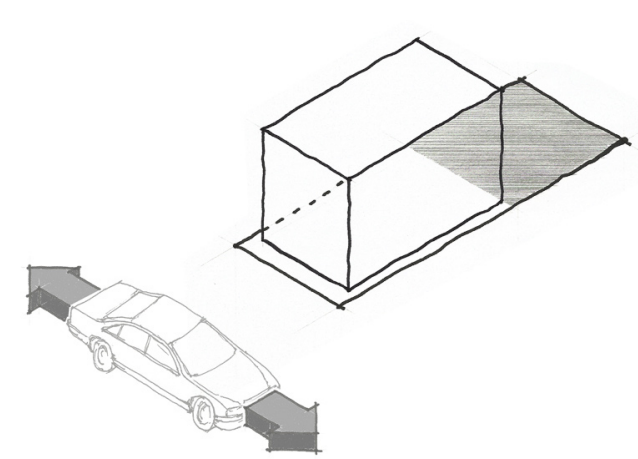

Ground Floor:

The building mass is pushed forward on the site to encourage an immediate interaction with the public realm of the street. The floor level slips back from the street edge creating a small front-yard to mediate the relationship between the street and the formal interior. The front-yard area is partially enclosed by a front fence to protect the integrity of the domestic area behind it. The angled part of this facade augments this characteristic, delineating the primary visual threshold and accentuating the withdrawal beneath the higher floors to the entrance alcove.

The ground floor includes all of the social functions of the home in a linear arrangement. A formal living area is located closest to the street and is restricted spatially by the adjacent the entrance alcove which controls the primary entrance threshold. Conversely, the most private functions on this floor including a shared toilet and laundry facilities, are positioned at the rear of the plan, protected from the street environment.

A circulation core, countering the direction of the alcove, restrains the transition from the entrance to the informal, family living area located at the rear of the house.

The informal living area is connected to the back-yard private open space. The kitchen is located in the mid section of the floor connected to both the informal and formal zones. A formal dining area functionally separates the kitchen activities from the formal living suite. 
Spatial Planning Strategies

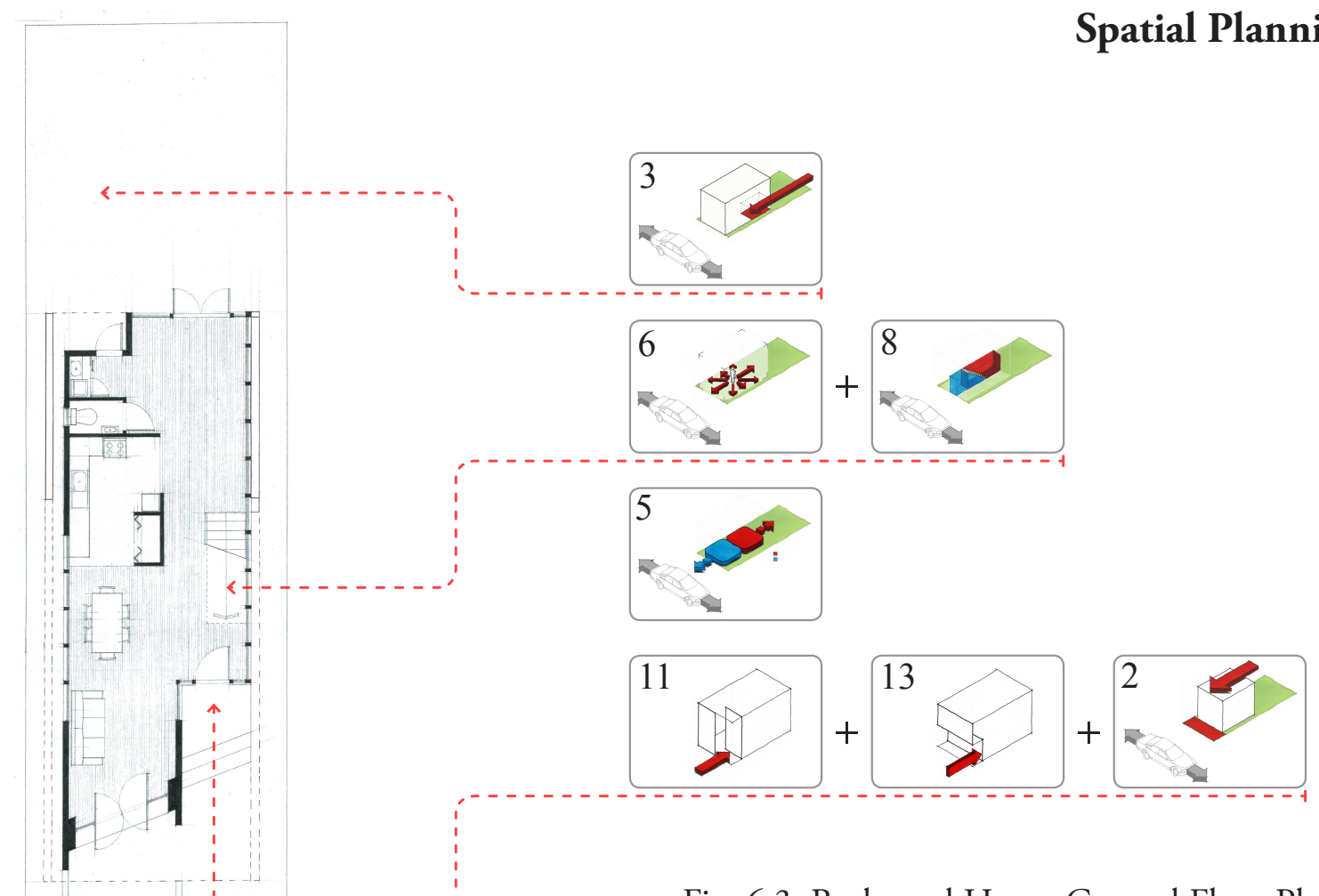

Fig. 6.3. Back-yard House Ground Floor Planning Strategies

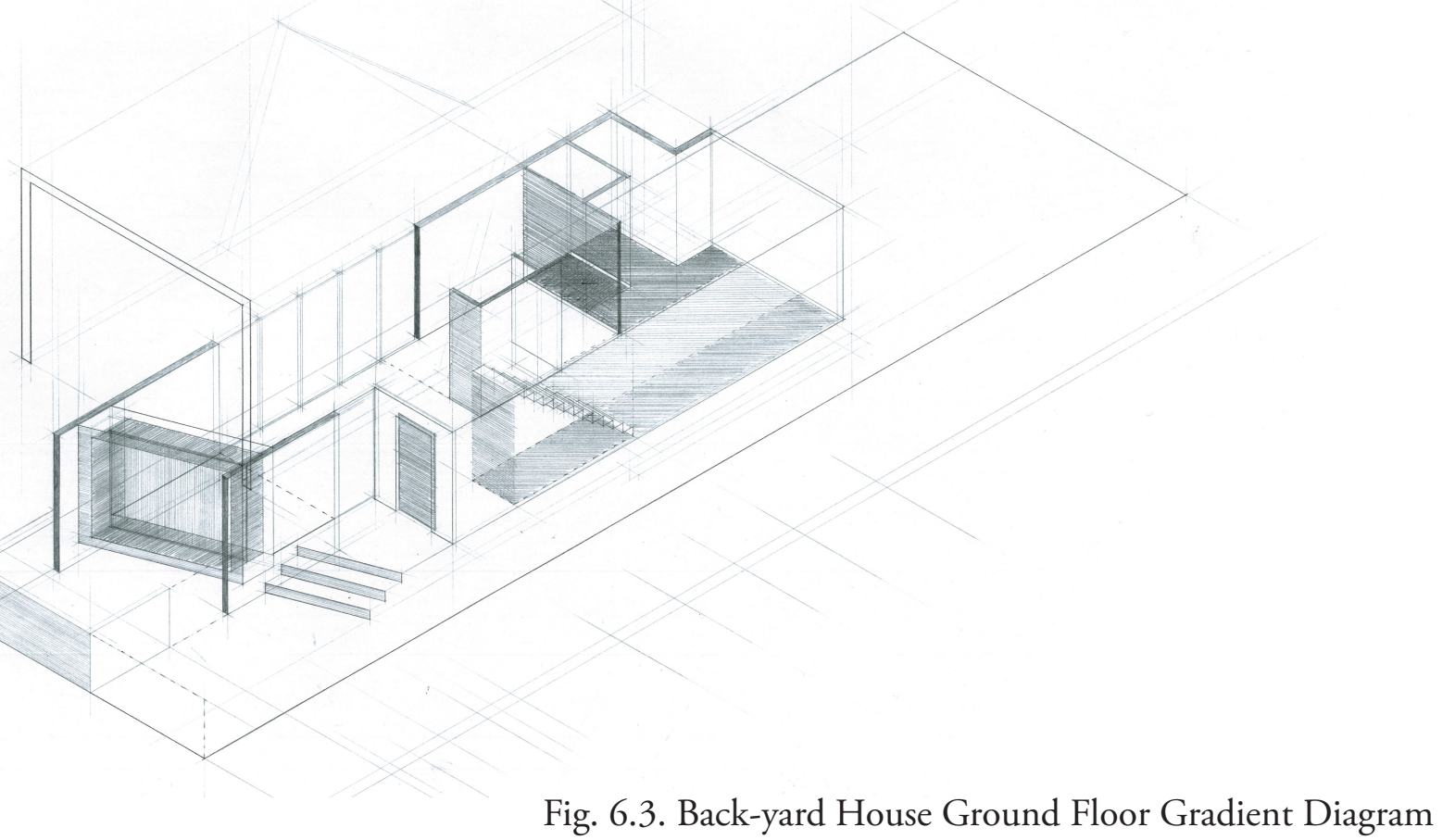

Threshold Strategies

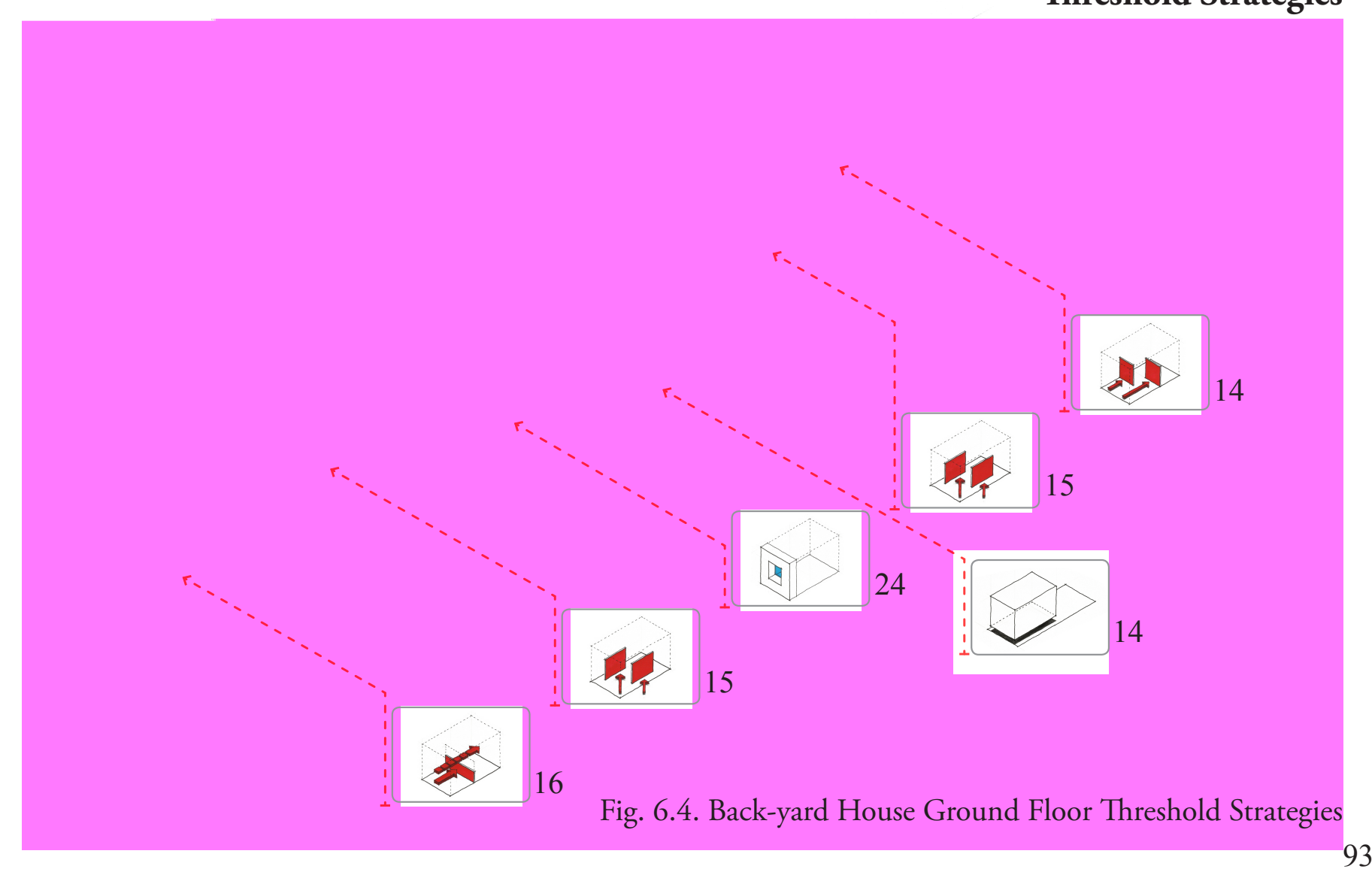




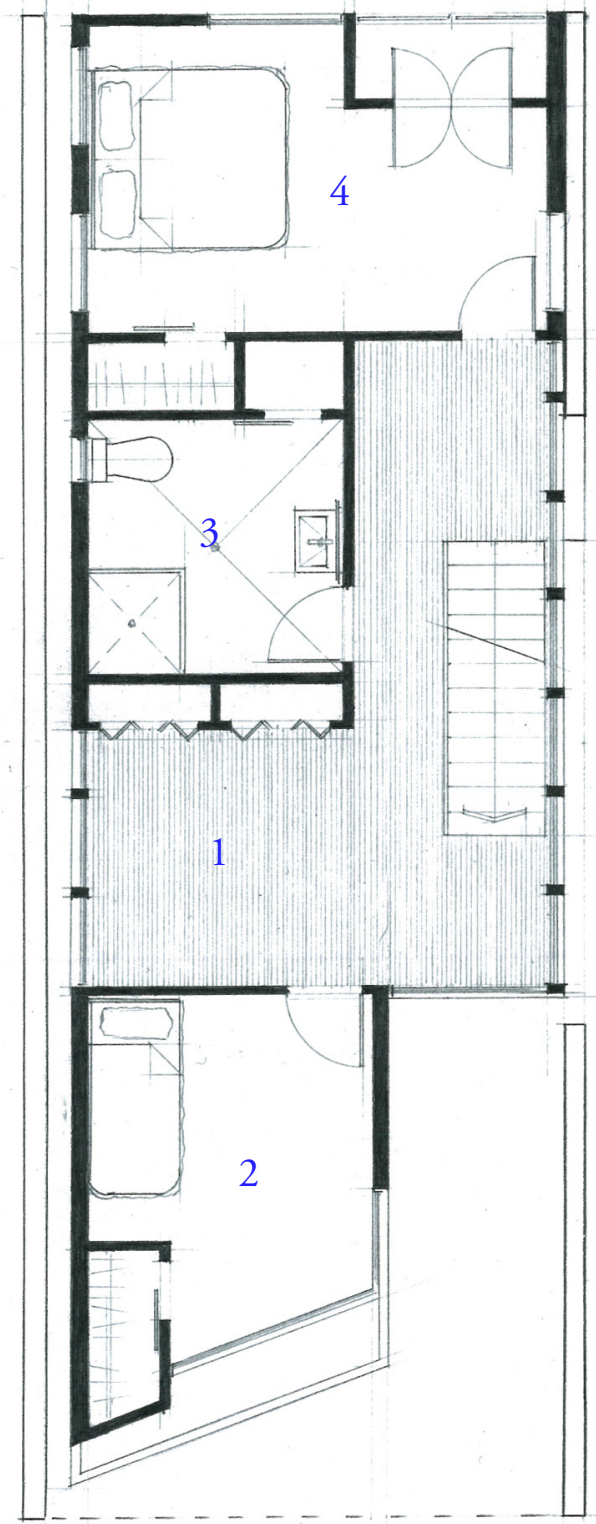

First Floor:

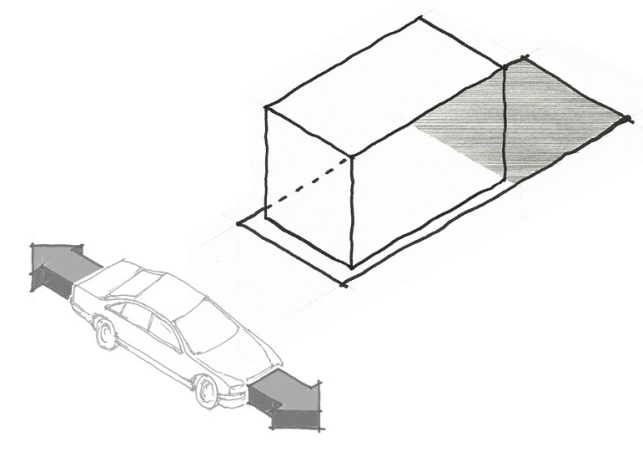

This floor consists of two bedrooms, a private bathroom and a flexible office area. The bathroom is located in the mid-section of the plan, above the kitchen, forming an efficient 'services stack.' The primary bedroom is positioned above the formal living area, sharing its contours. As a private space the bedroom, requires a more articulated mediation than the formal area below. The second bedroom occupies the full width of the building at the rear of the plan retaining strong visual links to the back yard.

The circulation configuration is retained from the ground floor but is altered to operate strictly as a core with the other functions radiating away from it.
1 Flexible Work Space

2 Bedroom 1

3 Bathroom

4 Bedroom 2 


\section{Spatial Planning Strategies}

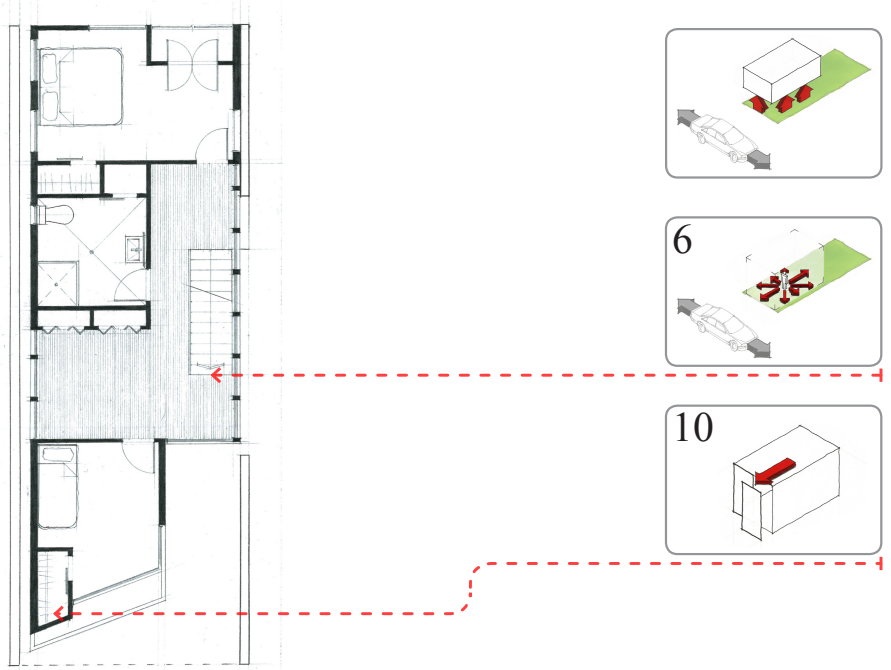

Fig. 6.6. Back-yard House First Floor Planning Strategies

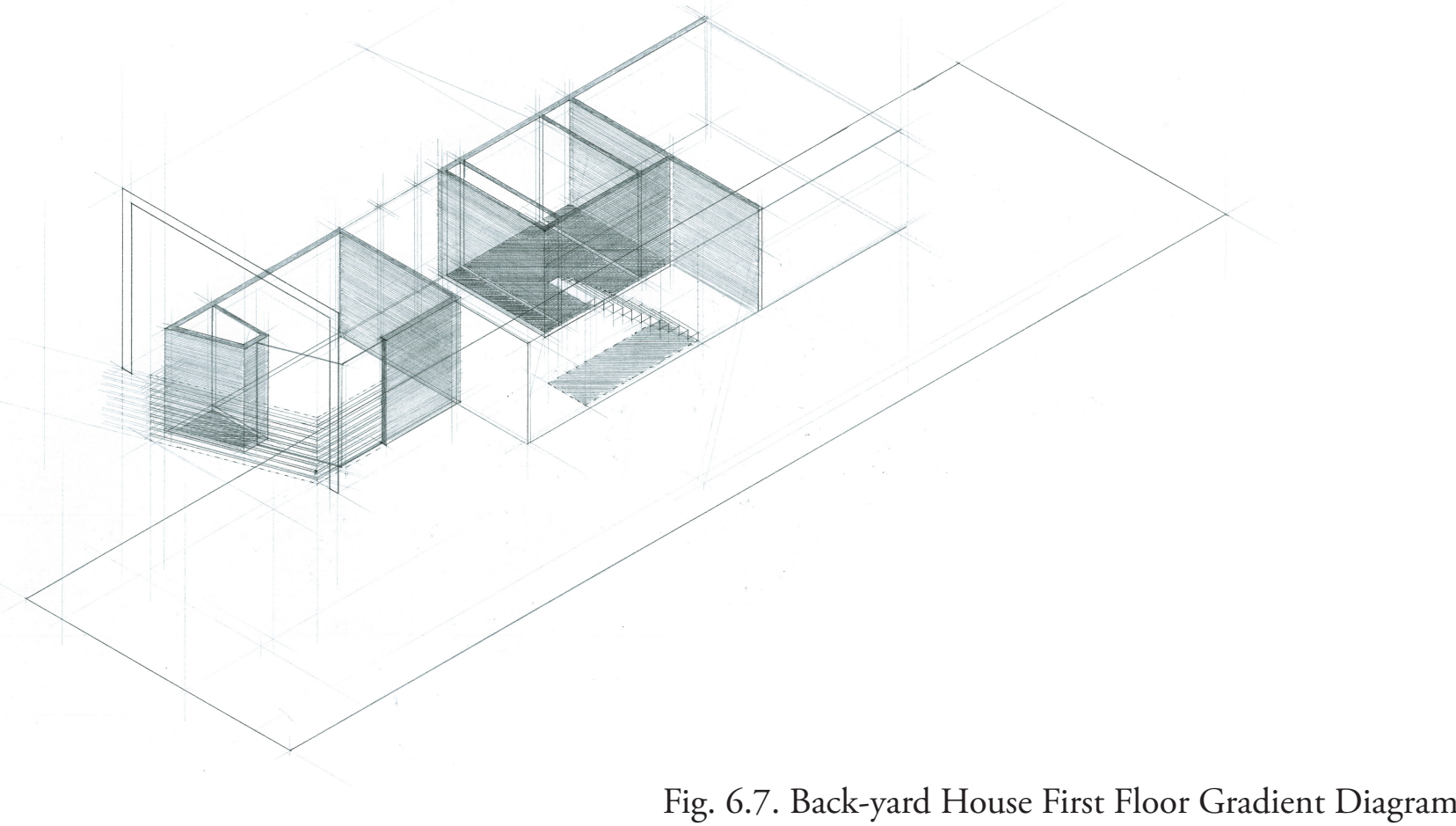

Threshold Strategies

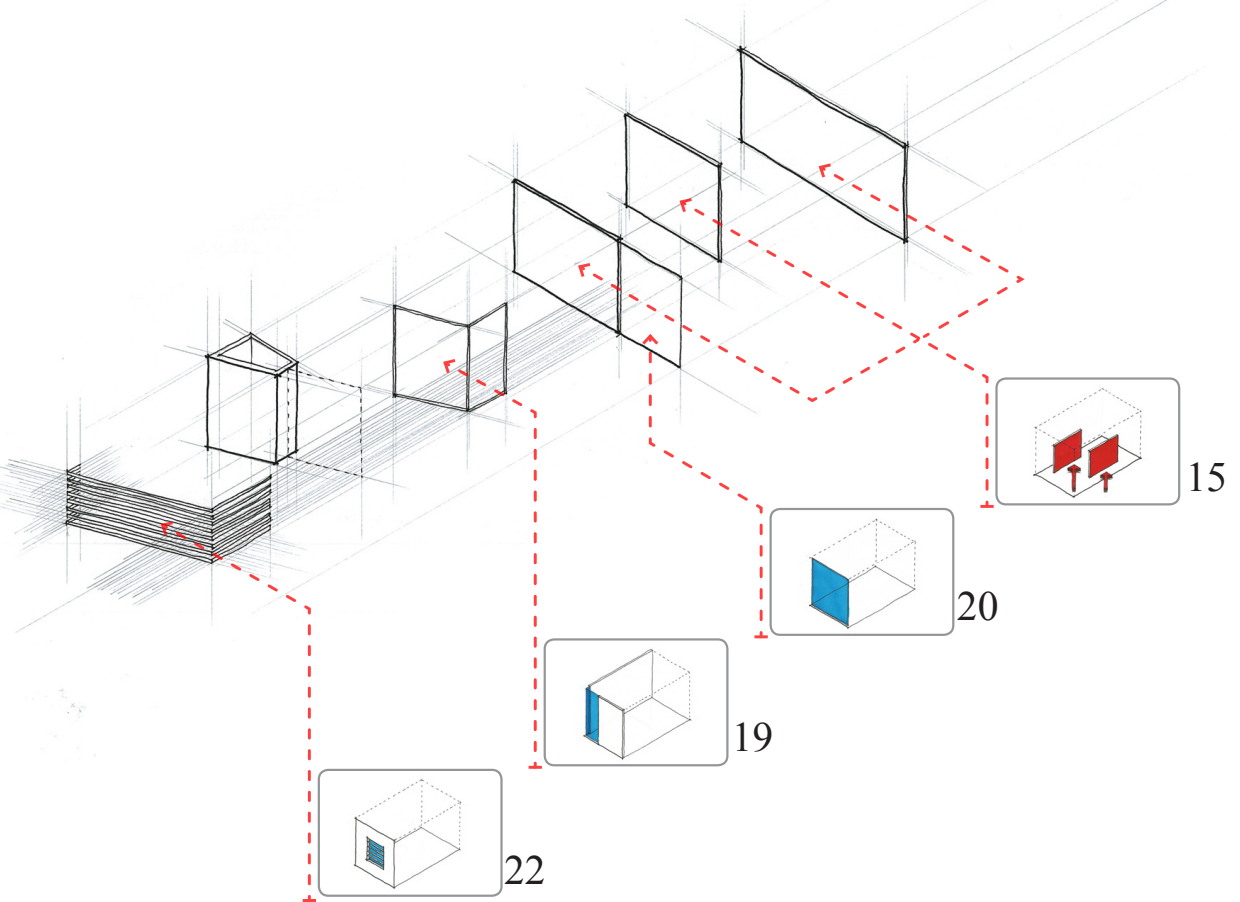

Fig. 6.8. Back-yard House First Floor Threshold Strategie 


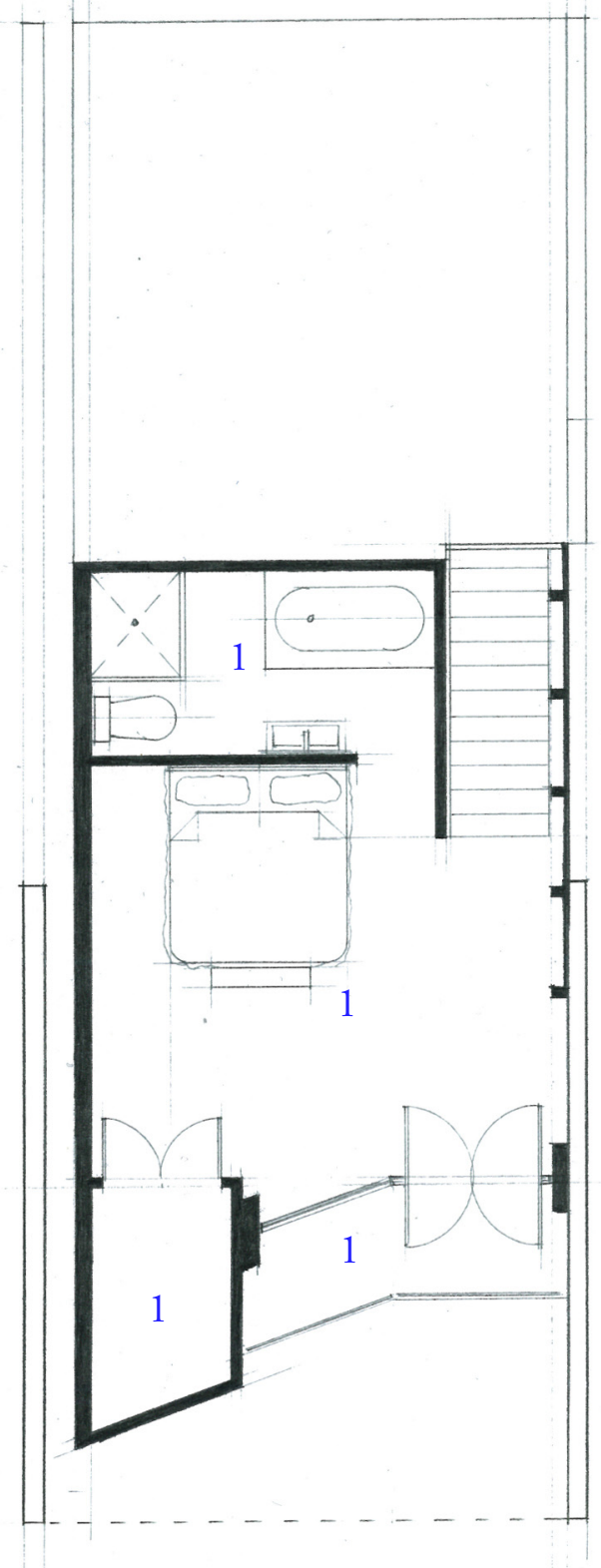

\section{Second Floor:}

The top floor contains the master bedroom and an adjoining en-suite. This room also occupies the full width of the building and is positioned at the front, overlooking the street. This strong address to the street is important to the establishent of the gradient.

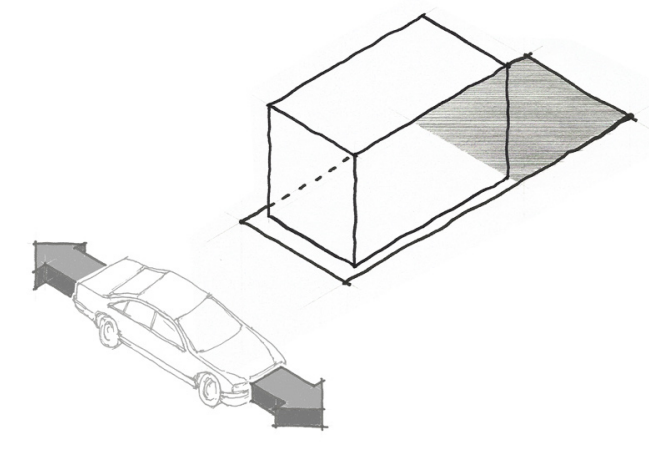

Master Bedroom

2 Balcony

3 Ensuite

4 Wardrobe 
Spatial Planning Strategies

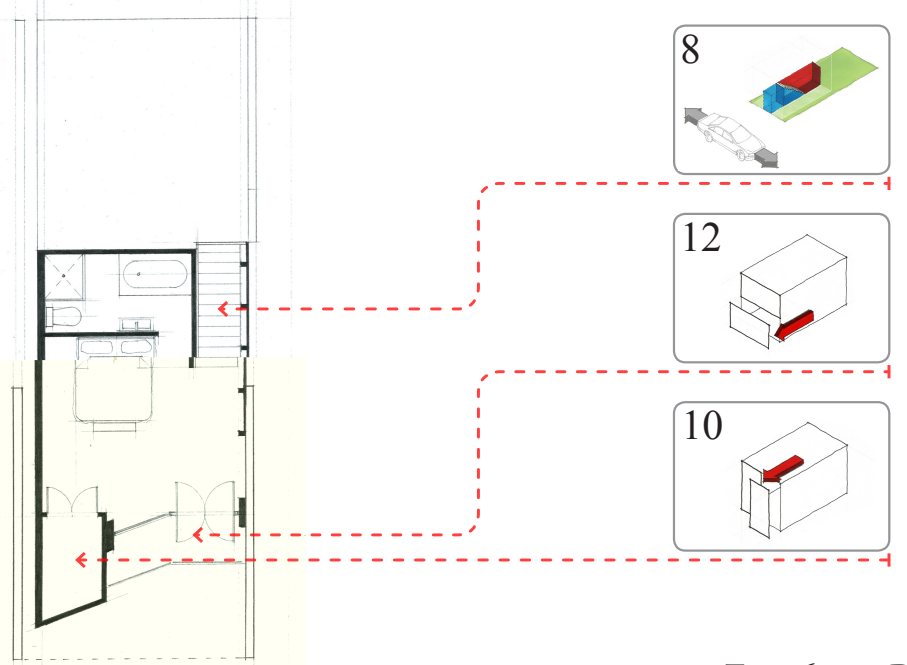

Fig. 6.10. Back-yard House Second Floor Planning Strategies

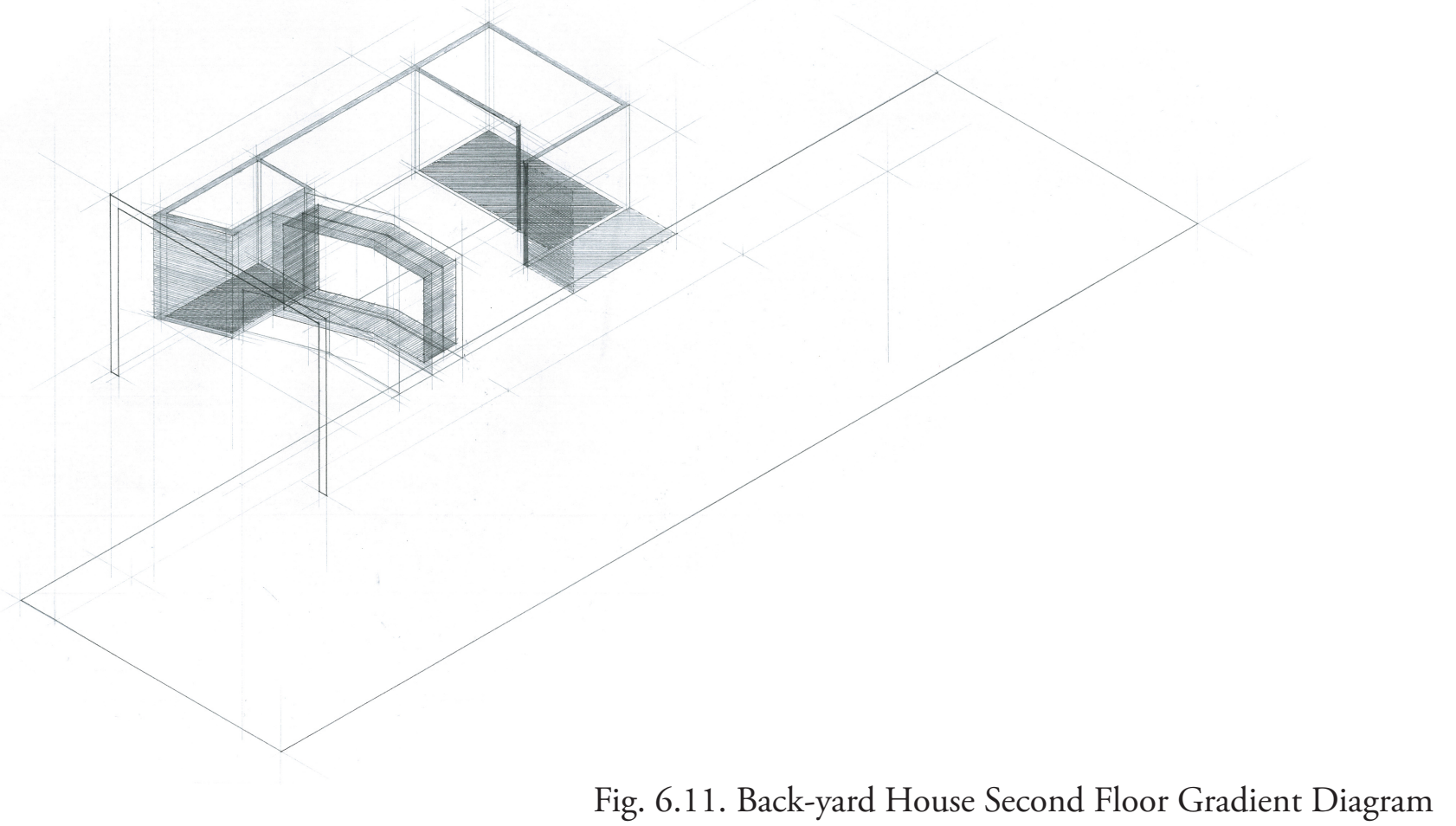

Threshold Strategies

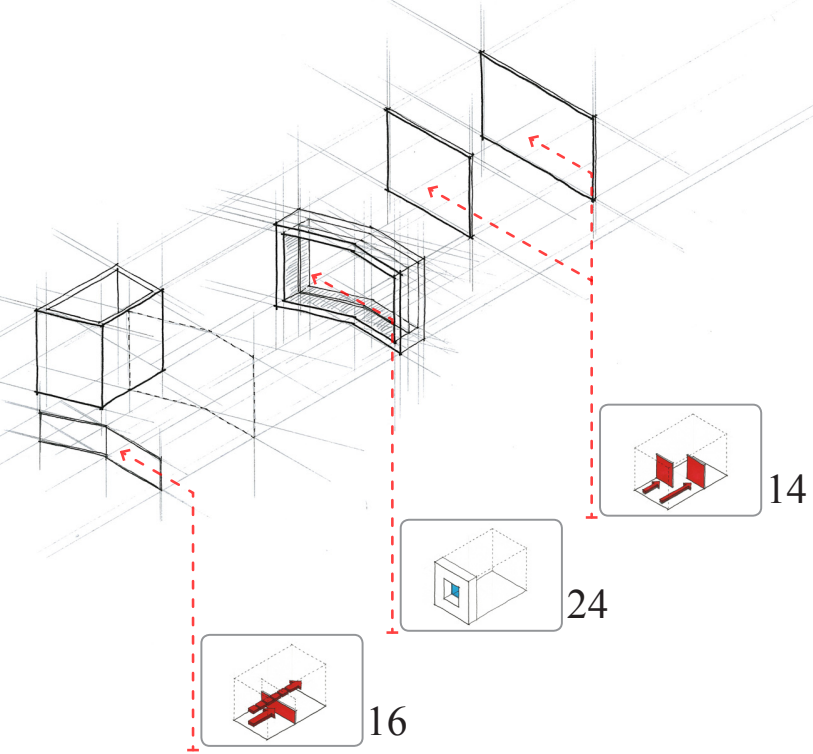

Fig. 6.12. Back-yard House Second Floor Threshold Strategies 


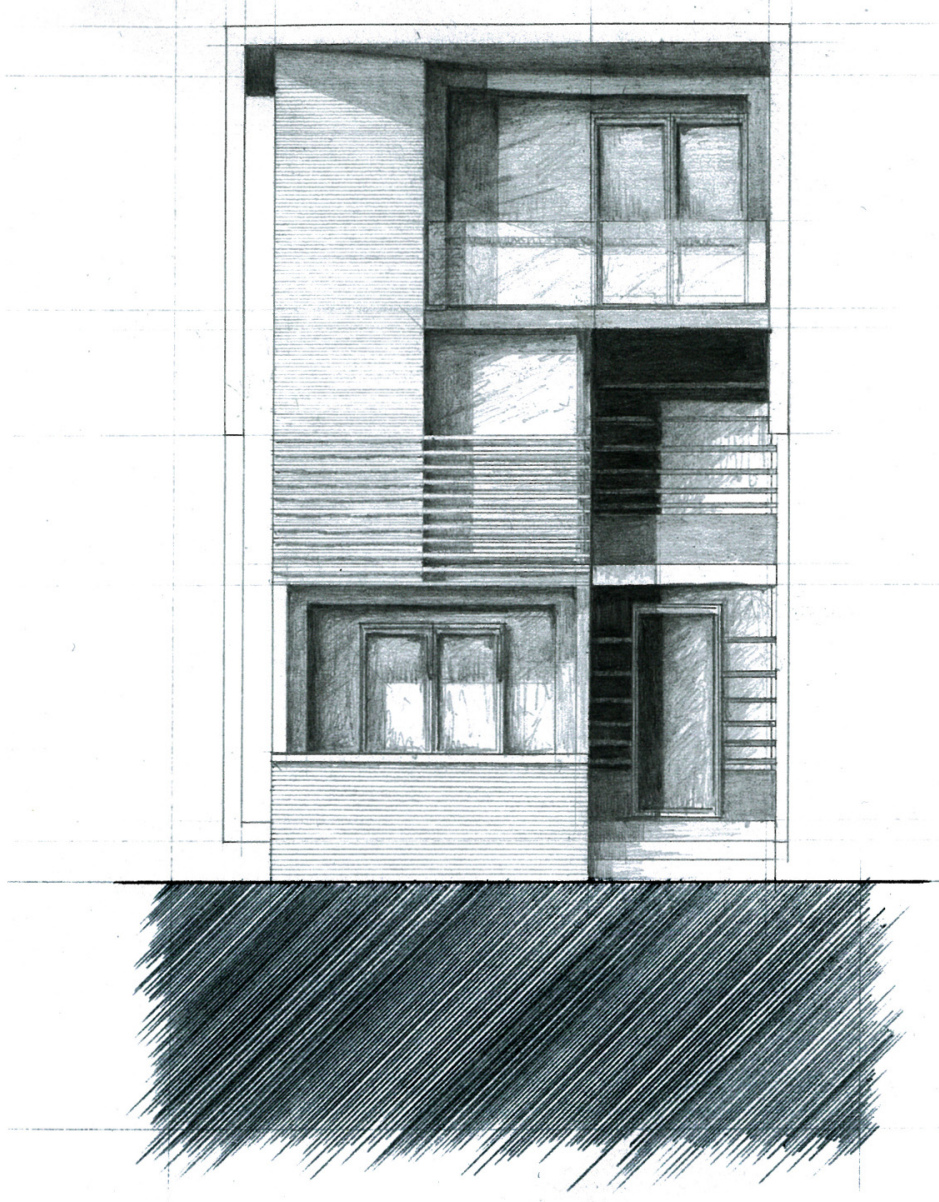

Fig. 6.13. Back-yard House Street Elevation

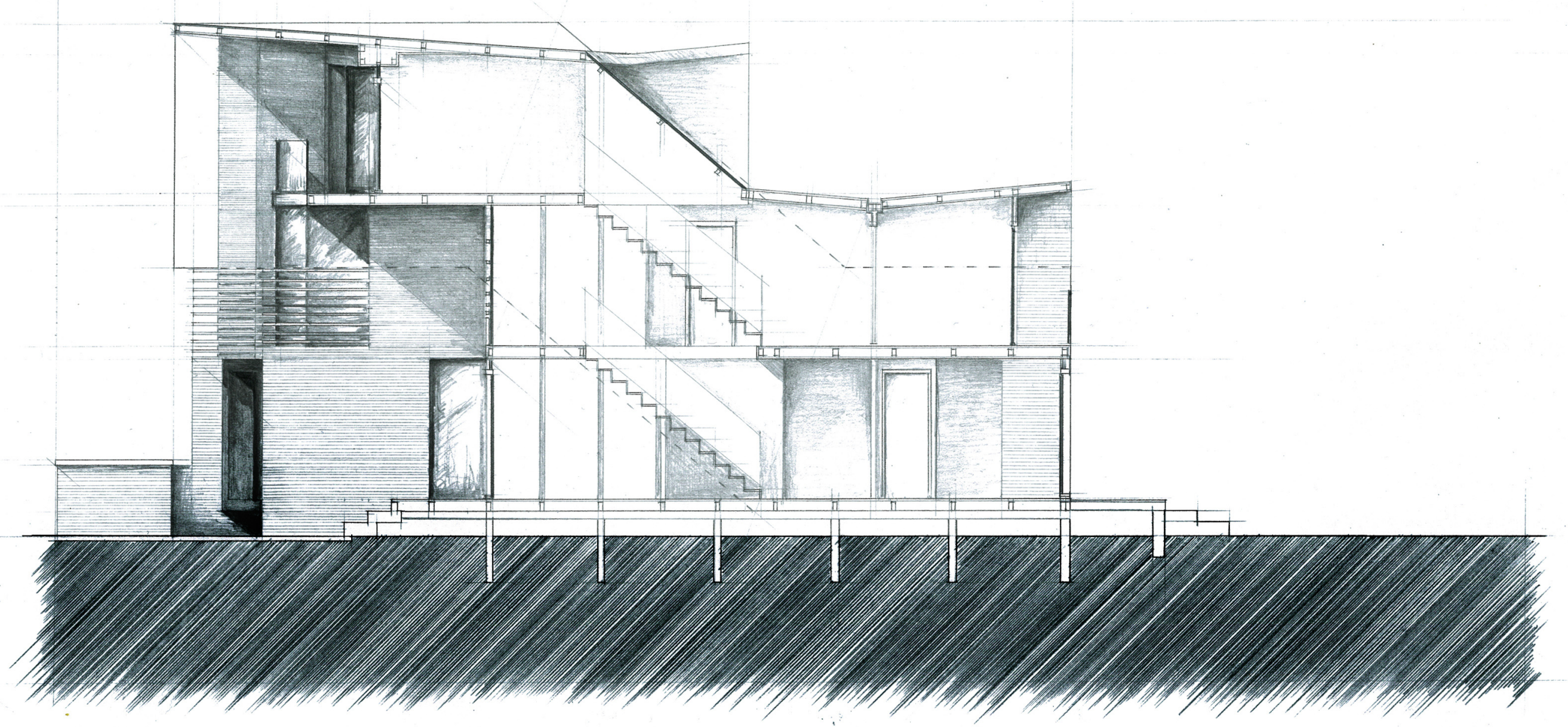

Fig. 6.14. Back-yard House Longitudinal Section 


$$
\text { In }
$$




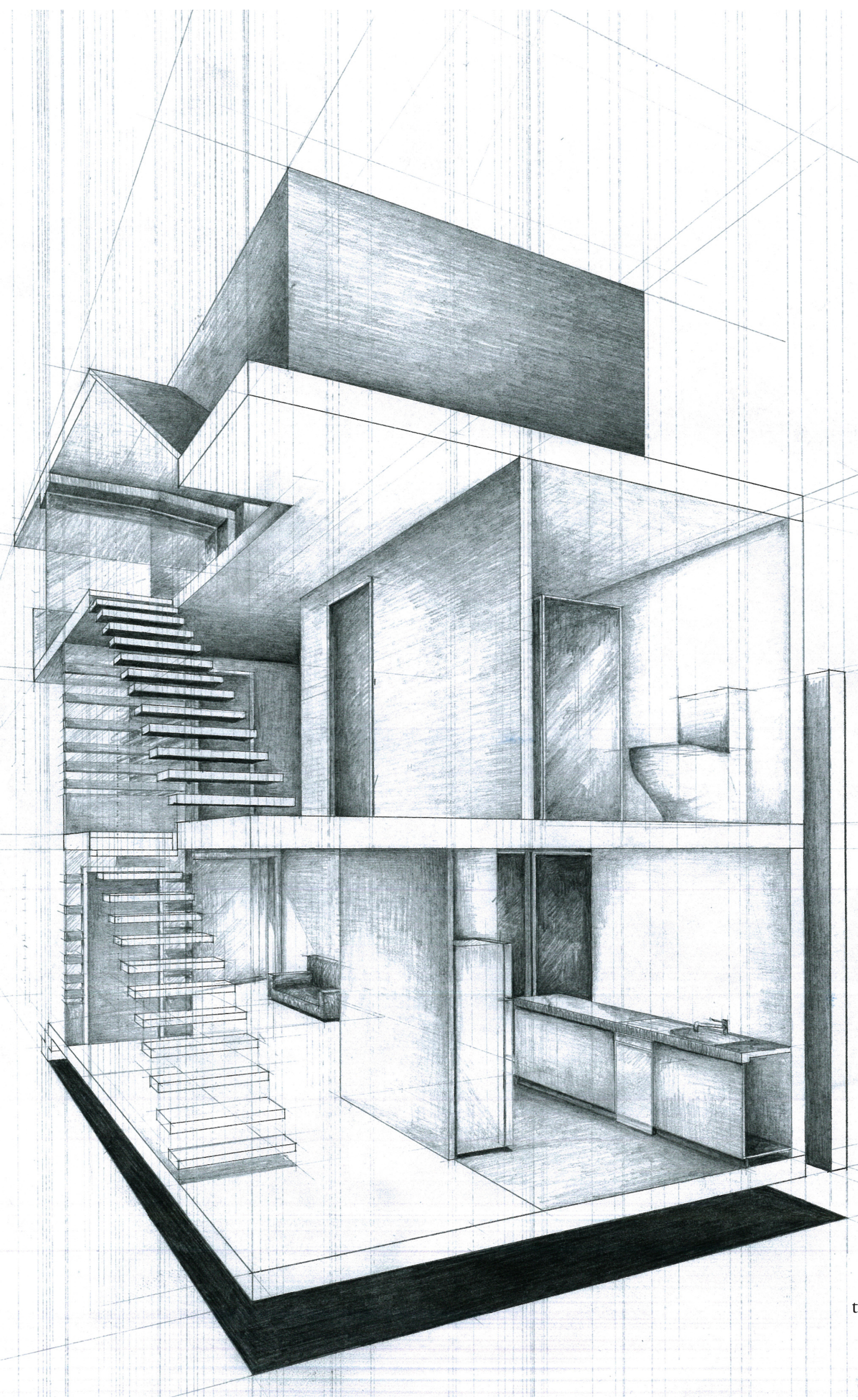

Fig. 6.16. Back-yard House Interior Perspective - from the back of the house looking towards the street. The eye level of the perspective is raised in order to show this relationship over two floor levels. 


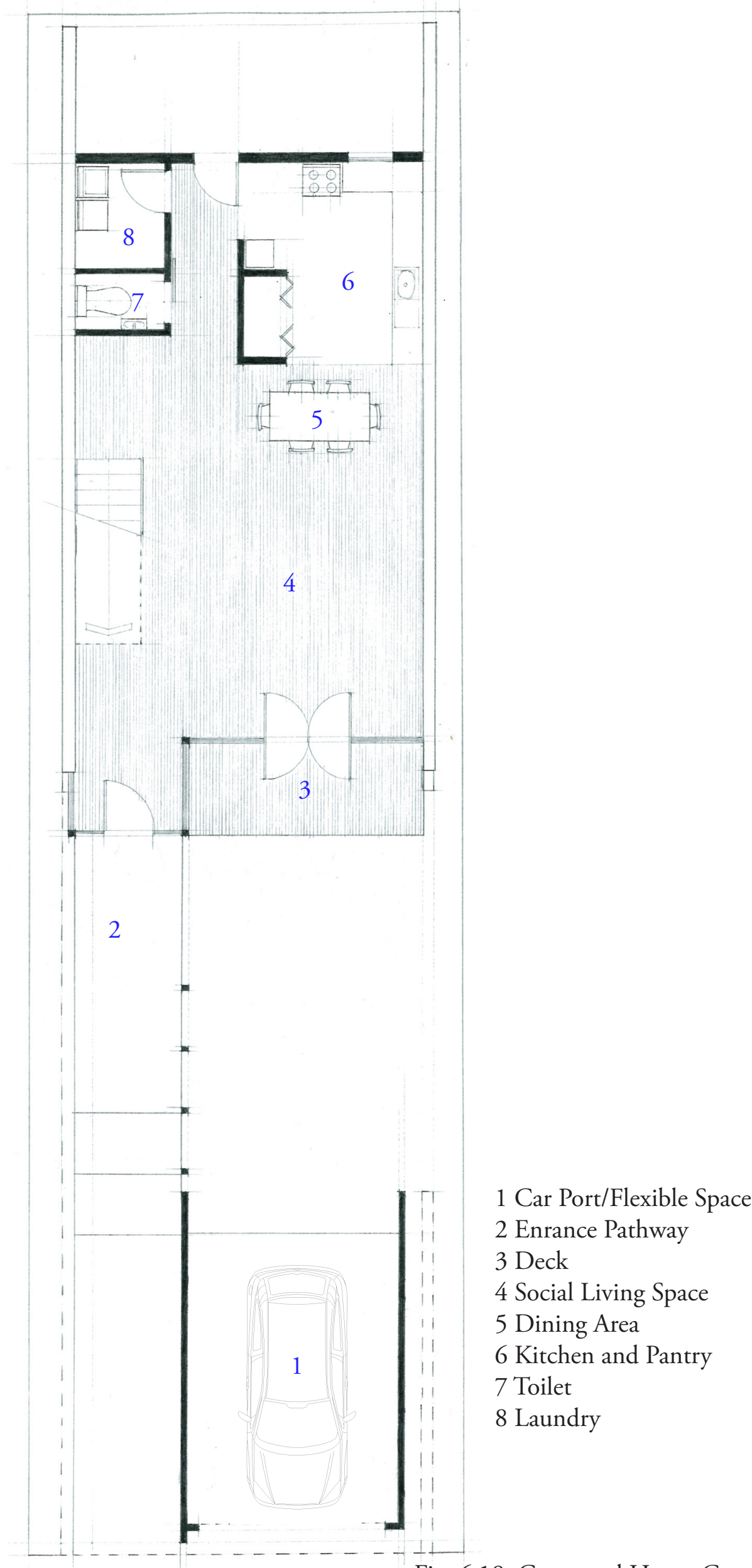

Fig. 6.18. Courtyard House Ground Floor Plan

\subsubsection{Case Study Two: Court-Yard House}

Ground Floor:

The ground floor of the second dwelling features a court-yard in the mid-section of the allotment. A secure car port is accessed directly off the street. This covered port is flexible and opens up to the landscaped courtyard to extend the functionality of the courtyard. The garage, which is an essential feature of any suburban home, is designed as a flexible, shared activity zone. This principle stems from the 'Adaptable House' project completed by Diego Ramirez-Lovering, Shane Murray and Graham Crist. The design team chose to concentrate on improving social sustainability through highly flexible planning of the house layout. The result of their design was a house layout that could be adapted to improve occupation rates. This ambiguous relationship serves to break down the front facade of the dwelling and introduce a permeable but elongated threshold mediating the transition from the street, through court-yard to the interior. A sheltered outdoor pathway lies adjacent to the car-port-to-court-yard transition, penetrating the forward volume of the building and framing the court-yard along one side. This pathway initiates an attenuated circulation spine leading to the front-door.

The front-door opens into an open-plan living area accommodating both formal and informal living roles.

The living space opens up to the court-yard assisting the graded transition to private. The kitchen area is closely associated with the open living area opposite the circulation spine.

Toward the rear of the building a shared toilet appears as an internal mass, terminating the circulation axis The toilet remains protected and privatised by the configuration of the stair leading to the first floor. The laundry at the back of the plan facilitates a private connection from the kitchen to the rear-lane. 
Spatial Planning Strategies
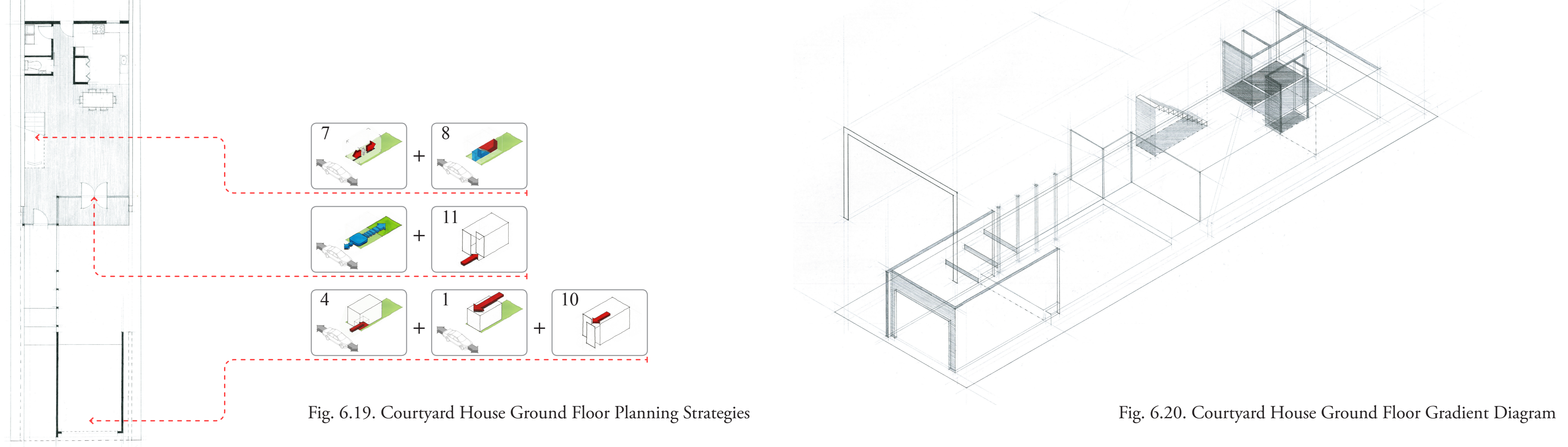

Threshold Strategies

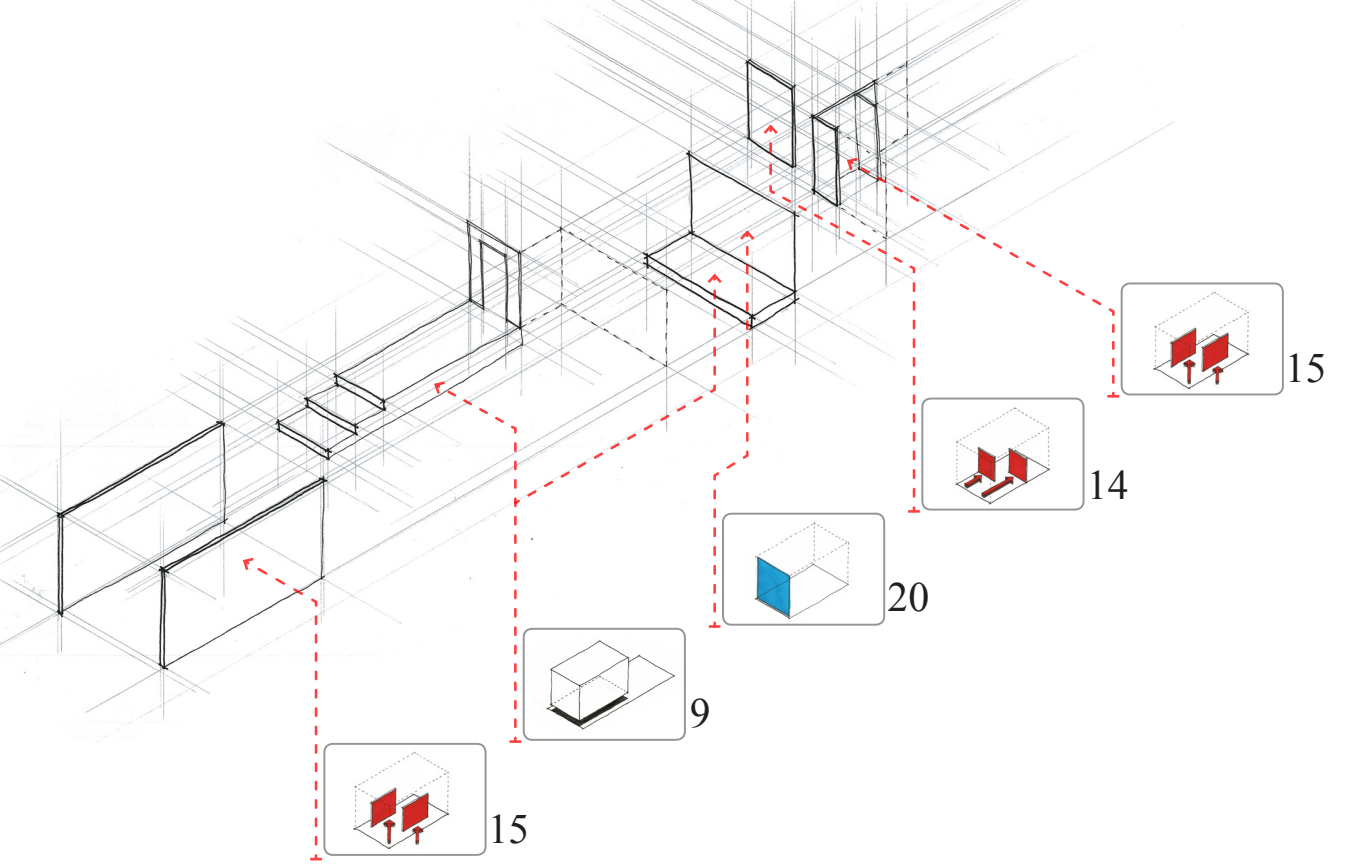

Fig. 6.21. Courtyard House Ground Floor Threshold Strategies 


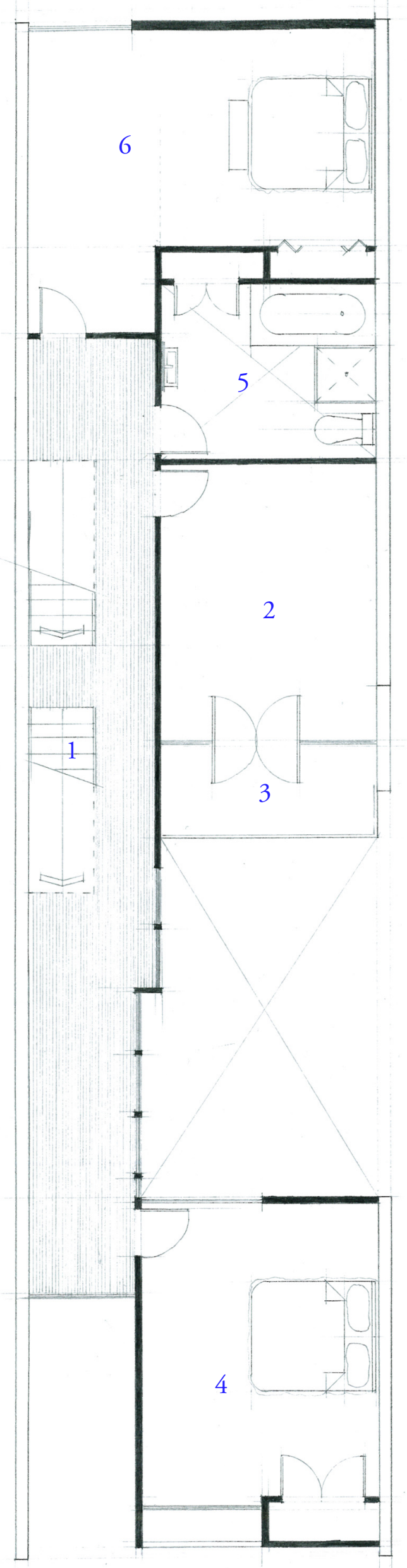

First Floor:

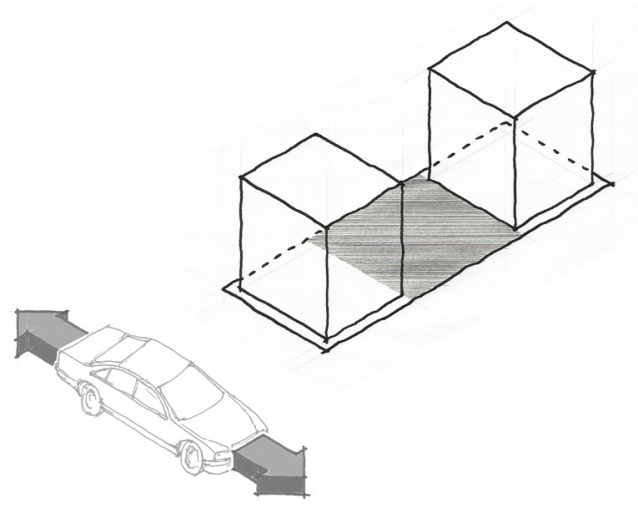

This floor consists of two bedrooms, a shared private bathroom and a spare bedroom or office space. The first bedroom is situated directly above the car port interacting with the court-yard and the street. The latter connection is regulated by the location of a wardrobe/storage unit projected slightly, opposing the screened window. These details introduce depth to the flat facade to help maintain the private integrity of the bedroom

The circulation spine from the ground floor is continued to provide access to all of these enclosed functions.

An opening to a balcony also elongates the transition between the semi-private activity of the court-yard and the guest bedroom or office. This room is also protected by an extended longitudinal wall from the shared space of the circulation spine.

The second bedroom is located at the rear of the plan, withdrawn slightly from the ground floor's rear edge

and overlooking the rear-lane.

ulation Hall

2 Work Room/Spare Room

3 Balcony

4 Bedroom 1

5 Bathroom

6 Bedroom 2

Fig. 6.22. Courtyard House First Floor Plan 

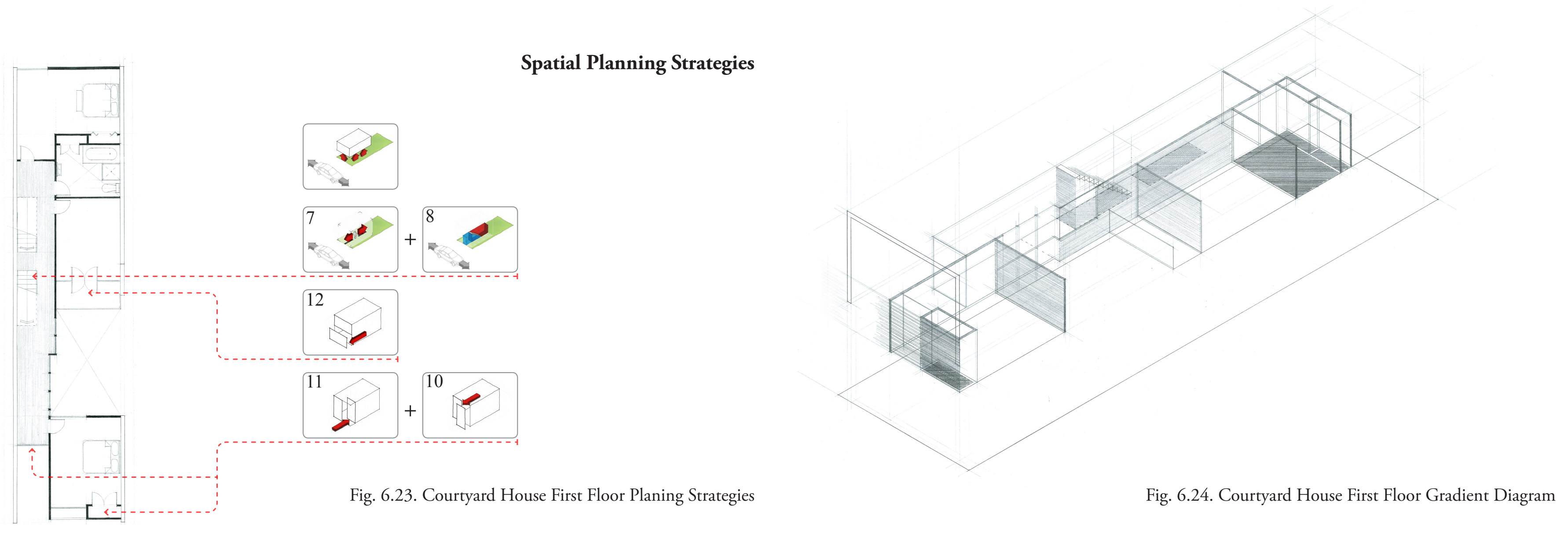

Threshold Strategies

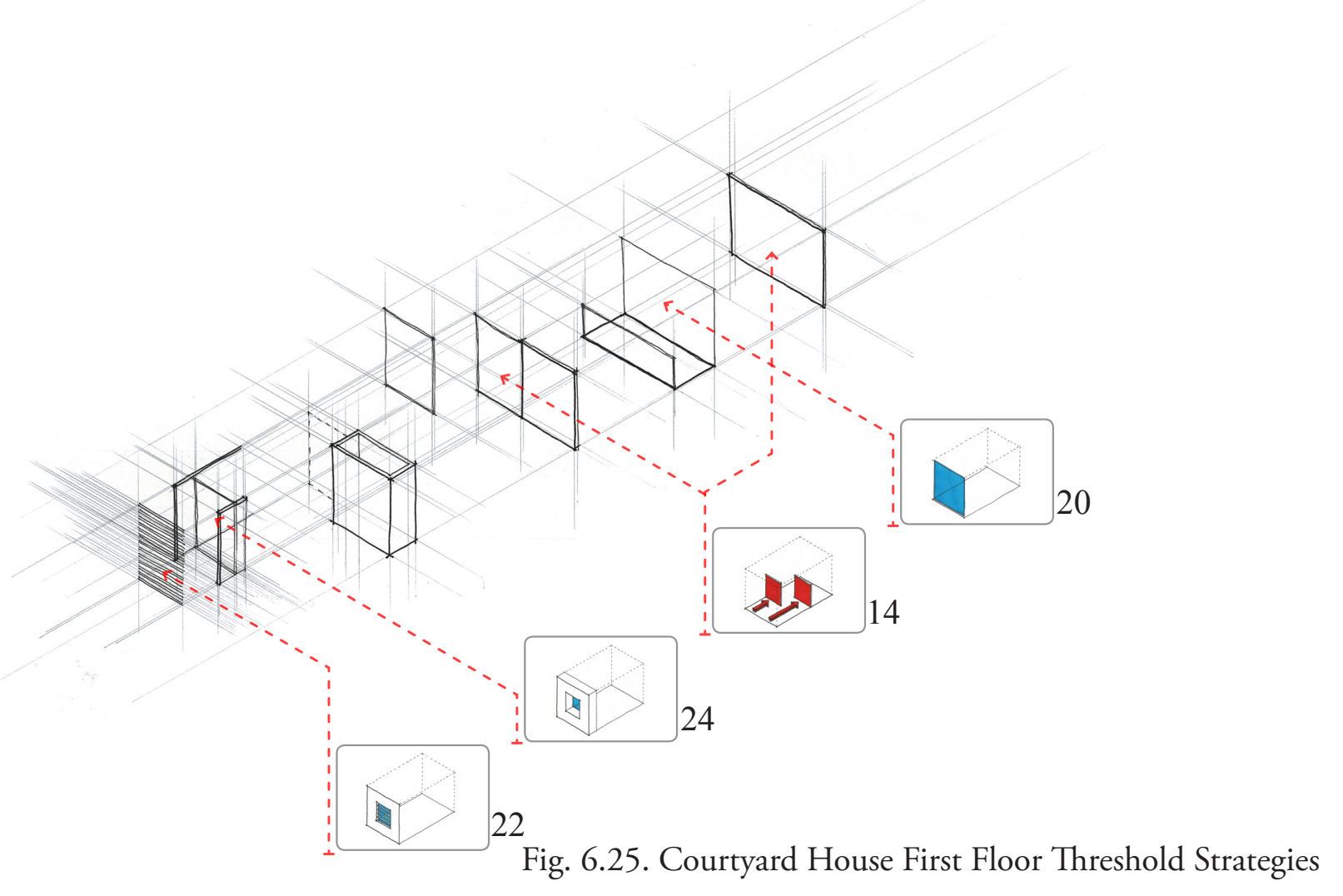




\section{Second Floor:}

The master bedroom and an adjoining en-suite occupy the top floor at the front of the house. This is a gradient related strategy, giving the house a stronger address to the street and it also fits the upward gesture of the formal design concept.
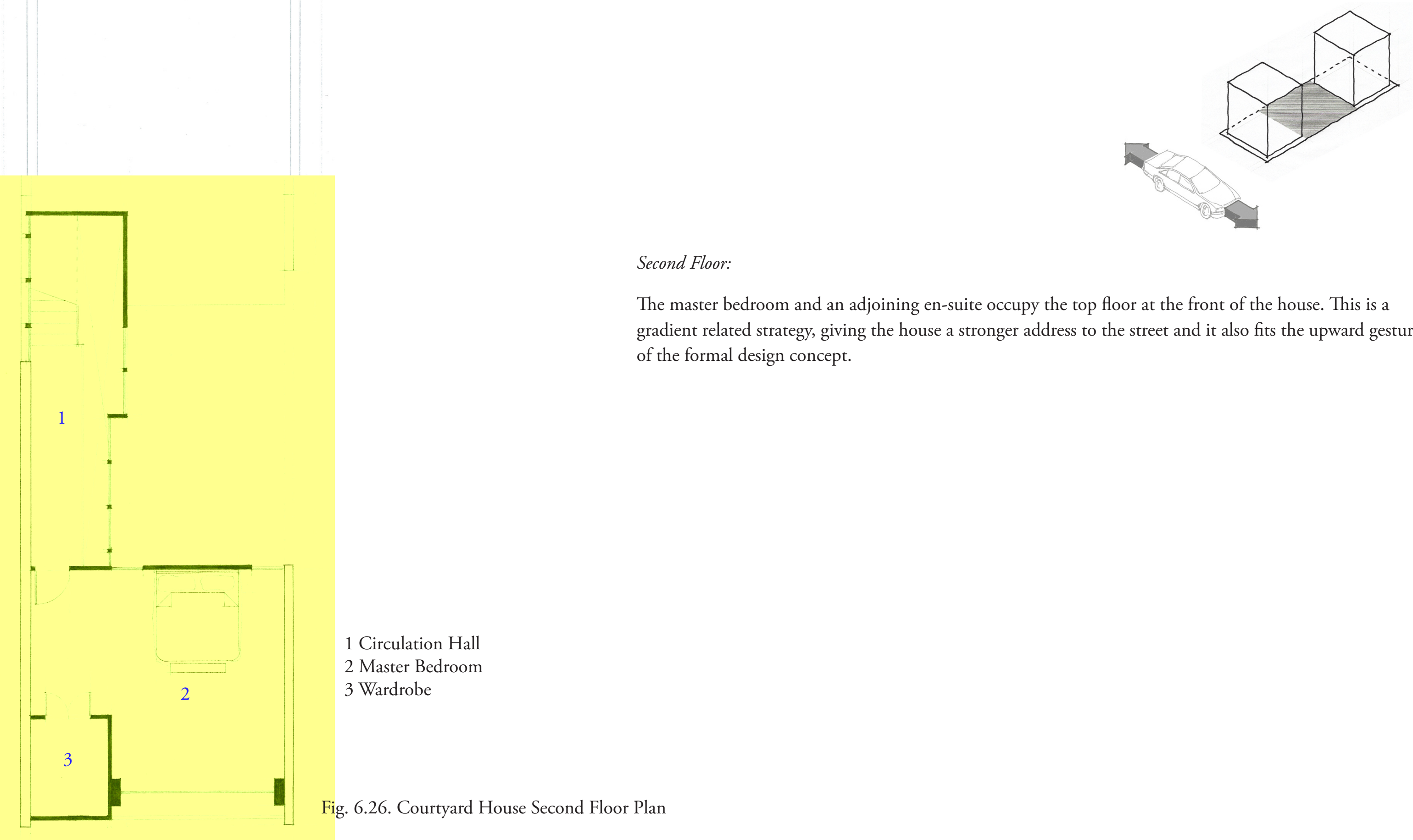


\section{Spatial Planning Strategies}
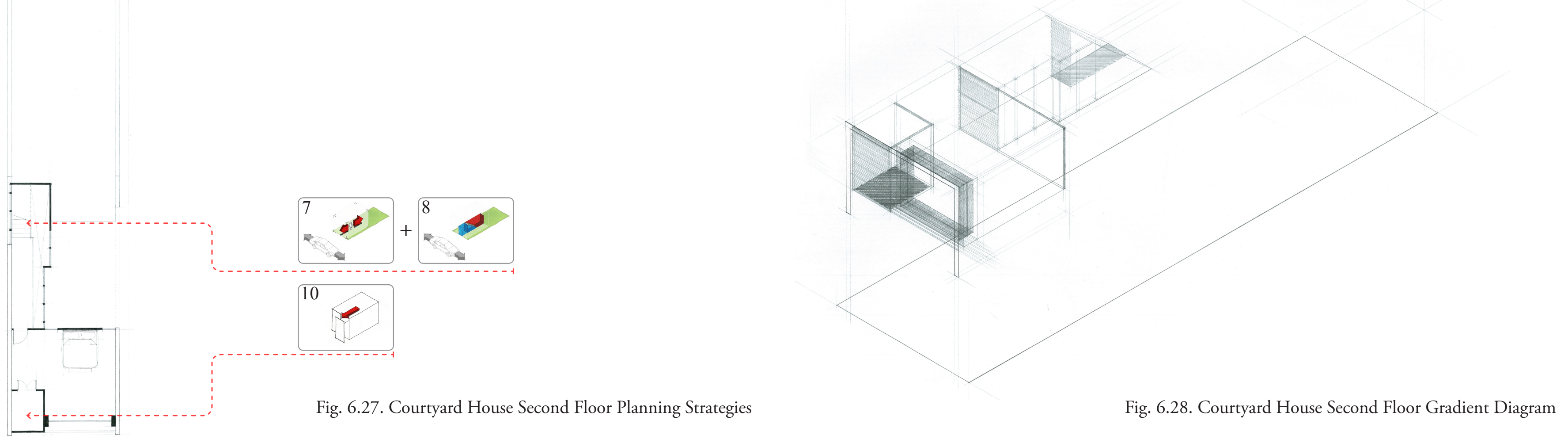

Threshold Strategies

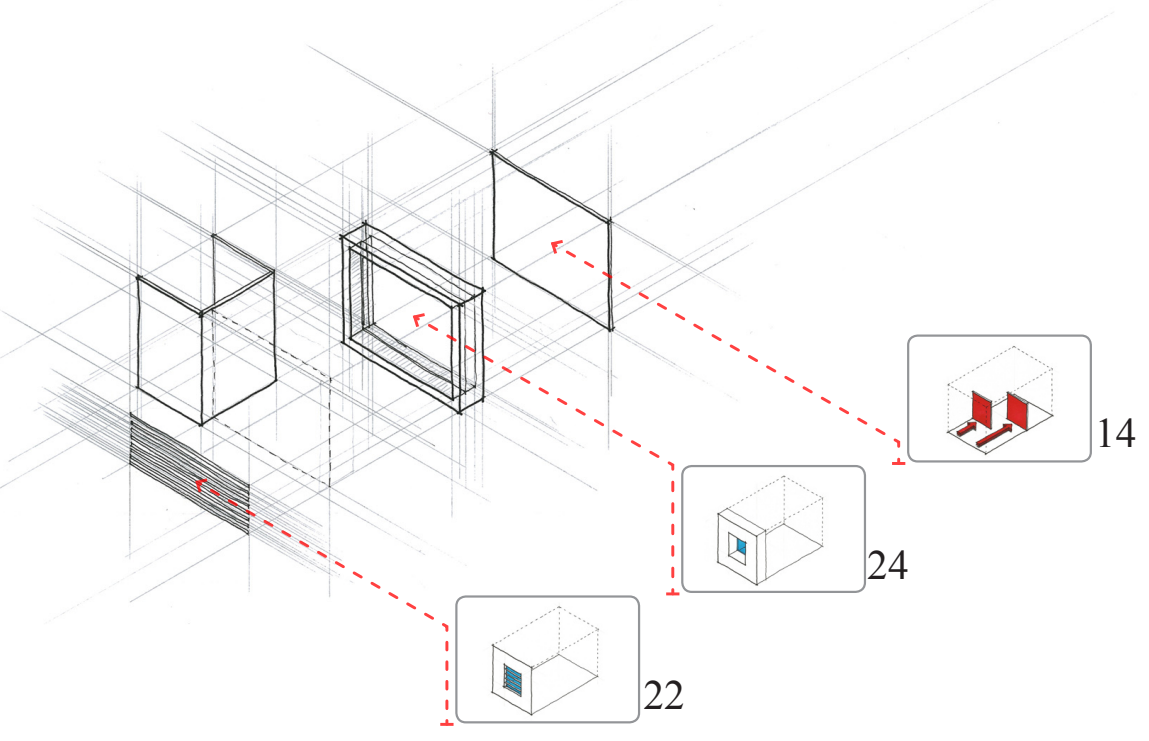

Fig. 6.29. Courtyard House Second Floor Threshold Strategies 


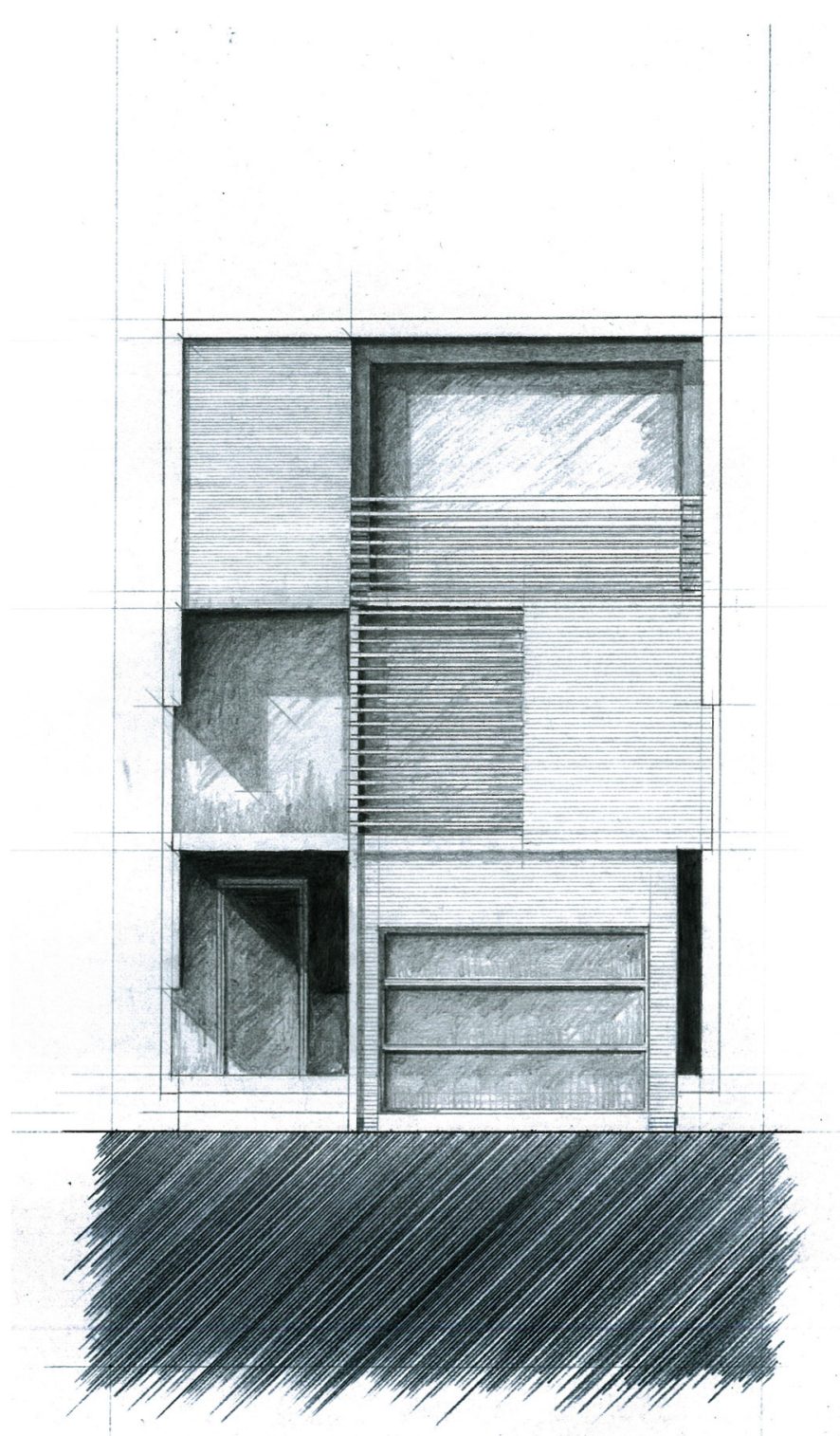

Fig. 6.30. Courtyard House Street Elevation

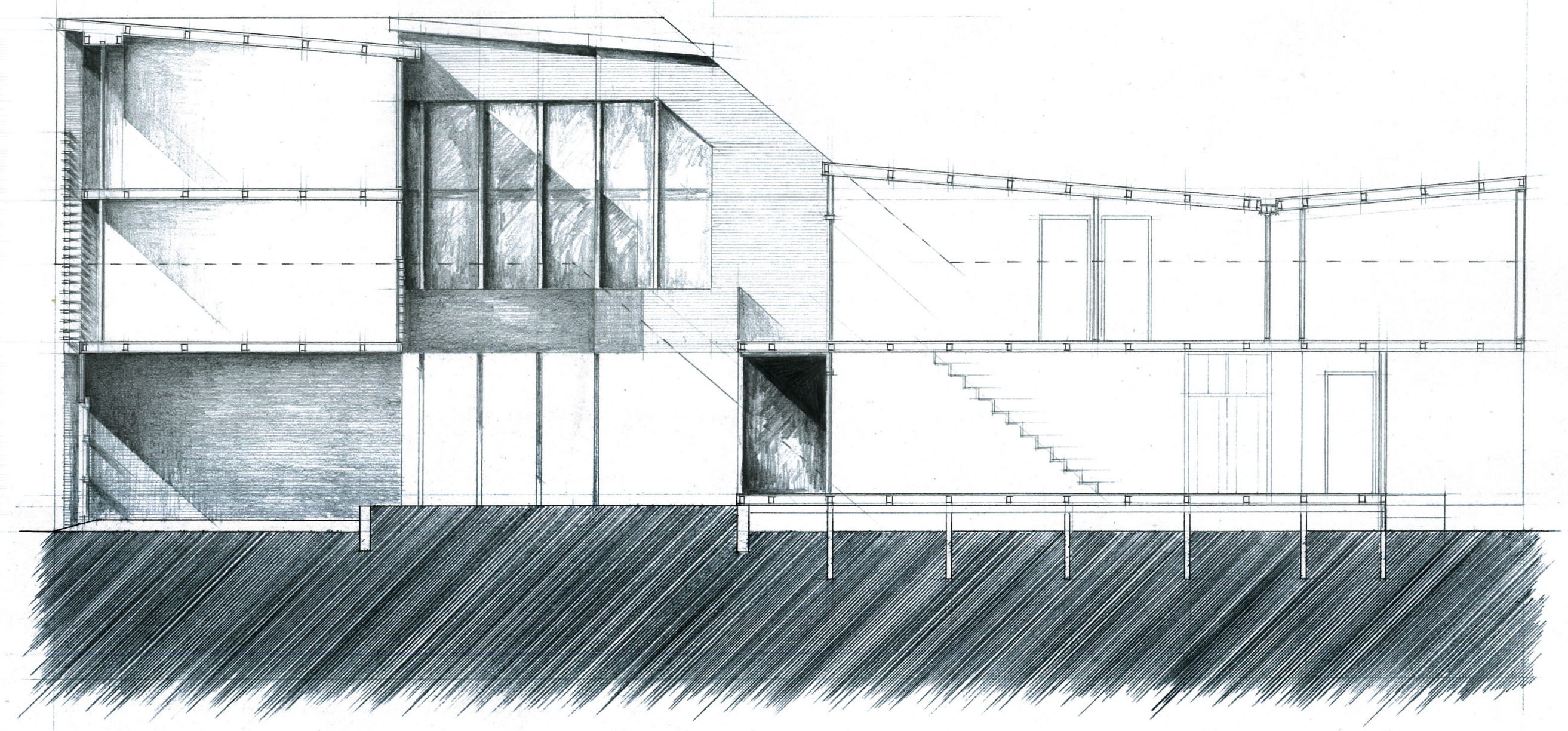

Fig. 6.31. Courtyard House Longitudinal Section 


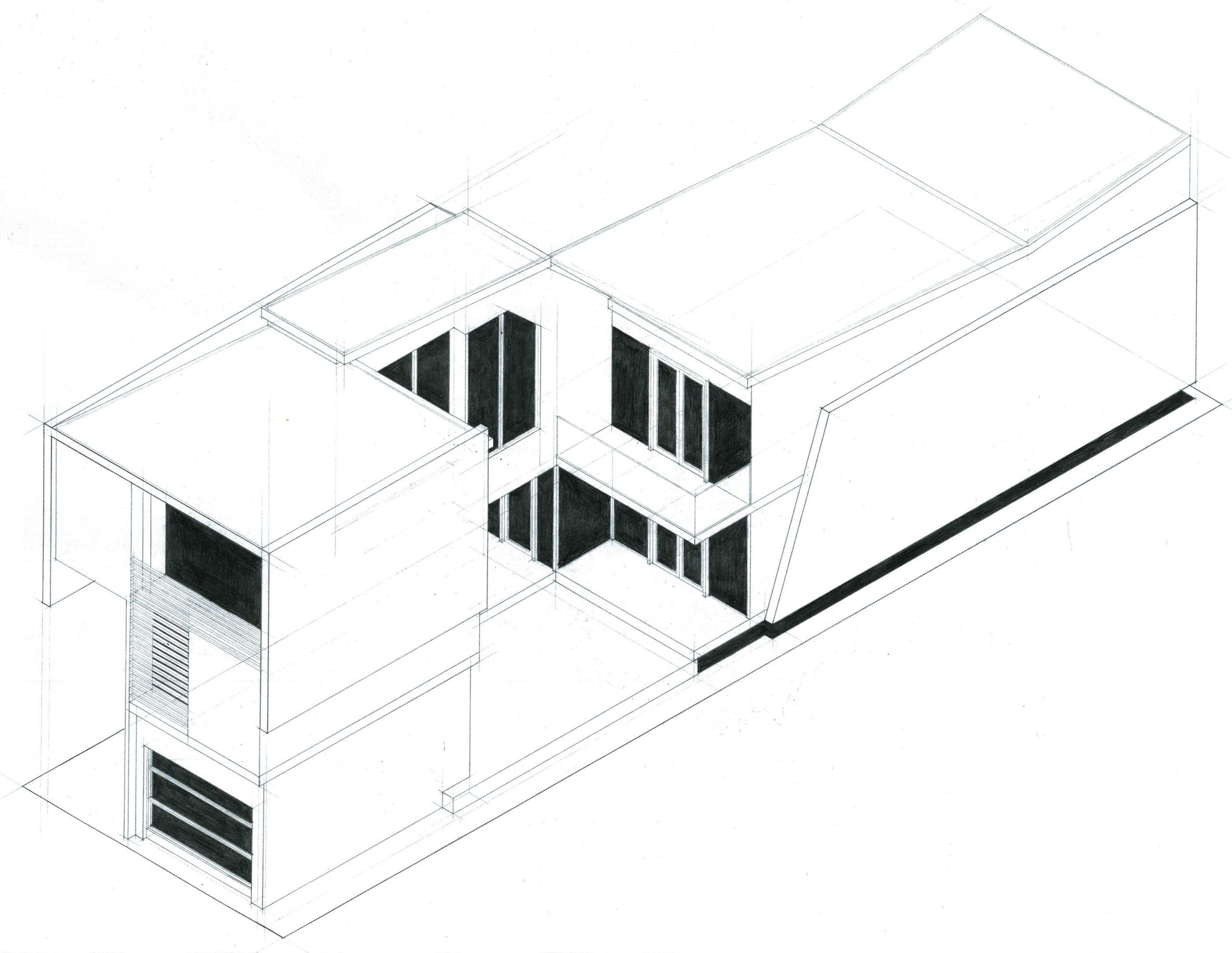

Fig. 6.32. Courtyard House Isometric 


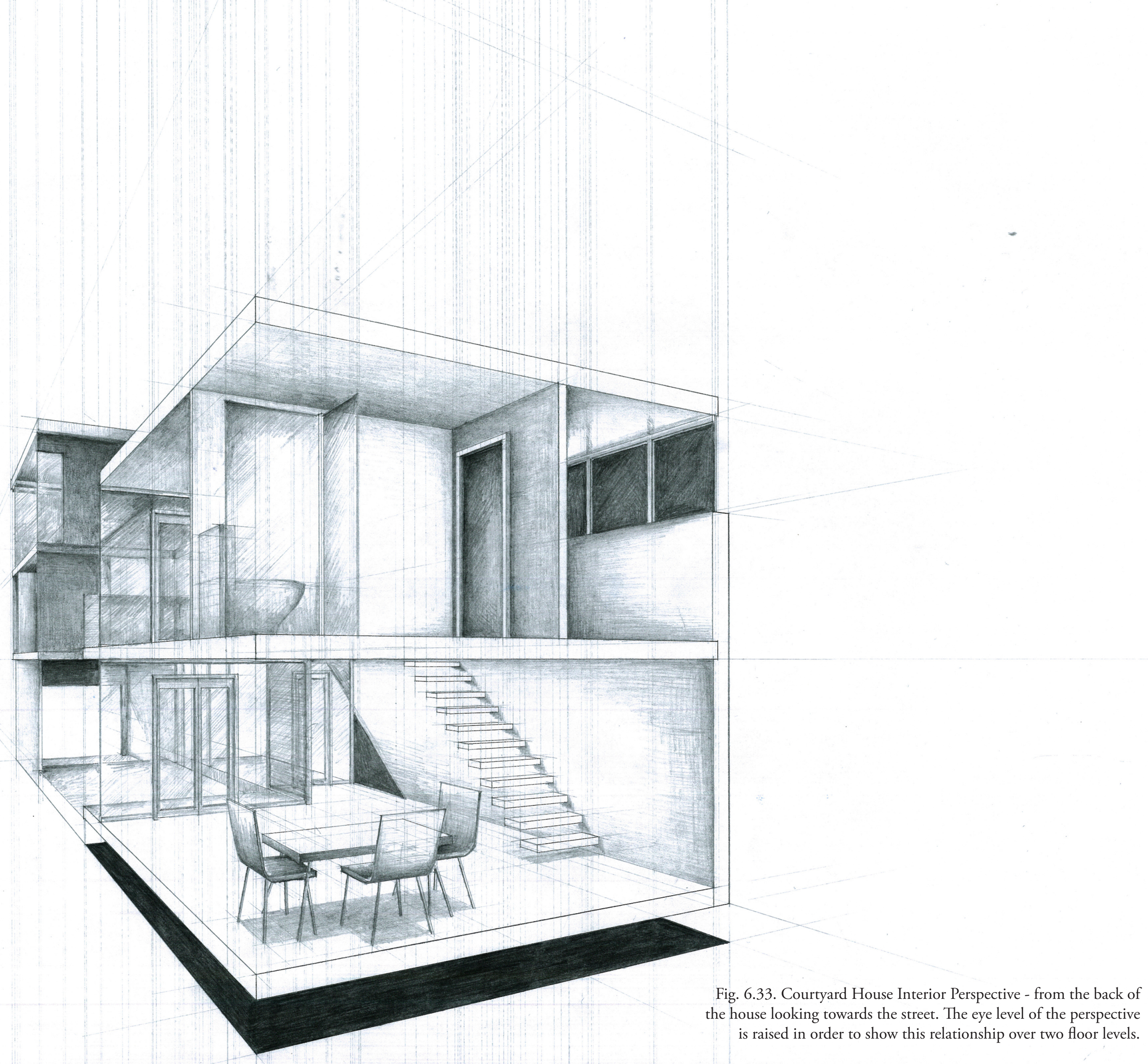




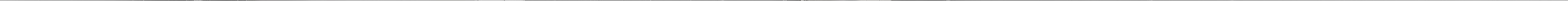


1 Entrance Alcove

2 Formal Sitting Room

3 Informal Living Area

4 Dining Area

5 Kitchen and Pantry

6 Toilet

7 Laundry and Storage

8 Garage

\subsubsection{Case Study Three: Front-Yard House}

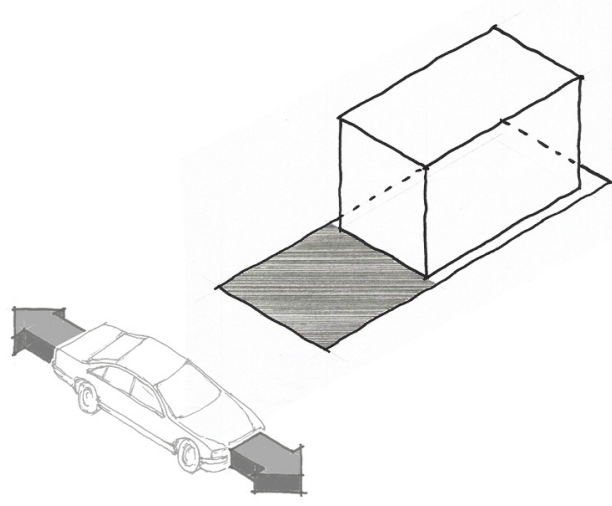

Ground Floor:

The building mass is pushed to the rear of the allotment assigning the open space the front. To maintain the value of the private open space for the household it is separated from the public street environment by a retaining-wall. A series of landscaped terraces elevate the ground plane of the front-yard acknowledging the desired regulated connection back over the front wall. The vertical displacement designates a

clear hierarchy of function between public and private. An access channel counters this hierarchy by withdrawing a section of the wall and extending a terraced path towards the building envelope from the street.

The access channel extends through the house creating a circulation axis. The front-door is withdrawn from ground floor edge creating a sheltered alcove. An entrance hallway between the more public path and two distinct living areas is established firstly, by a perpendicular partition bordering the formal living area and secondly, a series of steps leading up to the informal living area and then back to down the formal area.

The formal space opens onto an external deck connecting to the open space. The informal zone incorporates the kitchen and dining areas to establish a general family living area.

A shared toilet again terminates the circulation spine and helps to establish a secondary private circulation route on the same axis leading from the kitchen to the garage, laundry and storage. 

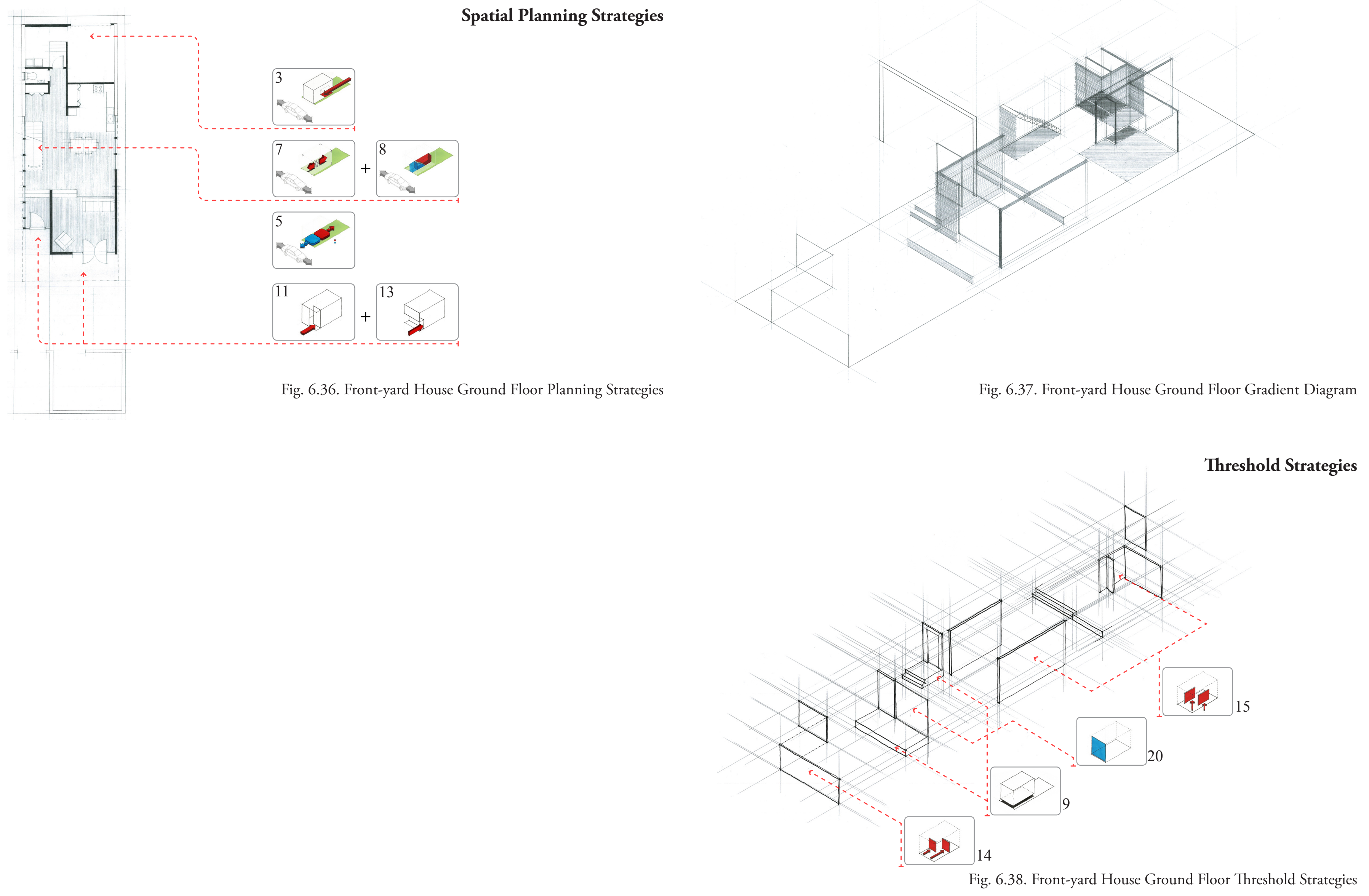

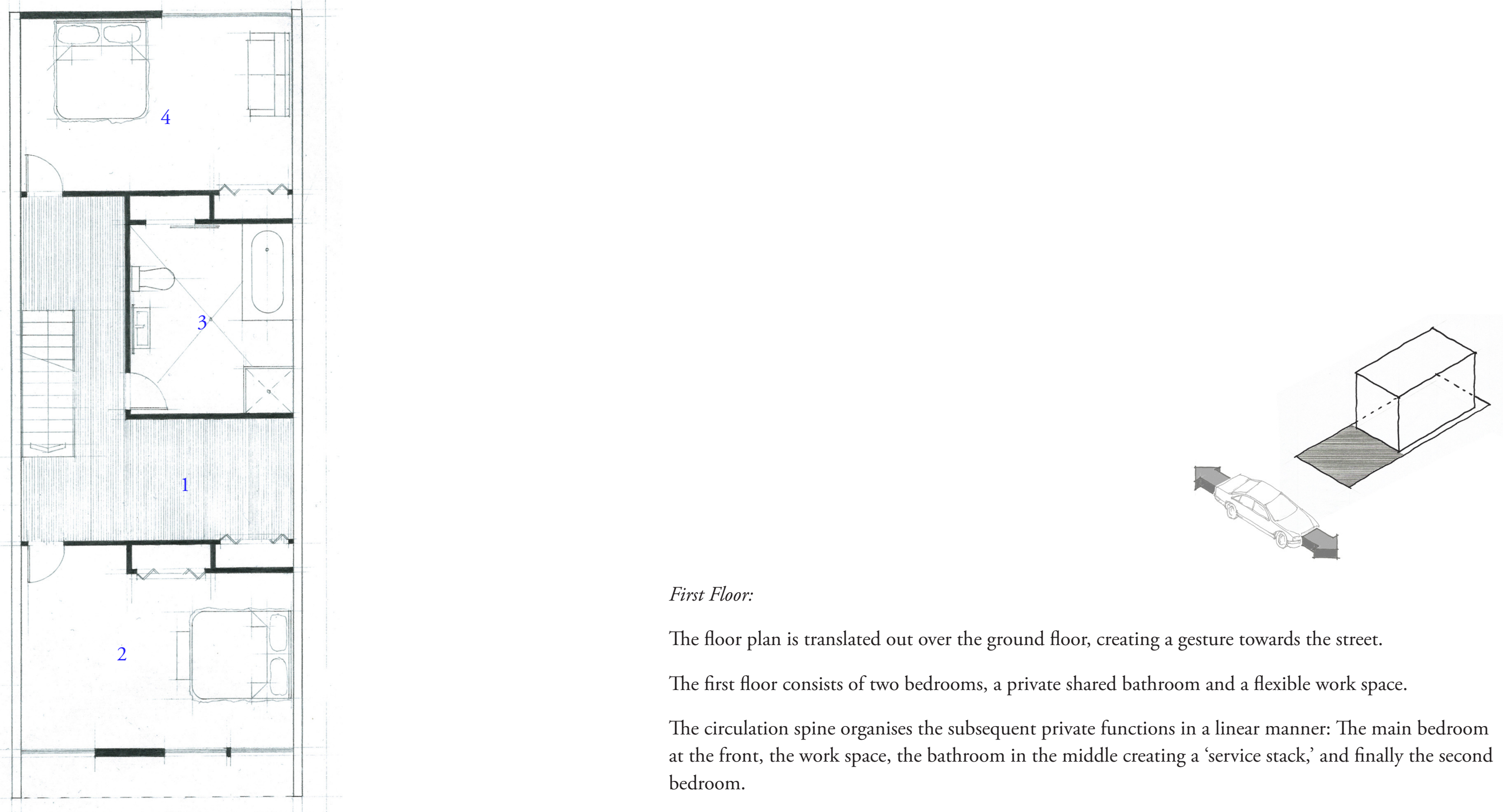

First Floor:

The floor plan is translated out over the ground floor, creating a gesture towards the street.

The first floor consists of two bedrooms, a private shared bathroom and a flexible work space.

The circulation spine organises the subsequent private functions in a linear manner: The main bedroom at the front, the work space, the bathroom in the middle creating a 'service stack,' and finally the second bedroom.

1 Flexible Work Space

2 Bedroom 1

3 Bathroom

4 Bedroom 2 


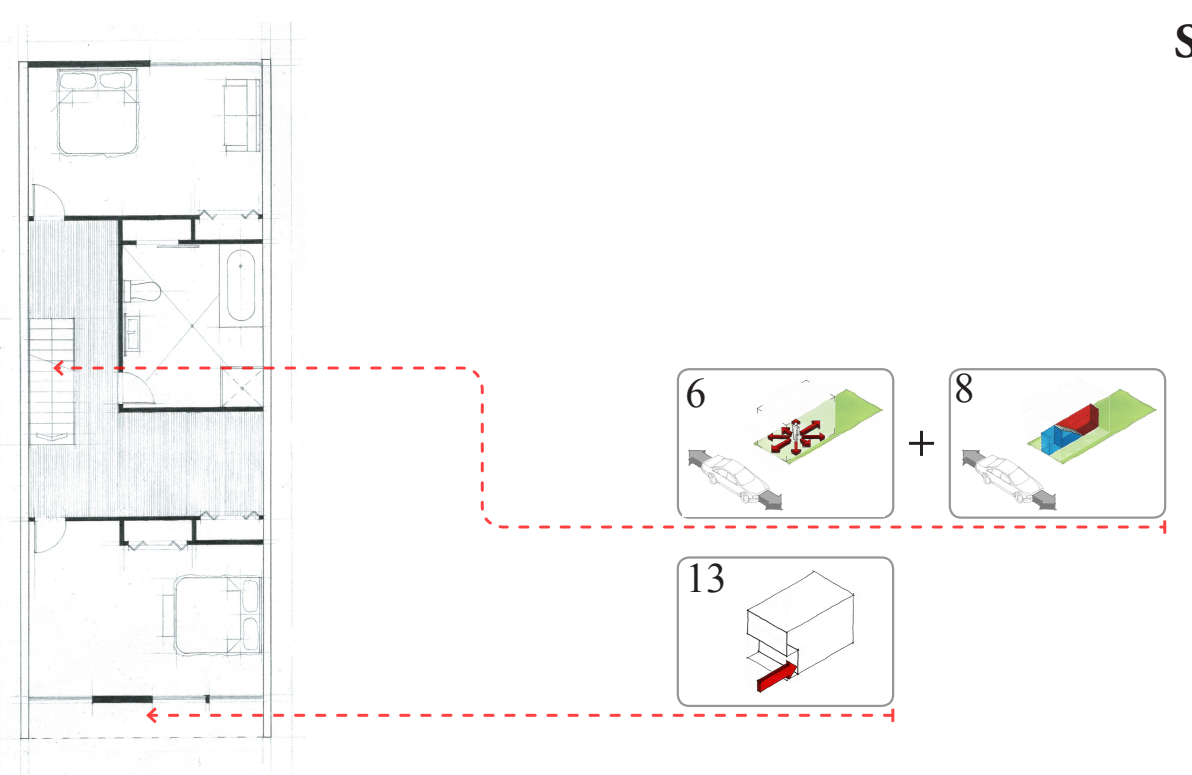

Spatial Planning Strategies

Fig. 6.40. Front-yard House First Floor Planning Strategies

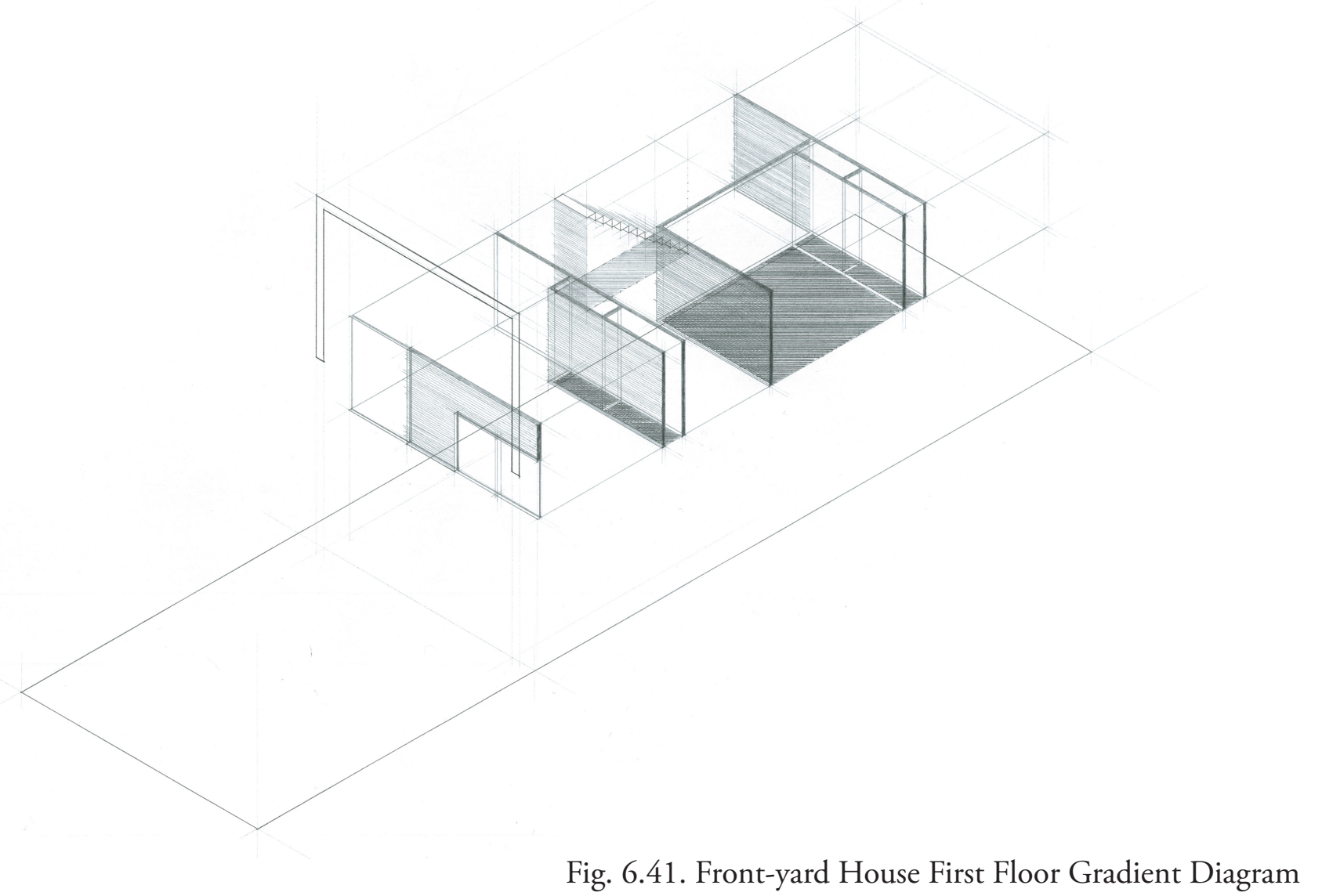

Threshold Strategies

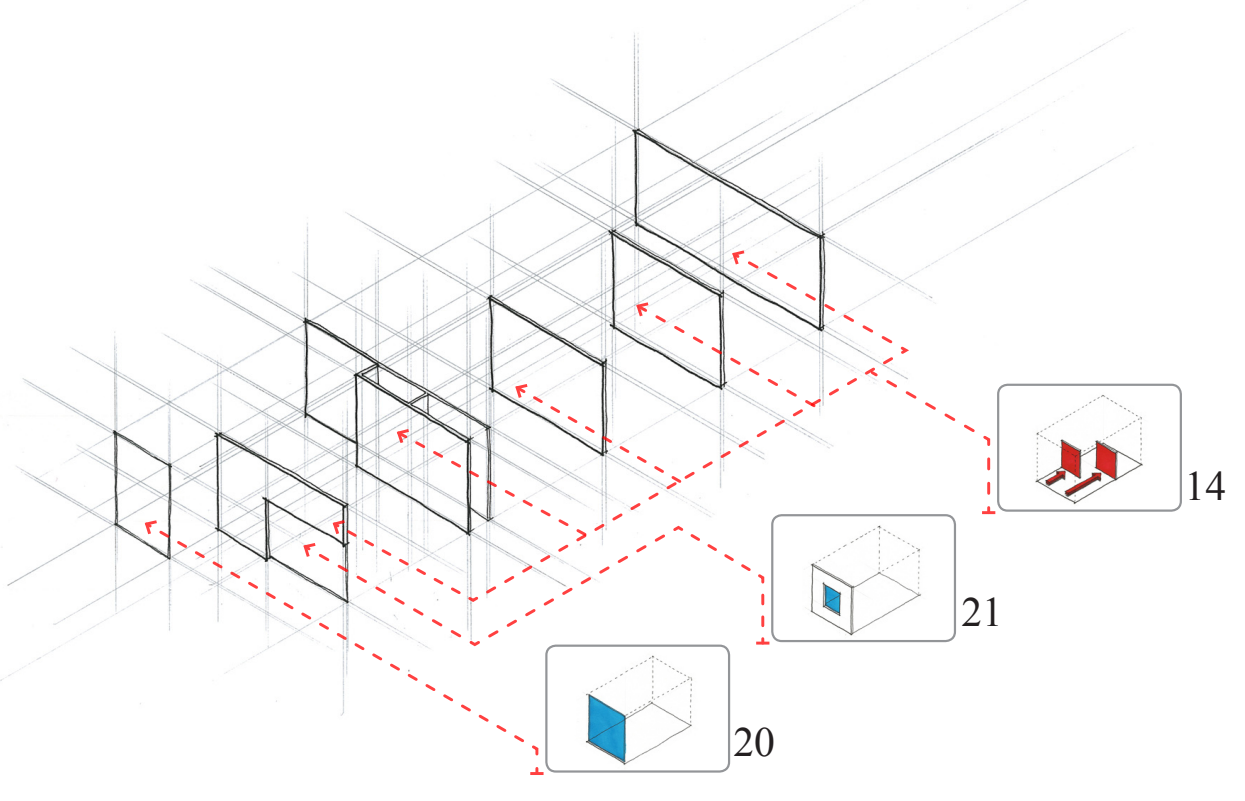

Fig. 6.42. Front-yard House First Floor Threshold Strategies 


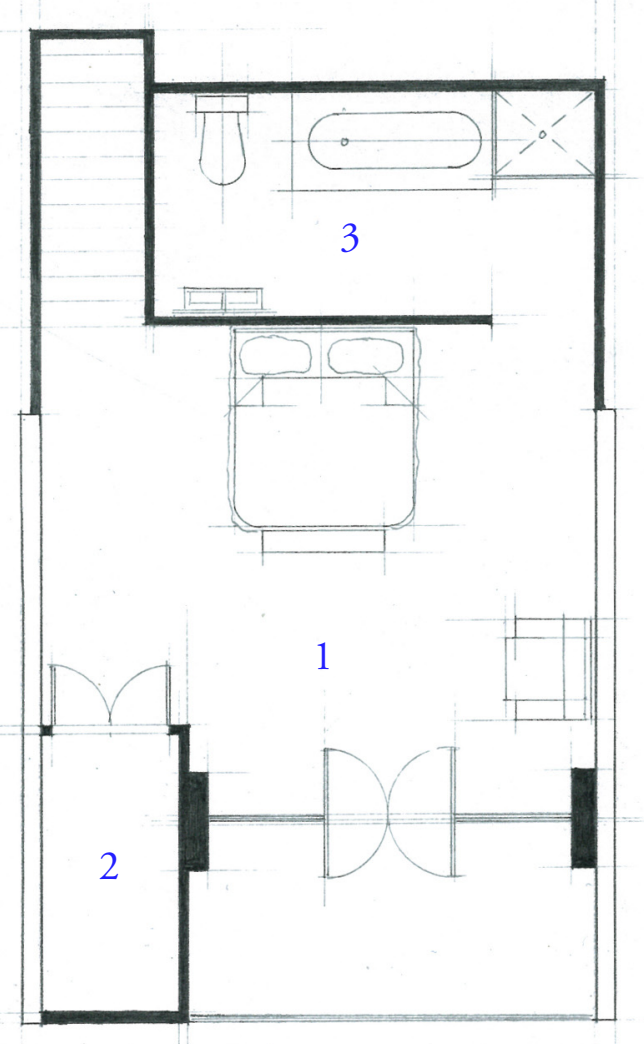

1 Master Bedroom

2 Wardrobe

3 Ensuite
Second Floor:

The top floor contains the master bedroom, an adjoining en-suite, and a private balcony installed to create an inhabited threshold at the building's edge emphasising the second floor translation out over the first floor. The wardrobe storage unit occupies a section of the frontage opposing the balcony and increasing the depth that it creates in the facade. The storage unit presents a closed projected feature in the front facade which is aligned with the circulation spine. 
Spatial Planning Strategies

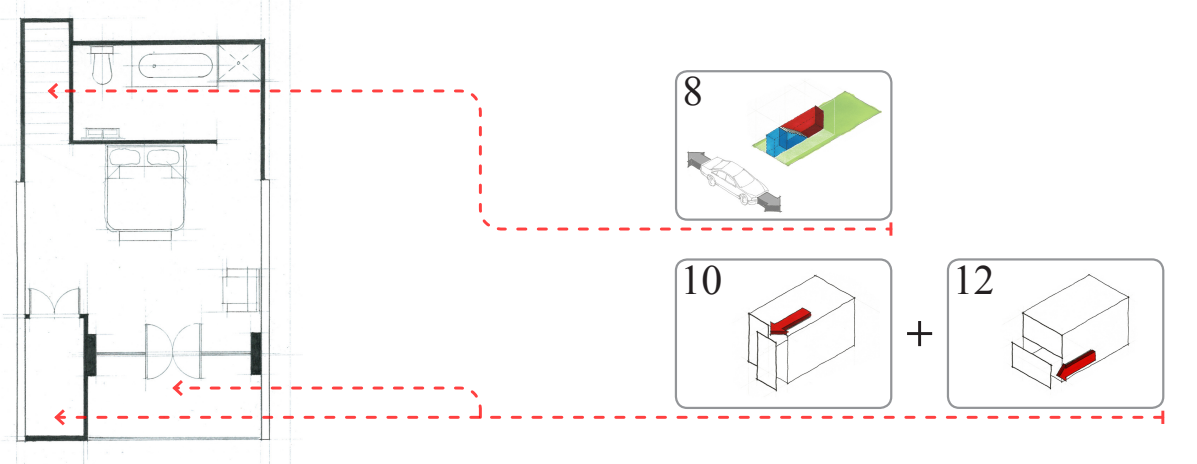

Fig. 6.44. Front-yard House Second Floor Planning Strategies

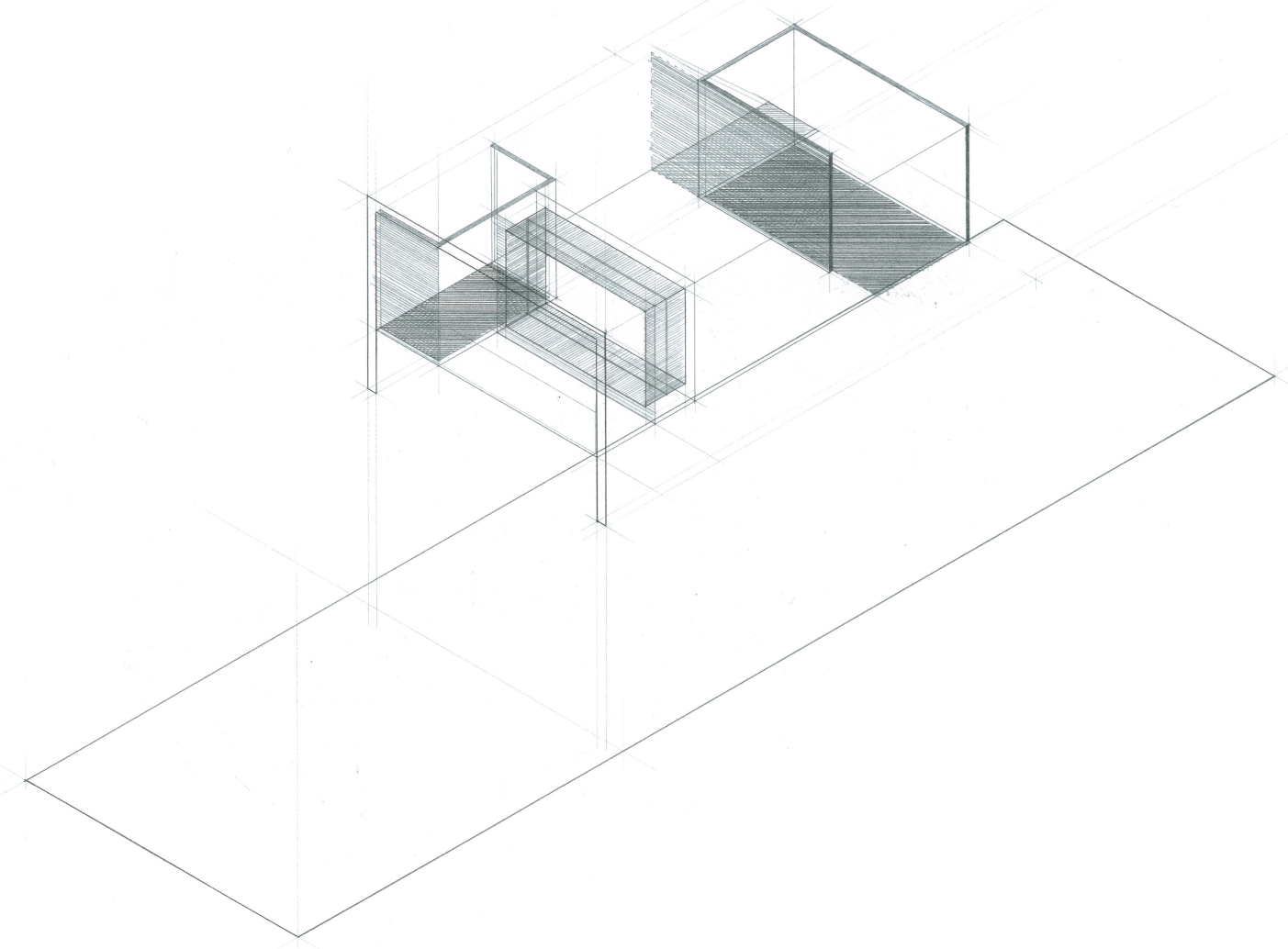

Fig. 6.45. Front-yard House Second Floor Gradient Diagram

Threshold Strategies

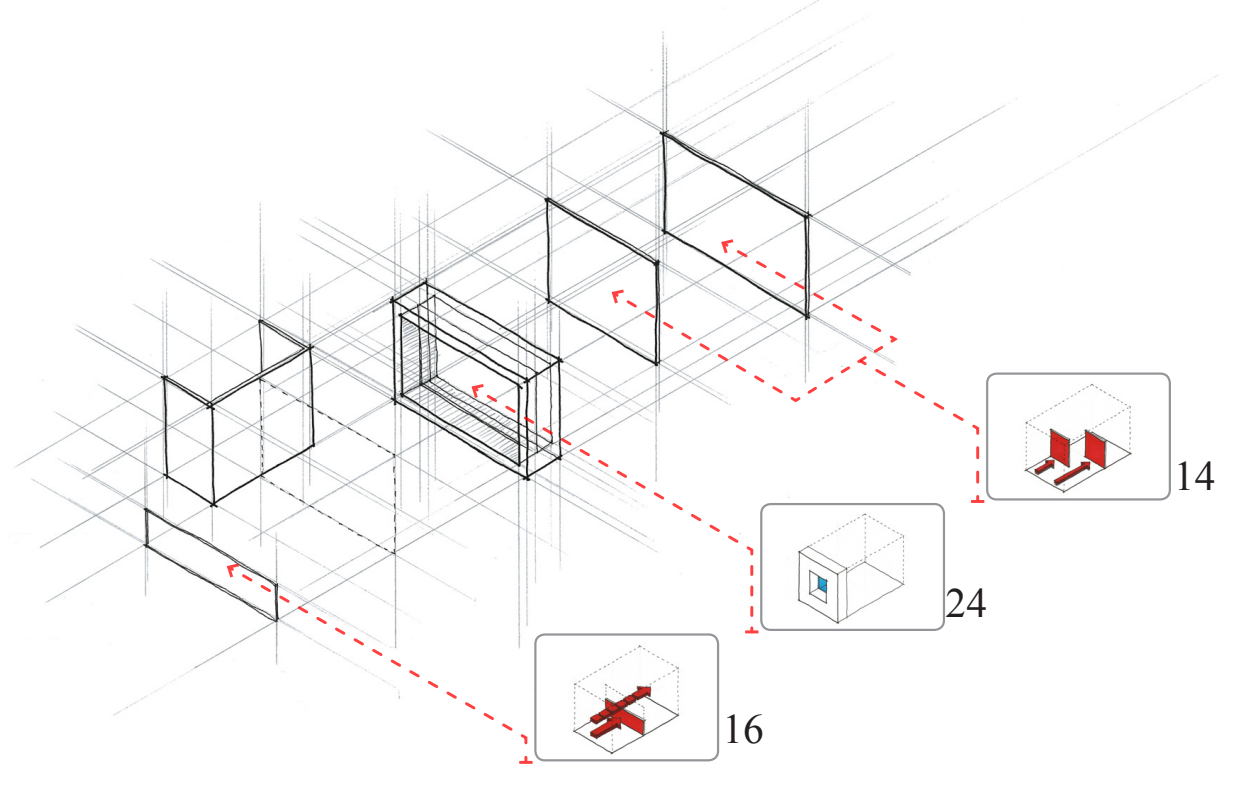

Fig. 6.46. Front-yard House Second Floor Threshold Strategies 


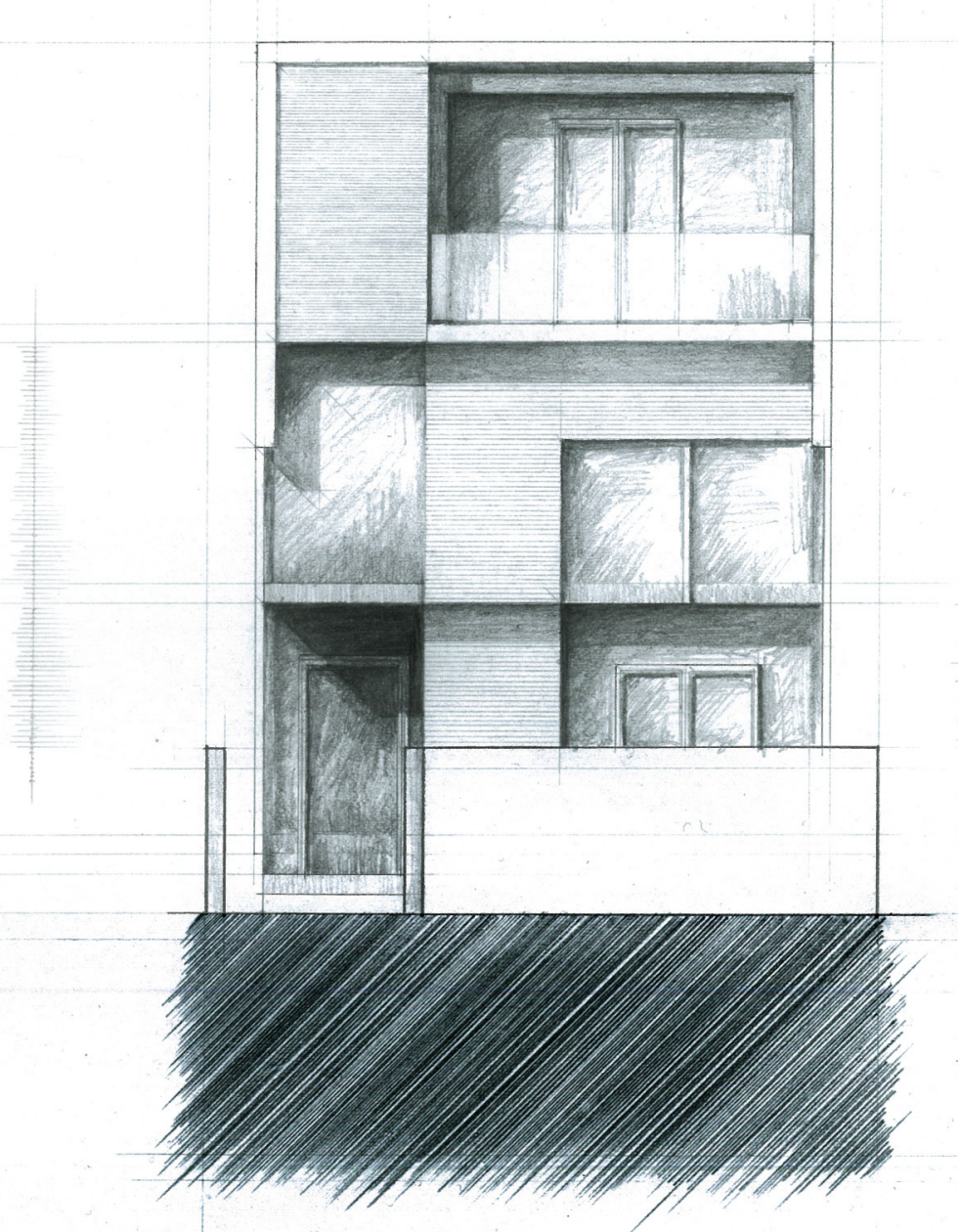

Fig. 6.47. Front-yard House Street Elevation

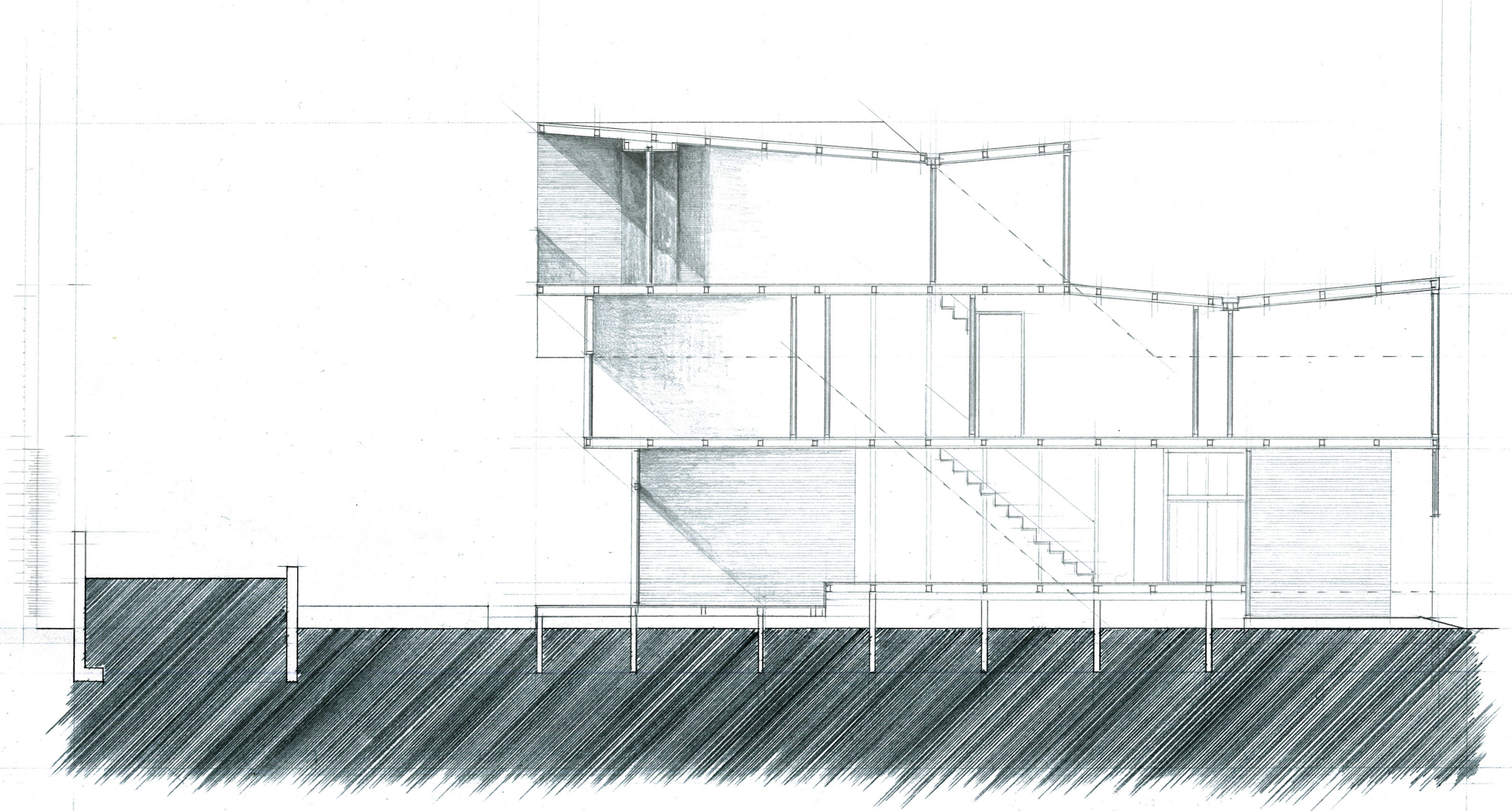

Fig. 6.48. Front-yard House Longitudinal Section 


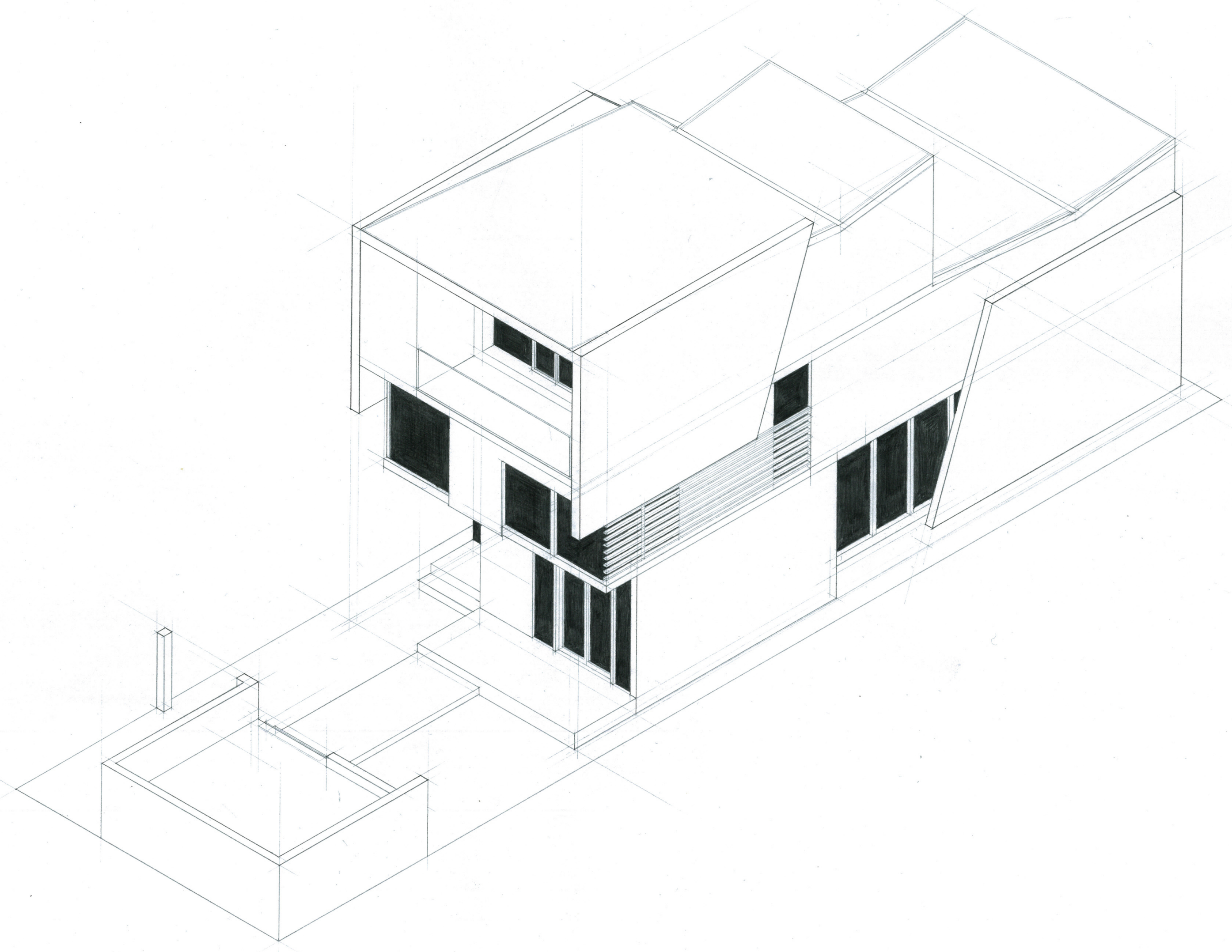



is raised in order to show this relationship over two floor levels. 


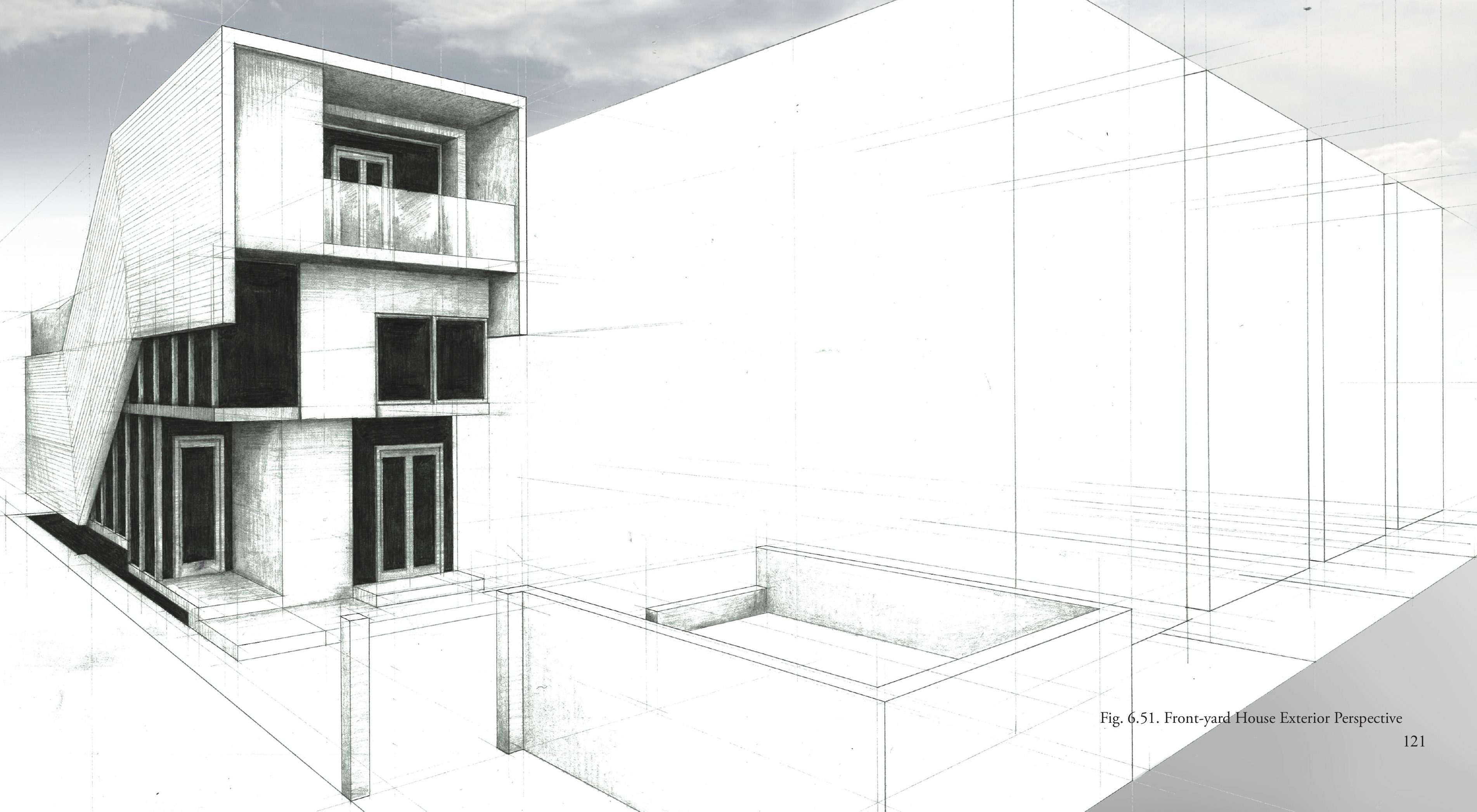




\subsection{Critical Reflection on Design Outcomes}

The final part of this chapter interprets and evaluates the design outcomes. The design phase of this research applies the ideas from the previous chapters in order to refine and finalise a repertoire of design strategies. These strategies ideally could be applied to successfully establish and manage a public-private gradient in any context. In this section each individual strategy implemented in the design is discussed, highlighting the main successes and discrepancies. This is followed by an examination of the connections and interrelationships within the series of strategies. The effect of the overarching formal concept on the application design strategies is the final topic of discussion in evaluating the extent to which a graduated transition between public and private is achieved.

\section{The Design Strategies}

Spatial Planning Design Strategies

- Rear-lane - Car Access: The absence of the garage door within the public street facade of the dwelling means that it is no longer the predominant element in the interface between public and private. In the 'Backyard House' and 'Frontyard House' case studies the street facade is afforded a greater freedom to facilitate an improved interaction between the domestic interior and the street environment. A graduated transition from public to private is achieved as a result. This transition is a significant and successful design strategy when considered in isolation. However, the full benefits of this strategy are not realised unless it is implemented together with further planning and threshold strategies which capitalise on the now unrestricted facade. For this reason, the strategy has limited effectiveness when applied in isolation.

- Flexible Car Space - Street Access: The implementation of this strategy in the 'Courtyard House' case study dwelling helps to establish a contained informal semi-private living zone which is openly connected to the courtyard open space beyond it. This zone is activated by its state of flux. Depending on whether it is opened or closed to the street, occupied by a car or by the house inhabitants the vehicular storage can become an unconventional and ambiguous zone of transition between public and private which is wholly flexible. The soft transition between public and private which emerges as a result of these characteristics is inherently beneficial to the establishment of a gradient. It is successful as a stand-alone design strategy because it directly aids the production of a graduated transition. But to ensure that it is consistently and actively beneficial to the interface between public and private, it requires parameters in the form of further design strategies to be established and utilised. The danger with this configuration is that the vehicle storage space can take on the characteristics of a traditional garage which renders it a static and unhelpful obstacle for the desired graded transition. The effectiveness of this strategy ultimately depends on the management of the space by the occupants and their intentions.

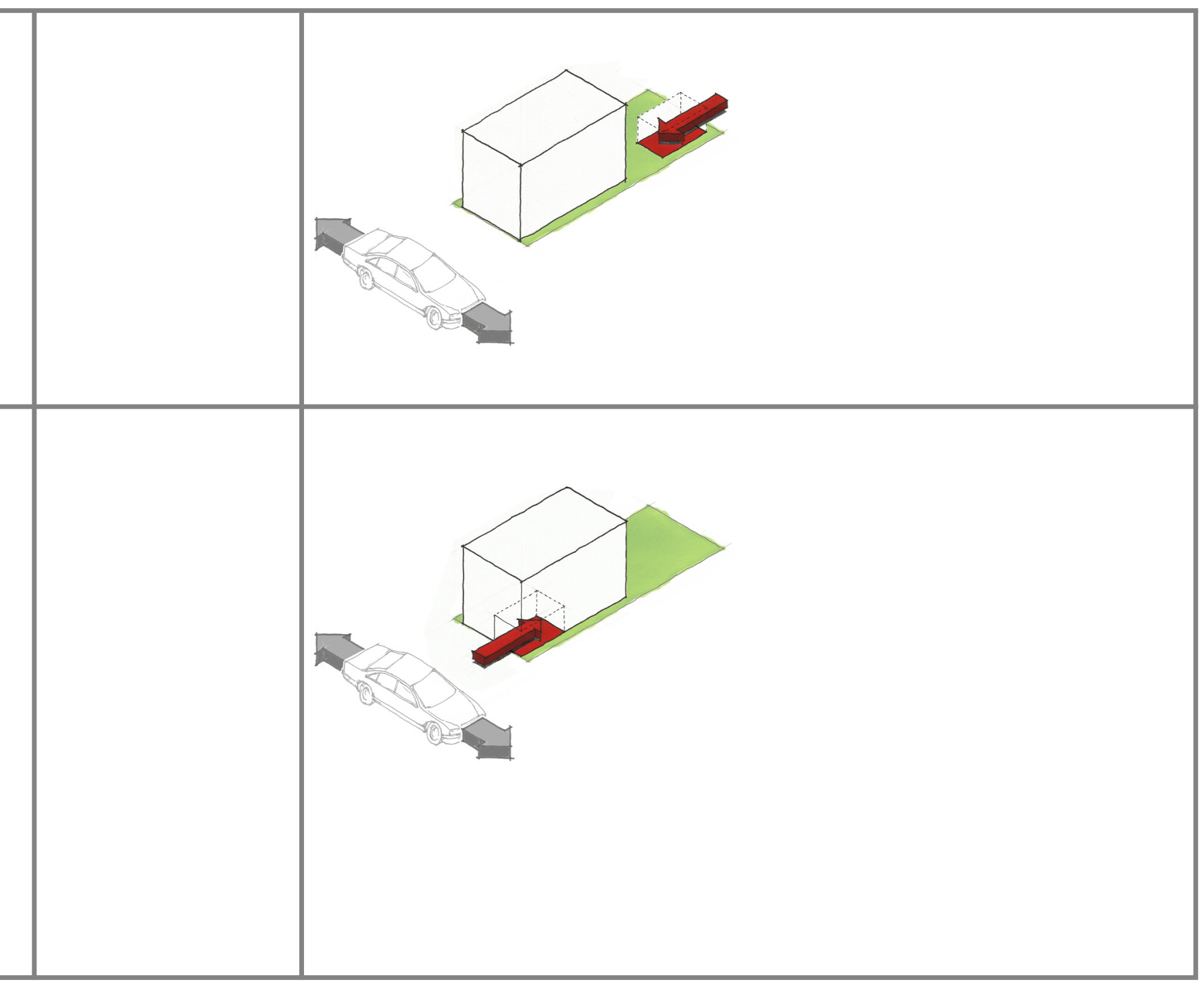


- Functional Layout: The prominence of this strategy is attributed to the previously established hierarchy of activity spaces within the house and the subsequent logical progression from public through to private. This strategy is used in all of the case study dwellings to order the domestic space. This concept is critical to the establishment of a gradient between public and private. It is important that the front areas of the house are functionally capable of an interaction with the public activity of the street. The 'Backyard House' case study dwelling demonstrates this strategy to best effect where the more public areas of the house, the formal living room and the dining area, have the most direct relationship to the street through their close proximity. The private areas, on the other hand are situated towards the rear, sufficiently protected and privatised to retain their functional integrity.

Another feature of this strategy is that the spatial transitions created by its use establish a useful framework for further application of design strategies. This principle augments the required functional characteristics of the domestic spaces ensuring appropriate relationships are properly managed. The framework also facilitates the application of further subtle thresholds which successfully elongate the transition from public to private. The addition of subtle thresholds within this framework allow the full benefit of this strategy to be realised.

- Bedrooms Removed from Ground Plane: The strategy removes the private functionality of the bedrooms from the ground floor. While the building footprint is smaller and consistent with achieving higher densities, This strategy ensures that the ground floor retains permeability and is conducive to a graded transition from public to private. Since the bedrooms do not have to contend with the social functions of the house, or be viewed from the street, the private integrity of security and privacy is more easily protected. The bedrooms can subsequently open up to reconnect and engage the public realm in a mediated overlooking capacity. Because it is applied in each version of the design, a significant implication of this study is that two or more floors are necessary in order to utilise this strategy and produce a good gradient.

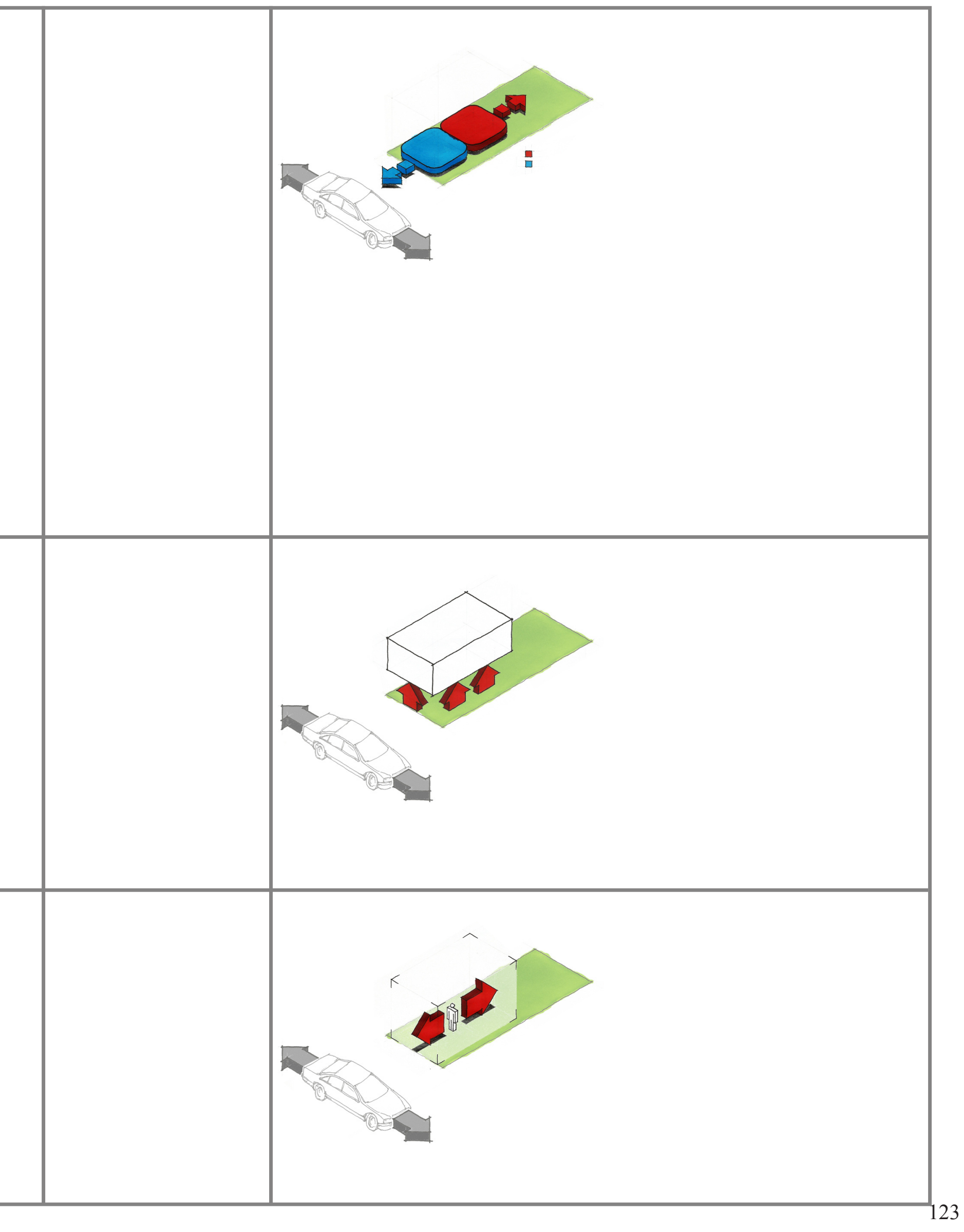

- Circulation Axis: The crucial factor of this strategy is that the configuration of the circulation determines the sequence of the other inhabited areas of the home. This reinforces the ideal arrangement of 'public' spaces at the front, and 'private' at the back. This attribute is demonstrated most clearly in the 'Courtyard House' case study dwelling, both externally and internally. The circulation forms a strong spine within the entire site which is a robust spatial organisation tool. The robustness is useful and successful as this house deals with more open and ambiguous spaces and relationships. In a narrow building this is also a successful strategy because of the mutual linea arrangement of habitable spaces transitioning from public to private. This transition is abundantly clear as one occupies and moves through the circulation axis. 
- Circulation Core: In the ground floor of the 'Backyard House' case study dwelling, the circulation core establishes a successful buffer to mediate the transition from the formal living area at the front and the informal family space at the back. Because access to the private open space was a prerequisite for the design mutual accessibility was important. The ambiguous connection and transient occupation provided by the circulation core ensures that each living space is freely connected but suitably separated. This relationship creates a successful transition from public to private which is also important in discerning the primary entrance point from the private family living space beyond.

- Vertical Circulation - Perpendicular to Street: In the ground floors of all case study dwellings the vertical circulation - stairs - have been utilised as visual thresholds which effectively filter the visual connection between the primary points of entrance and the adjacent living areas. The most successful example of this feature is in the 'Frontyard House' case study where the location of the stair and the configuration of the entrance combine to clearly demarcate the change in spatial function from 'entry' to 'living.'

- Forward Street Edge: The 'Courtyard House' case study dwelling employs this design strategy to establish the primary interface between the public environment of the street and the dwelling. This strategy ensures that there is an immediate relationship between public and private which is characterised as an edge situation. This edge characteristic, however, is undesirable and is fundamentally detrimental to the idea of a gradient. While it contends with the gradient, the key success of this strategy is that the resultant unconventional interface with the public realm propagates the use of further design strategies to facilitate a gradient. The application of this strategy is successful only because the informal and ambiguous household functions allocated to the front of the 'Courtyard House' soften the immediacy of the interface. Critical thresholds have been provided thus elongating the relationship between public and private. A successful gradient between public and private would not eventuate in alternative applications and contexts.

- Detached Street Edge: This strategy has been applied in the design of the 'Backyard House' case study. The withdrawal of the building mass from the street edge creates a useful buffer zone which helps to distinguish the public domain from the immediate domestic spaces. In this case all ambiguity has been removed and a very clear hierarchy of spatial functions eventuates. To emphasise the private possession of this zone, and the significance of this as the primary interface, a front fence is used as a symbol to reinforce the transition from the street through to the point of entry. All of these characteristics aid the production of a successful gradient between the public street and the domestic interior.

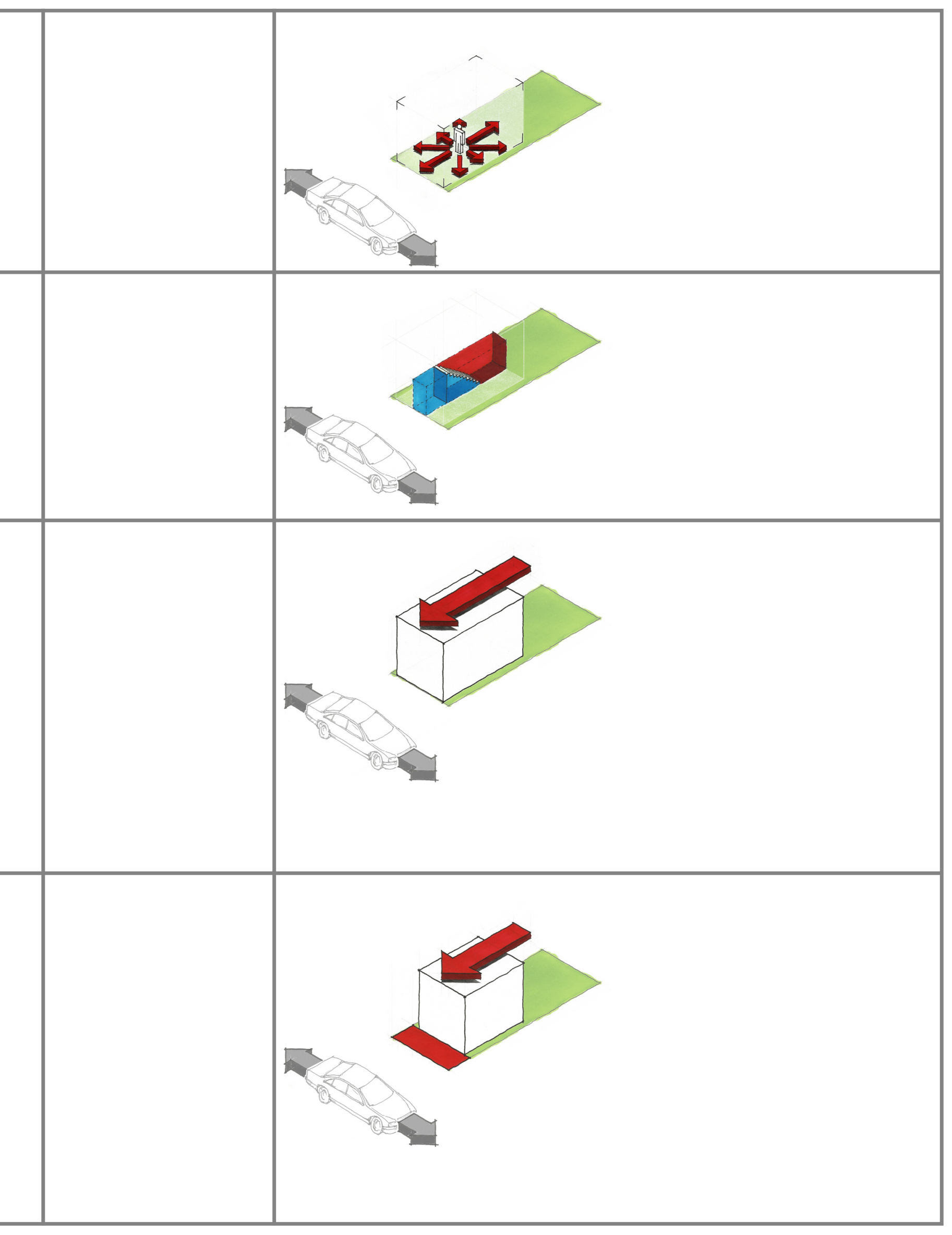


- Negative Facade Displacement: This strategy is implemented when a portion of the facade is withdrawn from the street. In the case study dwellings the most successful withdrawal of the facade occurs with the primary entrances. To varying degrees, the sections of the facades including the front-doors are withdrawn from the forward edges of the dwellings. This creates a semi-public sheltered alcove or pathway which is fundamentally different to the public street condition. A threshold is produced, similar to a veranda situation, which differentiates the street from the moment of entrance. The result is an elongated process of entrance which is a vitally successful component in establishing an initial zone of transition for the gradient between public and private. However, displacements in this manner produce very narrow spaces at the fronts of the houses which can be difficult to occupy, especially when the site frontage is already very narrow.

- Positive Facade Displacement: The facade projection strategy is implemented in a much more subtle manner. Primarily, the projecting parts of the facade serve to break up the mass of the dwelling and provide depth to the facade. In the case study dwellings this scale of 'projection' directly opposes an adjacent deep-set window or balcony to emphasise the depth being created in the facade. The resultant dialogue between 'mass' and 'void' created by the depth and change within the facade is critical and successful in establishing visual thresholds between the public and private realms.

- Recessing of Floor Level: This strategy is implemented when a portion of a floor level is withdrawn from the street. The 'Frontyard House' case study clearly demonstrates the strategy of progressively withdrawing lower floors away from the dwelling edge. As an architectural gesture, the higher floors require cantilevering suggesting that the dwelling is attempting to span the open space to reconnect with the street. However, the distance between the street edge and the dwelling is too great to mitigate effectively through this strategy alone. In this situation, the secondary attribute of a horizontal displacement serves to break up the facade. This introduces depth to the facade and visual movement through perceived thresholds. The distance from the street, though, reduces the success of this feature.

In the 'Backyard House' the ground floor is withdrawn slightly beneath the first and top floors to establish a greater perceived distance between the street and the formal living area directly adjacent. By slipping the floor back slightly, the depth of the walls and structural members are revealed, creating a visual threshold and emphasising the significance of the gradual transition between public and private. 


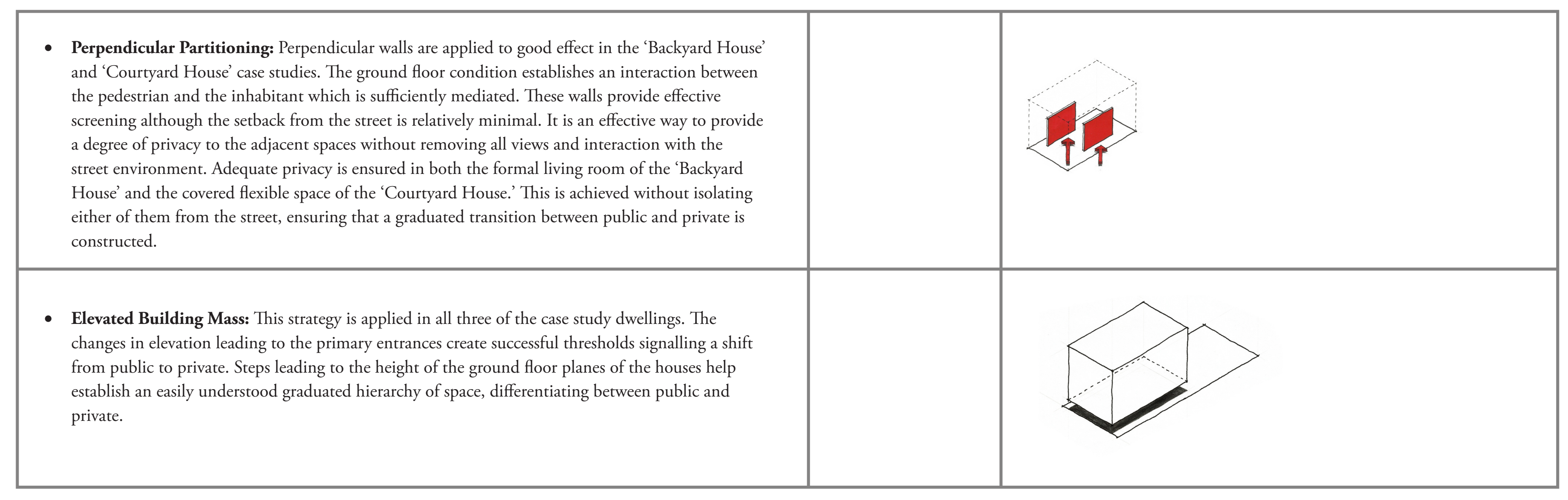

\section{Building Fenestration - the Conditions of Enclosure}

- Edge Window: This opening strategy is used in all three case study dwellings in the facades of the forward bedrooms on the first floors. This is an effective means to erode the sense of enclosure experienced from within the private spaces, and heighten the awareness of the street environment. This provides an opportunity for the public and private realms to negotiate the visual threshold of the window, as determined by the inhabitant. This engagement and passive awareness of the street assists the formation of a gradient between public and private. However, the immediacy of the relationship created by this strategy creates an overexposure the private quarters to the public realm. A significant view into the bedroom from the street conflicts with the private nature of the space, reducing its integrity.

- Visual Movement - Deep Reveals: This opening technique is applied to the top floor 'Glazed Walls' in all case study dwellings and also the window connecting the formal living area and the outdoor buffer zone of the 'Backyard House.' The application of this strategy results in the establishment of a strong frame to the openings and a greater depth to the facades. These characteristics effectively elongate the visual transition from public to private providing another threshold for the public private gradient.

(1)


- Glazed Wall: An entirely transparent wall enables a close and detailed visual interaction between the two situations on either side. In the 'Backyard House' case study the ground floor relationship between the formal living area and the outdoor buffer zone adjacent to the street is enabled and enriched by the full window opening strategy. In the top floors of all of the case study houses this strategy is employed providing an un-obscured view overlooking the street for the master bedrooms. While this enhances the awareness of the public realm and helps to produce a graded transition from public and private, the height separation means that the privacy of the bedroom is retained at least from near vantage points in the street.

On the other hand, the removal of an entire visual boundary makes the indoor environment more accessible to the public realm. Careful use of this strategy is required to ensure that the resultant spaces are functionally appropriate and avoid uncomfortable exposure.

- Screened Window: This strategy is applied in the 'Backyard House' and 'Courtyard House' case studies to mitigate the intimacy of the visual relationships between the street and the forward bedrooms first floors. This feature successfully mitigates the visual intrusion from beneath by providing a set of louvers to complicate the views into the bedroom. This restores some of the private balance to the space which was initially eroded by the edge window. The screening components re-articulate the visual boundary is a softer manner to the solid external walls facilitating a successful mediated transition from public to private. 


\section{Connections, Combinations and Interrelationships}

While it is important to understand how each design strategy affects the public-private gradient on its own, it is also important to recognise that they are not applied separately. It is critical that the design strategies are not viewed as stand-alone principles that simply aggregate to create successful gradients. Rather, they are options within a broader series of strategies. In this situation each individual strategy merely affects the gradient and further design decisions or options, as opposed to creating the gradient. A number of strategies have implicit connections with others and, consequently, are implemented in such a manner. The purpose of this section is to discuss how those strategies are interrelated by identifying and subsequently evaluating the variety of combined design strategies with specific regard to how the public-private gradient is affected. The key conclusion advanced in this section is that the main discrepancies exhibited by the isolated design strategies are mitigated and even improved when combined in a considered holistic manner with other design strategies.

\section{- Forward Street Edge + Flexible Car Space - Street Access + Functional Layout}

Positioning the building volume directly on the street edge creates an unwanted edge condition between the street and the domestic interior. To mitigate this condition and produce a graduated transition between public and private, this strategy is fundamentally connected to the idea that vehicular access off the public street can produce an ambiguous, sheltered space. This ambiguity softens the edge condition significantly. However, this is only successful if the orientation of the domestic spaces logically supports the large flexible space at the front of the site. The 'Courtyard

House' case study is an example of this combination operating successfully. In this circumstance, a further connection from the multi-use car port to the private courtyard and the indoor living area beyond is a result of careful consideration of the location and orientation of the internal function spaces. Individually, both the Forward Street Edge and the Public Street - Car Access strategies fail to produce any means of gradual transition between public and private. But in combination, along with the additional consideration of spatial organisation, their characteristics can alleviate the tension between public and private and holistically demonstrate a graduated change.

\section{- Rear-lane - Car Access + Functional Layout}

The evaluation of the Rear-lane - Car Access design strategy reveals that it indirectly affects the public-private gradient. This site planning strategy makes an ideal arrangement of inhabited domestic spaces possible. As an isolated strategy, the transition from public to private was not explicitly affected. To mitigate this limitation it is vital that the orientation and organisation of the internal domestic spaces is carefully considered. As shown by the 'Backyard House' case study in particular, these two strategies in combination capitalise on the opportunity to effectively mediate the transition from public to private. Positioning the garage at the rear of the site eliminated the problematic relationship between the public street and the entirely privatised garage volume. Consequently, the formal living area of the household and an elongated process of entry could suitably occupy the front of the site, providing a more adequate means of mediating a gradient from public to private.
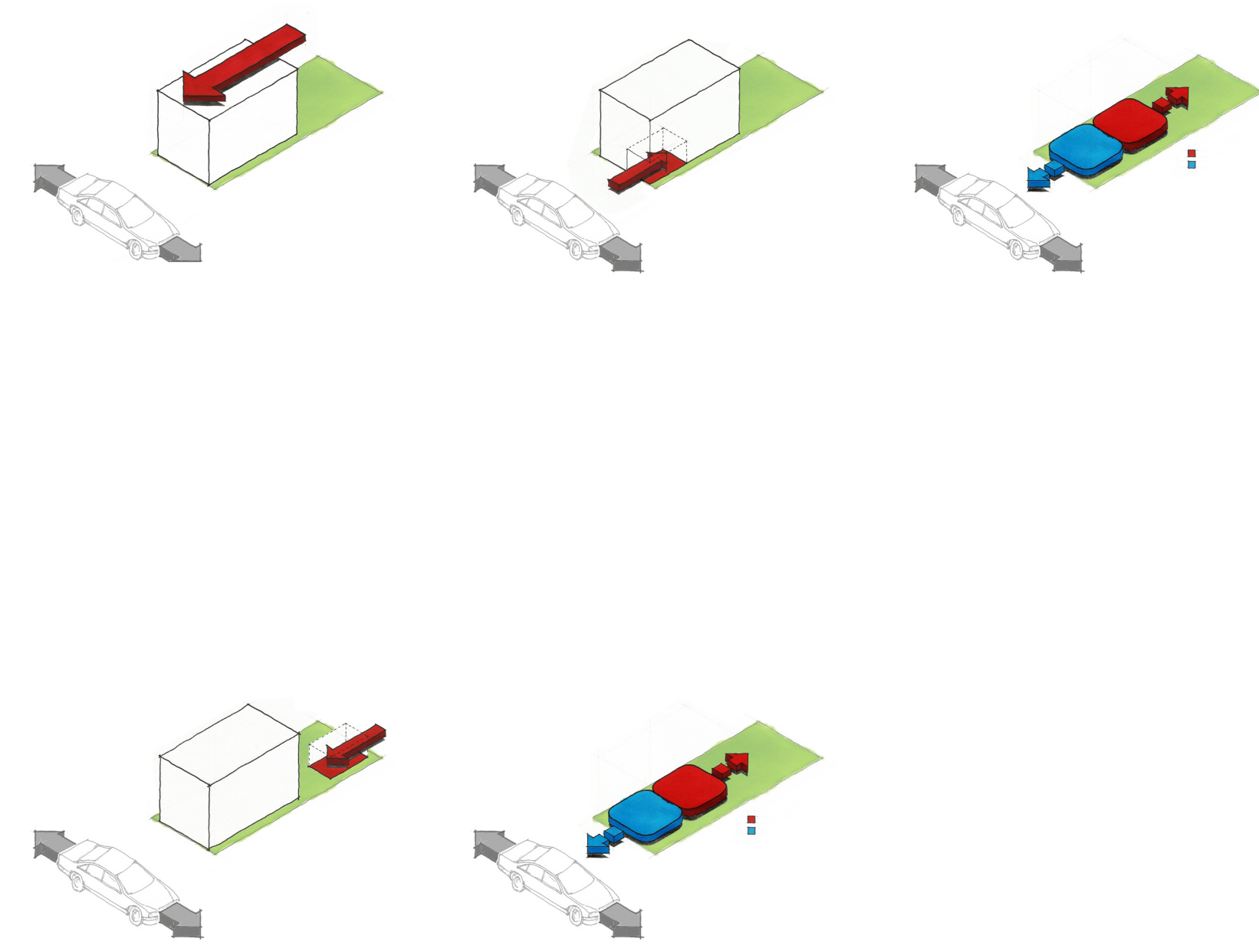


\section{- Circulation Axis + Vertical Circulation + Functional Layou}

There is a tendency throughout all three of the case study dwellings to implement the Circulation Axis planning strategy in tandem with the Vertical Circulation visual threshold strategy. This combination reinforces the ideal distribution of the Functional Layout strategy but within the circulation spaces. Being able to visually distinguish more public areas from the more private areas of the household establishes a clear hierarchy of accessible spaces from a visitor's perspective. The ground floor of the 'Courtyard House' case study demonstrates this characteristic particularly well: the visual threshold of the stairs signifies a point in the circulation spine where the public accessibility of the adjoining spaces space switches to a more privately accessible rear of the house.

\section{- Circulation Core + Functional Layout}

The evaluation of the Circulation Core design strategy advocates the example in the 'Backyard

House' case study where the circulation core firstly, connects the surrounding spaces, and secondly, provides a buffer zone between formal and informal living areas. The second key benefit of thi strategy is realised only when implemented in conjunction with the Functional Layout strategy. Its transient and ambiguous characteristics, the circulation core facilitates the fulfilment of the needs of the functional organisation of the household. The requirements to both provide a mutual connection to the rear private open space and retain a fundamental spatial disconnection between the formal and informal living areas are met in the combination of these two different strategies.

Because the transition between the formal and informal areas is mediated by the transient and ambiguous circulation core, the need for physical partitions is eliminated. This facet of the combination means that the overarching public-private gradient is graduated rather softly but ultimately quite successfully.

\section{- Functional Layout + Bedrooms Removed from Ground Plane}

The Functional Layout of the household is particularly important in establishing a public-private gradient between the street and the domestic interior. By removing the bedrooms from the ground floor, more subtle planning details are dealt with to create a permeable and mediated gradient.

The discussion of the second strategy in this combination reveals the planning motives driving its development. All of the case study dwellings demonstrate that the elimination of the conflict and tension induced by the presence of bedrooms on the ground floor reinforces the manifestation of the ideal functional progression from public to private advocated in the first strategy. A secondary consequence of this combination is the discernible shift from public to private occurring vertically within each of the houses. The ground floors meet communal and public social needs of the household, while the first and second floors become progressively more exclusive and private, replicating the lateral public-private gradient, in a vertical direction.
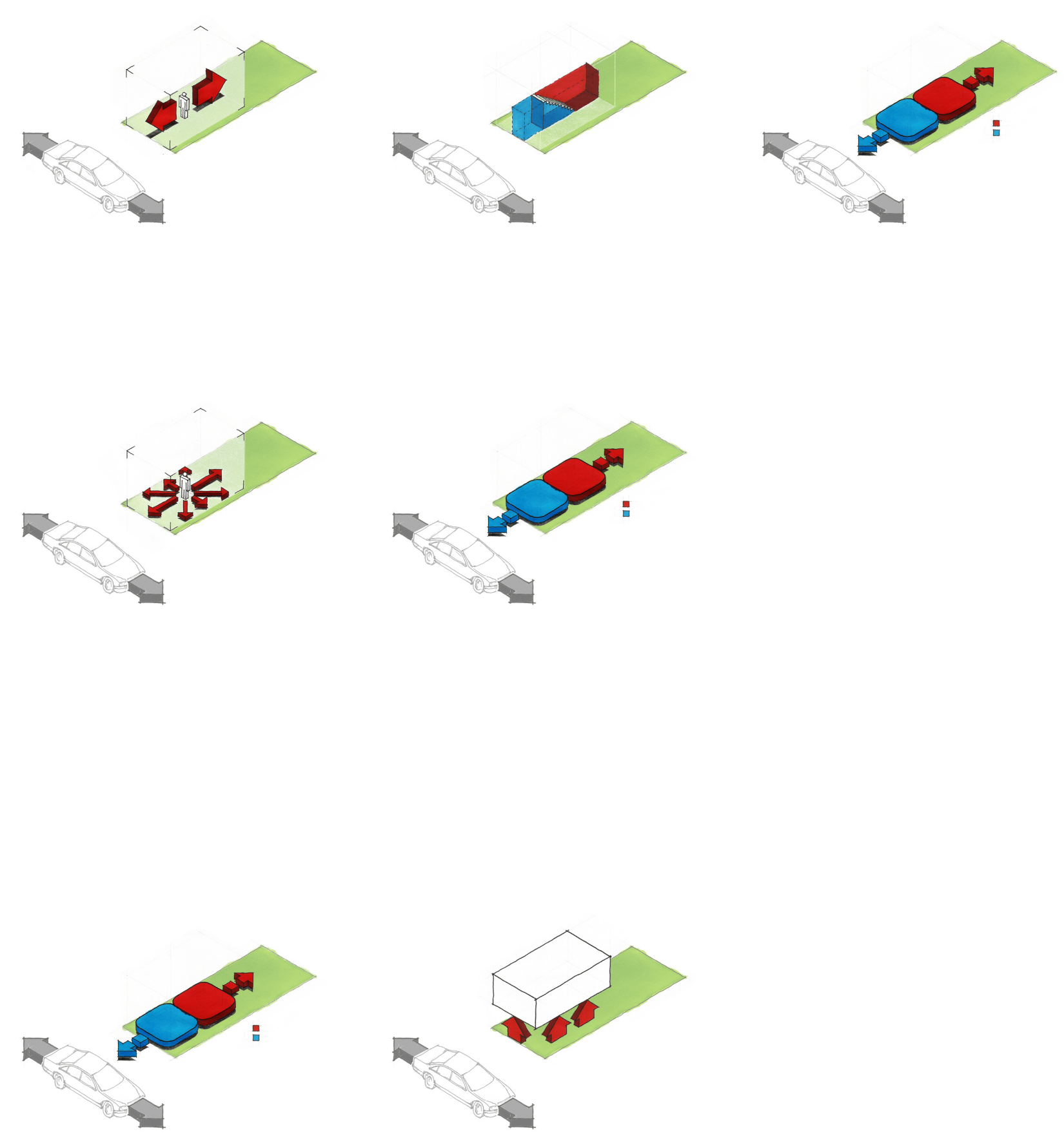
- Forward Street Edge/Detached Street Edge + Perpendicular Partitioning + Glazed Wall Both the 'Backyard House' and 'Courtyard House' case study dwellings are situated close to the street. To maintain a level of visual permeability in the facades of these houses without compromising the functionality of the household spaces a degree of mediation needed to occur. The glazed wall provides an easily traversed visual threshold with incredibly high connective qualities. This strategy was implemented to connect the formal living area with the landscaped buffer zone and the street environment beyond in the 'Backyard House.' However, the indoor environment is left rather sterile and exposed if the relationship is not mediated. The subsequent inclusion of the Perpendicular Partitioning provides a degree of seclusion to the formal living area, maintaining its integrity as part of the household. The relationship between these two strategies, in the context of the forward positioned dwelling volumes, is therefore critical in improving the gradual nature of the transition between public and private. This is achieved without compromising either the visual connectivity, or functional integrity of the spaces.

\section{- Edge Window + Screened Window}

These strategies are applied in tandem specifically to mediate the interface between public and private. In the first floor bedrooms the Edge Window increases the level of engagement between the public and private realms. This is good for the gradient but not for the private integrity of the bedroom, as discussed previously. To mitigate this conflict in design intentions it is critical that the unhelpful characteristics are removed. The secondary application of the Screened Window successfully moderates the visual connection from the street into the bedroom. As a combination the positive characteristics of the edge window strategy are retained, improving the graduated transition from public to private, and alleviate negative tensions.

\section{- Facade Displacement + Elevated Building Mass + Circulation Axis}

The connection between these three design strategies occurs naturally. They are applied to the case study dwellings due to their individual merits discussed earlier. However, with a specific focus on the process of access and entrance to the domestic interior, these three strategies combine to implicitly improve the gradient between public and private. The Circulation Axis facilitates a linear approach to the dwelling from the street which suits the narrow proportions of the site and dwelling. As has been established earlier, this linearity reinforces the ideal logical arrangement of public spaces at the front and private at the rear. All three case study dwellings show that the axial approach promotes the physical and visual thresholds. This clarifies and reinforces the subsequent graduated zones of change as the private domain draws near. The graduated zones of change are instigated by the Facade Displacement and the Elevated Building Mass design strategies. The withdrawal of the facade along the approach axis creates a physical void articulated by the remaining front edges of the building creating the first threshold and zone of transition. This is immediately followed by a set of steps which bring the pedestrian up to the ground floor level. This physical ascendancy is the second key threshold and establishes the second zone of transition leading to the primary access points in all of the dwellings.
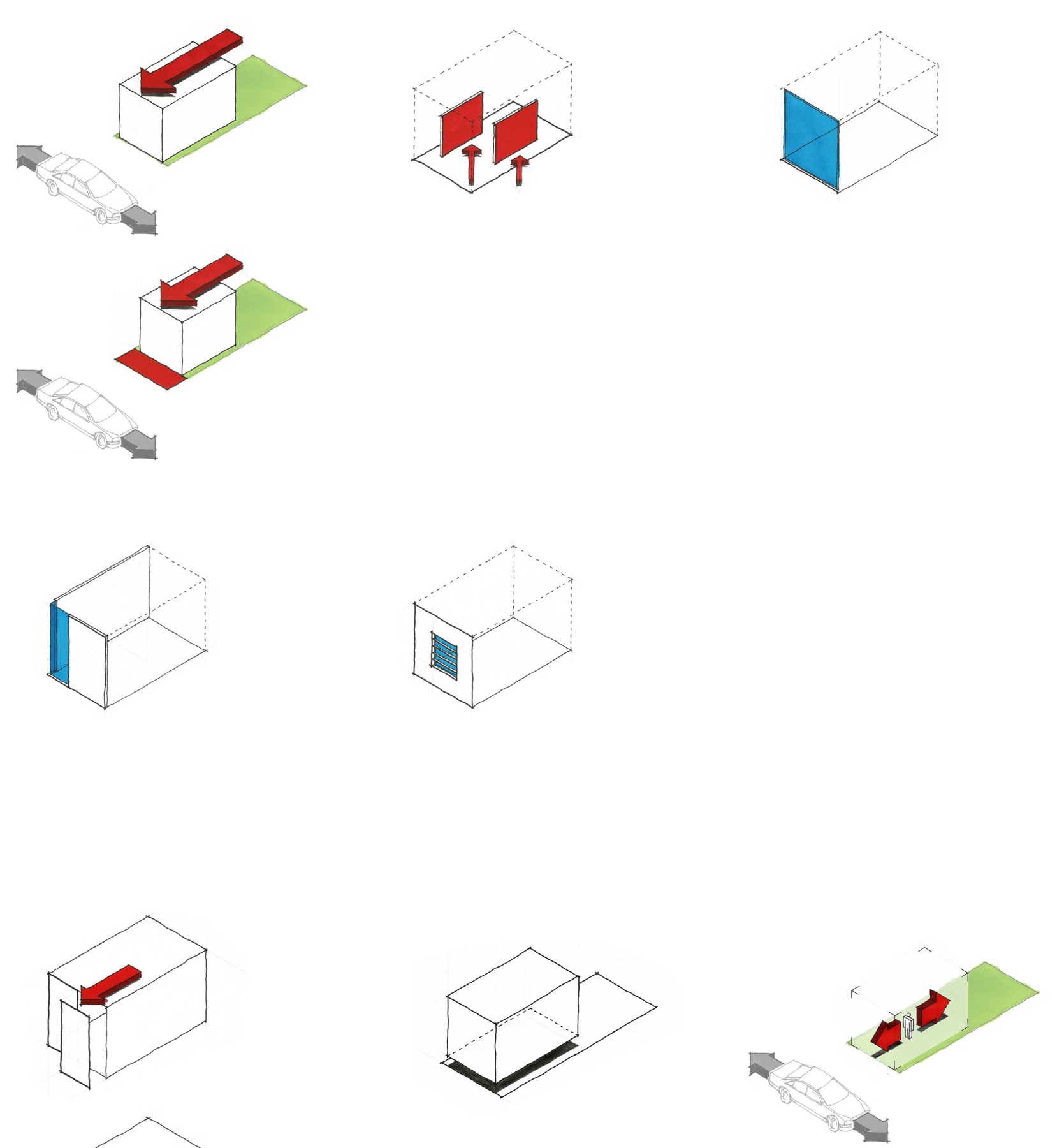


\section{- Functional Layout + Facade Displacement}

This combination of design strategies utilises the functional requirement of storage in the bedrooms to reinforce key moments in the facade. The spatial planning consideration of storage within the forward bedrooms provided a catalyst for the introduction of a projecting element in the facades of each case study dwelling. This feature serves to break up the plane of the facades, helping to further articulate the existing changes in depth created in balcony, or withdrawn window situations. This combination successfully offsets those aspects of the facade, adding a dynamic interplay between positive and negative elements.

\section{- Glazed Wall + Deep Reveals + Recessing of Floor Leve}

The final combination of design strategies serves to mitigate the negative aspects of the Glazed Wall fenestration strategy. These are applied to the master bedrooms on the top floors of all case study dwellings. The evaluation of the Glazed Wall strategy implies that it needs to be applied carefully to avoid a tension between the street and the privacy of the master bedrooms. The transparency of the threshold is put into perspective by introducing reveals into the window edge; withdrawing from the primary dwelling edge shifts the emphasis to the profile of the window surrounds. The Storey Horizontal Translation strategy adds a further mediating device in the form of a balcony. A balcony creates another zone of transition between the public and private realms, which is privately habitable. As a result of this combination the discrepancies of the primary fenestration strategy are mitigated and a graduated transition from public and private is achieved without compromising the privacy of the master bedrooms.
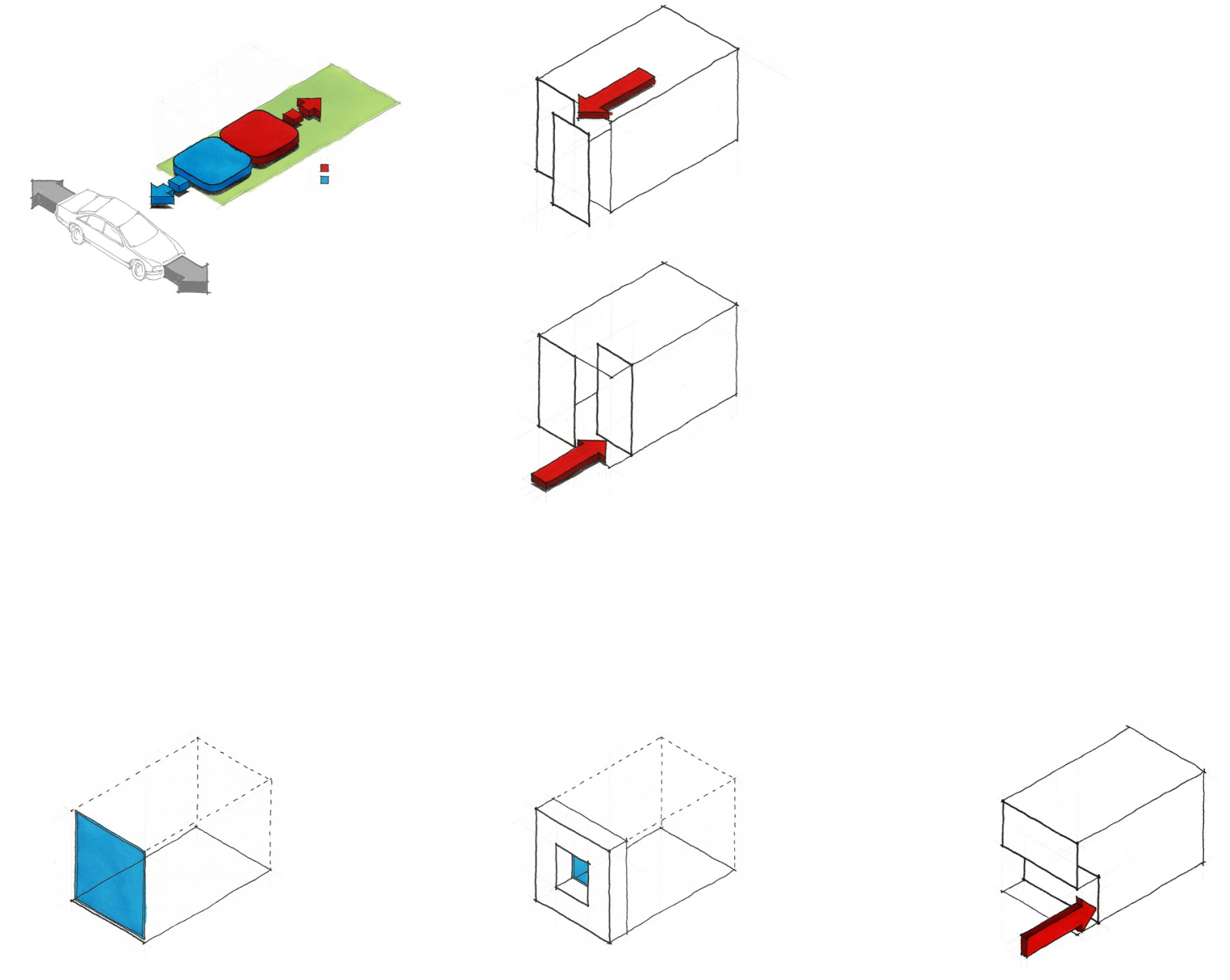


\section{Formal Concept vs. Design Strategies}

The final topic of discussion in this chapter is the neutrality and flexibility of the design concept and the effect it has on the application of the design strategies throughout the design process.

The form-making concept features a planar element which 'wraps' the building envelope simultaneously concealing and revealing particular areas of the enclosed environment. The interpretation of this concept results in an open-ended skin component that wraps the main building volume. It was initially anticipated that this type of form-making concept would not affect the application of design strategies to the case study dwellings. The site chosen for the design case study houses is a narrow midblock allotment which is consistent with higher overall densities and a detached 'single-family' development type. The dwelling proportions are constrained within the allotment dimensions ensuring a direct arbitrary correspondence between urban and domestic design motives. The subsequent application of design strategies to produce the domestic spaces also conform to the axial nature of the site and dwelling. Ultimately, this broader requirement works very well for the 'ideal' conceptual gradient arrangement of 'public' spaces at the front and 'private' at the rear. The predetermined framework for the application of the design strategies effectively simplifies the process to layering and combining them along a prescribed axis. Because it fundamentally follows the linear, front to back orientation, the form-making concept has largely no effect on this application methodology.

However, while the conceptual 'wrapping element' is essentially hollow and linear in nature, there are implied volumetric implications for the final form of the dwellings. The following points highlight the influence of the form-making concept on how the strategies could be applied and the extent to which they could be tested:

- The Positive Facade Displacement and Projection of Floor Level strategies are limited by the forma concept. The projection mode of this strategy is implemented in a much more subtle manner because it conflicted with the overarching design language. The 'wrapping' element effectively subdued any projecting components because the building edges and form limits are predetermined. While this ensures the legibility and predominance of the 'wrapping' element as an architectural gesture, the full potential of the 'projection' and 'bay window' strategies is not realised.

- Location of the vertical circulation. In each case study dwelling the location of the stairs coincides with the angled section of the wrapping element. While successful gradients are achieved in these situations, this aspect of the houses was a predetermined design solution, rather than the result of application and testing of design strategies. Alternatives for vertical circulation are not successfully explored because of this.

- The master bedroom in the 'Courtyard House' case study dwelling does not include an adjoining en-suite. This is the result of a necessary compromise of design objectives in favour of maintaining the overarching formal concept and reinforcing the initial courtyard open space configuration. It was decided that additional bathrooms would add significantly to the building mass and begin to eliminate the remaining open space for the courtyard. A further comment relates to sun and light penetration to the courtyard. This space becomes vulnerable to being built out because it is not o either the street or the rear lane. Furthermore, while specific orientations of a three-storey volume on the street might produce a successful courtyard space, other orientations might produce deep shadow in the courtyard reducing its desirability.

- Because the gradient is the focus of the research, visual and conceptual compromises are made while locating partitions which are perpendicular to the street. All three houses have perpendicular walls at the forward edge of the building on the ground floor where it is supposed to read as a conceptual void. While they conflict with the overarching design concept, the walls are necessary to improve the legitimacy of the enclosed spaces as part of the domestic interior.

The form-making concept itself does is not directly a strategy for mediating the gradient between public and private. However, because of the volumetric implications and assumptions made to ensure that the design language ultimately communicates the intention of the concept, it manipulates the type of strategy used and even the extent to which it can be used. Because of this evidence, another conclusion of the design case study is that the design concept is a fundamental technique for putting parameters around the use and application of design strategies. 


\section{Chapter Seven: Conclusion}

7.1. Introduction

7.2. Significant Research Outcomes

7.3. Shortcomings, Limitations and Opportunities for Further Research

7.4. Final Comments 


\subsection{Introduction}

This thesis is centred on the relationship between the public and private suburban realms. The research process uncovered a variety of design strategies for manipulating the public-private gradient. These strategies were then implemented in three design case studies demonstrating a graduated transition between the street and the domestic interior which is proven to be mutually beneficial for the occupants of both public and private domains. The intention of this chapter is firstly, to discuss the significant conclusions reached at each stage of the research process, and secondly, to consider the main limitations of the research and relevant issues which fall outside the scope.

\subsection{Significant Research Outcomes}

Chapter 2 explored the problematic interface between public and private. The research suggests two imperatives for change in the way residential suburban development is planned and built:

- Projected population growth ensures that land consumption propagated by the spread of suburbia is not sustainable;

- And, suburbia produces poor a poor public domain which affects the perception of 'community' in suburban neighbourhoods.

Discourse on contemporary suburban environments highlights the poor relationship between public and private. This flaw was found not to be an isolated problem but part of a broader web of issues. This assertion confirms that in addressing the research focus of the public private interface through design, a holistic understanding and design of both a wider residential subdivision and specific street conditions would be required.

The two imperatives for change led the inquiry setting a foundation for the design investigation of a positive interface between public and private. The evidence suggested that a hierarchical spatial approach featuring a gradient as a tool to manage the zones between the public and private realms establishes a constructive and mutually beneficial relationship. A gradient provides the means to balance and negotiate between the potential for social connection and also the desire for privacy through articulated intermediary spaces. In this context the importance of thresholds to the formation of intermediary spaces became apparent.

Chapter 2 determined that while the goal was ultimately an enriched and urbanised suburban domain, the establishment of a gradient between the public and private realms within suburbia would be the primary methodology employed to help transform the suburban street into a suburban place.
Chapter 3 investigates the public-private gradient through the historical progression of residential development in Wellington. The existing housing stock in five key suburban eras is subject to a comprehensive comparative graphic analysis.

The key observations from this study were:

- Over time the design of the house has become independent of the layout of the streets and lots which has led to a diminished relationship between the public and private realms;

- A significant disconnect between the 'social' and 'private' areas of the house has developed;

- There has been an increasing trend towards orientating the social and informal areas of the house towards the private open space transfering the majority of the social functionality of the home away from the pubic domain;

- Problematic spatial relationships between the street and informal areas of the home now occur due to the lack of consideration of the interface between public and private;

- The priority of the garage as a primary spatial element at the front of the house has increased which significantly impacts the character and experience of the street environment.

This study suggests that residential suburban development has come to emphasise the difference between the public and private realms rather than mediate,manage or modify the inherent tension between those two domains. However, this analysis also demonstrates that early models for residential development successfully established and managed the public-private interface. The lessons from early residential development models which remain valuable to the establishment of a successful public-private gradient are:

- The factors that defined house forms and street layouts of the time were interconnected;

- Interior spatial planning directly informed the arrangement of architectural modules which were displayed to the public realm of the street;

- A series of significant thresholds were established to create a hierarchy of spaces and intermediary zones, denoting a sequential change from public to private.

This chapter, while supporting the imperatives for change suggested in Chapter 2, begins to set out a series of practical and tangible ideas about how a public-private gradient can and cannot function a mediating device.

Chapter 4 presents a series of urban and architectural design precedent studies. The intention of this chapter is to gain a practical understanding of specific functions, characteristics and architectural components that contribute to a successful public-private gradient.

The precedents selected for this stage of the research fall into either one of two categories: urban or architectural precedents. The important design considerations coming from the urban precedents are: 
- The innovative approaches to the design of street environments facilitate more dynamic and active public realms in suburbia;

- Alternative off-street car storage strategies which effectively remove the garage door from the street facades of houses increase the likelihood of a successfully managed transition from public to private;

- Master-planning strategies which establish legible and distinctive precincts within the development enhance the legibility and clarity of the suburban environments;

- Speecific building design codes which encourage the use of architectural elements to create dynamic relationships between houses and streets are implemented to ahcieve strategic cohesion and ensure a degree of unanimity in the design intentions of the residents;

- And, by increasing the range of dwelling types and planning mechanisms, a more diverse distribution of density concentrations can be achieved.

The key design considerations coming from the architectural precedents are:

- Wider site or allotment planning considerations of how the house occupies the site, building setback, car access and the location/orientation of the private open space;

- Internal spatial planning objectives such as the logical hierarchy of more public and more private areas of the household, and the configuration of circulation areas;

- Building mass, form and geometry design primarily affecting the street facing facade as a significant interface between public and private;

- Threshold and permeability of the building volume - implications for visual connections and awareness of adjacent activity spaces.

The scope of Chapter 5 was to clearly establish the context for the design case studies that occur in Chapter 6. The focus of the first part of this chapter remains at an urban scale, addressing the redevelopment of an existing subdivision proposal north of Waikanae in the Kapiti Coast district. The holistic approach to the design of suburban development underpins the significance of this section. It is completed prior to the main design case study to demonstrate the interdependance of street, lot and house and also to maintain the internal clarity and coherence of the design. The site analysis, master-planning and suburban street design components are completed in Chapter 6 establishing a design vehicle for the intensive design testing of the public-private gradient in the following chapter.

Chapter 5 also introduces a set of design strategies for manipulation of the public-private gradient at an architectural scale. These are presented in tabulated form Each strategy is assigned a diagram which helps to identify the application of the strategy in the design case study.
Chapter 6 covers the crucial design phase of the research. The 'design strategies' are applied to three case study dwellings situated within the modified subdivision proposal identified in Chapter 5 . Throughout the process of designing, the application of mediating elements is demonstrated.

The site selection, design brief and programmatic requirements, overarching formal concept for all of the case study houses are demonstrated. The application of design strategies is portrayed in two modes, firstly the the formation of planning strategies, and secondly, strategies which determine critical thresholds and the permeability of the house volume. The subsequent visual material documenting the three case study dwellings is the primary outcome of the research.

Chapter 6 also features the exegesis component of the research in which the design outputs come under scrutiny and the key conclusions are made. Discussion of all of the employed strategies, evaluating the degree to which a graduated transition between the public and private suburban realms is achieved is followed by an examination of the interrelationships and combinations within the series of design strategies themselves. The independence and neutrality of the overarching design concept in relation to the application of the design strategies is the final topic of discussion.

Chapter 6 thus served to validate the key design principles obtained through the process of this research by applying them to a tangible project. The methodical rigor of the design process firmly establishes the plausibility and practicality of the design strategies. 


\subsection{Shortcomings, Limitations and Opportunities for Further Research}

This section outlines a number of limitations of the research. Additionally, a number of issues not specifically addressed because they fall outside the focus of this research are recognised. Further analysis and understanding in these areas would benefit this research.

The main weaknesses and uncertainties of this research are:

- The design does not fully address the need for car access and storage. Most households require more than two cars to meet their needs. The design decisions of narrow houses to fit correlating allotments, and the reduction of the number of garages on the public street facade, limit the conventional street front garage possibilities. More on-street parking options have been provided but the main ambition in this context is that the neighbourhood design and street pattern is more 'walkable' and easier to navigate with on foot or bicycle. Any subsequent improvement and establishment of more successful public transport hubs would ideally alleviate the need for cars. The rear lane concept provides a car access alternative within the street pattern, but it also increases the possible circulation space within the development increasing the overall infrastructure cost. Another weakness of this design decision is that rear lanes have been associated with higher crime rates.

- The narrow house type was selected for the beneficial reasons explained in Chapter 6. However, because of the houses' close proximity to each other, there is an increased risk of fire spread which requires further specialised design which falls outside the scope of this research. Alterations to district council planning policy which prescribe boundary setbacks and fire-proofing would address these issues, but would extend the research well beyond the intended focus.

- The design concept which informs the architecture of the house is fundamentally subjective and could vary significantly. It is also recognised that not all suburban houses are explicitly designed architectural works. Because any design concept is generally negotiated, or even absent, the outcome could impose difficulties for the application of the design strategies. This is another justification for presenting the strategies as a repertoire of loose-fit possibilities. A further remedy to this weakness would be to create design regulations for entire subdivisions which would be suitably flexible and neutral to encourage the application of the design strategies. This solution could increase the legibility and coherence of the suburban environments through a degree of design uniformity which could reinforce the desired characteristics. Also, poor quality future development could be curtailed.

- The return to a linear dwelling type familiar to some traditional villa models is significantly different to the contemporary vernacular suburban stand-alone house. The tall and narrow houses match the long narrow allotments of private land, helping to mitigate the urban impact of house design as discussed earlier. However, increased suburban densities and efficient land-use is not the focus of this research. Further investigation is required to legitimise the assumption that the desired place-based perception of 'community' also benefits from efficient use of the land, smaller footprints and higher concentrations of development densities.

- Similarities in planning, layout and appearance of the three case study dwellings to semi-detached and terraced house forms indicates that the strategies may be able to be applied to a variety of other house types. The design approach developed in this thesis could easily be applied to semidetached and terraced housing. The variation in house types offer even higher concentrations of densities while potentially introducing a different character to the street environment. However, the introduction of further house types to the design approach in this research is an important factor in confirming this statement. The assumption that the design methodology is flexible enough to be applied successfully to a variety of suburban house types is as yet untested. Further design case studies which critically investigate each house type while employing the design approach need to be completed.

- While economic considerations fall outside the scope of the research, it is necessary to recognise that the private open space configurations can result in much more unorthodox and unconventional buildings. The favoured and more familiar option of the three is to locate the private open space at the rear of the lot. Alternatively, the court-yard house is features a greater area of circulation and a comparatively large building envelope making it considerably more to design and construct financially. It is then questionable as to whether the prescribed design brief and programme would meet the higher expectations for a building of that price and scale. However, these costs and sacrifices are offset by the better quality environments that are evaluated and discussed in Chapter 6. Costs could also be mitigated through the development process if a developer could build and tenant the dwellings as a triplex or attached terrace type of building. The burden of the extra investment required for the court-yard dwelling could be distributed across the extent of the development. The unorthodox open space configurations are also more beneficial in situations where the preferred back-yard option is compromised. An adjacent apartment building overlooking the conceived back-yard would affect the value of that open space option, imposing the consideration of alternative models.

- The notion of facilitating an improved perception community is an important pretext fo examining the public-private gradient. Although a comprehensive understanding of community the effect of community and what initiates community would undoubtedly benefit this greatly, that study is in itself a broad literary subject requiring specific expertise. It is important though to recognise that even a perception of robust community that is place-based is valuable and that establishing a successful public-private gradient is conducive to an improved perception of community. 


\subsection{Final Comments}

In summary, the core focus of establishing a means to successfully negotiate the problematic interface between public and private is comprehensively understood and fulfilled in this design research.

The initial holistic design approach toward the site produced a street pattern and development framework suitable for an intensive specific interrogation of the interface between public and private. This

methodology provided the impetus to restore some of the traditional co-dependency amongst the suburban house, lot, and street in order to create a positive public realm in suburbia which has been lost over time.

The understanding of robust 'place-based' community acquired in the cours of this research has been critical in the development of ways to equip suburban streets with socialised infrastructure, or habitable and negotiated transitions between public and private. It is in this area that the research is most successful. The explicit imperative to target the improvement of the pedestrian environment gave rise to the acquisition of a repertoire of design strategies which ranged from having quite broad, holistic effects to

having rather specific functions as part of a sequence of thresholds. The carefully considered application of each of the specific design strategies enabled the establishment of a successful gradient between the public and private realms.

The limitations of the research outcomes has been discussed earlier and while the application of the standardised strategies is still questionable in particular circumstances, the evidence suggests that, overall, it has been a successful procedure. The range of design outcomes help to illustrate an attractive and flexible street environment with a distinctive character defined by the enclosing facades of the case study houses to reinforce the 'place' characteristics of the suburban street. 


\section{Bibliography}

Arbury, Joshua. "From Urban Sprawl to Compact City - An analysis of urban growth management in Auckland." Diss., Unpublished.

Arde, Stewart, Ian Bowman. New Zealand period house: a conservation guide. Auckland: Random House, 2004

Arnheim, Rudolf, Wolfgang M. Zucker, Joseph Watterson. "Inside and Outside in Architecture: A Symposium.” The Journal of Aesthetics and Art Criticism. Volume 25, Number 1 (1966): 3-15.

Brookes, Toni-Rose. "Inside/Outside and the [inbetween].” Diss., Victoria University of Wellington, 2012

Brueckner, Jan. K. “Urban Sprawl: Diagnosis and Remedies.” International Regional Science Review. Volume 23, Issue 2 (2000): 160-171.

Calthorpe, Peter and Sim Van der Ryn. Sustainable Communities: A New Design Synthesis for Cities, Suburbs and Towns. San Francisco: Sierra Club Books, 1986.

Chamberlain, Peter. "Community Commodified: The Prestons Road Residential Subdivision." Lincoln Planning Review. Volume 2, Issue 2 (2010): 14-16.

Davies-Yeang, Llewelyn. Urban Design Compendium: Homes and Community Agency. Location Unknown: English Partnerships, 2000.

Hayden, Dolores. Building Suburbia: Green Fields and Urban Growth, 1820-2000. New York: Vintage Books, 2003.
Jacobs, Jane. The Death and Life of Great American Cities. New York: Knopf Doubleday Publishing Group, 1961

Kolb, David. Sprawling Places. Athens, Georgia: The University of Georgia Press,2008.

Krugmeier, Paula Jean. “The Public/Private Interface: The Inhabitants Take Part.” Diss., Massachusetts Institute of Technology, 1980.

Kunstler, James. H. The Geography of Nowhere: The Rise and Decline of America's Man-made Landscape. New York: Touchstone, 1993.

Lo, Richard. "Between Two Worlds: The window and the relationship of inside to outside." Diss., Victoria University of Wellington, 1986

Lynch, Kevin. The Image of the City. Cambridge, Massachusetts: The MIT Press, 1960.

New Zealand. Department of Internal Affairs. "Setting the Scene - the background and context to sustainable urban development in New Zealand." 5 September 2012. <http://www.dia.govt. nz/diawebsite.nsf/wpg_URL/Resource-material-Sustainable-Urban-Development-Setting-theScene?OpenDocument>

New Zealand. Ministry for the Environment. The Value of Urban Design: The economic, environmental and social benefits of urban design. Wellington: Ministry for the Environment, 2005.

New Zealand. Ministry for the Environment. Urban Design Case Study: Addison Housing Development. Wellington: Ministry for the Environment, 2007. 
Norberg-Schulz, Christian. Genius Loci: Towards a Phenomenology of Architecture. New York: Rizzoli, 1980.

Opus International Consultants. New Zealand Transport Agency. "Scoping Report: Kapiti Strategic Study." Opus International Consultants. July 2008.

Radiant City. Dir. Brown and Burns. Perf. Daniel Jeffery, Bob Legare, Jane MacFarlane, Ashleigh Fidyk, Curt McKinstry, Karen Jeffery and Michaela Jeffery. Alliance Atlantis, 2006.

Ryan, V., Burgess, G., and Easton, L. New Zealand house typologies to inform energy retrofits. (2008). 19 May 2012.<http://www.beaconpathway.co.nz/images/uploads/Final_Report_EN6570(9)_NZ_House Typologies_to_Inform_Energy_Retrofits.pdf>

Stiles, Rose. "Intensifying the Grid: a typology for medium density housing to accommodate the changing demography of Wellington suburbs." Diss., Victoria University of Wellington, 2012.

Schrader, Ben. "Planning Happy Families: a history of the Naenae idea." Diss., Victoria University of Wellington, 1993.

Thompson, Kerstin. “Gradient architectures.” Architecture Australia. May/June 2001: 66-71.

Toomath, William. Built in New Zealand: the houses we live in. Auckland: Harper Collins, 1996.

Tuan, Yi-Fu. Space and Place: The Perspective of Experience. Minneapolis: University of Minnesota Press,

Tullimbar Village. “Tullimbar Village Centre: Building Design Guidelines.” Tullimbar Village, July 2006
Vernez-Moudon, Anne. Built for Change: Neighbourhood Architecture in San Francisco. Cambridge, Massachusetts: The MIT Press, 1986.

Venturi, Robert. Complexity and Contradiction on Architecture. New York: The Museum of Modern Art, 1966.

Wellington City Council. "Residential Intensification and the Wellington Urban Development Strategy: Creating the right conditions for intensive residential development along the growth spine." Wellington City Council. (2007): 24 September 2012. <http://wellington.govt.nz/ /media/your-council/projects/ fles/infill-resintens.pdf>

---. "Urban Development Strategy: Directing growth and delivering quality." Wellington City Council. (2006): 24 September 2012. <http://wellington.govt.nz/ /media/your-council/plans-policies-and-bylaws/ plans-and-policies/a-to-z/urbandev/files/urbandev.pdf> 


\section{List of Figures}

\section{Chapter 1:}

Fig. 1.1. The public-private gradient. A diagram demonstrating the area of interest: the transition from the public environment of the street to the private domestic interior.

\section{Chapter 3:}

Fig. 3.1. Newtown: Figure/Ground 1:10000 Fig. 3.2. Newtown: Street \& Block 1:10000 Fig. 3.3. Newtown: Roy Street Plan 1:2000 Fig. 3.3. Newtown: Roy Street Plan 1:2000

Fig. 3.5. Bay Villa Floor Plan

Fig. 3.6. Bay Villa Street Elevation

Fig. 3.7. Bay Villa Section

Fig. 3.8. Bay Villa Isometric

Fig. 3.9. Bay Villa Gradient Diagram

Fig. 3.10. Miramar: Figure/Ground 1:10000

Fig. 3.11. Miramar: Street \& Block 1:10000 Fig. 3.12. Miramar: Kauri Street Plan 1:2000 Fig. 3.13. Miramar: Kauri Street Section

Fig. 3.14. Bungalow Floor Plan

Fig. 3.15. Bungalow Street Elevation

Fig. 3.16. Bungalow Section

Fig. 3.17. Bungalow Isometric

Fig. 3.18. Bungalow Gradient Diagram

Fig. 3.19Naenae: Figure/Ground 1:10000

Fig. 3.20. Naenae: Street \& Block 1:10000

Fig. 3.21. Naenae: Feist Street Plan 1:2000

Fig. 3.22. Naenae: Feist Street Section

Fig. 3.23. State House Floor Plan

Fig. 3.24. State House Street Elevation

Fig. 3.25. State House Section

Fig. 3.26. State House Isometric

Fig. 3.27. State House Gradient Diagram

Fig. 3.28. Totara Park: Figure/Ground 1:10000

Fig. 3.29. Totara Park: Street \& Block 1:10000

Fig. 3.30. Totara Park:Dakota Grove Plan 1:2000

Fig. 3.31. Totara Park: Dakota Grove Section
Fig. 3.33. Typical House Street Elevation

Fig. 3.34. Typical House Section

Fig. 3.35. Typical House Isometric

Fig. 3.36. Typical House Gradient Diagram

Fig. 3.37. Otaihanga: Figure/Ground 1:10000

Fig. 3.38. Otaihanga: Street \& Block 1:10000

Fig. 3.39. Otaihanga: Leanne Way Plan 1:2000

Fig. 3.40. Otaihanga: Leanne Way Section

Fig. 3.41. Typical House Floor Plan

Fig. 3.42. Typical House Street Elevation

Fig. 3.43. Typical House Section

Fig. 3.44. Typical House Isometric

Fig. 3.45. Typical House Gradient Diagram

\section{Chapter 4:}

Fig. 4.1. Master-plan image of the Nar Ouse Regeneration Area produced by LSI Architects (p.10)

Fig. 4.2. Master-plan image of the Tullimbar development project (Tullimbar Village Centre Building Design Guidelines 10)

Fig. 4.3. Master-plan image of the Addison Housing Project produced by Harrison Grierson Consultants

Fig. 4.4. Harold Street Residence Ground Floor

Fig. 4.5. Harold Street Residence First Floor

Fig. 4.6. Harold Street Residence Gradient Diagram

Fig. 4.7. Sound House Ground Floor

Fig. 4.8. Sound House First Floor

Fig. 4.9. Sound House Gradient Diagram

Fig. 4.10. Bernal Heights Residence Ground Floor

Fig. 4.11. Bernal Heights Residence First Floor

Fig. 4.12. Bernal Heights Residence Second Floor

Fig. 4.13. Bernal Heights Residence Gradient Diagram

Fig. 4.14. Slot House Ground Floor

Fig. 4.15. Slot House First Floor

Fig. 4.16. Slot House Gradient Diagram

Fig. 4.17. Madrona Residence Ground Floor

Fig. 4.18. Madrona Residence First Floor

Fig. 4.19. Madrona Residence Second Floor

Fig. 4.20. Madrona Residence Gradient Diagram

Fig. 4.21. Chen House Ground Floor 
Fig. 4.22. Chen House Gradient Diagram Fig. 4.23. PC-1 Residence Ground Floo Fig. 4.24. PC-1 Residence First Floor

Fig, 4.25. PC-1 Residence Second Floor Fig. 2.26. PC-1 Residence Gradient Diagram Fig. 4.27. Slip House Ground Floor

Fig. 4.28. Slip House First Floor

Fig. 4.29. Slip House Second Floor

Fig. 4.30. Slip House Gradient Diagram

Fig. 4.31. Hanging Home Ground Floor

Fig. 4.32. Hanging Home First Floor

Fig. 4.33. Hanging Home Second Floor

Fig. 4.34. Hanging Home Gradient Diagram

Fig. 4.35. Hintonberg Home Ground Floor

Fig. 4.36. Hintonberg Home First Floor

Fig. 4.37. Hintonberg Home Second Floor

Fig. 4.38. Hintonberg Home Gradient Diagram

\section{Chapter 5:}

Fig. 5.1. Broader Kapiti Context

Fig. 5.2. Landlink Proposal for a section of the Waikanae North Residential Area

Fig. 5.3. Landlink Proposal Figure Ground

Fig. 5.4. Landlink Proposal Streetand Block

Fig. 5.5. Landlink Proposal Building Use

Fig. 5.6. Landlink Proposal Street Hierarchy

Fig. 5.7. Amended Master-Plan

Fig. 5.8. Selected Street Plan - Homezone

Fig. 5.9.Selected Street Section - Homezone

Table 1. Design Strategies

Table 2. Building Mass and Form Design Strategies

Table 3. Threshold and Permeability Design Strategies

\section{Chapter 6:}

Fig. 6.2. Back-yard House Ground Floor Plan

Fig. 6.3. Back-yard House Ground Floor Planning Strategies

Fig. 6.3. Back-yard House Ground Floor Gradient Diagram

Fig. 6.4. Back-yard House Ground Floor Threshold Strategies

Fig. 6.5. Back-yard House First Floor Plan

Fig. 6.6. Back-yard House First Floor Planning Strategies

Fig. 6.7. Back-yard House First Floor Gradient Diagram

Fig. 6.8. Back-yard House First Floor Threshold Strategies

Fig. 6.9. Back-yard House Second Floor Plan
Fig. 6.10. Back-yard House Second Floor Planning Strategies Fig. 6.11. Back-yard House Second Floor Gradient Diagram Fig. 6.12. Back-yard House Second Floor Threshold Strategies Fig. 6.13. Back-yard House Street Elevation

Fig. 6.14. Back-yard House Longitudinal Section Fig. 6.15. Back-yard House Isometric

Fig. 6.16. Back-yard House Interior Perspective Fig. 6.17. Back-yard House Exterior Perspective Fig. 6.18. Court-yard House Ground Floor Plan

Fig. 6.19. Court-yard House Ground Floor Planning Strategies Fig. 6.20. Court-yard House Ground Floor Gradient Diagram Fig. 6.21. Court-yard House Ground Floor Threshold Strategies Fig. 6.22. Court-yard House First Floor Plan

Fig. 6.23. Court-yard House First Floor Planning Strategie Fig. 6.24. Court-yard House First Floor Gradient Diagram

Fig. 6.25. Court-yard House First Floor Threshold Strategies Fig. 6.26. Court-yard House Second Floor Plan

Fig. 6.27. Court-yard House Second Floor Planning Strategies Fig. 6.28. Court-yard House Second Floor Gradient Diagram Fig. 6.29. Court-yard House Second Floor Threshold Strategies Fig. 6.30. Court-yard House Street Elevation

Fig. 6.31. Court-yard House Longitudinal Section

Fig. 6.32. Court-yard House Isometric

Fig. 6.33. Court-yard House Interior Perspective

Fig. 6.34. Court-yard House Exterior Perspective

Fig. 6.35. Front-yard House Ground Floor Plan

Fig. 6.36. Front-yard House Ground Floor Planning Strategies Fig. 6.37. Front-yard House Ground Floor Gradient Diagram

Fig. 6.38. Front-yard House Ground Floor Threshold Strategies Fig. 6.39. Front-yard House First Floor Plan

Fig. 6.40. Front-yard House First Floor Planning Strategies

Fig. 6.41. Front-yard House First Floor Gradient Diagram Fig. 6.42. Front-yard House First Floor Threshold Strategies Fig. 6.43. Front-yard House Second Floor Plan

Fig. 6.44. Front-yard House Second Floor Planning Strategies Fig. 6.45. Front-yard House Second Floor Gradient Diagram Fig. 6.46. Front-yard House Second Floor Threshold Strategies

Fig. 6.47. Front-yard House Street Elevation

Fig. 6.48. Front-yard House Longitudinal Section

Fig. 6.49. Front-yard House Isometric

Fig. 6.50. Front-yard House Interior Perspective

Fig. 6.51. Front-yard House Exterior Perspective

Table 4. Design Strategies Evaluation 


\section{Appendix One}

Newtown Street, Block and Figure/Ground Relationships

The gridiron street patterns are highly evident in the plan of Newtown. Two angled grids merge at a centra axis which aids the cohesion and legibility of the layout. The merging of the two grids creates strong point of change along the spine connecting them. These points of transition between the two grids are natural distribution points and help to establish a clear street hierarchy. Because of the large rectangular blocks the land has been subject to further subdivision and intensification. The proportions of the individual lots, and consequently the blocks, usually correspond to the accepted house forms of the time (VernezMoudon, p.51.). The regularity of the grid bestows a particular logic and legibility to the street pattern and imposes order on subsequent building development. A conventional 'back to back' arrangement of the lots has produced blocks of quite narrow dimensions. Consequently the majority of the houses built in this example are uniformly exposed and engaged with a street, with clear front and back conditions.

Roy Street was chosen for this particular study because the majority of the housing stock is original. Other streets have been developed further with infill, demolition or renovation as permitted by the gridiron network. These modifications render such streets inappropriate for the type of analysis needed. The street plan and section demonstrate how the houses have been built close to the street edge leaving a small front yard while establishing large back yards. The street was originally a shared zone for pedestrians and horses and carriages permitted by the low intensity, low speed traffic. The original town planners also did not have to account for car access to lots. However, the advent of automobiles and higher intensity traffic required re-structuring of the street spaces to segregate uses and clearer spatial establish a hierarchy: a carriage way, footpath, and median. Access to car storage currently disrupts the original appearance of the street. With the linear streets, visual boundaries like front fences and vegetation were used prolifically to separate public and private spaces and reinforce individual property rights.

The street plan shows the long narrow house types which fundamentally informed the original land subdivision and produced narrow lots. Narrow house types encouraged vertical spatial displacement in order to accommodate the necessary domestic functions. The result of this is seen in a compact urban form and a high building coverage where a range of house types can be positioned very close together. The narrow houses appear in detached and semi-detached forms.

\section{Miramar Street, Block and Figure/Ground Relationships}

The street layout of Miramar demonstrates a geometrically evolved type of grid layout. While the streets are still reasonably straight there are a number of unexplained bends and angles in the plan demonstrating a move towards the 'artful' geometric planning concepts prompted in the Garden City movement. familiarity of the grid, and the novelty and variety of progressive Garden City design. The plan of Miramar locates a clear centre to the south, and implements a more obvious street hierarchy. These attributes in particular are absent in a pure grid plan.

The block sizes and shapes are more irregular than those in the Newtown example. The streets are fewer in number requiring them to be longer in length which has created larger blocks in general. Based on Garden City ideals which advocate a strong connection to the rural landscape, the conclusion is that the original subdivision of the blocks allocated generous amounts of land to each allotment. This resulted in a relatively low density in comparison to the Victorian villas. The drawings indicate that up to four properties span the breadth of the block. The hypothesis is that further subdivision has occurred in places increasing the number of houses from just two. While it falls outside the scope of the research, it has not been discovered if this was a planned feature of the master layout or a process of infill development and general suburban densification as the base population of Wellington has expanded.

Kauri Street was chosen for this part of the analysis once again because of the largely unaffected housing stock. While the street conforms to the gridiron structure and would seem to fit the Victorian villa model quite easily, the data gathered at this scale is not affected by the street and block layout, but instead focuses on the buildings and spatial relationships. The plan of Kauri Street shows that the carriage way is wider than in Newtown, no doubt to accommodate the rise of the automobile in the 1920's (Schrader, p.24). The street plan and section show that the houses are still oriented towards the street but are set back further from the street than in the previous example. The individual land parcels appear to be more uniform in size and bigger in general when compared to the Roy street equivalents. Larger, wider lots accommodated the more spreading layout of the California bungalow and allowed this house form to be placed in a more extensive garden.

Naenae Street, Block and Figure/Ground Relationships

The master-plan of the Naenae suburb signifies a significant shift towards a more comprehensive manifestation of the 'Garden City' ideal. The Government of the time believed that it was the right of all citizens to be properly housed. When the market failed to deliver that right during the depression, it was necessary for the Government to eliminate the resulting overcrowding and slum environment, and build houses for those who could not afford to do it themselves (Schrader, p.53). What occurred was a mass produced suburb. Organic and curvilinear street layouts with sweeping bends and cul-de-sacs spread off a central spine which links the suburb to the existing suburban fabric. The consistency in the treatment of each street and road reveals that the entire area was master-planned rather than incrementally developed. However, the most significant change from the previous examples is that it is harder to discern a hierarchy or network of streets, besides the main axis/spine, within this pattern. The street pattern does not articulate 
a centre or focal point within the master-plan and the decentralised layout lacks legibility. The figure ground diagram demonstrates a low density and a uniform distribution across the entire suburb, suggesting mass production of mainly detached, single use houses.

The plan and section drawings of Feist Street highlight an important change in planning traditions from the previous examples where the popular house form no longer determined the proportions, size and shape of the land parcels. While the street pattern and allotment size and shapes still interconnected, as the street plans incorporated more curves and more complex geometries, the lots became increasingly irregular. Because the lot sizes were generally larger than both of the previous models, the 'fit' of the houses onto the allotments was not so critical. Both the street plan and section demonstrate that the house is no longer oriented so that is engaged the street. Rather, the living rooms are situated to receive the sun. Houses were apparently sited "in harmony with each other, and the front of each house was to remain unfenced... to allow for a community garden." (Schrader, p.68). The front yard acted as the primary mediator between the public and the private realms. Front fences have since been added suggesting that the residents required demarcation, probably to assert ownership and territoriality.

\section{Totara Park Street, Block and Figure/Ground Relationships}

The Totara Park private-sector residential development is a recognizable evolution from the Naenae project. The Garden City ideals appear to have taken root in New Zealand's suburban development tradition by this stage. The suburb is isolated from surrounding development by the Hutt River. This segregation helps to give the suburb a distinct identity which includes a strong relationship to the surrounding rural land.

Cul-de-sacs and curvilinear streets are clearly evident in the drawings, but implemented in a more hierarchical manner. It is clear that particular streets function in a more arterial fashion while others distribute and deliver the residential traffic. A ring road appears to be the primary organisational movement corridor which then feeds a relatively loose network of connecting roads and cul-de-sacs. Busier roads within the network of streets is evidenced by greater street widths and building setbacks.

Totara Park has a higher building density than the Naenae example which is mainly due to the increase in building footprint. The uniform distribution of houses across the land suggests equal land parcels and consistent development method across the entire suburb.

The subdivision of the land has occurred in a similar manner to Naenae where the directionality and shape of the street has a larger influence on the division of land into allotments than the popular house form. This is again demonstrated in the street plan of Dakota Grove where there seems to be little correlation between the building footprints and the lot shape. It does seem though, that the house is generally pushed towards the street edge thereby establishing a larger back yard. Orientation on site appears to have been at the discretion of the individual builder or owner as shown where the house footprint is angled away from the street, but also at odds with the alignment of the lot.

\section{Otaihanga Street, Block and Figure/Ground Relationships}

It appears that the Otaihanga subdivision also uses natural features to isolate its suburban development from the pre-existing development and tie it to landscape ideals. This area appears to have developed incrementally beginning with a series of baches along the coast represented by the fine grain of small houses close to the coast. These are isolated by a road which follows the coastline. Building footprints become larger and coarser further inland, suggesting gradual intensification and expansion of the original beach community. Eventually the area will have evolved into a suburban residential area at the periphery of Wellington's urban area. Land has become more valuable, requiring smaller lots even while the houses get bigger. This effect achieves a reasonably high building density but not necessarily a high population density. Infill and the addition of whole new streets increasingly characterise contemporary development as land becomes scarcer. The change in grain represented in the figure ground image documents a series of different development periods each with typical spaces and buildings as well as distinct scale.

Larger building footprints mean that the houses on Leanne Way occupy most of their sites. Only when the lot is restricted is there a correlation between the street and the orientation of the house.

The sectional drawing expresses the dominance of the car and, by default, the carriage-way of the street environment. The pedestrian footpath is bordered by the carriage way on one side, and on the other by a private fence, a concrete driveway or a small and impersonal front yard subject to the influence of a garage door. The garage door is the largest element in the street facade of the house making it a significant factor in determining the nature of the interface between public and private. 